\title{
Evolution of laparoscopic techniques in bariatric surgery
}

Citation for published version (APA):

Dapri, G. (2013). Evolution of laparoscopic techniques in bariatric surgery. [Doctoral Thesis, Maastricht University]. Datawyse / Universitaire Pers Maastricht. https://doi.org/10.26481/dis.20130517gd

Document status and date:

Published: 01/01/2013

DOI:

10.26481/dis.20130517gd

Document Version:

Publisher's PDF, also known as Version of record

\section{Please check the document version of this publication:}

- A submitted manuscript is the version of the article upon submission and before peer-review. There can be important differences between the submitted version and the official published version of record.

People interested in the research are advised to contact the author for the final version of the publication, or visit the DOI to the publisher's website.

- The final author version and the galley proof are versions of the publication after peer review.

- The final published version features the final layout of the paper including the volume, issue and page numbers.

Link to publication

\footnotetext{
General rights rights.

- You may freely distribute the URL identifying the publication in the public portal. please follow below link for the End User Agreement:

www.umlib.nl/taverne-license

Take down policy

If you believe that this document breaches copyright please contact us at:

repository@maastrichtuniversity.nl

providing details and we will investigate your claim.
}

Copyright and moral rights for the publications made accessible in the public portal are retained by the authors and/or other copyright owners and it is a condition of accessing publications that users recognise and abide by the legal requirements associated with these

- Users may download and print one copy of any publication from the public portal for the purpose of private study or research.

- You may not further distribute the material or use it for any profit-making activity or commercial gain

If the publication is distributed under the terms of Article $25 \mathrm{fa}$ of the Dutch Copyright Act, indicated by the "Taverne" license above, 


\section{EVOLUTION OF LAPAROSCOPIC TECHNIQUES IN BARIATRIC SURGERY}


(c) Copyright Giovanni DAPRI, Maastricht 2013.

All rights reserved. No part of this thesis may be reproduced or transmitted in any form or by any means, electronic or mechanical, including photocopying, recording, or any information storage or retrieval system without permission from the author, or when appropriate, from the publishers of the publications.

Production: Datawyse | Universitaire Pers Maastricht ISBN 9789461592286 


\title{
EVOLUTION OF LAPAROSCOPIC TECHNIQUES IN BARIATRIC SURGERY
}

\author{
DISSERTATION \\ to obtain the degree of Doctor at Maastricht University, \\ on the authority of the Rector Magnificus, Prof. dr. L.L.G. Soete \\ in accordance with the decision of the Board of Deans, \\ to be defended in public \\ on Friday 17 May 2013, at 10.00 hours
}

by

\section{Giovanni Dapri}

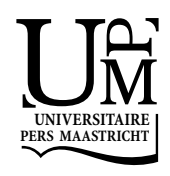


Promotor

Prof. dr. J.W.M. Greve

\section{Co-Promotors}

Prof. dr. G-B. Cadière

Prof. dr. J. Himpens

Assessment Committee

Prof. dr. J.G. Maessen

Prof. dr. L.P.S. Stassen

Prof. dr. P.B. Soeters

Prof. dr. R. Weiner

Dr. R. Schouten
Centre Hospitalier Universitaire Saint-Pierre, Brussels, Belgium

AZ Sint-Blasius, Dendermonde, Belgium

(Chair)

University of Frankfurt, Germany

Bariatrisch Centrum Lievensberg Ziekenhuis, Bergen op

Zoom 


\section{CONTENTS}

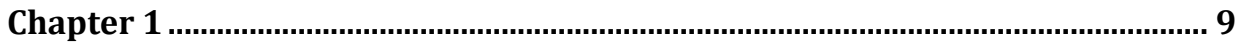

\section{GENERAL INTRODUCTION}

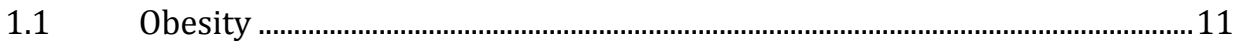

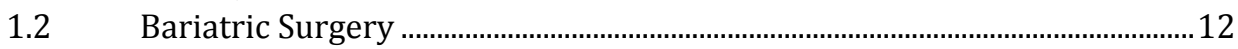

1.3 Development of Laparoscopic Procedures ........................................................12

1.4 Failures/Complications and Need for Revisions.............................................13

1.5 Search for Possible Strategies to Treat Failures .................................................14

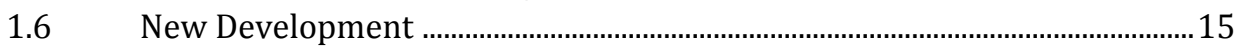

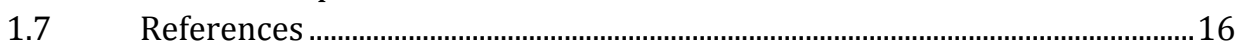

Chapter 1b.....................................................................................................23

INTRODUCTION TO THE STUDIES AND AIM OF THE THESIS

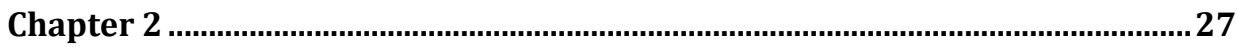

RANDOMIZED STUDY COMPARING TWO DIFFERENT TECHNIQUES FOR

LAPAROSCOPIC SLEEVE GASTRECTOMY

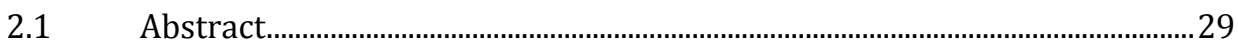

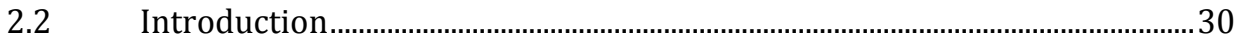

2.3 Patients and Methods ........................................................................................... 30

2.3.1 Surgical Technique..........................................................................................31

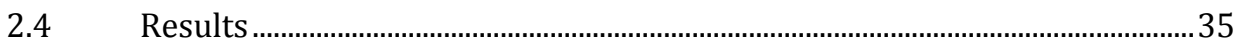

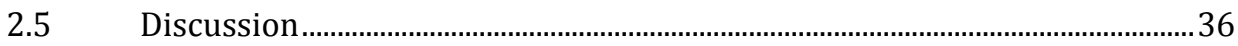

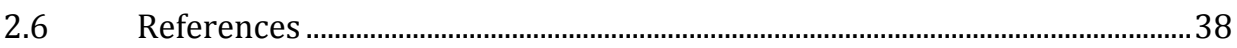

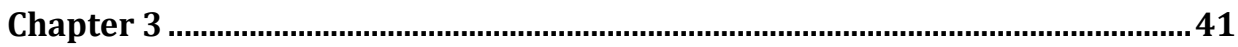

RANDOMIZED STUDY IN LAPAROSCOPIC SLEEVE GASTRECTOMY COMPARING THE REINFORCEMENT OF THE STAPLE LINE

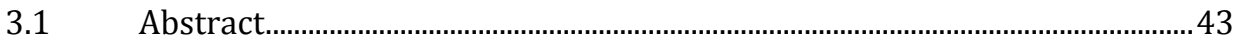

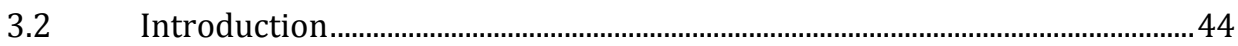

3.3 Patients and Methods ......................................................................................... 44

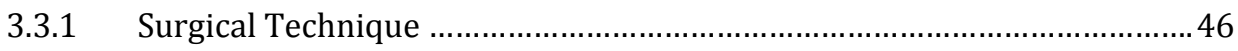

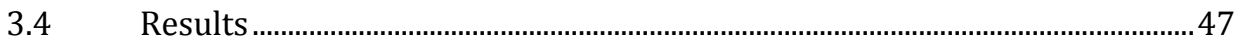

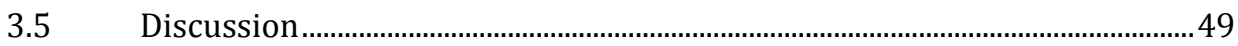

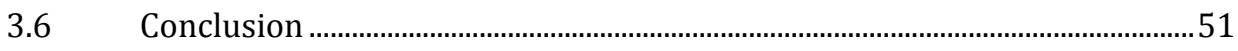

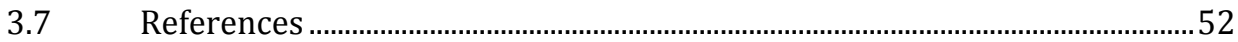


Chapter 4

LAPAROSCOPIC CONVERSION OF ADJUSTABLE GASTRIC BAND TO SLEEVE GASTRECTOMY

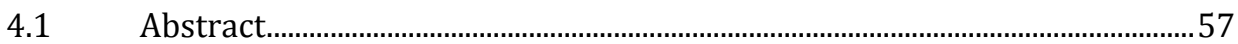

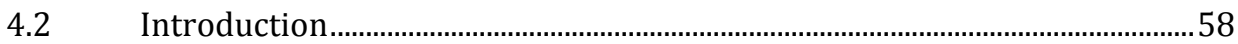

4.3 Patients and Methods ………………………….................................................. 58

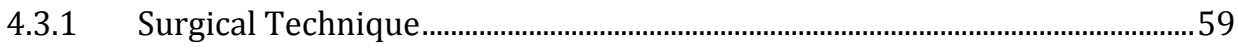

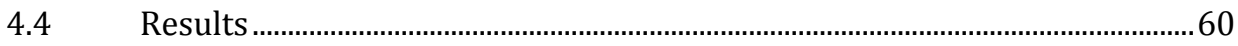

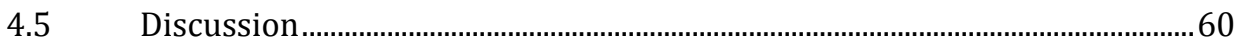

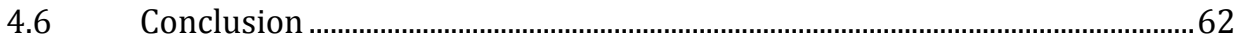

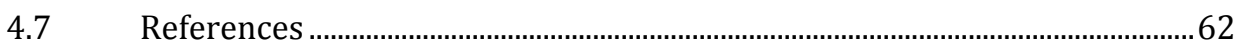

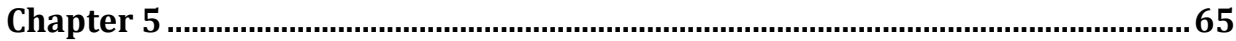

LAPAROSCOPIC REVISION OF SLEEVE GASTRECTOMY: RE-SLEEVE VERSUS DUODENAL SWITCH

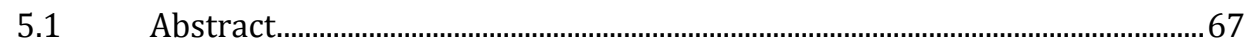

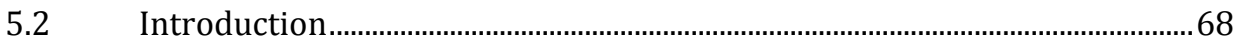

5.3 Patients and Methods .......................................................................................... 68

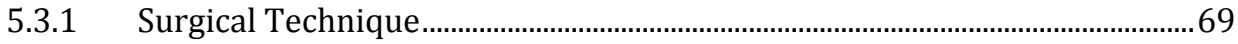

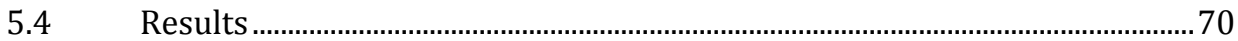

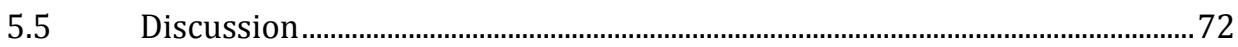

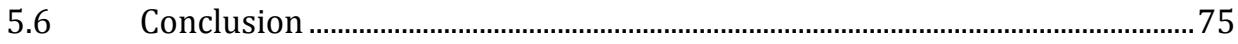

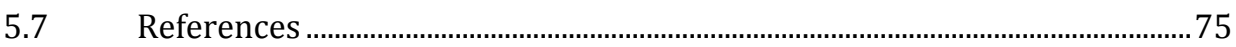

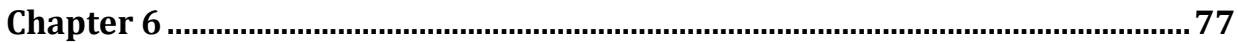

LAPAROSCOPIC CONVERSION OF ADJUSTABLE GASTRIC BAND AND VERTICAL BANDED GASTROPLASTY TO DUODENAL SWITCH

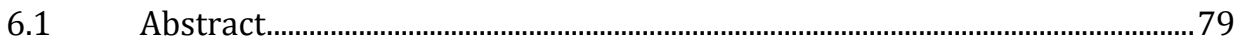

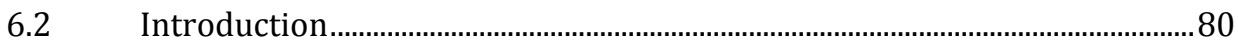

6.3 Patients and Methods ........................................................................................

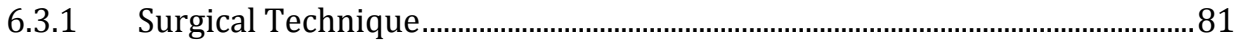

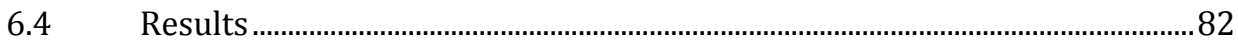

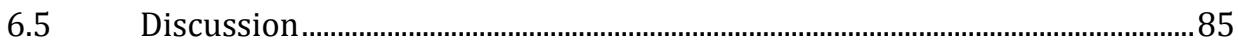

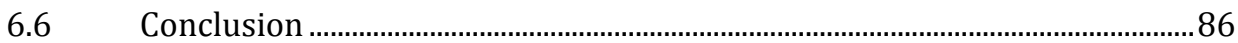

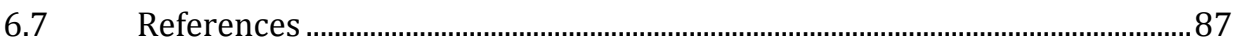

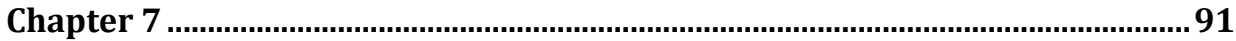

TWO-STEP LAPAROSCOPIC DUODENAL SWITCH

7.1 Abstract.......................................................................................................93

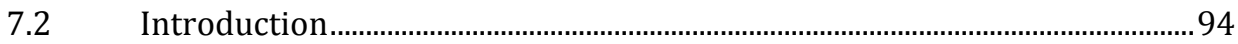

7.3 Patients and Methods .......................................................................................... 94

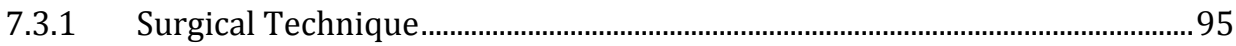

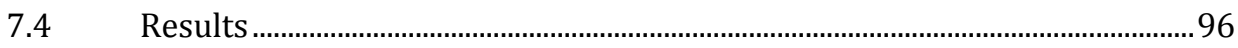




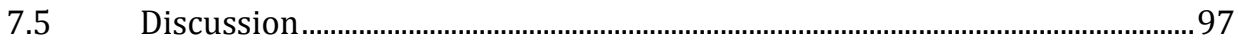

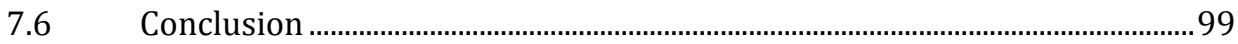

$7.7 \quad$ References ............................................................................................................. 99

Chapter 8 ..................................................................................................... 103

LAPAROSCOPIC REVISION OF ROUX-EN-Y GASTRIC BYPASS TO BANDED ROUX-EN-Y GASTRIC BYPASS

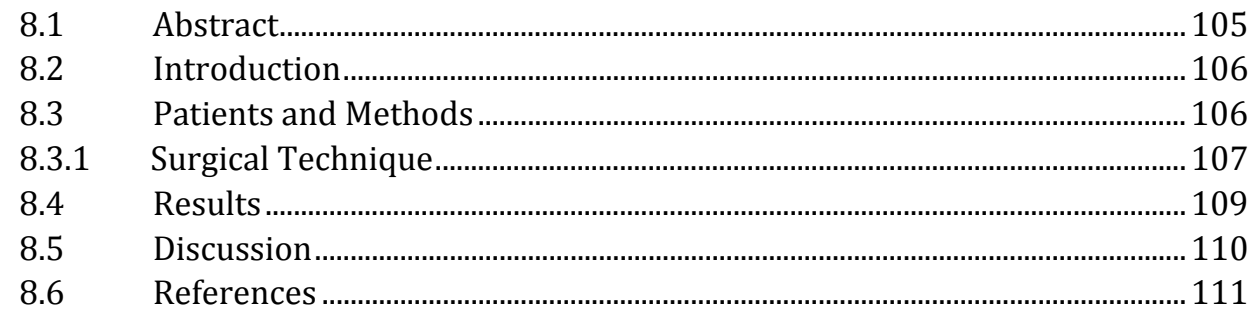

Chapter 9 ..................................................................................................... 113

LAPAROSCOPIC CONVERSION OF ROUX-EN-Y GASTRIC BYPASS TO DISTAL GASTRIC BYPASS

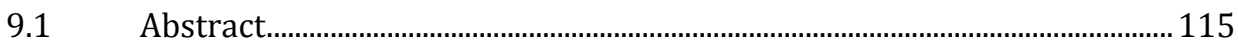

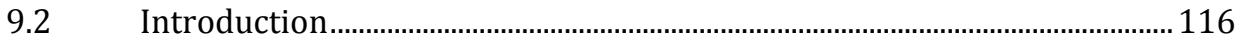

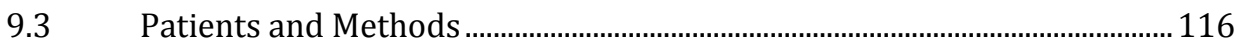

9.3.1 Surgical Technique..............................................................................................

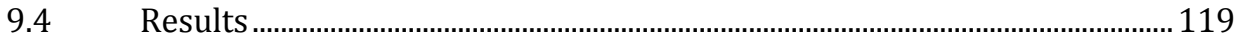

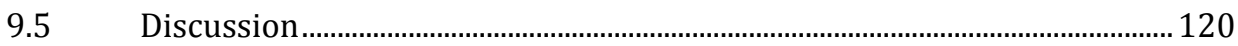

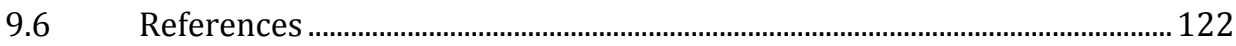

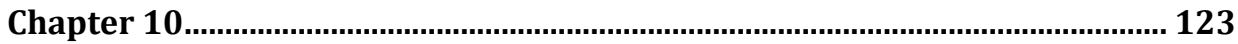

LAPAROSCOPIC CONVERSION OF ROUX-EN-Y GASTRIC BYPASS TO SLEEVE GASTRECTOMY AS FIRST STEP OF DUODENAL SWITCH

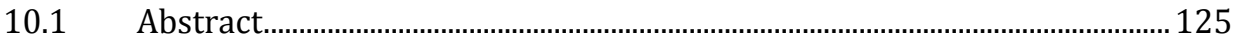

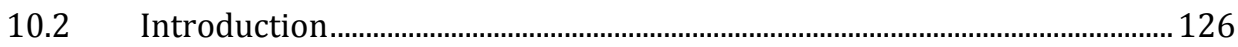

$10.3 \quad$ Patients and Methods .........................................................................................126

10.3.1 Surgical Technique.........................................................................................

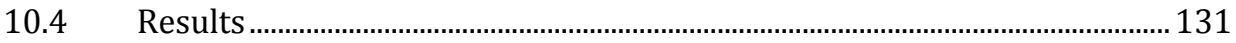

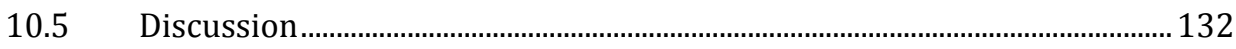

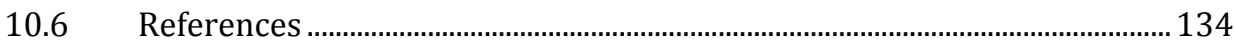

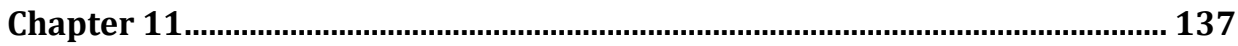

LAPAROSCOPIC CONVERSION OF ROUX-EN-Y GASTRIC BYPASS TO ORIGINAL ANATOMY

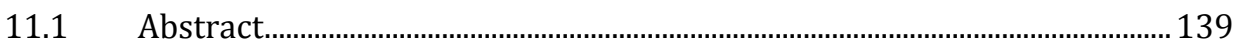

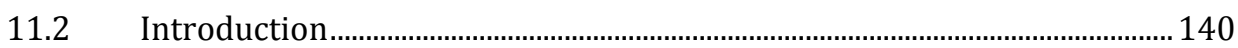

$11.3 \quad$ Patients and Methods ......................................................................................... 140 


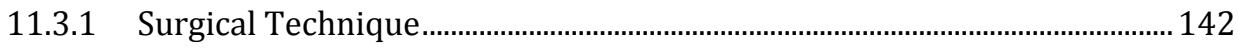

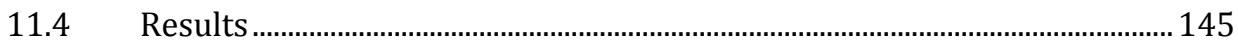

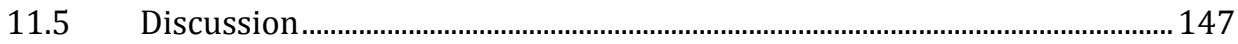

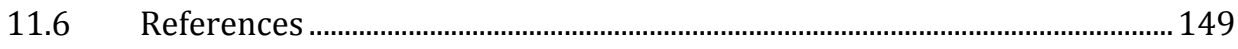

Chapter 12

SINGLE-ACCESS LAPAROSCOPIC ADJUSTABLE GASTRIC BAND REMOVAL

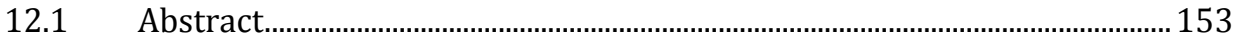

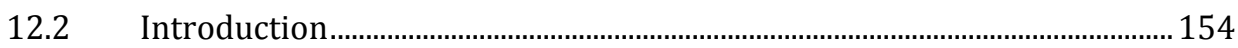

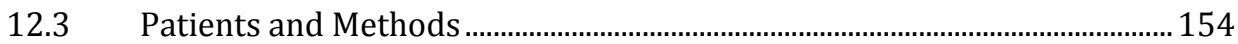

12.3.1 Surgical Technique........................................................................................... 155

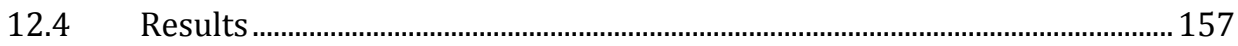

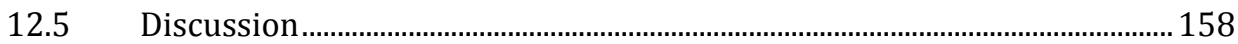

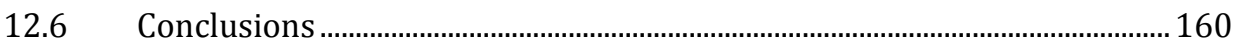

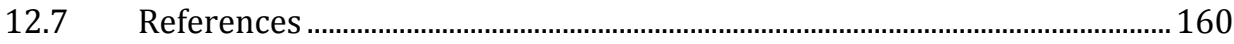

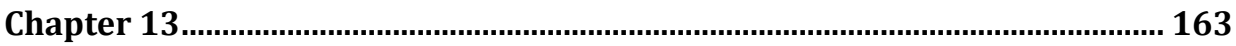

SUMMARY \& CONCLUSIONS

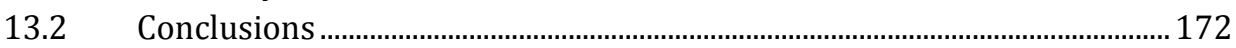

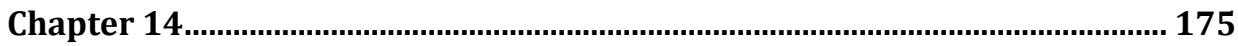

SAMENVATTING \& CONCLUSIE

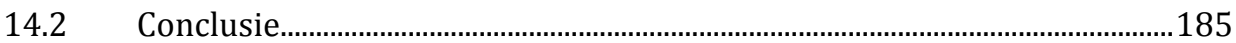

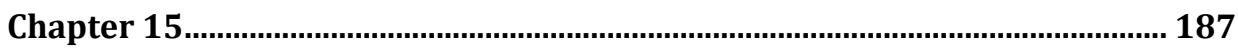

RIASSUNTO \& CONCLUSIONI

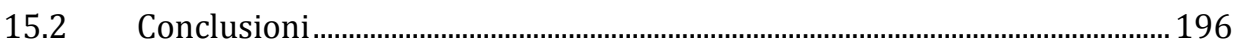

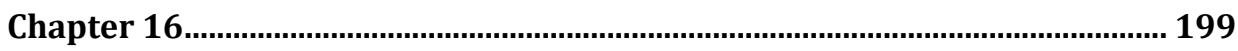

ADDENDUM

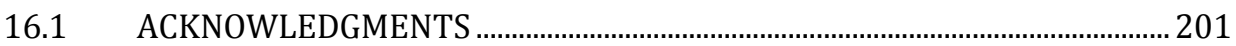

16.2 CURRICULUM VITAE..........................................................................................2202

16.3 BIBLIOGRAPHY ................................................................................................. 206 
Chapter 1

GENERAL INTRODUCTION 



\subsection{OBESITY}

Morbid obesity is a disease in which the body stores excess energy in the form of fat. This energy imbalance often leads to overweight and obesity. The body needs a certain amount of energy (calories) from food to sustain basic life functions. Body weight is maintained when the number of calories consumed equals the number of calories expended or "burned" by the body. When more calories are consumed than burned, the energy balance is tipped toward weight gain, overweight, and obesity. Overweight and obesity are classified considering the body mass index (BMI), which considers weight in relation to height $\left(\mathrm{kg} / \mathrm{m}^{2}\right)$. Obesity is classified into the following 3 groups: moderate $\left(30<\mathrm{BMI}<35 \mathrm{~kg} / \mathrm{m}^{2}\right)$, severe $(35<\mathrm{BMI}<40$ $\mathrm{kg} / \mathrm{m}^{2}$ ), and morbid (BMI $>40 \mathrm{~kg} / \mathrm{m}^{2}$ ). When the BMI is greater than $50 \mathrm{~kg} / \mathrm{m}^{2}$, it is referred to as super-obesity $\left(50<\mathrm{BMI}<60 \mathrm{~kg} / \mathrm{m}^{2}\right)$ and super super-obesity $\left(\mathrm{BMI}>60 \mathrm{~kg} / \mathrm{m}^{2}\right)$.

The biological basis for morbid obesity is unknown, but it has been demonstrated that there is genetic component may account for between 25 and $50 \%$ of cases (1), while environmental, cultural, socioeconomic, and psychological aspects represent the other influencing factors. Several studies have confirmed the influence of adipokines produced by fat cells $(2,3)$ to be among the many mechanisms that play a role in the control of satiety (4). These studies confirmed that morbid obesity, in general, is a disease and not a disorder of willpower, as is sometimes implied. Hence, considering all of these factors, morbid obesity must be considered a complex disorder.

There is significant evidence that obesity, especially in young people, results in a lower life expectancy than that of their lean counterparts $(5,6)$. While obesity itself is a risk factor (7), mortality and morbidity are mainly associated with obesity-related co-morbid conditions. These conditions are outlined in the $1985 \mathrm{Na}-$ tional Institutes of Health Consensus Conference and include arterial hypertension, diabetes, obstructive sleep apnea, degenerative arthritis, hypertrophic cardiomyopathy, hyperlipidemia, cholelithiasis, hypoventilation and psychosocial impairments $(7,8)$. Obesity result in significant increased health care costs. On average, people who are considered obese pay $\$ 1,429$ (42\%) more each year in health care costs and drugs than normal-weight individuals (9).

Because of the multifactorial etiology of overweight and obesity, it is unlikely that there is a single way to prevent or treat overweight and obesity. Treatment may include a combination of diet, exercise, behavior modification, and sometimes weight-loss drugs. However, non-operative methods alone have not been effective in achieving medically significant long-term weight loss in severely obese adults. The majority of patients on a conservative regimen regain all the weight lost within five years $(10,11)$. Furthermore, dietary weight loss attempts often cause depression, anxiety, irritability, weakness and preoccupation with food (12), as well as weight gain in the end (the "yoyo" effect). 
The treatment goal for morbid obesity should be an improvement in health achieved by a durable weight loss that reduces life-threatening risk factors and improves the performance of daily life activities and the quality of life.

Surgical treatment is medically necessary because it is the only proven method of achieving long-term weight control for the morbidly obese. Following the 1991 National Institutes of Health (NIH) Consensus Conference guidelines, the basic eligibility criteria include the presence of severe obesity with a BMI greater than $40 \mathrm{~kg} / \mathrm{m}^{2}$ or a BMI greater than $35 \mathrm{~kg} / \mathrm{m}^{2}$ in patients with comorbid conditions (13). These comorbid conditions include hypertension, diabetes, sleep apnea and dyslipidemia. Additional basic eligibility criteria include appropriate patient motivation and understanding, the absence of severe psychiatric illness, and age between 18 and 60 years. Moreover, surgery should only be considered in patients who have attempted nonsurgical methods of weight loss for a minimum of 1 year.

\subsection{BARIATRIC SURGERY}

Bariatric surgery emerged in the 1950s with the jejunoileal bypass, which is considered a malabsorptive bariatric procedure (14).

In the 1960s, a combination of intestinal malabsorption and gastric restriction has been developed that is recognized currently as the Roux-en-Y gastric bypass (RYGB). This procedure is considered a mixed procedure, joining both restrictive and malabsorptive compartments. Other procedures can be classified as restrictive or purely malabsorptive procedures.

Restrictive procedures decrease food intake and promote an early feeling of fullness (satiety) after meals. These include laparoscopic adjustable gastric band (LAGB), vertical banded gastroplasty (VBG), and sleeve gastrectomy (SG).

Malabsorptive procedures such as biliopancreatic diversion (BPD), biliopancreatic diversion with duodenal switch (DS), and distal Roux-en-Y gastric bypass (DRYGB), reduce the absorption of calories, proteins and other nutrients.

\subsection{DEVELOPMENT OF LAPAROSCOPIC PROCEDURES}

With the advent of laparoscopy in the 1980s, bariatric surgery began to be performed through minimally invasive techniques. The main advantages of laparoscopy compared to traditional open surgery are less trauma and adhesions, reduced postoperative pain, lower incidence of abdominal wall infections and incisional hernia, reduced hospital stay, reduced convalescence and, finally, better patient outcome.

The fundamental differences between laparoscopic and open surgery are the method of access and the method of operative exposure. By reducing the size of the surgical incision and the trauma associated with the operative field exposure, the 
surgical insult is less after laparoscopy compared with open surgery. The reduction in surgical insult during laparoscopy has been considered the physiologic basis for the observed clinical advantages of this approach. The physiological advantages include less impairment of postoperative pulmonary function and less pulmonary atelectasis. Finally, better visualization reduces the risk of perioperative and postoperative complications (15).

A worldwide survey on bariatric surgery conducted in 2008 (16) showed that there are 344,221 bariatric surgery operations performed by 4,680 bariatric surgeons annually. Over $90 \%$ of the procedures are performed laparoscopically. In Belgium-Netherlands-Luxembourg, a total of 12,200 bariatric surgery operations are performed annually by 127 bariatric surgeons.

\subsection{FAILURES/COMPLICATIONS AND NEED FOR REVISIONS}

Patients who submit to bariatric surgery can present a failure or complications related to the procedure performed during follow-up. Failure is usually considered to be insufficient weight loss or weight regain with obesity recidivism after an initial success, and in these cases, revisional surgery is usually required. Complications include severe side effects, such as excessive vomiting, exaggerated dumping syndrome, invalidating reflux symptoms, development of malnutrition leading to cachexia, liver cirrhosis with associated hepatic failure and even death.

Insufficient weight loss or weight regain are the most common indications for revisional surgery (17), and it is estimated that over 250,000 patients will be potential candidates for revisional intervention by 2014 (18). These problems must be evaluated first by a multidisciplinary counseling team, including a psychologist, dietician, internist, endocrinologist, gastroenterologist, radiologist and surgeon, to identify the cause of obesity recidivism and to offer adequate therapy. Insufficient weight loss can be due to technical mishaps, such as incomplete stomach division after RYGB, or to a poor procedure choice related to alimentary behavior. Weight regain or obesity recidivism can be caused by a lack of dietary compliance, but it can also be induced by technical failure or bodily adaptation to the new anatomy, such as hypertrophy of the non bypassed bowel, dilation of the gastric pouch and/or gastrojejunostomy after RYGB, or dilation of the gastric remnant after SG, or by a delayed complication, such as the development of gastro-gastric fistulae after RYGB or the breakdown of the staple line after VBG.

Excessive vomiting can be a cause for revision as well, and both technical and patient compliance are involved at the origin of this complication. This condition can be related to poor comprehension of the procedure and the inability to adapt eating behavior to the new anatomical situation. Some patients cannot cope with this situation despite extensive dietary and psychological counseling. Excessive vomiting can lead to poor dietary choices, resulting in hypoproteinemia and anemia. The latter conditions can be life threatening in malabsorptive procedures, 
even in the absence of excessive vomiting. Side effects can be invalidating as well, such as dumping syndrome after RYGB or severe diarrhea after BPD or DS. Whereas medical treatment or revision of the surgical procedure can alleviate these symptoms, reconversion to the original anatomy $(\mathrm{OA})$ rarely is the only remaining solution in therapy-resistant cases. Obvious anatomical flaws, such as stenotic anastomosis or too-short bowel segment after BPD or DS, must be ruled out. However, postoperative complications can originate from the technical aspects of the procedure performed, such as the appearance of excessive gastro-esophageal reflux after restrictive procedures.

When a revision is needed, multidisciplinary counseling is fundamental in the assessment of why the procedure failed. More importantly, the risks involved with the revision must be considered because revisional bariatric surgery is more complicated to perform and with more complications than the primary bariatric procedures.

\subsection{SEARCH FOR POSSIBLE STRATEGIES TO TREAT FAILURES}

Laparoscopic surgery has another particular advantage in revisional surgery because it permits revision of a previous bariatric procedure with a magnified image, exposing a better operative field, maintaining a lower blood loss and offering improved patient comfort.

In the case of insufficient weight loss, weight regain or other complications after previous restrictive procedures such as gastroplasty (LAGB, VBG), patients can benefit from the conversion into SG (19-34), RYGB $(29,32,35-53)$, BPD $(32,54,55)$ or DS (32,56-58).

After a SG procedure, patients can be submitted for conversion into RYGB (52,59-64), for the placement of a band on the gastric tube (65-67), for a repeat SG (re-SG) $(68,69)$, or for the addition of a malabsorptive component with DS $(70,71)$. The final option has been shown to be the preferred strategy for patients who were originally classified as super-obese or super super-obese to reduce their obesity-related morbidity and mortality (71-74).

In patients after RYGB who present such weight issues or other complications, different conversions can be considered, such as the conversion to SG $(75,76)$, DS (75), DRYGB (77-80), banded RYGB (81-85), or BPD (86). In the case of excessive weight loss (cachexia), conversion to the OA can always be considered.

Finally, even patients with a DS who exhibit insufficient weight loss can benefit from revisions such as re-SG (87). In the case of cachexia, a reversal into SG by reestablishing gastrointestinal continuity has been shown to be feasible as well (88). 


\subsection{NEW DEVELOPMENT}

In 2004, a new surgical technique termed Natural Orifices Translumenal Endoscopic Surgery (NOTES) was developed. The main purpose of NOTES was to perform laparoscopic procedures with less invasiveness to improve cosmetic outcomes. Surgeons and gastroenterologists contributed to the exiting development of new operative endoscopes and devices adapted to endoscopes that permit the performance of procedures through the vagina, the stomach, the bladder and the rectum. Different procedures ranging from the foregut to colorectal surgery have been attempted, with the transvaginal cholecystectomy being the most popular one (89). Unfortunately, significant problems, such as safe and reliable closure of the visceral access route, remains unresolved and thus prevent the popularization of this approach (90).

In bariatric surgery, the most attempted NOTES procedure has been laparoscopic SG performed with the endoscope transvaginally and 2-3 additional trocars in the abdomen. This procedure has been reported to be feasible in humans (9192), but careful patient selection is mandatory (93). Only in human cadaver studies have other bariatric NOTES procedures been described, such as RYGB using transvaginal and transgastric routes (94).

In recent years, a new approach of laparoscopy, named single-incision laparoscopic surgery (SILS), single-port or single-access laparoscopy (SAL), has gained interest, mainly because it can improve the cosmetic outcomes similar to NOTES. This approach was first described in 1992 (95) during appendectomy. After more than 20 years, it has been reconsidered in search of lesser invasiveness.

In bariatric surgery the first SILS procedures have been described in 2008 and have been shown to be feasible $(96,97)$. To date, LAGB (96), SG (97), RYGB (98) and BPD (99) have been performed by SILS. Beyond the cosmetic results, SILS might contribute to a decrease in abdominal trauma, postoperative pain and the development of an incisional hernia, but these data need further confirmation by prospective trials.

The main technical difficulties during SILS appear to be the lack of working triangulation inside the abdomen, the clashing of the instruments' tips inside the access-site and the crossing of the surgeon's hands. Furthermore, one of the essential laparoscopic rules, namely, to keep the surgeon's two effectors at a right angle with the optical system as the bisector of this angle (100), is frequently lost during SILS procedures.

To solve these problems and to maintain valid the laparoscopic principles, different companies have worked to develop new materials allowing surgeons to work as they do during conventional multitrocar laparoscopy. Hence, different port-devices, optical systems, and instruments have been developed de-novo or revised from previous existing models (101). An interesting aspect that has started to be considered with SILS is the general cost of these procedures because most of 
the material used is disposable. Hence, different companies have developed reusable port-devices. The development of specifically designed curved reusable instruments has contributed to reduce the cost of SILS procedures as well as to achieving the classic laparoscopic triangulation inside and outside the abdomen (Fig. 1a,b,c).

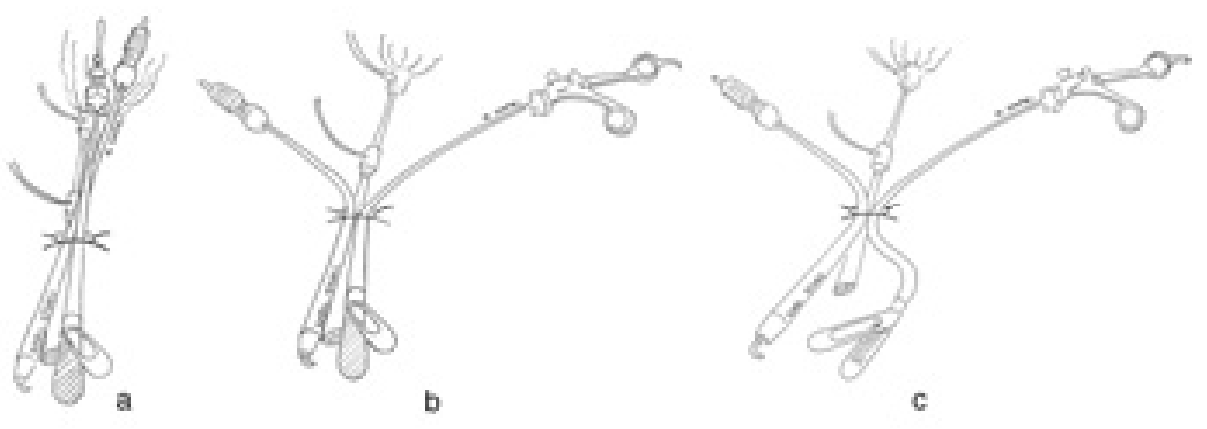

Fig.1 The straight classic laparoscopic instruments (a) are curved outside the access (b), and inside the abdomen (c) to permit the establishment of the conventional laparoscopic triangulation

Furthermore, the effectiveness of the technique developed using these curved reusable instruments is approaching the effectiveness of conventional multitrocar laparoscopy because classic trocars and optical systems have been adopted (102).

Finally, obesity surgery has been invested in the last 2-3 years of a new procedure named gastric plication, which consists into create a gastric tube similar to SG, after have devascularized the greater curvature, but without stapling the stomach. Hence this procedure is less expensive because any linear stapler will be used and postoperative complications like gastric leak may be reduced. This procedure has been described in 2007 (103) and recently some authors have evaluated its efficacy (104). Obviously, as it was for the other bariatric procedures, mid- and long-term results are needed.

\subsection{REFERENCES}

1. Bouchard C. The genetics of obesity 1994, Boca Raton: CRC Press. 245

2. Francke S, Clemnt K, Dina C, et al. Genetic studies of the leptin receptor gene in morbidly obese French Caucasian families. Hum Genet 1997;100:491-6

3. Freidman J, Halaas J. Leptin and the regulation of body weight in mammals. Nature 1998;395:763-70

4. York DA. Peripheral and central mechanisms regulating food intake and macronutrient selection. Obes Surg 1999;9:471-9 
5. Blair DF, Haines LW. Mortality experience according to build at higher durations. Society of Actuaries 1966;18:35-46

6. Stevens J, Cai J, Pamuk ER, et al. The effect of age on the association between body-mass index and mortality. N Engl J Med 1998;338:1-7

7. Hubert HB, Feinleib M, McNamara PM, Castelli WP. Obesity as an independent risk factor for cardiovascular disease: a 26-year follow-up of participants in the Framingham Heart Study. Circulation 1983;67:968-77

8. Health Implications of Obesity. NIH Consensus Development Conference Statement. Ann Int Med 1985;103:1073-7

9. Finkelstein EA, Trogdon JG, Cohen JW, Dietz W. Annual Medical Spending Attributable to obesity: payer- and service-specific estimates. Health Affairs 2009;28:w822-w831

10. Perri MG, Fuller PR. Success and failure in the treatment of obesity: where do we go from here ? Med Exerc Nutr Health 1995;4:255-72

11. Very low-calorie diets. National Task Force on the prevention and treatment of obesity, National Institutes of Health. JAMA 1993;270:967-74

12. Power PS. Conservative treatments for morbid obesity. In M.Deitel (ed), Surgery for the morbidly obese patient, Lea \& Febiger Philadelphia, 1989, pp 27-37

13. Gastrointestinal surgery for severe obesity: National Institutes of Health Consensus Development Conference Statement. Am J Clin Nutr 1992;55:615-9S

14. Buchwald H. Overview of bariatric surgery. J Am Coll Surg 2002;194:367-5

15. Nguyen NT, Wolfe BM. Open versus laparoscopic bariatric surgery. In Buchwald H, Cowan GSM, Pories W (eds), Surgical Management of Obesity, Saunders Elsevier, 2007, pp 287-90

16. Buchwald H, Oien DM. Metabolic/bariatric surgery worldwide 2008. Obes Surg 2009;19:1605-11

17. Behrns KE, Smith CD, Kelly KA, Sarr MG. Reoperative bariatric surgery. Lessons learned to improve patient selection and results. Ann Surg 1993;218:646-53

18. Statistics related to overweight and obesity: the economic costs. http://www.win.niddk.nih.gov/statistics/index.htm. Accessed: May 2008

19. Krawczykowski DR, Lecko M, Nore O. Preliminary results with laparoscopic sleeve gastrectomy. Chir Gastroenterol 2005;21:1-5

20. Baltasar A, Serra C, Pérez C, Bou R, Bengochea M, Ferri L. Laparoscopic sleeve gastrectomy: a multi-purpose bariatric operation. Obes Surg 2005;15:1124-8

21. Mognol P, Chosidow D, Marmuse JP. Laparoscopic sleeve gastrectomy as an initial bariatric operation for high-risk patients: initial results in 10 patients. Obes Surg 2005;15:1030-3

22. Langer FB, Bohdjalian A, Felberbauer FX, et al. Does gastric dilatation limit the success of sleeve gastrectomy as a sole operation for morbid obesity? Obes Surg 2006;16:166-71

23. Bernante $\mathrm{P}$, Foletto $\mathrm{M}$, Busetto $\mathrm{L}$, et al. Feasibility of laparoscopic sleeve gastrectomy as a revision procedure for prior laparoscopic gastric banding. Obes Surg 2006;16:1327-30

24. Lalor PF, Tucker ON, Szomstein S, Rosenthal RJ. Complications after laparoscopic sleeve gastrectomy. Surg Obes Relat Dis 2008;4:33-8

25. Foletto M, Prevedello L, Bernante P, et al. Sleeve gastrectomy as revisional procedure for failed gastric banding or gastroplasty. Surg Obes Relat Dis 2010;4:146-51

26. Goitein D, Feigin A, Segal-Lieberman G, Goitein O, Papa MZ, Zippel D. Laparoscopic sleeve gastrectomy as a revisional option after gastric band failure. Surg Endosc 2011;25:2626-30

27. Elazary R, Hazzan D, Appelbaum L, Rivkind AI, Keidar A. Feasibility of sleeve gastrectomy as a revision operation for failed silastic ring vertical gastroplasty. Obes Surg 2009;19:645-9

28. Iannelli A, Schneck AS, Ragot E, et al. Laparoscopic sleeve gastrectomy as revisional procedure for failed gastric banding and vertical banded gastroplasty. Obes Surg 2009;19:1216-20

29. Patel S, Eckstein J, Acholonu E, Abu-Jaish W, Szomstein S, Rosenthal RJ. Reasons and outcomes of laparoscopic revisional surgery after laparoscopic adjustable gastric banding for morbid obesity. Surg Obes Relat Dis 2010;6:391-8

30. Jacobs M, Gomez E, Romero R, Jorge I, Fogel R, Celaya C. Failed restrictive surgery: is sleeve gastrectomy a good revisional procedure ? Obes Surg 2011;21:157-60 
31. Gagnière J, Slim K, Lainay-Savary MV, Raspado O, Flamein R, Chipponi J. Previous gastric banding increases morbidity and gastric leaks after laparoscopic sleeve gastrectomy for obesity. J Visc Surg 2011;148:205-9

32. Abu-Gazala S, Keidar A. Conversion of failed gastric banding into four different bariatric procedures. Surg Obes Relat Dis 2011 Jun 30 (Epub ahead of print)

33. Berende CA, de Zoete JP, Smulders JF, Nienhuijs SW. Laparoscopic sleeve gastrectomy feasible for bariatric revision surgery. Obes Surg 2012;22:330-4

34. Rebibo L, Mensah E, Verhaeghe $\mathrm{P}$, et al. Simultaneous gastric band removal and sleeve gastrectomy: a comparison with front-line sleeve gastrectomy. Obes Surg 2012 Jul 12 (Epub ahead of print)

35. Kothari SN, DeMaria EJ, Sugerman HJ, Kellum JM, Meador J, Wolfe. Lap-Band failures: conversion to gastric bypass and their preliminary outcomes. Surgery 2002;131:625-9

36. Weber M, Muller MK, Michel JM, et al. Laparoscopic Roux-en-Y gastric bypass, but not rebanding, should be proposed as rescue procedure for patients with failed laparoscopic gastric banding. Ann Surg 2003;238:827-34

37. Mognol P, Chosidow D, Marmuse JP. Laparoscopic conversion of laparoscopic gastric banding to Roux-en-Y gastric bypass: a review of 70 patients. Obes Surg 2004;14:1349-53

38. Van Wageningen B, Berends FJ, Van Ramshorst B, Janssen IF. Revision of failed laparoscopic adjustable gastric banding to Roux- en-Y gastric bypass. Obes Surg 2006;16:137-41

39. Spivak H, Beltran OR, Slavchev P, Wilson EB. Laparoscopic revision from Lap-Band to gastric bypass. Surg Endosc 2007;21:1388-92

40. Langer FB, Bohdjalian A, Shakeri-Manesch S, et al. Inadequate weight loss vs secondary weight regain: laparoscopic conversion from gastric banding to Roux-en-Y gastric bypass. Obes Surg 2008;18:1381-6

41. Van Dessel E, Hubens G, Ruppett M, Balliu L, Weyler J, Vaneer- deweg W. Roux-en-Y gastric bypass as a re-do procedure for failed restrictive gastric surgery. Surg Endosc 2008;22:1014-8

42. Te Riele WW, Sze YK, Wiezer MJ, et al. Conversion of failed laparoscopic gastric banding to gastric bypass as safe and effective as primary gastric bypass in morbidly obese patients. Surg Obes Relat Dis 2008; 4:735-9

43. Topart Ph, Becouarn G, Ritz P. One-year weight loss after primary or revisional Roux-en-Y gastric bypass for failed adjustable gastric banding. Surg Obes Relat Dis 2009;5:459-62

44. Mognol P, Chosidow D, Marmuse JP. Roux-en-Y gastric bypass after failed vertical banded gastroplasty. Obes Surg 2007;17:1431-4

45. Sanchez H, Cabrera A, Cabrera K, et al. Laparoscopic Roux-en-Y gastric bypass as a revision procedure after restrictive bariatric surgery. Obes Surg 2008;18:1539-43

46. Schouten R, Wiryasaputra DC, van Dielen FM, van Gemert WG, Greve JW. Long-term results of bariatric restrictive procdures: a prospective study. Obes Surg 2010;20:1617-26

47. Tevis S, Garren MJ, Gould JC. Revisional surgery for failed vertical-banded gastroplasty. Obes Surg 2011;21:1220-4

48. Ardestani A, Lautz DB, Tavakkolizadeh A. Band revision versus Roux-en-Y gastric bypass conversion as salvage operation after laparoscopic adjustable gastric banding. Surg Obes Relat Dis 2011;7:33-7

49. Gagne' DJ, Dovec E, Urbandt JE. Laparosocpic revision of vertical banded gastroplasty to Roux-enY gastric bypass: outcomes of 105 patients. Surg Obes Relat Dis 2011;7:493-9

50. Ekelund M, Oberg S, Peterli R, Frederiksen SG, Hedenbro JL. Gastroesophageal reflux after vertical banded gastroplasty is alleviated by conversion to gastric bypass. Obes Surg 2012;22:851-4

51. Hii MW, Lake AC, Kenfield C, Hopkins GH. Laparoscopic conversion of failed gastric banding to Roux-en-Y gastric bypass. Short-term follow-up and technical considerations. Obes Surg 2012;22:1022-8

52. Deylgat B, D'Hondt M, Pottel H, Vansteenkiste F, Van Rooy F, Devriendt D. Indications, safety, and feasibility of conversion of failed bariatric surgery to Roux-en-Y gastric bypass: a retrospective comparative study with primary laparoscopic Roux-en-Y gastric bypass. Surg Endosc 2012;26:1997-2002 
53. Suter M, Ralea S, Millo P, Allé JL. Laparoscopic Roux-en-Y gastric bypass after failed vertical banded gastroplasty: a multicenter experience with 203 patients. Obes Surg 2012 Jun 15 (Epub ahead of print)

54. Dolan K, Fielding G. Biliopancreatic diversion following failure of laparoscopic adjustable gastric banding. Surg Endosc 2004;18:60-3

55. de Csepel J, Quinn T, Pomp A, Gagner M. Conversion to a laparoscopic biliopancreatic diversion with a duodenal switch for failed laparoscopic adjustable silicone gastric banding. J Laparoendosc Adv Surg Tech A 2002;12:237-40

56. Gagner M, Gumbs AA. Gastric banding: conversion to sleeve, bypass, or DS. Surg Endosc 2007;21:1931-5

57. Topart P, Becouarn G, Ritz P. Biliopancreatic diversion with duodenal switch or gastric bypass for failed gastric banding: retrospective study from two institutions with preliminary results. Surg Obes Relat Dis 2007;3:521-5

58. Sudan R, Desai S. Conversion of laparoscopic adjustable gastric band to robot-assisted laparoscopic biliopancreatic diversion with duodenal switch. Surg Obes Relat Dis 2011;7:546-7

59. Cottam D, Qureshi FG, Mattar SG, et al. Laparoscopic sleeve gastrectomy as an initial weight-loss procedure for high-risk patients with morbid obesity. Surg Endosc 2006;20:859-63

60. Langer FB, Bohdjalian A, Shakeri-Leidenmuhler S, Schoppmann SF, Zacherl J, Prager G. Conversion from sleeve gastrectomy to Roux-en-Y gastric bypass-indications and outcome. Obes Surg 2010;20:835-40

61. Bellorin O, Lieb J, Szomstein S, Rosenthal RJ. Laparoscopic conversion of sleeve gastrectomy to Roux-en-Y gastric bypass for acute gastric outlet obstruction after laparoscopic sleee gastrectomy for morbid obesity. Surg Obes Relat Dis 2010;6:566-8

62. Weiner RA, Theodoridou S, Weiner S. Failure of laparoscopic sleeve gasterctomy-further procedure? Obes Facts 2011;4 Suppl 1:42-6

63. Parikh A, Alley JB, Peterson RM, et al. Management options for symptomatic stenosis after laparoscopic vertical sleeve gastrectomy in the morbidly obese. Surg Endosc 2012;26:738-46

64. Abdemur A, Fendrich I, Rosenthal R. Laparoscopic conversion of laparoscopic sleeve gastrecomy to gastric bypass for intractable gastroeosphageal reflux disease. Surg Obes Relat Dis 2011 Jun 17 (Epub ahead of print)

65. Greenstein AJ, Jacob BP. Placement of a laparoscopic adjustable gastric band after failed sleeve gastrectomy. Surg Obes Relat Dis 2008;4:556-8

66. Alexander JW, Martin Hawver LR, Goodman HR. Banded sleeve gastrectomy-initial experience. Obes Surg 2009;19:1591-6

67. Karcz WK, Marjanovic G, Grueneberger J, et al. Banded sleeve gastrectomy using the GaBP ringsurgical technique. Obes Facts 2011;4:77-80

68. Baltasar A, Serra C, Perez N, Bou R, Bengochea M. Re-sleeve gastrectomy. Obes Surg 2006;16:1535-8

69. Parikh M, Gagner M. Laparoscopic hiatal hernia repair and repeat sleeve gastrectomy for gastroesophageal reflux disease after duodenal switch. Surg Obes Relat Dis 2008;4:73-5

70. Iannelli A, Schneck AS, Topart P, Carles M, Hébuterne X, Gugenheim J. Laparoscopic sleeve gastrectomy followed by duodenal switch in selected patients versus single-stage duodenal switch for superobesity: case-control study. Surg Obes Relat Dis 2012 Mar 3 (Epub ahead of print)

71. Ren CJ, Patterson E, Gagner M. Early results of laparoscopic biliopancreatic diversion with duodenal switch: a case series of 40 consecutive patients. Obes Surg 2000;10:514-23

72. Silecchia G, Rizzello M, Casella G, Fioriti M, Soricelli E, Basso N. Two-stage laparoscopic biliopancreatic diversion with duodenal switch as treatment of high-risk super-obese patients: analysis of complications. Surg Endosc 2009;23:1032-7

73. Iannelli A, Schneck AS, Dahman M, Negri C, Gugenheim J. Two-step laparoscopic duodenal switch for superobesity: a feasibility study. Surg Endosc 2009;23:2385-9

74. Mukherjee S, Devalia K, Rahman MG, Mannur KR. Sleeve gastrectomy as bridge to second bariatric procedure in superobese patients-a single institution experience. Surg Obes Relat Dis 2012;8:140-4 
75. Parikh M, Pomp A, Gagner M. Laparoscopic conversion of failed gastric bypass to duodenal switch: technical considerations and preliminary outcomes. Surg Obes Relat Dis 2007;3:611-8

76. Simper SC, Erzinger JM, McKinlay RD, Smith SC. Laparoscopic reversal of gastric bypass with sleeve gastrectomy for treatment of recurrent retrograde intussusception and Roux stasis syndrome. Surg Obes Relat Dis 2010;6:684-8

77. Sugerman HJ, Kellum JM, De Maria EJ. Conversion of proximal to distal gastric bypass for failed gastric bypass for superobesity. J Gastrointest Surg 1997;1:517-25

78. Fobi MAL, Lee H, Igwe D Jr, et al. Revision of failed gastric bypass to distal Roux-en-Y gastric bypass: a review of 65 cases. Obes Surg 2001;11:190-5

79. Brolin RE, LaMarca LB, Kenler HA, Cody RP. Malabsorptive gastric bypass in patients with superobesity. J Gastrointest Surg 2002;6:195-205

80. Rawlins ML, Tell D 2nd, Hedgcorth K, Maguire JP. Revision of Roux-en-Y gastric bypass to distal bypass for failed weight loss. Surg Obes Relat Dis 2011;7:45-9

81. Bessler M, Doud A, DiGiorgi MF, et al. Adjustable gastric banding as a revisional bariatric procedure after failed gastric bypass. Obes Surg 2005;15:1443-8

82. Gobble RM, Parikh MS, Greives MR, et al. Gastric banding as a salvage procedure for patients with weight loss failure after Roux-en-Y gastric bypass. Surg Endosc 2008;22:1019-22

83. Chin PL, Ali M, Francis K, LePort PC. Adjustable gastric band placed around gastric bypass pouch as revision operation for failed gastric bypass. Surg Obes Relat Dis 2009;5:38-42

84. Bessler M, Daud A, Inabnet WB, Schrope B. Adjustable gastric banding as revisional bariatric procedure after failed gastric bypass-intermediate results. Surg Obes Relat Dis 2010;6:31-5

85. Irani K, Youn HA, Ren-Fielding CJ, Fielding GA, Kurian M. Midterm results for gastric banding as salvage procedure for patients with weight loss failure after Roux-en-Y gastric bypass. Surg Obes Relat Dis 2011;7:219-24

86. Dapri G, Himpens J, Cadière GB. Laparoscopic conversion of Roux-en-Y gastric bypass to biliopancreatic diversion. Surg Endosc 2010;24:1490-3

87. Gagner M, Rogula T. Laparoscopic reoperative sleeve gastrectomy for poor weight loss after biliopancreatic diversion with duodenal switch. Obes Surg 2003;13:649-54

88. Dapri G, Cadière GB, Himpens J. Laparoscopic restoration of gastrointestinal continuity after duodenal switch. Surg Obes Relat Dis 2008;4:451-4

89. Lehmann KS, Ritz JP, Wibmer A, et al. The German registry for natural orifice translumenal endoscopic surgery: report of the first 551 patients. Ann Surg 2010;252:263-70

90. Rattner DW, Hawes R, Schwaitzberg S, Kochman M, Swanstrom L. The second SAGES/ASGE white paper on natural orifice transluminal endoscopic surgery: 5 years of progress. Surg Endosc 2011;25:2441-8

91. Ramos AC, Zundel N, Neto MG, Maalouf M. Human hybrid NOTES transvaginal sleeve gastrectomy: initial experience. Surg Obes Relat Dis 2008;4:660-3

92. Marchesini JC, Cardoso AR, Nora M et al. Laparoscopic sleeve gastrectomy with NOTES visualization - a step toward NOTES procedures. Surg Obes Relat Dis 2008;4:773-6

93. Chouillard EK, Al Khoury M, Bader G, Heitz D, Elrassi Z, Fauconnier A. Combined vaginal and abdominal approach to sleeve gastrectomy for morbid obesity in women: a preliminary experience. Surg Obes Relat Dis 2011;7:581-6

94. Madan AK, Tichansky DS, Khan KA. Natural orifice transluminal endoscopic gastric bypass performed in a cadaver. Obes Surg 2008;18:1192-9

95. Pelosi MA, Pelosi MA III. Laparoscopic appendectomy using a single umbilical puncture. J Reprod Med 1992;37:588-94

96. Nguyen NT, Hinojosa MW, Smith BR, Reavis KM. Single laparoscopic incision transabdominal (SLIT) surgery - adjustable gastric banding: a novel minimally invasive surgical approach. Obes Surg 2008;18:1628-31

97. Saber AA, Elgamal MH, Itawi EA, Rao AJ. Single incision laparoscopic sleeve gastrectomy (SILS): a novel technique. Obes Surg 2008;18:1338-42

98. Huang CK, Houng JY, Chiang CJ, Chen YS, Lee PH. Single incision transumbilical laparoscopic Roux-en-Y gastric bypass: a first case report. Obes Surg 2009;19:1711-5 
99. Tacchino RM, Greco F, Matera D. Single-incision laparoscopic biliopancreatic diversion. Surg Obes Relat Dis 2010;6:444-5

100. Hanna GB, Drew T, Clinch P, Hunter B, Cuschieri A. Computer-controlled endoscopic performance assessment system. Surg Endosc 1998;12:997-1000

101. Romanelli JR, Earle DB. Single-port laparoscopic surgry: an overview. Surg Endosc 2009;23:141927

102. Dapri G. Specially designed curved reusable instruments for single-access laparoscopy: 2.5-year experience in 265 patients. Minim Invasive Ther Allied Technol 2012;21:31-9

103. Talebpour M, Amoli BS. Laparoscopic total gastric vertical plication in morbid obesity. J Laparoendosc Adv Surg Tech A 2007;17:793-8

104. Abdelbaki TN, Huang CK, Ramos A, Neto MG, Talebpour M, Saber AA. Gastric plication for morbid obesity: a systematic review. Obes Surg 2012;22:1633-9 

Chapter 1b

INTRODUCTION TO THE STUDIES AND AIM OF THE THESIS 

This thesis evaluates the evolution of laparoscopic techniques in bariatric surgery and mainly can be summarized in four sections.

The first section includes chapters 2-3 and discusses some technical aspects to perform sleeve gastrectomy (SG). Chapter 2 describes the technique of sectioning the stomach before or after the devascularization of the greater curvature in a randomized trial. Chapter 3 reports the management of the staple line during this procedure, randomly comparing three different techniques.

The second section compromises chapters 4-7 and describes the different conversions in patients with previous restrictive bariatric procedures like laparoscopic adjustable gastric banding (LAGB), vertical banded gastroplasty (VBG) or SG. Chapter 4 reports the conversion of LAGB into SG. Chapter 5 reports the possibility to repeat $S G$ in patients already submitted to $S G$, or the addition of the biliopancreatic diversion component to a previous $\mathrm{SG}$, transforming the procedure into a duodenal switch (DS). Chapter 6 reports the one-step conversion to DS from restrictive procedures, like LAGB or VBG. Chapter 7 describes the second step of DS after $\mathrm{SG}$, in super-obese patients (BMI $\left.>50 \mathrm{~kg} / \mathrm{m}^{2}\right)$ or super super-obese patients $\left(\mathrm{BMI}>60 \mathrm{~kg} / \mathrm{m}^{2}\right)$.

The third section, chapters $8-11$, describes the different conversions in patients after Roux-en-Y gastric bypass (RYGB). Chapter 8 describes the placement of a non-adjustable ring on the gastric pouch, transforming the RYGB into a banded RYGB. Chapter 9 reports the transformation of a standard RYGB into a distal RYGB. Chapter 10 describes the direct conversion of RYGB into SG, after restoring the original anatomy (OA). Chapter 11 shows the restoration of RYGB to OA, demonstrating that RYGB procedure is no more considered as a non-reversible procedure. Once the normal anatomy is re-established, the patient can directly undergo a new bariatric procedure or the new bariatric procedure can be planned after a certain interval time (second step).

The fourth section includes chapter 12 and reports the evolution for conventional multitrocar laparoscopy to single-access laparoscopic bariatric surgery. Chapter 12 describes the removal of the LAGB through single-access laparoscopy. 



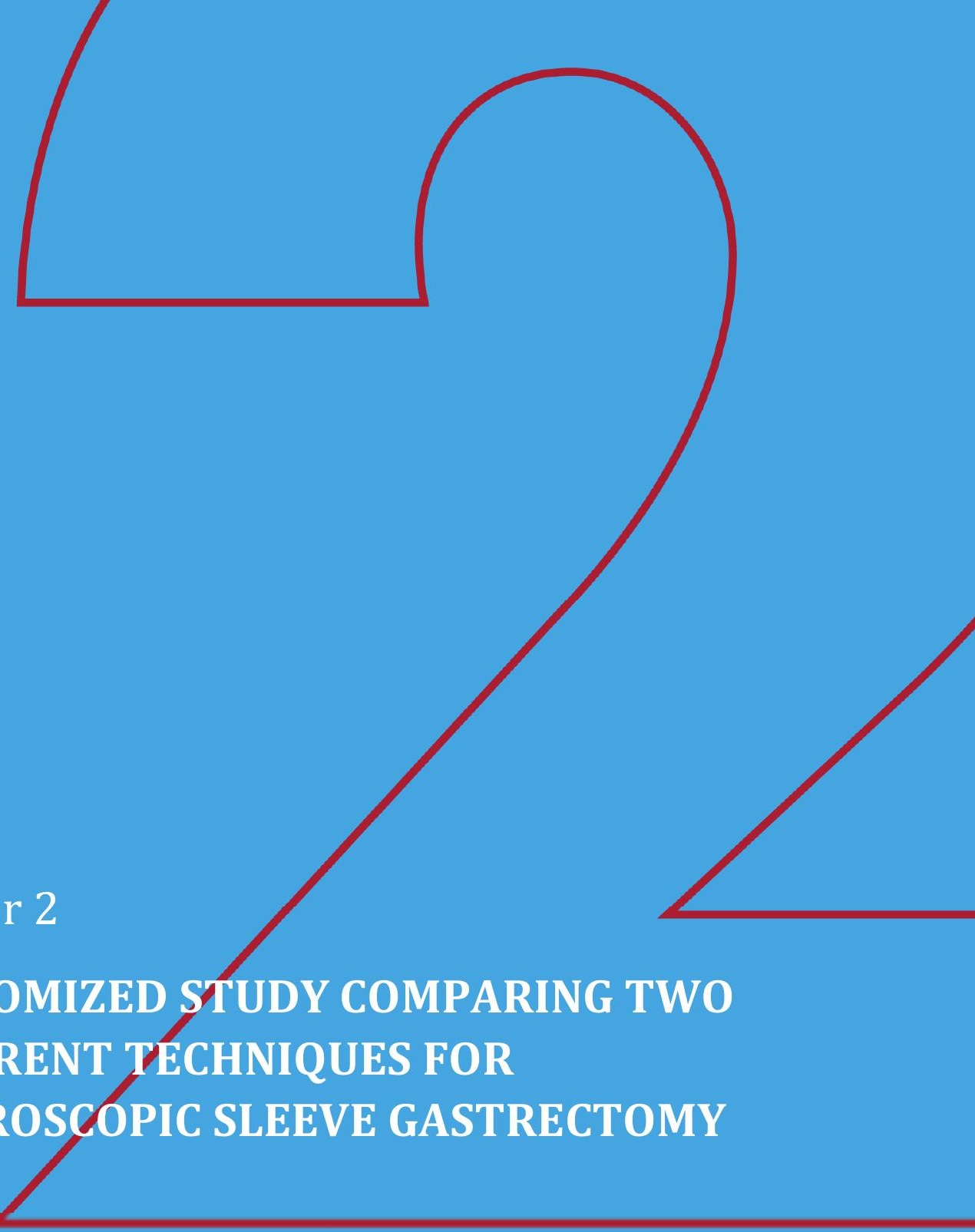

Chapter 2

\section{RANDOMIZED STUDY COMPARING TWO DIFFERENT TECHNIQUES FOR LAPAROSCOPIC SLEEVE GASTRECTOMY}

Dapri G, Vaz C, Cadière GB, Himpens J

Obesity Surgery 2007;17(11):1435-1441 



\section{$2.1 \quad$ ABSTRACT}

Background: Laparoscopic sleeve gastrectomy (LSG) represents a relatively new restrictive operation for obesity. We report a prospective randomized study comparing two different techniques of performing this procedure.

Patients and Methods: Between January and August 2006, 20 patients (group A) and 20 patients (group B) were prospectively and randomly submitted to LSG. The characteristics of the patients in the two groups were similar for age and sex.The median preoperative weight was of $120 \mathrm{~kg}$ (range 95-180) (A) and $133 \mathrm{~kg}$ (range 83-175) (B) (NS). The median preoperative BMI was of $42.5 \mathrm{~kg} / \mathrm{m}^{2}$ (range 35-58) (A) and $47 \mathrm{~kg} / \mathrm{m}^{2}$ (range 37-58) (B) (NS). The two techniques differ in that in A, stapling is performed after full devascularization and mobilization of the gastric curve, whereas in B stapling is performed as soon as the lesser sac is entered and the greater curve is devascularized after full completion of the sleeve. The stapleline is reinforced at the end of stapling in both techniques.

Results: Median operative time was $34 \mathrm{~min}$ (range 12-54) (A) and $25 \mathrm{~min}$ (range 9-51) (B) ( $\mathrm{p}=0.06)$. Median peroperative bleeding was $5 \mathrm{~mL}$ (range $0-450$ ) (A) and $5 \mathrm{~mL}$ (range $0-100)(B)(p=0.37)$. Median number of staple cartridges used was 6 (range 5-7) (A) and 6 (range 4-7) (B) ( $p=0.63)$. Peroperative complications were a small hiatal hernia requiring repair and a bleeding in two patients of $A$. Postoperative leak occurred in 1 patient of $\mathrm{A}$, and minor early complications affected 2 patients of $A$ and 1 patient of B. Peroperative and postoperative mortality was 0 . Median hospital stay was 3 days (range 1-10) (A) and 3 days (range 2-7) (B) $(\mathrm{p}=0.59)$. One stenosis as a late complication appeared in a patient of B. \%EWL at 6 months and 1 year was respectively $43.4 \%$ (A), 42.2\% (B) and $48.3 \%$ (A) $49.5 \%$ (B) $(\mathrm{p}=0.82)$.

Conclusion: LSG can be performed by two different techniques. The technique B (section of the stomach followed by its mobilization) appears familiar to surgeons usually performing laparoscopic RYGB. No observed differences are significant, but the technique $\mathrm{B}$ when looking at observed distributions, seems to be better than the technique A (mobilization of the stomach followed by its section) in terms of operative time, peroperative bleeding and hospital stay. 


\subsection{INTRODUCTION}

Laparoscopic sleeve gastrectomy (LSG) is considered as a restrictive operation for bariatric surgery. It was described in 1988 as the restrictive part of duodenal switch (DS) by Hess [1] and Marceau [2] and in 1993 as an isolated form by Johnston [3]. LSG is currently less popular than laparoscopic adjustable gastric banding (LAGB) in Europe and than laparoscopic Roux-en-Y gastric bypass (LRYGB) and LAGB in the United States [4]. In the literature, more reports described the LSG as the first-step of other bariatric procedures such as DS [5-9] or RYGB [7,10-13], offering the possibility to reduce the operative risks and postoperative morbidity and mortality. Percentage of excess weight loss (\%EWL) after LSG is reported to be $35-61 \%$ at 6 months $[4,7,14-17], 46-83 \%$ at 1 year $[8,10,15,18,19], 56-83 \%$ at 2 years $[9,10]$, and $66 \%$ at 3 years [16]. The technique of performing LSG has been described generally in the same fashion $[4,5-7,9,17,19]$, but the most demanding step in this procedure is the dissection of the angle of His, that must consider the risks of esophageal injury, redundant stomach after the last firing of the stapler, and bleeding in the deep splenic region. We hereby compare in a prospective randomized study two different techniques to perform the LSG. The two techniques differ in that in one (group A) stapling is performed after full devascularization and mobilization of the gastric greater curve, whereas in the other (group B) stapling is performed as soon as the lesser sac is entered and the greater curve is devascularized after full completion of the sleeve.

\subsection{PATIENTS AND METHODS}

Between January $1^{\text {st }}$ and August $31^{\text {st }} 2006,40$ patients were consecutively and randomly assigned to LSG as the technique A (20) or the technique B (20). Surgical technique was randomly decided by opening sealed envelopes before laparoscopy. One patient of group B was converted to an LRYGB because a giant hiatal hernia was discovered peroperatively (despite normal preoperative gastroscopy); the latter was excluded from the study after randomization and this exclusion was not related to the surgical procedure. LSG was performed as the sole operation in 14 patients of $A$ and 8 patients of $B$, as the first step of a DS in 1 patient of $A$ and 5 patients of $\mathrm{B}$, and during a laparoscopic DS in 5 patients of $\mathrm{A}$ and 6 patients of $\mathrm{B}$. The characteristics of the patients were similar for the two groups: 10 males and 10 females (A) versus 8 males and 11 females (B) (NS), a median age of 43.5 years (range 29-62) (A) and 48 years (range 19-64) (B) (NS), a median preoperative weight of $120 \mathrm{~kg}$ (range 95-180) (A) and $133 \mathrm{~kg}$ (range 83-175) (B) (NS), and a median preoperative BMI of $42.5 \mathrm{~kg} / \mathrm{m}^{2}$ (range $35-58$ ) (A) and $47 \mathrm{~kg} / \mathrm{m}^{2}$ (range 37-58) (B) (NS). Eleven patients (55\%) of A and 9 patients (45\%) of B suffered preoperatively from one or more morbidity related to the obesity. The following variables were chosen as outcome measures considered as continuous: operative 
time, peroperative bleeding, number of staple cartridges used, hospital stay, weight loss and the following categorical variables: peroperative complications, early and late postoperative complications, and peroperative and postoperative mortality. The distributions of the continuous variables were compared using nonparametric Mann-Whitney tests and the distributions of categorical variables were compared using Fisher's exact tests (twotailed tests). A statistical difference was considered significant for $\mathrm{p}<0.05$. The patients were followed-up in the office at 10 days, 1, 3, 6 months and 1 year.

\subsubsection{SURGICAL TECHNIQUE}

\subsubsection{Technique $A$ and $B$}

The patient is positioned in dorsal decubitus, with the legs apart and in reversed Trendelenburg position with a $10^{\circ}$ tilt, carefully strapped to the operating table, with the arms placed in abduction. Shoulder supports are placed and extreme care is taken to pad the pressure points and joints with foam cushions. The surgeon stands between the patient's legs, the assistant to the patient's left and the cameraman to the patient's right. Abdominal insufflation is set at $15 \mathrm{mmHg}$. Trocars are placed as fellows: a $10-\mathrm{mm}$ trocar (T1) $20 \mathrm{~cm}$ below the xyphoid process for the $30^{\circ}$ optical system, a 5-mm trocar (T2) on the left anterior axillary line, a 12$\mathrm{mm}$ trocar (T3) on the left mid-clavicular line just between the 1st and the $2 \mathrm{nd}$ trocars, a $12-\mathrm{mm}$ trocar (T4) on the right mid-clavicular line and a 5-mm trocar (T5) below the xyphoid process (Fig.1).

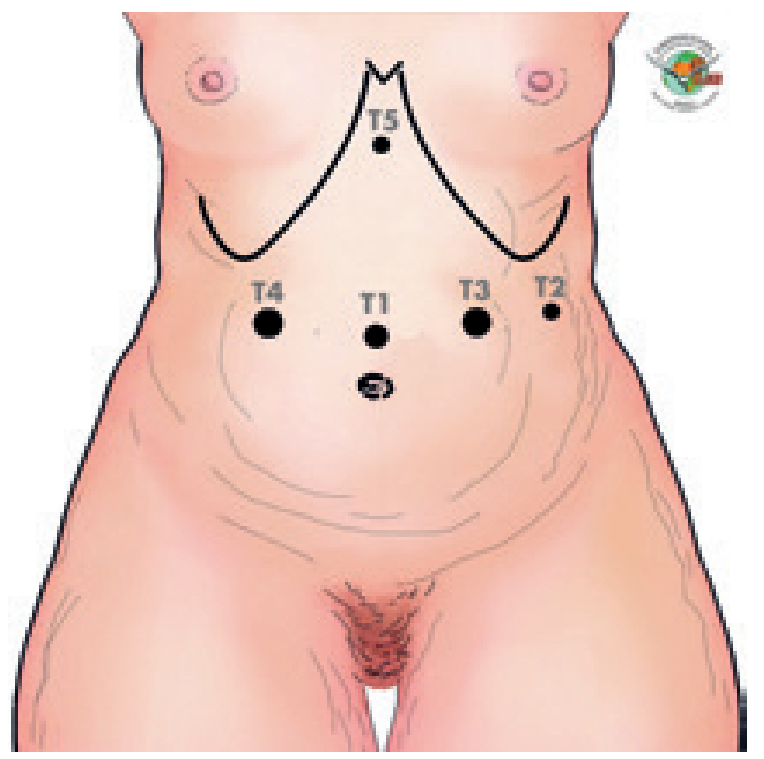

Fig.1 Laparoscopic sleeve gastrectomy: position of the 5 abdominal trocars 
After identification of the Crow's foot, a straight line is marked with the coagulating hook up to the greater curve, delimiting the spared antrum (Fig.2).

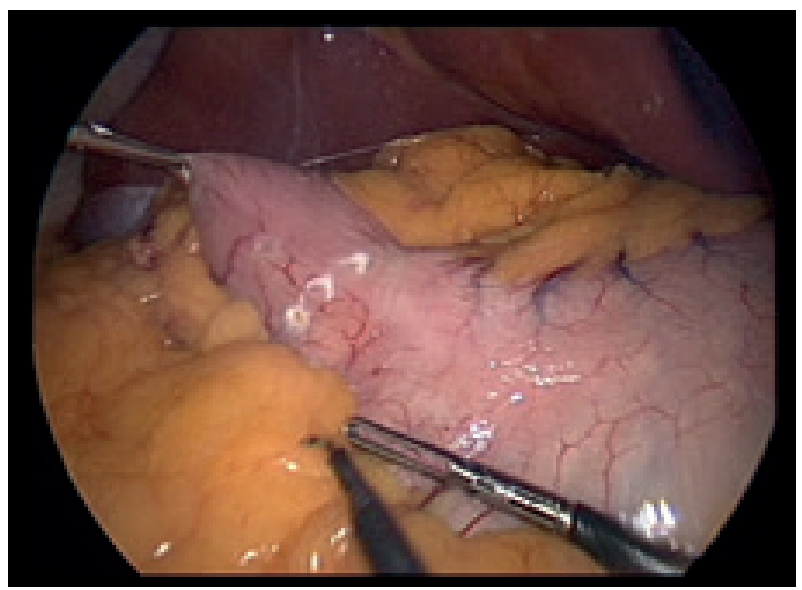

Fig.2 Technique A and B (first step): the limit of the spared antrum indicated by marking

The lesser sac is accessed through a window made in the greater omentum $3 \mathrm{~cm}$ laterally from the marking, close to the greater curve and within the epiploic arch.

\subsubsection{Technique A}

The dissection proceeds cranially in order to completely dissect the omentum off the greater curve using the coagulating hook. The dissection reaches the left diaphragmatic crus which is entirely freed as well as the base of the right diaphragmatic crus (Fig.3).

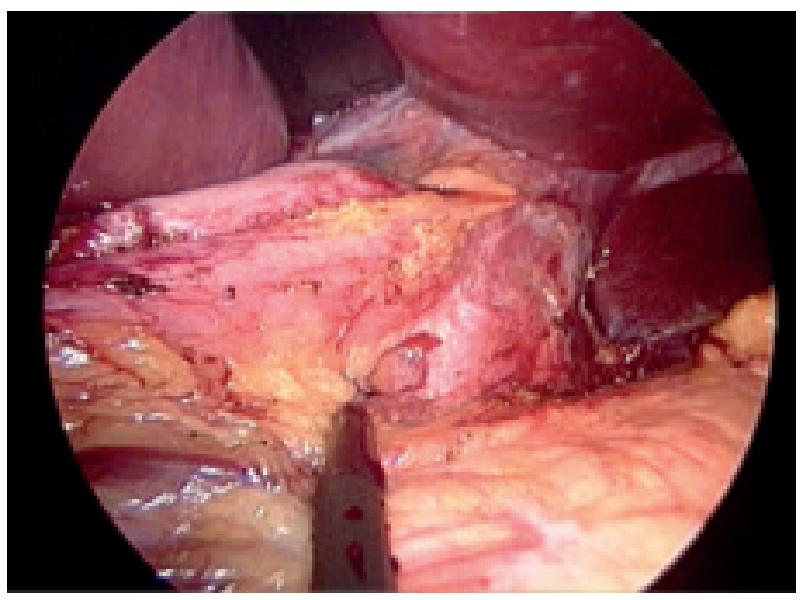

Fig.3 Technique A: the left crus and base of right crus freed 
It is completed caudally in the direction of the pylorus, reaching the previously marked proximal border of the antrum. All retrogastric adhesions must be divided, respecting the left gastric vessels. A first firing of the linear stapler blue or green load (EndoGIA 60-mm), inserted in the abdomen through T4, divides the greater curve in the direction of the Crow's foot, aiming towards the endings of the small gastric vessels on the lesser curve (Fig.4).

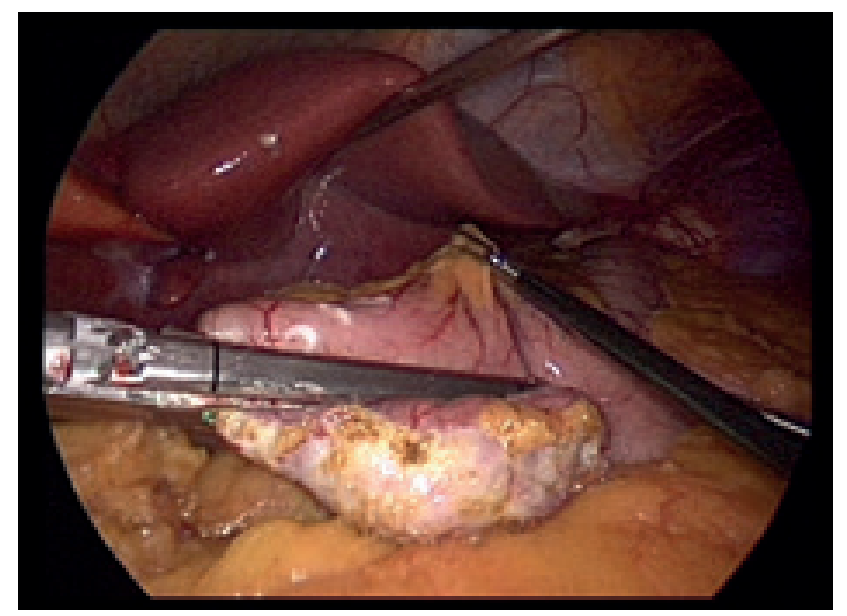

Fig.4 Technique A and B: first firing of linear stapler and the endings of the small gastric vessels on the lesser curve

Other firings of the linear stapler blue or green load (EndoGIA 60-mm), inserted through T3, transect the stomach parallel to the lesser curve, from the antrum to the angle of His. Before the third firing of the stapler, the anesthesiologist passes down a gastric tube of 34 French, in order to guide the gastric section. During section, the assistant grasper, inserted through $\mathrm{T} 2$, takes laterally the greater curve in the direction of the spleen. A running suture, using absorbable material (e.g. PDS 1) reinforces the staple-line, starting from the area of the angle of His until the marking (Fig.5). 


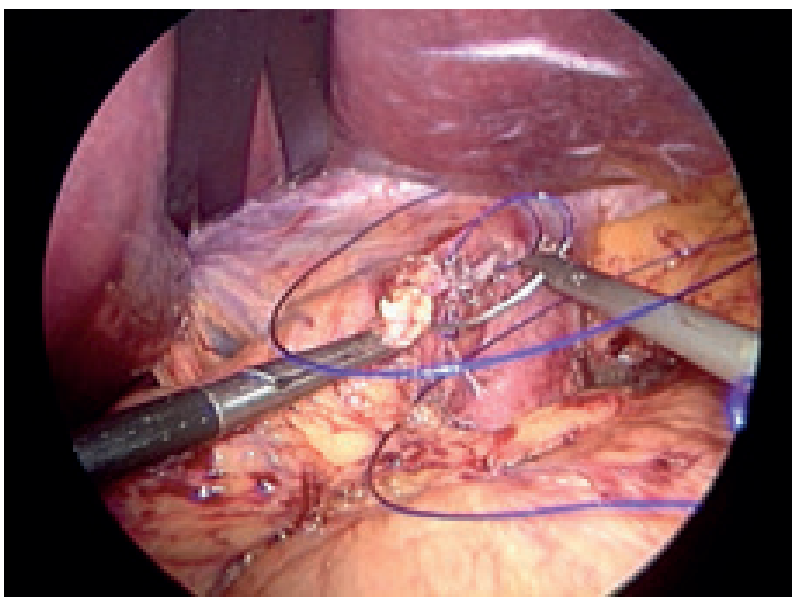

Fig.5 Technique A: start of the running suture oversewing the staple-line

\subsubsection{Technique $B$}

The window in the greater omentum is opened, close to the greater curve, from 3 $\mathrm{cm}$ laterally until the marked stomach. It is made just sufficiently large enough to permit the introduction of the first firing of the linear stapler, blue or green load (EndoGIA 60-mm) through T4. The stapler arrives in contact with the endings of the small gastric vessels on the lesser curveand is fired (Fig.4). Further firings of linear stapler, inserted through T3, should be parallel to the lesser curve. Posterior gastric adhesions are divided. Before the third firing of the stapler, the anesthesiologist passes down the 34 French gastric tube in order to guide the gastric section in the direction of the angle of His. Before the last firing of the stapler the angle of His is freed from top to bottom and vice versa (Fig.6);

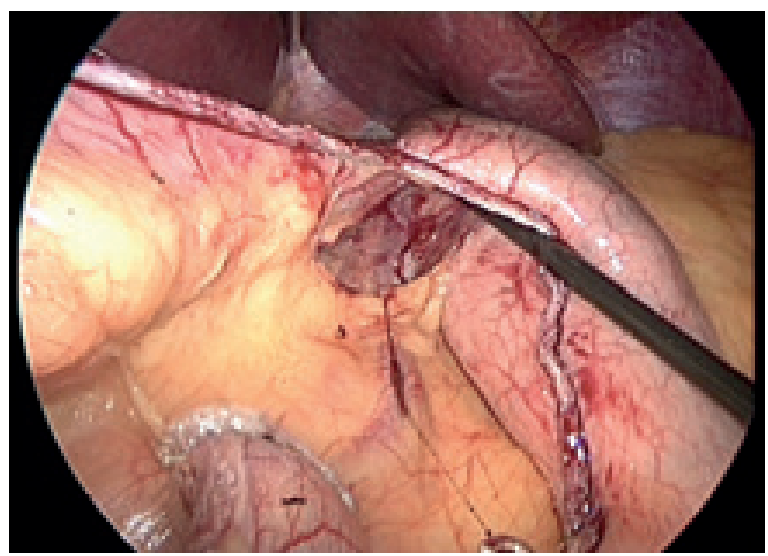

Fig.6 Technique B: angle of His freed from bottom to top, and the left crus as landmark 
The stomach is transected without tension, staying distant from the gastroesophageal junction (Fig.7).

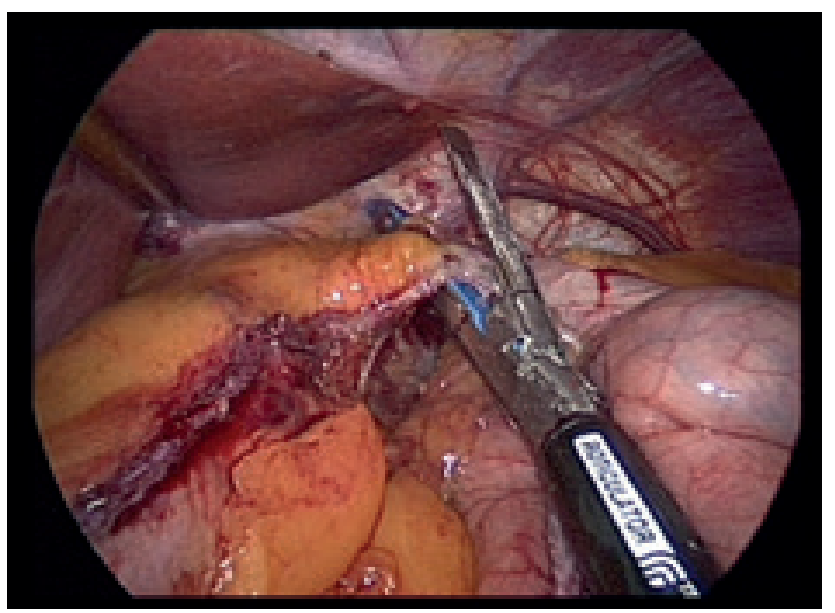

Fig.7 Technique B: last firing of linear stapler placed so as to stay distant from the gastroesophageal junction

The staple-line is reinforced by a running suture using absorbable material (e.g. PDS 1) starting from the last firing of the stapler until the marking. The greater omentum is now dissected off the stomach along the greater curve by a coagulating hook, reaching the left diaphragmatic crus.

\subsubsection{Technique $A$ and $B$}

The resected part of the stomach is extracted through T3. The patient is positioned in Trendelenburg position and the operative field is immersed in saline solution. Compressed air insufflated through the gastric tube by the anesthesiologist tests the integrity and symmetry of the sleeve. A drain is placed along the sleeve until the upper pole of the spleen and the T3 is closed in layers. The gastric tube is extracted at the end of the operation.

\section{$2.4 \quad$ RESULTS}

The median operative time was 34 minutes (range 12-54) (A) and 25 minutes (range 9-51) (B) $(\mathrm{p}=0.06)$. The median peroperative bleeding was $5 \mathrm{~mL}$ (range 0 450) (A) and $5 \mathrm{~mL}$ (range $0-100)(\mathrm{B})(\mathrm{p}=0.37)$. The median number of staple cartridges used was 6 (range 5-7) (A) and 6 (range 4-7) (B) $(p=0.63)$. Peroperative complications were registered in group A. Diaphragmatic crura repair was performed in a patient for a small hiatal hernia evidenced preoperatively and a significant peroperative bleeding $(450 \mathrm{~mL})$ during the dissection of the greater omentum 
occurred in another patient of this group. Postoperative major complication occurred in one patient of group A, who presented a leak at the site of the angle of His, treated by placement of an endoscopic stent (Ultraflex/Polyflex, Boston Scientific, Natick, MA). The enterocutaneous fistula was successfully healed on the 65th postoperative day. Postoperative minor complications for A were a bronchospasm with tachycardia and a pneumonia in another patient, both treated medically; for B an abdominal wall cellulitis at the extraction site, treated medically. The median hospital stay was 3 days (range 1-10) (A) and 3 days (range 2-7) (B) (p=0.59). There was no peroperative and postoperative mortality in either group. Postoperative late complication occurred in one patient of group B, who presented a stenosis of the sleeve on the $41^{\text {st }}$ postoperative day, treated by a single endoscopic dilation. Average weight loss for group A at 10 days, 1, 3, 6 months and 1 year, for the isolated sleeve and as a first step, was respectively of 4, 11, 30, 35, $40 \mathrm{~kg}$ for A, and for group $\mathrm{B}, 3,12,29,33,42 \mathrm{~kg}$ for $\mathrm{B}(\mathrm{p}=0.82)$. \%EWL (using the Metropolitan tables) at $1,3,6$ months and 1 year for $A$ was $16.2 \%, 38.3 \%, 43.4 \%, 48.3 \%$, and for $B$ was $16.8 \%, 37.7 \%, 42.2 \%, 49.5 \%$, respectively ( $\mathrm{p}=0.82$ ).

\subsection{DISCUSSION}

LSG as an isolated operation has become increasingly popular in Europe, because it represents a relatively simple restrictive procedure for obesity. After having performed > 350 isolated LSG using the technique A, one of the authors (JH) had the idea to perform a new technique (B). Two essential technical aspects must be considered during the LSG: the complete liberation of the gastric fundus, and the final firing of the linear stapler near the angle of His, avoiding encroachment on the esophagus. These two aspects are very important in order to obtain a narrow gastric tube without any redundant part and to avoid a postoperative leak at the site of the angle of His. The technique $B$, regarding the division of the stomach performed at the end of the procedure, appears to be easier than A, because the last firing of the stapler is given in the same condition as the gastric pouch construction during LRYGB. This is probably due to the learning curve obtained with LRYGB, because this manoeuvre can thus appear familiar to the surgeon. Before firing of the last stapler, the angle of His is freed from top to bottom and viceversa, and this permits the introduction of the stapler and the successive section without any undue tension of the tissue. With this method, the stomach can be sectioned without tension because the greater curve is not taken laterally in the direction of the spleen, unlike with technique A. Postoperative leaks can probably be avoided because of the absence of tissue tension during the last division of the stomach. Moreover, during the posterior dissection, conditions are very similar to LRYGB. Analysis of the results does not show statistically significant differences in terms of operative time, peroperative bleeding, number of cartridges used, hospital stay and weight loss. Operative time seems to be lower after the technique B than A. 
This result is probably related to the dissection of the greater curve of the stomach. In technique $B$, this step appears to be easier and faster, because the most difficult part of devascularization of the stomach is performed without endangering the angle of His. The risk of peroperative bleeding during LSG always exists at the moment of the dissection of the gastrosplenic ligament, as appeared in one of our patients of group A. Dissection of the greater omentum was performed by the coagulating hook for cost reasons. However, it is preferable to be performed using the Ultracision device (Ethicon EndoSurgery, Cincinnati, $\mathrm{OH}$ ) or the Ligasure device, in order to control any possible bleeding from the small gastric vessels of the greater curve. Absence of hiatal hernia or gastroesophageal reflux is one of the factors to be considered for the selection of the patients for LSG or DS, because this procedure actually worsens this condition, unlike after LRYGB [21,22]. In the case of hiatal hernia discovered peroperatively in an asymptomatic patient, a plasty of the diaphragmatic crura must be performed, as was done for a patient of group A. On the contrary, when a giant hiatal hernia is discovered, as appeared in one patient of group B, we believe empirically that LSG must be replaced by LRYGB. Postoperative leak after LSG is reported with an incidence of $0-1.4 \%$ [23] up to 5.3\% [19]. Management of gastric leak after LSG is usually difficult to treat. Clinical status of the patient, volume of the leak and position of the drain must be considered. The site of the leak after LSG is usually the angle of His, as presented in a patient of group A, and this is probably related to the tissue-tension maintained by the assistant grasper during section of the stomach, which causes transsection to occur too close to the esophageal wall. Our management of postoperative leak after LSG is as follows: if the patient is hemodynamically stable (patient without dyspnea, tachycardia or fever) and the drain appears to be properly placed, the patient is treated conservatively with parenteral nutrition and antibiotics, as is well reported in bariatric surgery [24-28]. If the patient is not hemodynamically stable or the drain is not well positioned resulting in a source of local peritonitis, a relaparoscopy is mandatory. Laparoscopy with toilette of the cavity, placement of the drain near the leak, and a feeding jejunostomy is our first choice of treatment, because suturecontrol does not achieve permanent closure. Unfortunately, an enterocutaneous fistula after LSG does not heal in a few days; hence, collaboration with a gastroenterologist is mandatory, as has already been reported after other bariatric procedures [29]. We then consider placement of a stent by endoscopy [30], if the treatment is unsuccessful and the gastric leak is again present after 3 weeks. The treatment by endoscopic stent is usually performed in two steps: firstly a metallic stent (Ultraflex, Boston Scientific, Natick, MA) is placed for 4 or 6 weeks followed by the placement of one or more plastic stents (Polyflex, Boston Scientific, Natick, MA) for another 4 weeks. With the healing of the leak, the plastic stent is removed. Cottam and colleagues [10] reported 5 cases of strictures in a series of 126 LSG, probably due to oversewing of the staple-line, as appeared in one of our patients of group B. 
The latter was successfully treated by a single endoscopic dilation, but seromyotomy performed by laparoscopy remains another valuable option (Fig.8).

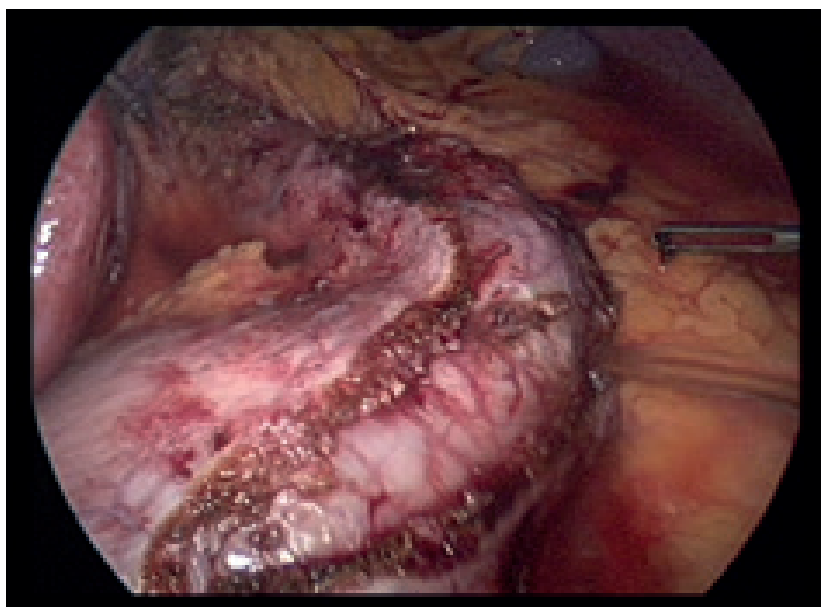

Fig.8 Final view of laparoscopic seromyotomy of the sleeve: both edges of seromyotomy

\subsection{REFERENCES}

1. Hess DS, Hess DW. Biliopancreatic diversion with a duodenal switch. Obes Surg 1988;8:267-82

2. Marceau P, Hould FS, Simard S et al. Biliopancreatic diversion with duodenal switch. World J Surg 1998;22:947-54

3. Johnston D, Dachtler J, Sue-Ling HM et al. The Magenstrasse and Mill operation for morbid obesity. Obes Surg 2003;13:10-6

4. Roa PE, Kaidar-Person O, Pinto D et al. Laparoscopic sleeve gastrectomy as treatment for morbid obesity: technique and short-term outcome. Obes Surg 2006;16:1323-6

5. Gagner M, Inabnet WB, Pomp A. Laparoscopic sleeve gastrectomy with second stage biliopancreatic diversion and duodenal switch in the superobese. In: Inabnet WB, DeMaria EJ, Ikramuddin S, eds. Laparoscopic bariatric surgery. Philadelphia: Lippincott William \& Wilkins 2005:143-50

6. Silecchia GF, Boru C, Pecchia A et al. Effectiveness of laparoscopic sleeve gastrectomy (first stage of biliopancreatic diversion with duodenal switch) on comorbidities in super-obese high-risk patients. Obes Surg 2006;16:1138-44

7. Mognol P, Chosidow D, Marmuse JP. Laparoscopic sleeve gastrectomy as an initial bariatric operation for high-risk patients: initial results in 10 patients. Obes Surg 2005;15:1030-3

8. Almogy G, Crookes PF, Anthone GJ. Longitudinal gastrectomy as a treatment for the high-risk superobese patient. Obes Surg 2004;14:492-7

9. Baltasar A, Serra C, Perez N et al. Laparoscopic sleeve gastrectomy: a multi-purpose bariatric operation. Obes Surg 2005; $15: 1124-8$

10. Cottam D, Qureshi FG, Mattar SG et al. Laparoscopic sleeve gastrectomy as an initial weight-loss procedure for high-risk patients with morbid obesity. Surg Endosc 2006;20:859-63

11. Robinson J, Sue-Ling H, Johnston D. The Magenstrasse and Mill procedure can be combined with a Roux-en-Y gastric bypass to produce greater and sustained weight loss. Obes Surg 2006;16:891-6 
12. Nguyen NT, Longoria M, Gelfand DV et al. Staged laparoscopic Roux-en-Y: a novel two-stage bariatric operation as an alternative in the super-obese with massively enlarged liver. Obes Surg 2005;15:1077-81

13. Regan JP, Inabnet WB, Gagner M et al. Early experience with two-stage laparoscopic Roux-en-Y gastric bypass as an alternative in the super-super-obese patients. Obes Surg 2003;13:861-4

14. Milone L, Strong V, Gagner M. Laparoscopic sleeve gastrectomy is superior to endoscopic intragastric balloon as a first stage procedure for super-obese patients (BMI>50). Obes Surg 2005;15:612-7

15. Hamoui N, Anthone GJ, Kaufman HS et al. Sleeve gastrectomy in the high-risk patient. Obes Surg 2006;16:1445-9

16. Himpens J, Dapri G, Cadière GB. A prospective randomized study between laparoscopic gastric banding and laparoscopic isolated sleeve gastrectomy: results after 1 and 3 years. Obes Surg 2006;16:1450-6

17. Langer FB, Reza Hoda MA, Bohdjalian A et al. Sleeve gastrectopmy and gastric banding: effects on plasma ghrelin levels. Obes Surg 2005;15:1024-9

18. Han SM, Kim WW, Oh JH. Results of laparoscopic sleeve gastrectomy (LSG) at 1 year in morbidly obese Korean patients. Obes Surg 2005;15:1469-75

19. Melissas J, Koukouraki S, Askoxylakis J et al. Sleeve gastrectomy - a restrictive procedure? Obes Surg 2007; 17:57-62

20. Lee CM, Feng JJ, Cirangle PT et al. Laparoscopic vertical sleeve gastrectomy for morbid obesity in 216 patients: report of two-year results. Surg Endosc 2006;20(Suppl):255(abst)

21. Kellogg TA, Andrade R, Maddaus $\mathrm{M}$ et al. Anatomic findings and outcomes after antireflux procedures in morbidly obese patients undergoing laparoscopic to Roux-en-Y gastric bypass. Surg Obes Relat Dis 2007;3:52-7

22. Csendes A, Burgos AM, Smok G et al. Effect of gastric bypass on Barrett's esophagus and intestinal metaplasia of the cardia in patients with morbid obesity. J Gastrointest Surg 2006;10:259-64

23. Aggarwal S, Kini SU, Herron DM. Laparoscopic sleeve gastrectomy for morbid obesity: a review. Surg Obes Relat Dis 2007;3:189-94

24. Gonzales R, Nelson LG, Gallagher S et al. Anastomotic leaks after laparoscopic gastric bypass. Obes Surg 2004;14:1299-307

25. Thodiyil PA, Rogula T, Mattar SG et al. Management of complications after laparoscopic gastric bypass. In: Inabnet W, DeMaria EJ, Ikramuddin S, eds. Laparoscopic Bariatric Surgery. Philadelphia: Lippincott William \& Wilkins 2005:225-37

26. Marshall JS, Srivastava A, Gupta SK et al. Roux-en-Y gastric bypass leak complications. Arch Surg 2003;138:520-4

27. Csendes A, Burdiles P, Burgos AM et al. Conservative management of anastomotic leaks after 557 open gastric bypasses. Obes Surg 2005;15:1252-6.

28. Papasavas PK, Caushaj PF, McCormick JT et al. Laparoscopic management of complications following laparoscopic Roux-en-Y gastric bypass for morbid obesity. Surg Endosc 2003;17:610-4.

29. Kriwanek S, Ott N, Ali-Abdullah S et al. Treatment of gastro-jejunal leakage and fistulization after gastric bypass with coated self-expanding stents. Obes Surg 2006;16:1669-74

30. Eisendrath P, Cremer M, Himpens J et al. Endotherapy including temporary stenting of fistulas of the upper gastrointentinal tract after laparoscopic bariatric surgery. Endoscopy 2007;39:625-30 



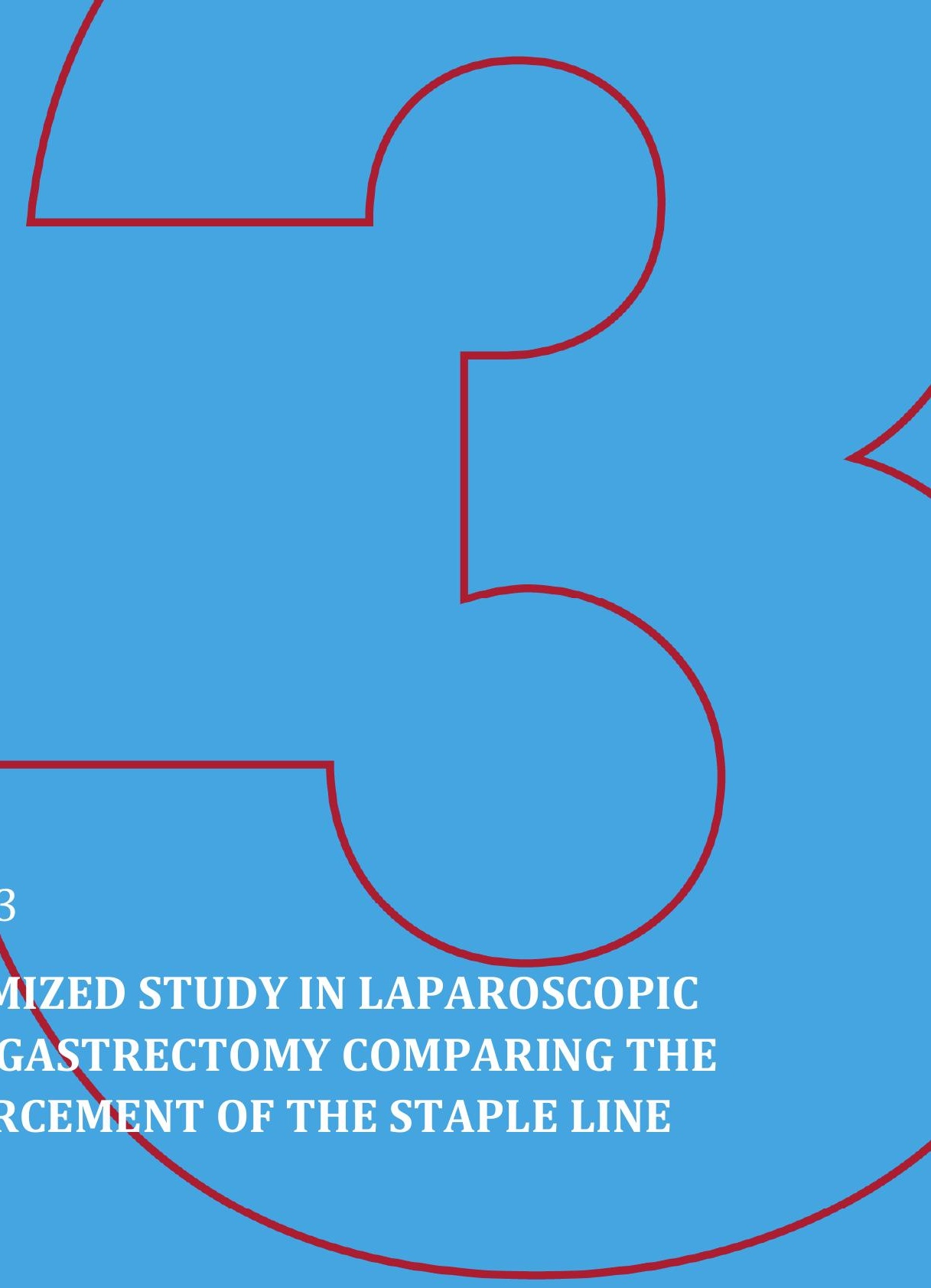

Dapri G, Cadière GB, Himpens J

Obesity Surgery 2010;20(4):462-467 



\subsection{ABSTRACT}

Background: Gastric leak and hemorrhage are the most important challenges after laparoscopic sleeve gastrectomy (LSG). In order to reduce these complications, the staple line can be reinforced by absorbable sutures or by the use of glycolide trimethylene carbonate copolymer onto the linear stapler (Gore Seamguard $^{\circledR}$; W.L. Gore \& Associates, Inc, Flagstaff, AZ). To our knowledge, there are no randomized studies showing the utility of staple line reinforcement during LSG. The purpose of this study was to randomly compare three techniques in LSG: no staple line reinforcement (group 1), buttressing of the staple line with Gore Seamguard $^{\circledR}$ (group 2), and staple line suturing (group 3).

Patients and Methods: Between January 2008 and February 2009, 75 patients were prospectively and randomly enrolled in the three different techniques of handling the staple line during LSG. The patient groups were similar (NS).

Results: Mean operative time to perform the stomach sectioning was $15.9 \pm 5.9$ min (group 1), 20.8 $\pm 8.1 \mathrm{~min}$ (group 2), and 30.8 $\pm 10.1 \mathrm{~min}$ (group 3) $(\mathrm{p}<0.001$ ). Mean total operative time was $47.4 \pm 10.7$ min (group 1), $48.9 \pm 18.4$ min (group 2), and 59.9 $\pm 19.6 \mathrm{~min}$ (group 3) ( $\mathrm{p}=0.02)$. Mean blood loss during stomach sectioning was $19.5 \pm 21.3 \mathrm{~mL}$ (group 1), $3.6 \pm 4.7 \mathrm{~mL}$ (group 2), and $16.7 \pm 23.5 \mathrm{~mL}$ (group 3) $(\mathrm{p}<0.001)$. Mean total blood loss was $48.9 \pm 67.1 \mathrm{~mL}$ (group 1), $32.5 \pm 46.5 \mathrm{~mL}$ (group 2), and $61.9 \pm 69.4 \mathrm{~mL}$ (group 3) ( $\mathrm{p}=0.03)$. Mean number of stapler cartridges used was $5.6 \pm 0.7$ (group 1), $5.7 \pm 0.7$ (group 2), and 5.8 \pm 0.6 (group 3) (NS). Postoperative leak affected one patient (group 1), two patients (group 2), and one patient (group 3) (NS). Mean hospital stay was 3.6 \pm 1.4 days (group 1), 3.9 \pm 1.5 days (group 2), and $2.8 \pm 0.8$ days (group 3$)(\mathrm{p}=0.01)$.

Conclusion: In LSG, buttressing the staple line with Gore Seamguard ${ }^{\circledR}$ statistically reduces blood loss during stomach sectioning as well as overall blood loss. No staple line reinforcement statistically decreases the time to perform stomach sectioning and the total operative time. No significant difference is evidenced in terms of postoperative leak between the three techniques of LSG. 


\section{$3.2 \quad$ INTRODUCTION}

Laparoscopic sleeve gastrectomy (LSG) is becoming a popular restrictive procedure for morbid obesity [1,2]. Complications varies betweeen postoperative bleeding [3], appearance of gastric leak [4], development of gastroesophageal reflux disease (GERD) [5], appearance of stricture [6], dilation of the gastric tube [7], and insufficient weight loss [8]. The main complications in the early postoperative course are postoperative bleeding and the appearance of a gastric leak. Bleeding can occur along the staple line as well as along the greater omentum, which has been freed from the greater curvature, allowing the resection of the fundus and body of the stomach. Sometimes, this complication cannot be treated conservatively [9], and the patient has to go back to the operative theatre for revision [10]. The appearance of a leak after LSG is related to the tubulization of the stomach with a long vertical staple line going from the antrum to the gastroesophageal junction. Typically, after LSG, leaks appear just below the gastroesophageal junction because of the high internal pressure created with the vertical tubulization of the stomach [11]. Management of the leak is difficult, with longer hospital stay, and quite often demanding placement of endoscopic stents [12]. Management of the staple line is actually not well standardized. Three options are available: no staple line reinforcement, buttressing the staple line with specific bioabsorbable material, and oversewing the staple line. Buttressing the staple line can be performed using glycolide trimethylene carbonate copolymer (Gore Seamguard ${ }^{\circledR}$; W.L. Gore \& Associates, Inc, Flagstaff, AZ) $[13,14]$, or bovine pericardium strips (Peristrips Dry and PSD Veritas; Synovis Surgical Innovations, St Paul, MN) [15,16], or porcine small intestinal submucosa (Surgisis Biodesign, Cook Medical, Inc, Bloomington, IN) $[17,18]$. The aim of this study was to prospectively and randomly compare in LSG the technique of no staple line reinforcement (group 1), buttressing the staple line with Gore Seamguard ${ }^{\circledR}$ (group 2), and staple line suturing (group 3). So far, to our knowledge, no randomized study has been published comparing these three different techniques during this procedure.

\subsection{PATIENTS AND METHODS}

Between January 2008 and February 2009, 75 patients were prospectively and randomly enrolled in the study, which compared three different techniques of staple line reinforcement during LSG. Twenty-five patients were allocated to the arm with no staple line reinforcement (group 1), 25 patients to the buttressing the staple line with Gore Seamguard ${ }^{\circledR}$ (group 2), and 25 patients to the staple line suturing (group 3). Patient characteristics were similar between the groups (NS) (Tab.1). 
Table 1 Patient characteristics

\begin{tabular}{|c|c|c|c|c|}
\hline Characteristics & $\begin{array}{l}\text { Group } 1 \\
\text { No reinforcement }\end{array}$ & $\begin{array}{l}\text { Group } 2 \\
\text { Seamguard }\end{array}$ & $\begin{array}{l}\text { Group } 3 \\
\text { Suturing }\end{array}$ & $p$ \\
\hline \multicolumn{5}{|l|}{ Gender (n) } \\
\hline Female & 15 & 14 & 8 & 0.19 \\
\hline Male & 10 & 11 & 17 & \\
\hline \multicolumn{5}{|l|}{ Age (years) } \\
\hline Mean $\pm \mathrm{SD}$ & $44.3=12.6$ & $39.4=9.1$ & $41.3 \pm 12.4$ & 0.43 \\
\hline Range & $21-65$ & $22-58$ & $21-61$ & \\
\hline \multicolumn{5}{|l|}{ Weight (kg) } \\
\hline Mean \pm SD & $124.3 \pm 18.1$ & $138.8 \pm 25.1$ & $143.5 \pm 35.7$ & 0.09 \\
\hline Range & $97-168$ & $98-196$ & $80-225$ & \\
\hline \multicolumn{5}{|l|}{ BMI $\left(\mathrm{kg}^{2} \mathrm{~m}^{2}\right)$} \\
\hline Mean $\pm \mathrm{SD}$ & $44.2 \pm 6.3$ & $49.7 \pm 7$ & $47.7 \pm 10.5$ & 0.06 \\
\hline Range & $36-60$ & $38-65$ & $35-70$ & \\
\hline \multicolumn{5}{|l|}{ ASA score } \\
\hline Mean $\pm \mathrm{SD}$ & $2.5 \pm 0.5$ & $2.4 \pm 0.5$ & $2.5 \pm 0.5$ & 0.69 \\
\hline Range & $2-3$ & $2-3$ & $2-3$ & \\
\hline
\end{tabular}

B.MI body mass index, ASA American Society of Anesthesiologists

Obesity-related comorbidities affected 22 patients (group 1), 14 patients (group 2), and 17 patients (group 3), respectively (Tab.2).

Table 2 Obesity-related comorbidities

\begin{tabular}{lccc}
\hline Comorbidities & $\begin{array}{c}\text { Group 1 } \\
\text { No reinforcement }\end{array}$ & $\begin{array}{c}\text { Group 2 } \\
\text { Seamguard }\end{array}$ & $\begin{array}{c}\text { Group 3 } \\
\text { Suturing }\end{array}$ \\
\hline Arterial hypertension & 13 & 8 & 13 \\
Type II diabetes & 6 & 5 & 6 \\
Sleep apnea & 4 & 5 & 4 \\
Degenerative joint disease & 13 & 4 & 2 \\
\hline
\end{tabular}

This study was designed as a pilot study. Therefore, we did not specifically choose one primary endpoint and did not estimate a priori the required sample size. Main outcome measures were defined as the operative time to perform the stomach sectioning, the total operative time, blood loss during stomach sectioning, total blood loss, and the number of stapler cartridges used. Time to perform the stomach sectioning was calculated as the time between the introduction in the abdomen of the first linear stapler and the end of the last firing of stapler for group 1 and group 2, and the time between the introduction of the first linear stapler and the end of the oversewing the staple line for group 3. Total operative time was calculated in all groups as the time between the introduction of the trocars in the abdo- 
men and the placement of the drain along the staple line. Blood loss was calculated by measuring the volume of blood in suction pump at the end of sectioning and at the end of the procedure. Secondary outcome measures were peroperative complications, hospital stay, early complications, and late complications. Since leak is a seldom event, our study had no possibility to detect between the groups a statistically significant difference in terms of this event. Hence, this complication has not been considered as a main outcome of this study.

\subsubsection{STATISTICAL METHODS}

Randomization was performed using randomly permuted blocks of sizes 6 and 9 . The analysis included descriptive statistical methods: calculation of mean and standard deviation for continuous variables and contingency tables for categorical variables. The characteristics of patients between arms were compared using chisquare tests for categorical variables and analysis of variance for continuous outcomes. All the outcomes of the study were continuous variables. We compared therefore the arms using one-way analyses of variance and Fisher Snededore tests for assessing the statistical significance between the means of the outcome variables. A p value $<0.05$ was considered as statistically significant, and all reported $p$ values were two-tailed.

\subsubsection{SURGICAL TECHNIQUE}

The patient is positioned in supine position, with the legs apart and in reverse Trendelenburg position with a $10^{\circ}$ tilt, carefully strapped to the operation table, and with the arms placed in abduction. Extreme care is taken to pad the pressure points and joints with foam cushions. The surgeon stands between the patient's legs, the assistant to the patient's left, and the cameraperson to the patient's right. Abdominal insufflation is set at $15 \mathrm{mmHg}$. Trocars are placed as follows: a $10-\mathrm{mm}$ trocar (T1) $20 \mathrm{~cm}$ below the xyphoid process for the $30^{\circ}$ optical system, a $5 \mathrm{~mm}$ trocar (T2) on the left anterior axillary line, a 12-mm trocar (T3) on the left midclavicular line just between the first and the second trocars, a 15-mm trocar (T4) on the right midclavicular line, and a 5-mm trocar (T5) below the xyphoid process. After identification of the Crow's foot, a straight line is marked with the coagulating hook from the Crow's foot up to the greater curve, delimiting the spared antrum. The lesser sac is accessed through a window made in the greater omentum 3 $\mathrm{cm}$ laterally from the marking, close to the greater curve and within the gastroepiploeic vessels. This window is opened, close to the greater curve, from left to right until the marked stomach is reached. It is made just sufficiently large enough so as to permit the performance of the first two firings of linear stapler 4.80/60mm green load (EndoGIA, Covidien, New Haven, CT) through T4. In group 2, the linear stapler is supported by the application of the Gore Seamguard ${ }^{\circledR}$ before the introduction of the device in the abdomen. The first and the second linear staplers 
are oriented aiming in contact toward the endings of the small gastric vessels on the lesser curve and are fired. Further firings (3.5/60-mm blue cartridges), inserted through T3, are performed parallel to the lesser curve, and posterior gastric adhesions are sectioned before when present. Before the third firing of stapler, the anesthesiologist pushes down a 34-French orogastric bougie in order to guide the gastric section in the direction of the angle of His. Before the last firing of stapler (3.5/60-mm blue cartridge), the angle of His is freed and the stomach is transected without tension, staying at a distance from the gastroesophageal junction. In group 3 , the staple line is reinforced by transfixing non sero-serosal running sutures using absorbable material (polydiaxone, 1 PDS), starting from the last firing of staple going caudad until the level of the antrum marked. The greater omentum is now dissected off the stomach along the greater curve using the Ligasure device (Covidien) until the left diaphragmatic crus is reached. The resected stomach is extracted from the abdomen by enlargement of the left upper quadrant 12-mm trocar, which subsequently is closed in layers, as well as the $15-\mathrm{mm}$ trocar at the end of the procedure. A leak test is performed by insufflating air under pressure while keeping the stomach under water. A drain is left along the staple line before the removal of the trocars under visual control. The orogastric bougie is removed at the end of the procedure. No nasogastric tube is left in the following postoperative course.

\subsection{RESULTS}

Main outcome measures are shown in Tab.3. 
Table 3 Main outcome measures

\begin{tabular}{|c|c|c|c|c|}
\hline $\begin{array}{l}\text { Main outcome } \\
\text { measures }\end{array}$ & $\begin{array}{l}\text { Group I } \\
\text { No reinforcement }\end{array}$ & $\begin{array}{l}\text { Group } 2 \\
\text { Seamguard }\end{array}$ & $\begin{array}{l}\text { Group } 3 \\
\text { Suturing }\end{array}$ & $p$ \\
\hline \multicolumn{5}{|c|}{ Stomach sectioning tims (min) } \\
\hline Mean \pm SD & $15.9 \pm 5.9$ & $20.8 \pm 8.1$ & $30.8 \pm 10.1$ & \multirow[t]{2}{*}{$\varsigma 0.001$} \\
\hline Range & $8-26$ & $10-44$ & $13-55$ & \\
\hline \multicolumn{5}{|c|}{ Total operative time (min) } \\
\hline Mean \pm SD & $47.4 \pm 10.7$ & $48.9 \pm 18.4$ & $59.9 \pm 19.6$ & \multirow[t]{2}{*}{0.02} \\
\hline Range & $27-65$ & $27-95$ & $22-105$ & \\
\hline \multicolumn{5}{|c|}{ Stomach sectioning blood loss (mL) } \\
\hline Mean $\pm \mathrm{SD}$ & $19.5 \pm 21.3$ & $3.6 \pm 4.7$ & $16.7 \pm 2.3 .5$ & \multirow[t]{2}{*}{40.001} \\
\hline Range & $5-80$ & $0-20$ & $0-100$ & \\
\hline \multicolumn{5}{|c|}{ Total blood loss (mL) } \\
\hline Mean $\pm \mathrm{SD}$ & $48.9 \pm 67.1$ & $32.5 \pm 46.5$ & $61.9 \pm 69.4$ & \multirow[t]{2}{*}{0.03} \\
\hline Range & $5-280$ & $0-200$ & $10-280$ & \\
\hline \multicolumn{5}{|c|}{ Stapler cartridges $(n)$} \\
\hline Mean \pm SD & $5.6 \pm 0.7$ & $5.7 \pm 0.7$ & $5.8 \pm 0.6$ & \multirow[t]{2}{*}{0.65} \\
\hline Range & $4-7$ & $5-7$ & $5-7$ & \\
\hline
\end{tabular}

Mean operative time to perform the stomach sectioning was statistically significantly different between the three groups $(\mathrm{p}<0.001)$, lower for group $1,15.9 \pm 5.9$ min versus $20.8 \pm 8.1 \mathrm{~min}$ (group 2) and 30.8 $\pm 10.1 \mathrm{~min}$ (group 3). Mean total operative time was statistically significantly different too $(\mathrm{p}=0.02)$, smaller for group 1 , $47.4 \pm 10.7$ min versus $48.9 \pm 18.4 \mathrm{~min}$ (group 2) and 59.9 \pm 19.6 min (group 3). Mean blood loss during stomach sectioning was statistically significantly different between the three groups ( $\mathrm{p}<0.001$ ), lesser for group 2, $3.6 \pm 4.7 \mathrm{~mL}$ versus $19.5 \pm 21.3$ $\mathrm{mL}$ (group 1) and $16.7 \pm 23.5 \mathrm{~mL}$ (group 3 ). Mean total blood loss was statistically significantly different too $(\mathrm{p}=0.03)$ smaller for group $2,32.5 \pm 46.5 \mathrm{~mL}$ versus $48.9 \pm 67.1 \mathrm{~mL}$ (group 1) and $61.9 \pm 69.4 \mathrm{~mL}$ (group 3). Mean number of stapler loads used during the stomach sectioning was not statistically different between the groups ( $\mathrm{p}=0.65$ ), $5.6 \pm 0.7$ (group 1), $5.7 \pm 0.7$ (group 2), and 5.8 \pm 0.6 (group 3). Peroperative complications are summarized in Tab.4.

Table 4 Peroperative complications

\begin{tabular}{llll}
\hline Peroperative complications & $\begin{array}{l}\text { Group 1 } \\
\text { No reinforement }\end{array}$ & $\begin{array}{l}\text { Group 2 } \\
\text { Seanguard }\end{array}$ & $\begin{array}{l}\text { Group 3 } \\
\text { Suturing }\end{array}$ \\
\hline $\begin{array}{l}\text { Short splenic vessels } \\
\text { bleeding }\end{array}$ & 1 & - & - \\
Left hiatal crura blocding & 1 & - & - \\
Splenic blecding & 1 & - & - \\
Hepatic bleeding & - & 4 & - \\
\hline
\end{tabular}


Mean hospital stay was 3.6 \pm 1.4 days (group 1, range 2-9), 3.9 \pm 1.5 days (group 2, range 1-6), and $2.8 \pm 0.8$ days (group 3 , range $2-5)(p=0.01)$. Postoperative leaks appeared in one patient (group 1), two patients (group 2), and one patient (group 3) (NS). Level of the leak was different between group 2 and others. Group 2 is the only one where the appearance of the leak was at the level of the antrum. Patients in groups 1 and 3 evidenced a leak under the gastroesophageal junction. A patient in group 1 presented a clinical leak on postoperative day 35, and after placement of covered metallic endoscopic stents, a complete fistula healing was reached on postoperative day 87. A patient in group 3 was discharged on postoperative day 3 , and a clinical leak appeared on postoperative day 25. Thanks to the placement of endoscopic stents, the fistula healing was completed after 57 days of the procedure. Two patients in group 2 were readmitted to the hospital, respectively, on postoperative days 30 and 11 for sepsis due to abscesses around the area of the gastric antrum. The first patient was treated by percutaneous drain, transforming the leak into a gastrocutaneous fistula with a complete healing after 15 days. The second patient was taken to the operative theatre for laparoscopic lavage and drainage and subsequently underwent the placement of endoscopic stents, with a complete fistula healing after 74 days. Other early complications were recorded in groups 1 and 3. One patient of group 1 presented a subphrenic hematoma 10 days after the procedure which was successfully treated by percutaneous drain. A patient in group 3 developed a subcutaneous abscess at the site of extraction of the specimen from the abdomen, 17 days after the procedure, which was resolved by medical treatment. A late complication was noted in one patient in group 3 who developed a de novo GERD after 5 months of LSG and was treated by proton pump inihibitor (PPI) therapy.

\subsection{DISCUSSION}

This study showed statistically significant differences in terms of operative time and operative blood loss between no staple line reinforcement (group 1), buttressing the staple line with Gore Seamguard ${ }^{\circledR}$ (group 2), and staple line suturing (group 3) in LSG. Operative time to perform stomach sectioning appeared lower in the group without staple line reinforcement compared with the group using Gore Seamguard ${ }^{\circledR}$ or suture oversewing. Application of Gore Seamguard ${ }^{\circledR}$ on each firing of linear stapler required additional time, even with welltrained operating room personnel. The time to perform stomach sectioning is higher in group 3, obviously because of oversewing of the staple line. Suturing the entire staple line appeared time-consuming in this study and is dependent on the surgeon's learning curve. Considering total operative time, the difference between the groups reflected the difference of time needed for stomach sectioning since the time spent to finish the procedure after the section of the stomach was not different between the groups. In terms of blood loss, this study showed that buttressing the staple line with ab- 
sorbable material as Gore Seamguard ${ }^{\circledR}$ is superior to no staple line reinforcement or oversewing the staple line. These data have already been evidenced in a previous consecutive not randomized study enrolling 20 patients with LSG [13]. The authors reported a significant difference in mean blood loss of $120 \mathrm{~mL}$ in the group with Gore Seamguard ${ }^{\circledR}$ versus $210 \mathrm{~mL}$ in the group without Gore Seamguard ${ }^{\circledR}$ $(\mathrm{p}<0.05)$. Mechanism of blood loss reduction using Gore Seamguard ${ }^{\circledR}$ can be related to the compressive effect of the reinforcement material on the transected tissue [14]. The bioabsorbable material was specifically engineered so as to measure maximum $0.5 \mathrm{~mm}$ thickness, aiming at perfectioning the balance between the buttressing strength and the amount of material implanted. This effect is maintained for the following 4-5 weeks, and the bioabsorbable material is completely absorbed within 6 months [13]. Total blood loss differences between the three groups reflected the main difference of blood loss during stomach sectioning. However, in our study, this result appeared less significant than the partial one because peroperative bleeding can obviously occur during the dissection of the resected stomach from the greater omentum, with an increase of the value. No statistically significant difference was evidenced between the groups in this study regarding the number of linear stapler loads used during stomach sectioning. This result is in accordance with earlier findings that between five and seven firings of linear stapler are usually required during the procedure of LSG [9]. Hence, the additional cost of the Gore Seamguard ${ }^{\circledR}$ par procedure (in Belgium) ranged between 640 euro (128 euro x 5) and 896 euro (128 euro x 7). The additional cost of Gore Seamguard ${ }^{\circledR}$ and increased operative time must be weighed against the potential benefit of its use in bleeding reduction and consequently associated management of staple line hemorrhages. Staple line leak after LSG may still occur despite the use of buttressing material or oversewing the staple line by resorbable suture. Leak after LSG usually appears just distal to the gastroesophageal junction, with an incidence between $0 \%$ and $5.7 \%[2,19,20]$. Reason of the leak in this area could be related to the development of high intraluminal pressure related to the long vertical tubulization of the stomach [11]. Moreover, this pressure is amplified by the fact that the compliance of the sleeve is ten times less than the complete stomach or the resected fundus $[11,21]$. This physical situation could be the culprit for the leaks because in humans, the thickness of the gastric tissue is different between the antrum, the body, and the fundus, with a mean value reported to be of $3.1 \mathrm{~mm}, 2.4 \mathrm{~mm}$, and $1.7 \mathrm{~mm}$, respectively [22]. For these reasons, the gastric tissue at the angle of His appears more prone to developing leak. These theories might explain the nature of the leaks after LSG, which appear much later than could be accounted for by technical flaws. Our patients in groups 1 and 3 were, respectively, readmitted to the hospital on postoperative days 35 and 25. Similar to our experience, other authors [23] evidenced the appearance of a leak at the gastroesophageal junction rather late in the postoperative course. This complication can occur in patients without reinforcement of the staple line as well as in 
whom it had been oversewn [23], as our study confirmed. This result contrasts with the theory of increased risk of tearing at the point of suture penetration in the distended gastric pouch [24]. The development of gastric leak at the level of the antrum, as was seen in two of our patients in group 2, is conceptually different. The thickness of the stomach increases approaching the pyloric antrum with significant patient to patient variability [22]. Therefore this increased tissue thickness could have compromised the complete closure of even the longest available staple height (green). Gore Seamguard ${ }^{\circledR}$ will increase the thickness of the area to be stapled by up to $0.5 \mathrm{~mm}$, which should be considered especially in regions of thick tissue. Leaks at the antrum of the stomach can occur with the use of other buttressing material as well. Chen et al. [20] reported two leaks on 35 procedures (5.7\%) with the use of bovine pericardium strips. Due to the potential for leaks in this region, additional care should be taken to inspect the staple line for proper staple formation. In this study, we achieved a significantly shorter hospital stay in group 3 compared to groups 1 and 2. This was due to prolonged discomfort postoperatively in one patient in each group. Later, both patients developed the presence of the leak. Regarding the early complications, one patient in group 1 developed a subphrenic hematoma. This complication has been reported after LSG [13] and probably occurred in our patient at the left hiatal crus because bleeding had been noted peroperatively. One patient in group 3 showed a subcutaneous abscess at the level of extraction of the specimen, probably due to local contamination of the muscular aponeurosis at this step, as reported in two out of 61 patients of Kasalicky's series [19]. A late complication was the development of de novo GERD in one patient (1.3\%) in group 3. Appearance of de novo GERD during the first year is one of the possible complications occurring after LSG [1,2]. This can be explained by the fact that the gastroesophageal antireflux barriers, such as the phrenogastric ligament and the angle of His, are altered during this procedure. This complication can initially be treated with PPI. In case of persistence of the GERD symptoms after several years, conversion of LSG to a Roux-en-Y gastric bypass (RYGB) could abolish GERD, as reported in patients submitted to primary RYGB and affected with GERD symptoms [25,26]. Crookes [5] reported a complete resolution of GERD in 11 patients converted from LSG to RYGB more effectively and with less morbidity than the seven patients converted to DS.

\subsection{CONCLUSION}

During LSG, staple line buttressing with Gore Seamguard ${ }^{\circledR}$ statistically reduces blood loss during stomach sectioning as well as overall blood loss. Absence of staple line reinforcement statistically decreases the time required for stomach sectioning as well as total operative time. No significant difference is evidenced in terms of postoperative leak between the three techniques of staple line reinforcement. 


\subsection{REFERENCES}

1. Deitel M, Crosby RD, Gagner M. The First International Consensus Summit for Sleeve Gastrectomy (SG), New York City, October 25-27, 2007. Obes Surg 2008;18:487-96

2. Gagner M, Deitel M, Kalberer TL, et al. The second International Consensus Summit for Sleeve Gastrectomy, March 19-21, 2009. Surg Obes Relat Dis 2009;5:476-85

3. Brethauer SA, Hammel JP, Schauer PR. Systematic review of sleeve gastrectomy as staging and primary bariatric procedure. Surg Obes Relat Dis 2009;5:469-75

4. Serra C, Baltasar A, Andreo L, et al. Treatment of gastric leaks with coated self-expanding stents after sleeve gastrectomy. Obes Surg 2007;17:866-72

5. Crookes P. Management of severe reflux after sleeve gastrectomy. Second International Consensus Summit for Sleeve Gastrectomy, Miami Beach (FL, USA), March 19-21, 2009 (abstract)

6. Dapri G, Cadière GB, Himpens J. Laparoscopic seromyotomy for long stenosis after sleeve gastrectomy with or without duodenal switch. Obes Surg 2009;19:495-9

7. Langer FB, Bohdjalian A, Felberbauer FX, et al. Does gastric dilatation limit the success of sleeve gastrectomy as a sole operation for morbid obesity? Obes Surg 2006;16:166-71

8. Gagner M, Gumbs AA, Milone L, et al. Laparoscopic sleeve gastrectomy for the super-super-obese (body mass index $>60 \mathrm{~kg} / \mathrm{m}^{2}$ ). Surg Today 2008;38:399-403

9. Dapri G, Vaz C, Cadière GB, et al. A prospective randomized study comparing two different techniques for laparoscopic sleeve gastrectomy. Obes Surg 2007;17:1435-41

10. Dapri G, Cadière GB, Himpens J. Laparoscopic conversion of adjustable gastric banding and vertical gastroplasty to duodenal switch. Surg Obes Relat Dis 2009;5:678-83

11. Baltasar A, Bou R, Bengochea M, et al. Use of a Roux limb to correct esophagogastric junction fistula after sleeve gastrcetomy. Obes Surg 2007;17:1408-10

12. Eisendrath P, Cremer M, Himpens J, et al. Endotherapy including temporary stenting of fistula of the upper gastrointetsinal tract after laparoscopic bariatric surgery. Endoscopy 2007;39:625-30

13. Consten ECJ, Gagner M, Pomp A, et al. Decreased bleeding after laparoscopic sleeve gastrectomy with or without duodenal switch for morbid obesity using a stapled buttresses absorbable polymer membrane. Obes Surg 2004;14:1360-6

14. Miller KA, Pump A. Use of bioabsorbable staple reinforcement material in gastric bypass: a prospective randomized clinical trial. Surg Obes Relat Dis 2007;3:417-22

15. Shikora SA, Kim JJ, Tarnoff ME. Comparison of permanent and nonpermanent staple line buttressing materials for linear gastric staple lines during laparoscopic Roux-en-Y gastric bypass. Surg Obes Relat Dis 2008;4:729-34

16. Angrisani $\mathrm{L}$, Lorenzo $\mathrm{M}$, Borrelli $\mathrm{V}$, et al. The use of bovine pericardial strips on linear stapler to reduce extraluminal bleeding during laparoscopic gastric bypass: prospective randomized clinical trial. Obes Surg 2004;14:1198-202

17. Pinheiro JS, Correa JL, Cohen RV, et al. Staple line reinforcement with new biomaterial increased burst strength pressure: an animal study. Surg Obes Relat Dis 2006;2:397-9

18. Downey DM, Harre JG, Dolan JP. Increased burst pressure in gastrointestinal staple-lines using reinforcement with a bioprosthetic material. Obes Surg 2005;15:1379-83

19. Kasalicky M, Michalsky D, Housova J, et al. Laparoscopic sleeve gastrectomy without an oversewing of the staple line. Obes Surg 2008;18:1257-62

20. Chen B, Kiriakopoulos A, Tsakayannis D. Reinforcement does not necessarily reduce the rate of staple line leaks after sleeve gastrectomy. A review of the literature and clinical experiences. Obes Surg 2009;19:166-72

21. Yehoshua RT, Eidelman LA, Stein M, et al. Laparoscopic sleeve gastrectomy-volume and pressure assessment. Obes Surg 2008;18:1083-8

22. Elariny H, Gonzales H, Wang B. Tissue thickness of human stomach measured on excised gastric specimens from obese patients. Surg Technol Int 2005;14:119-24

23. Casella G, Soricelli E, Rizzello M, et al. Nonsurgical treatment of staple line leaks after laparoscopic sleeve gastrectomy. Obes Surg 2009;19:821-6

24. Baker RS, Foote J, Kemmeter P, et al. The science of stapling and leaks. Obes Surg 2004;14:1290-8 
25. Nelson LG, Gonzales R, Haines K, et al. Amelioration of gastroesophageal reflux symptoms following Roux-en-Y gastric bypass for clinically significant obesity. Am Surg 2005;71:950-3

26. Merrouche M, Sabate' JM, Jouet P, et al. Gastro-esophageal reflux and esophageal motility disorders in morbidly obese patients before and after bariatric surgery. Obes Surg 2007;17:894-900 




\subsection{ABSTRACT}

Background: To evaluate the feasibility, safety, and short-term efficacy of the conversion of laparoscopic adjustable gastric banding (LAGB) to laparoscopic sleeve gastrectomy (LSG) because of inadequate weight loss.

Patients and Methods: The inclusion criteria were an inadequate percentage of excess weight loss (\%EWL), defined as $<30 \%$ at $\geq 1$ year after LAGB. From August 2002 to October 2007, 27 patients (17 women and $10 \mathrm{men}$ ) had undergone removal of their LAGB and conversion to LSG. The average age at LSG was $43.6 \pm 11.4$ years (range 25-66). Before LAGB, the mean weight and body mass index was $129.8 \pm 21.9 \mathrm{~kg}$ (range $95-178$ ) and $45 \pm 8.1 \mathrm{~kg} / \mathrm{m}^{2}$ (range 35-64), respectively. The average interval between LAGB and LSG was 51.2 \pm 30.1 months (range 22-132). Before conversion, the mean weight, body mass index, and \%EWL was $117.9 \pm 27.3$ $\mathrm{kg}$ (range 63-170), $39 \pm 9.6 \mathrm{~kg} / \mathrm{m}^{2}$ (range 24-61), and $18.1 \pm 18.3 \%$, respectively. Of the 27 patients, 12 had 19 obesity-related co-morbidities, including arterial hypertension in 7, type 2 diabetes mellitus in 2, degenerative joint disease in 7 , and sleep apnea in 3.

Results: The mean operative time was $120.6 \pm 32.4$ minutes (range $65-195$ ). No conversion to open surgery was required, and no patient died. The postoperative complications included a subphrenic hematoma that required laparoscopic drainage; no postoperative leaks developed. The mean hospital stay was $3.2 \pm 1.4$ days (range 2-8). After a mean follow-up of $18.6 \pm 14.8$ months (range 1-59) for 23 patients ( 4 patients were lost to follow-up), the mean weight, body mass index, and weight loss was $100.7 \pm 23.5 \mathrm{~kg}$ (range $61-152$ ), $34.6 \pm 8.7 \mathrm{~kg} / \mathrm{m}^{2}$ (range 21-50.4), and $23 \pm 12.4 \mathrm{~kg}$ (range $2-55$ ), respectively. The patients had had an additional $16.7 \%$ EWL after LSG for a total average \%EWL of $34.8 \pm 21.8 \%(\mathrm{p}<0.05)$. Of the 12 patients with obesity-related co-morbidities, 5 had had resolution, including arterial hypertension in 1 , type 2 diabetes mellitus in 1 , degenerative joint disease in 2 , and sleep apnea in 2.

Conclusion: The results of this study support the safety of LSG in the case of an inadequate \%EWL after LAGB. However, the degree of weight loss and comorbidity resolution is of concern. 


\section{$4.2 \quad$ INTRODUCTION}

Since we performed the first laparoscopic adjustable gastric banding (LAGB) procedure [1], it has become one of the most popular in the treatment of morbid obesity in Europe [2] and Australia [3]. This is because of the encouraging results, low morbidity, and minimal operative mortality [4,5]. Laparoscopic sleeve gastrectomy (LSG) was first described as a component of the duodenal switch procedure [6,7], but, more recently, it has been reported as a stand alone bariatric operation [8]. LSG is gaining popularity in some European countries [9-16] and in South America [17], but long-term results are lacking [18]. Inadequate weight loss after LAGB, using Reinhold's criteria [19], affects $10.5 \%$ of patients at 5 years and increases to $14 \%$ after 7 years [20]. The success rate (percentage of excess weight loss [\%EWL] ? $50 \%$ ) reaches a peak at 2 years (53.8\%) but declines progressively to $42.9 \%$ after 7 years [20]. The reasons can be related to dilation of the gastric pouch [21] but also to poor compliance by both patient and surgeon regarding the need for frequent band adjustments. Changes in alimentary behavior are often mentioned as another reason for failure [22]. In the case of LAGB failure, conversion to another bariatric procedure can be considered. The possibility of conversion to laparoscopic Roux-en-Y gastric bypass (LRYGBP) has been previously reported after both band removal [23-27] and keeping the band in place [28]. Other options include conversion to laparoscopic biliopancreatic diversion (LBPD) with removal of the band [29] and laparoscopic duodenal switch (LDS) with [27,29] or without [30,31] removal of the band. A final option could be to perform repeat LAGB [24,32-34]. Only a few case reports and small cohort studies have reported on the possibility of removing the band and converting the procedure to LSG [9-12,35,36]. The aim of this study was to evaluate the feasibility, safety, and efficacy at 18 months of conversion of LAGB to LSG because of an inadequate \%EWL.

\subsection{PATIENTS AND METHODS}

The inclusion criteria were an inadequate $\% \mathrm{EWL}$, defined as $030 \%$ at 1 year after LAGB. From August 2002 to October 2007, 27 patients (17 women and 10 men) had undergone removal of the LAGB and conversion to LSG. The average age was $43.6 \pm 11.4$ years (range 25-66). Before LAGB, the mean weight and body mass index (BMI) was $129.8 \pm 21.9 \mathrm{~kg}$ (range $95-178$ ) and $45 \pm 8.1 \mathrm{~kg} / \mathrm{m}^{2}$ (range $35-64$ ), respectively. The average interval between LAGB and LSG was 51.2 \pm 30.1 months (range 22-132). Before the conversion to LSG, the mean weight, BMI, and \%EWL was $117.9 \pm 27.3 \mathrm{~kg}$ (range 63-170), $39 \pm 9.6 \mathrm{~kg} / \mathrm{m}^{2}$ (range 24-61), and $18.1 \pm 18.3 \%$, respectively. Of the 27 patients, 12 had had 19 obesity-related co-morbidities, including arterial hypertension in 7 , type 2 diabetes mellitus in 2 , degenerative joint disease in 7 , and sleep apnea in 3. 


\subsubsection{SURGICAL TECHNIQUE}

The patient was positioned supine with the legs apart and with both arms in abduction (French position). The surgeon stood between the patient's legs. The camera person was to the patient's right and the assistant to the patient's left. Five trocars were placed in the abdomen as follows: a $10-\mathrm{mm}$ trocar (for the $30^{\circ}$ optical system) $20 \mathrm{~cm}$ distal to the xiphoid process, a 5-mm trocar on the left anterior axillary line and $5 \mathrm{~cm}$ distal to the costal margin, a 12-mm trocar on the left midclavicular line between the first and second trocars, a 12-mm trocar on the right mid-clavicular line on the same horizontal line, and a 5-mm trocar just distal and to the left of the xiphoid process. Adhesiolysis between the left liver lobe and the band was performed with the coagulating hook; the tubing system of the band helped to identify its position. The right and left crus of the hiatus were completely freed. Finally, the band was completely exposed for its entire circumference by sectioning the gastrogastric tunnel covering the band. The distal limit of resection at the antrum was scored on the stomach surface. It extended vertically from the crow's foot toward the greater curvature, thus sparing 6-8 cm of antrum proximal to the pylorus. The greater curvature of the stomach, at the left side of the scoring marks, was freed from the greater omentum using the LigaSure device (Covidien, New Haven, CT) or the coagulating hook, going cephalad until the left crus was reached. The band was not retrieved at the conclusion of devascularization of the greater curve; instead, it was kept as a landmark for stapling (Fig.1).

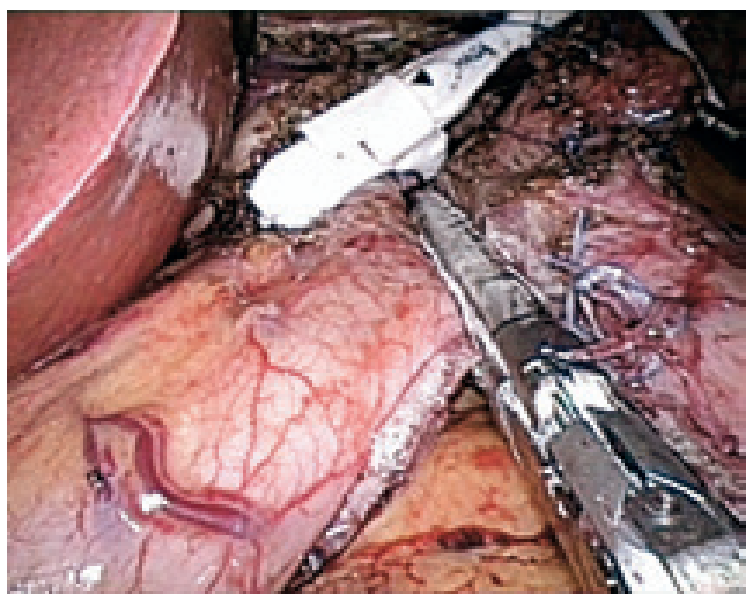

Fig.1 Firing of linear stapler (green load) inside gastric band and along orogastric bougie

The stomach was transected with sequential firings of a linear stapler, using green loads (Covidien), under a guidance of $34 \mathrm{~F}$ orogastric tube, which was kept on the lesser curvature side. The band was finally opened and retrieved just after the last 
stapler was fired. The fibrotic perigastric capsule created by the band was opened vertically with scissors. Two seroserosal running sutures, starting respectively at the angle of His and at the gastric antrum, were used to buttress the staple line and were tied together halfway down the staple line. The band and the specimen were extracted from the abdomen by enlarging the left $12-\mathrm{mm}$ trocar opening. A leak test, using compressed air inflated through the orogastric tube, confirmed the absence of leak along the staple line. A drain was left in place along the resected line, with its end at the angle of His. The enlarged left $12-\mathrm{mm}$ port site was closed in layers, and the band port and orogastric tube were removed. A methylene blue test was performed on the first postoperative day and, if negative, a liquid diet was started on the second postoperative day. Usually, the patient was discharged from the hospital on the third postoperative day.

\subsection{RESULTS}

The mean operative time was $120.6 \pm 32.4$ minutes (range $65-195$ ). No patient required conversion to open surgery, and no mortality occurred. The postoperative complications included a patient with a subphrenic hematoma that required laparoscopic drainage on the second postoperative day; no postoperative leaks developed. The mean hospital stay was 3.2 \pm 1.4 days (range 2-8). After a mean follow-up of 18.6 \pm 14.8 months (range 1-59), with 4 patients lost to follow-up, the mean weight, BMI, and weight loss for the remaining 23 patients was $100.7 \pm 23.5 \mathrm{~kg}$ (range $61-152$ ), $34.6 \pm 8.7 \mathrm{~kg} / \mathrm{m}^{2}$ (range $21-50.4$ ), and $23 \pm 12.4 \mathrm{~kg}$ (range 20-55), respectively. The patients had had an $18.1 \%$ EWL after LAGB and before conversion and had an additional 16.7\% EWL after LSG, for a total average \%EWL of $34.8 \pm 21.8 \%(\mathrm{p}<0.05)$. Of the 12 patients with obesity-related co-morbidities, 5 had resolution, including arterial hypertension in 1 , type 2 diabetes mellitus in 1 , degenerative joint disease in 2 , and sleep apnea in 2 .

\subsection{DISCUSSION}

The choice of conversion of LAGB to another bariatric procedure has not been well defined in the published data [37]. The final choice depends on the surgeon's personal experience and philosophy. It sometimes depends on the anticipated difficulty of the surgery resulting from the previous obesity procedure. Usually, in our department, the policy after a "failing" restrictive procedure is to change the type of operation. Hence, LAGB patients will usually benefit from band removal and conversion to LRYGBP or LDS. However, a small group of patients are still considered candidates for conversion to LSG. These patients were those who clearly had been volume eaters before the band procedure, and in whom the weight loss failure could be attributed to poor food choices and poor compliance to the strenu- 
ous follow-up needed for a successful LAGB operation [38]. Poor compliance can result because band adjustments cost a substantial amount of money for the patient, especially if fluoroscopy is used. Only 1 study of LAGB removal and immediate conversion to isolated LSG has been reported and included 8 patients [35]. Isolated case reports from LSG series have also been reported [9-12,36]. The operative times were longer than for primary LSG [39]. This results from the time needed for adhesiolysis and isolation of the band from both crura and to dismantle the gastrogastric tunnel. The latter maneuver is essential to avoid double tissue stapling and to avoid missing a dilated pouch proximal to the band and/or a subclinical hiatal hernia, very often only apparent at the end of the dissection when a large lipoma becomes visible. We believe it is very helpful to keep the band in situ until the last stapler firing. This can avoid the risk of constructing an asymmetric tube, because the exact limit of the lesser curvature is often obscured by fibrosis. Asymmetry of the sleeve can result in gastroesophageal reflux, reduced weight loss, and dysphagia. No conversion or mortality occurred in the present study, in agreement with other reports [35] and confirming the possibility of bariatric revision by laparoscopy [40,41]. Postoperatively, we had 1 major complication $(3.7 \%)$ : a subphrenic hematoma that required laparoscopic drainage. The probable cause of the hematoma was bleeding of an artery along the left crus. The most feared complication of LSG is a leak, usually located at the angle of His. To address the thickness of the gastric wall, we usually performed LSG using green staple loads and buttressed the staple line with a seroserosal running suture. This included the area of the previous LAGB, which usually appeared fibrotic. We are aware of good arguments against the need for oversewing the staple line; however, we were guided by the vast experience of Hess and Hess [7], who reportedly eliminated leaks by oversewing the staple line. The 23 patients in the present study achieved a mean \%EWL of $34.8 \%$ at 18.6 months. The $16.7 \%$ increase in the $\% E W L$ after conversion from LAGB to LSG can probably be explained by the resection of the gastric fundus, which constitutes the main capacity area of the stomach. Moreover, the fundus is the predominant area of ghrelin production. Ghrelin levels remain decreased at 6 months after LSG but increase after LAGB [42-44]. The \%EWL in the present study was less than the 57\% EWL reported by another study after conversion from LAGB to LSG [35], but that study included a smaller sample (5 of 8 patients). The BMI decrease in the present study was similar to that obtained with removal of the LAGB and conversion to LRYGBP. With the latter approach, the BMI reportedly decreases from $42.0-45.8 \mathrm{~kg} / \mathrm{m}^{2}$ to $31.8-37.7 \mathrm{~kg} / \mathrm{m}^{2}$ after $12-18$ months [24-26]. The removal of the LAGB and synchronous conversion to LBPD or LDS is another option [27,29]. Dolan and Fielding [29] reported a mean \%EWL at 12 months after LBPD and LDS of $37 \%$ and $28 \%$, respectively. Topart et al. [27] recently compared the removal of the LAGB and simultaneous conversion to laparoscopic gastric bypass and LDS and found a similar BMI after these 2 procedures, $33.4 \mathrm{~kg} / \mathrm{m}^{2}$ and $31.4 \mathrm{~kg} / \mathrm{m}^{2}$, respectively, at 12 and 18 months. These data are 
similar to those in the present study. Another revision procedure reported consists of adding a malabsorptive element to the restrictive one [45-47]. However, only few isolated cases have been reported [30,31]. We are concerned that this procedure might eventually fail, and the band would still need to be removed [37]. A final option for patients with a LAGB and an inadequate \%EWL is a repeat banding procedure $[32,33]$. The data regarding repeat banding have not been encouraging, because BMI appears unchanged after 1 year [24]. We have not achieved the results reported in published studies for obesity-related co-morbidity remission or improvement [48], with remission in only 5 of 12 patients. This might have been related to the less than optimal weight loss obtained with LSG. A clear correlation appears to exist between weight loss and the resolution of co-morbidities, especially diabetes [49]. Finally LSG after LAGB for weight loss failure in a small and select group of patients and in our hands had a success rate (\%EWL < ?30\%) of only $40 \%$. Hence, our concept of replacing a restrictive procedure with another restrictive procedure remains open to question.

\subsection{CONCLUSION}

The results of the present study support the safety of LSG after unsuccessful LAGB $(\% \mathrm{EWL}<30 \%)$ in select patients; however, the low \%EWL and co-morbidity resolution is of concern.

\subsection{REFERENCES}

1. Cadière GB, Bruyns J, Himpens J, Favretti F. Laparoscopic gastroplasty for morbid obesity. Br J Surg 1994;81:1524

2. Vella M, Galloway DJ. Laparoscopic adjustable gastric banding for severe obesity. Obes Surg 2003;13:642-8

3. O'Brien PE, Dixon JB, Brown W. Obesity is a surgical disease: overview of obesity and bariatric surgery. ANZ J Surg 2004;74:200-4

4. Chelala E, Cadière GB, Favretti F, et al. Conversions and complications in 185 laparoscopic adjustable gastric banding cases. Surg Endosc 1997;11:268-71

5. Favretti F, Segato G, Ashton D, et al. Laparoscopic adjustable gastric banding in 1791 consecutive obese patients: 12-year results. Obes Surg 2007;17:168-75

6. Marceau P, Hould FS, Simard S, et al. Biliopancreatic diversion with duodenal switch. World J Surg 1998;22:947-54

7. Hess DS, Hess DW. Biliopancreatic diversion with a duodenal switch. Obes Surg 1998;8:267-82

8. Johnston D, Dachtler J, Sue-Ling HM, King RF, Martin G. The Magenstrasse and Mill operation for morbid obesity. Obes Surg 2003;13:10-6

9. Krawczykowski DR, Lecko M, Nore O. Preliminary results with laparoscopic sleeve gastrectomy. Chir Gastroenterol 2005;21:1-5

10. Baltasar A, Serra C, Pérez C, Bou R, Bengochea M, Ferri L. Laparoscopic sleeve gastrectomy: a multi-purpose bariatric operation. Obes Surg 2005;15:1124-8

11. Mognol P, Chosidow D, Marmuse JP. Laparoscopic sleeve gastrectomy as an initial bariatric operation for high-risk patients: initial results in 10 patients. Obes Surg 2005;15:1030-3 
12. Langer FB, Bohdjalian A, Felberbauer FX, et al. Does gastric dilatation limit the success of sleeve gastrectomy as a sole operation for morbid obesity? Obes Surg 2006;16:166-71

13. Silecchia GF, Boru C, Pecchia A, et al. Effectiveness of laparoscopic sleeve gastrectomy (first stage of biliopancreatic diversion with duodenal switch) on co-morbidities in super-obese high-risk patients. Obes Surg 2006;16:1138-44

14. Himpens J, Dapri G, Cadière GB. A prospective randomized study between laparoscopic gastric banding and laparoscopic isolated sleeve gastrectomy: results after 1 and 3 years. Obes Surg 2006;16:1450-6

15. Weiner RA, Weiner S, Pomhoff I, Jacobi C, Makarewicz W, Weigand G. Laparoscopic sleeve gastrectomy-influence of sleeve size and resected gastric volume. Obes Surg 2007;17:1297-305

16. Nocca D, Krawczykowsky D, Bomans B, et al. A prospective multicenter study of 163 sleeve gastrectomies: results at 1 and 2 years. Obes Surg 2008;18:560-5

17. Ramos AC, Galvao Neto M, Santana Galvao M, et al. Simplified laparoscopic duodenal switch. Surg Obes Relat Dis 2007;3:565-8

18. Deitel M, Crosby RD, Gagner M. The First International Consensus Summit for Sleeve Gastrectomy (SG), New York City, October 25-27, 2007. Obes Surg 2008;18:487-96

19. Reinhold RB. Critical analysis of long term weight loss following gastric bypass. Surg Gynecol Obstet 1982;155:385-94

20. Suter M, Calmes JM, Paroz A, Giusti V. A 10-year experience with laparoscopic gastric banding for morbid obesity: high long-term complication and failure rates. Obes Surg 2006;16:829-35

21. Brown WA, Burton PR, Anderson M, et al. Symmetrical pouch dilatation after laparoscopic adjustable gastric banding: incidence and management. Obes Surg 2008;18:1104-8

22. Colles SL, Dixon JB, O'Brien PE. Grazing and loss of control related to eating: two high-risk factors following bariatric surgery. Obesity (Silver Spring) 2008;16:615-22

23. Kothari SN, DeMaria EJ, Sugerman HJ, Kellum JM, Meador J, Wolfe. Lap-Band failures: conversion to gastric bypass and their preliminary outcomes. Surgery 2002;131:625-9

24. Weber M, Muller MK, Michel JM, et al. Laparoscopic Roux-en-Y gastric bypass, but not rebanding, should be proposed as rescue procedure for patients with failed laparoscopic gastric banding. Ann Surg 2003;238:827-34

25. Mognol P, Chosidow D, Marmuse JP. Laparoscopic conversion of laparoscopic gastric banding to Roux-en-Y gastric bypass: a review of 70 patients. Obes Surg 2004;14:1349-53

26. Van Wageningen B, Berends FJ, Van Ramshorst B, Janssen IF. Revision of failed laparoscopic adjustable gastric banding to Roux- en-Y gastric bypass. Obes Surg 2006;16:137-41

27. Topart P, Becouarn G, Ritz P. Biliopancreatic diversion with duodenal switch or gastric bypass for failed gastric banding: retrospective study from two institutions with preliminary results. Surg Obes Relat Dis 2007;3:521-5

28. Weiner R, Blanco-Engert R, Weiner S, Matkowitz R, Schaefer L, Pomhoff I. Outcome after laparoscopic adjustable gastric banding-8 years' experience. Obes Surg 2003;13:427-34

29. Dolan K, Fielding G. Biliopancreatic diversion following failure of laparoscopic adjustable gastric banding. Surg Endosc 2004;18:60-3

30. de Csepel J, Quinn T, Pomp A, Gagner M. Conversion to a laparoscopic biliopancreatic diversion with a duodenal switch for failed laparoscopic adjustable silicone gastric banding. J Laparoendosc Adv Surg Tech A 2002;12:237-40

31. Slater GH, Fielding GA. Combining laparoscopic adjustable gastric banding and biliopancreatic diversion after failed bariatric surgery. Obes Surg 2004;14:677-82

32. Peterli R, Wolnerhanssen BK, Peters T, Kern B, Ackermann C, von Flue M. Prospective study of a two-stage operative concept in the treatment of morbid obesity: primary Lap-Band followed if needed by sleeve gastrectomy with duodenal switch. Obes Surg 2007;17:334-40

33. Schouten R, van Dielen FM, Greve JW. Re-operation after laparoscopic adjustable gastric banding leads to a further decrease in BMI and obesity-related co-morbidities: results in 33 patients. Obes Surg 2006;16:821-8

34. Muller MK, Attigah N, Wildi S, et al. High secondary failure rate of rebanding after failed gastric banding. Surg Endosc 2008;22:448-53 
35. Bernante $\mathrm{P}$, Foletto $\mathrm{M}$, Busetto $\mathrm{L}$, et al. Feasibility of laparoscopic sleeve gastrectomy as a revision procedure for prior laparoscopic gastric banding. Obes Surg 2006;16:1327-30

36. Lalor PF, Tucker ON, Szomstein S, Rosenthal RJ. Complications after laparoscopic sleeve gastrectomy. Surg Obes Relat Dis 2008;4:33-8

37. Gagner M, Gumbs AA. Gastric banding: conversion to sleeve, bypass, or DS. Surg Endosc 2007;21:1931-5

38. Favretti F, O’Brien PE, Dixon JB. Patient management after Lap-Band placement. Am J Surg 2002;184:38S-41S

39. Dapri G, Vaz C, Cadière GB, Himpens J. A prospective randomized study comparing two different techniques of laparoscopic sleeve gastrectomy. Obes Surg 2007;17:1435-41

40. Spivak H, Beltran OR, Slavchev P, Wilson EB. Laparoscopic revision from Lap-Band to gastric bypass. Surg Endosc 2007;21:1388-92

41. Calmes JM, Giusti V, Suter M. Re-operative laparoscopic Roux-en-Y gastric bypass: an experience with 49 cases. Obes Surg 2005;15:316-22

42. Langer FB, Reza Hoda MA, Bohdjalian A, et al. Sleeve gastrectomy and gastric banding: effects on plasma ghrelin levels. Obes Surg 2005;15:1024-9

43. Cohen R, Uzzan B, Bihan H, Khochtali I, Reach G, Catheline JM. Ghrelin levels and sleeve gastrectomy in super-super-obesity. Obes Surg 2005;15:1501-2

44. Ram E, Vishne T, Diker D, et al. Impact of gastric banding on plasma ghrelin, growth hormone, cortisol, DHEA and DHEA-S levels. Obes Surg 2005;15:1118-23

45. Vassallo C, Negri L, Rovati $\mathrm{P}$, et al. Biliopancreatic diversion with transitory gastric restriction and duodenal bulb preservation: 88 patients since 1992. Obes Surg 2004;14:773-6

46. Cadière GB, Favretti F, Himpens J, Segato G, Capelluto E. Anneau gastrique et dérivation biliopancréatique par laparoscopie. J Coelio 2001;38:33-5

47. Gagner M, Steffen R, Biertho L, Horber F. Laparoscopic adjustable gastric banding with duodenal switch for morbid obesity: technique and preliminary results. Obes Surg 2003;13:444-9

48. Buchwald H, Avidor Y, Braunwald E, et al. Bariatric surgery: a systematic review and metaanalysis. JAMA 2004;292:1724-37

49. Dixon JB, O'Brien PE, Plavfair J, et al. Adjustable gastric banding and conventional therapy for type 2 diabetes: a randomized controlled trial. JAMA 2008;299:316-23 



\subsection{ABSTRACT}

Background: Repeat sleeve gastrectomy (re-SG) and the addition of the duodenal switch (DS) are possible options to increase weight loss after isolated SG (ISG). We report the feasibility, safety, and outcomes of laparoscopic re-SG versus DS in patients presenting with insufficient weight loss or weight regain after ISG.

Patients and Methods: From November 2003 to December 2009, 7 and 19 patients underwent laparoscopic re-SG and DS, respectively, mainly because of the patients' dietary habits: volume eating (hyperphagia) was treated by re-SG and eating meals too frequently (polyphagia) by DS.

Results: At ISG, the mean weight and BMI was $127.7 \pm 31.4 \mathrm{~kg}$, and $45.1 \pm 11.8$ $\mathrm{kg} / \mathrm{m}^{2}$ for the re-SG group and $119.8 \pm 20.9 \mathrm{~kg}$ and $41.2 \pm 5.5 \mathrm{~kg} / \mathrm{m}^{2}$ for the DS group, respectively. The mean interval between ISG and reoperation was $37.1 \pm 20.3$ months for the re-SG group and 29.8 \pm 24.9 months for the DS group. At reoperation, the mean weight, BMI, and percentage of excess weight loss (\%EWL) was $109.7 \pm 21 \mathrm{~kg}, 38.9 \pm 8.7 \mathrm{~kg} / \mathrm{m}^{2}, 24.3 \pm 16.6 \%$ for the re-SG group and $107.6 \pm 19.6 \mathrm{~kg}$, $36.9 \pm 4.2 \mathrm{~kg} / \mathrm{m}^{2}$, and $19.5 \pm 19.9 \%$ for the DS group, respectively. The mean operative time was $137.5 \pm 75.5$ minutes for the re-SG group and $152.6 \pm 54.3$ minutes for the DS group. No conversion to open surgery was required, and no mortality occurred. One patient in the re-SG group developed a leak at the angle of His. In the DS group, 1 patient presented with bleeding, 1 patient with a duodenoileostomy leak, and 1 patient with a duodenoileostomy stenosis. The mean hospital stay was $11.5 \pm 20.5$ days for the re-SG group and $4.7 \pm 2.7$ days for the DS group. The mean follow-up was $23.2 \pm 11.1$ months for the re-SG group and $24.9 \pm 20.1$ months for the DS group. The mean weight, BMI, and \%EWL was $100 \pm 21.1 \mathrm{~kg}, 35.3 \pm 8.3 \mathrm{~kg} / \mathrm{m}^{2}$, $43.7 \pm 24.9 \%$ for the re-SG group and $80.7 \pm 22.5 \mathrm{~kg}, 27.3 \pm 5.2 \mathrm{~kg} / \mathrm{m}^{2}, 73.7 \pm 27.7 \%$ for the DS group, respectively. During follow-up, 3 patients in the DS group required corrective surgery for late complications.

Conclusion: The results of the present study have shown that laparoscopic reSG is feasible but carries the risk of fistula development, which is difficult to treat. Laparoscopic DS was also shown to be feasible at a cost of not negligible complications, which are easier to manage than with re-SG. The efficacy seemed greater after DS than after re-SG. 


\section{$5.2 \quad$ INTRODUCTION}

Morbid obesity can be treated by different procedures, currently usually performed with a laparoscopic approach. Since the first description of sleeve gastrectomy (SG) as an isolated procedure [1] or as a part of a duodenal switch (DS) procedure [2,3], laparoscopic SG has been introduced as one of the procedures for the treatment of obesity. Owing to the 2 International Consensus Summits for SG, held in 2007 [4] and 2009 [5], this procedure has been recognized as an established bariatric procedure [6] and is rapidly becoming accepted as a common procedure for morbid obesity. As with other procedures, isolated SG (ISG) can result in various postoperative complications, such as leak [7,8], stricture [9], new-onset gastroesophageal reflux disease (GERD) [10], insufficient weight loss, and weight regain [11]. The early results of the efficacy of SG have shown a percentage of excess weight loss (\%EWL) of $64.7 \pm 12.9 \%$ at 2 years and $48.5 \pm 8.7 \%$ after the first 4 years [5]. The problem of insufficient weight loss and weight regain after bariatric surgery has also been an issue after ISG, just as with adjustable gastric banding and Roux-en-Y gastric bypass (RYGB). Multidisciplinary counseling is indicated for patients presenting with insufficient weight loss to determine the contributive factors. The psychologist must evaluate the patient for the presence of mental disorders as binge eating disorder (BED), the nutritionist for possible new dietary behavior (including volume eating to grazing), the gastroenterologist for the appearance of GERD, and, finally, the radiologist for possible gastric dilation of the ISG. The treatment will depend on the findings of the different evaluations. The present retrospective study was done to determine the feasibility, safety, and outcomes of laparoscopic repeat SG (re-SG) versus DS in patients presenting with insufficient weight loss or weight regain after ISG.

\subsection{PATIENTS AND METHODS}

From November 2003 to December 2009, 7 patients (3 women and 4 men) underwent laparoscopic re-SG and 19 patients (16 women and 3 men) underwent DS after ISG. Their mean age was $44 \pm 11.7$ years (range 30-61) in the re-SG group and 47.2 \pm 9.2 years (range 29-60) in the DS group. All 26 patients had undergone ISG, using a $34 \mathrm{~F}$ orogastric bougie. The indication for revision in our treatment strategy was mainly determined by the patients' new dietary habits: volume eating (hyperphagia) was treated by re-SG and eating meals too frequently (polyphagia) by DS. In both groups, psychological disorders had been ruled out. Evident ISG dilation and de novo GERD had also been ruled out, the former using a barium swallow test and the latter by gastroscopy. Because of the retrospective nature of the present study, the statistical analysis should only be considered descriptive because the treatment groups were not comparable and the sample size of the 2 groups was small. Our co-primary endpoint was the \%EWL, calculated from the initial weight 
before ISG, and the ideal weight set at a BMI of $22 \mathrm{~kg} / \mathrm{m}^{2}$. We have reported the distributions of continuous variables using the observed mean and standard deviation. For categorical variables, we calculated the frequencies of the categories of interest. Thus, we did not attempt to determine statistical inferences.

\subsubsection{SURGICAL TECHNIQUE}

The procedure was started with the insertion in the abdomen of the first 12-mm trocar using the Hasson technique in the left upper quadrant mid-clavicular line. Additional trocars (4 for re-SG and 5 for DS) were placed under direct view, usually at the same position as for the original ISG.

\subsubsection{Repeat $S G$}

Re-SG started with complete adhesiolysis using the Ligasure device (Covidien, New Haven, CT). The greater omentum was freed from the abdominal wall, and the left liver lobe was dissected off the gastric sleeve until the entire stomach was freed from the antrum up to the left crus. The stomach tube was freed from the greater omentum along the previous staple line. The anatomy of the stomach was checked using insufflation of compressed air. To repeat the stapling of the SG, the anesthesiologist inserted a $34 \mathrm{~F}$ orogastric bougie to reach the pylorus, and different applications of linear stapler green loads (Covidien) were fired (Fig.1).

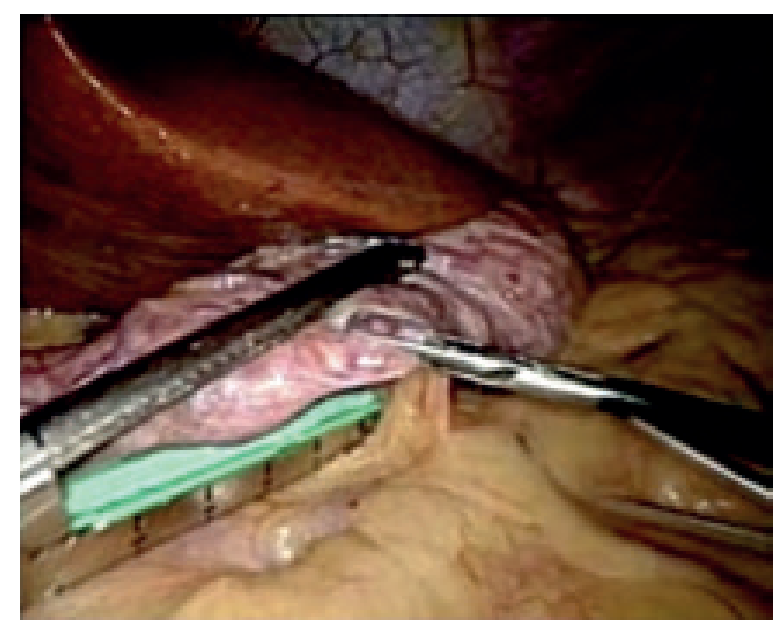

Fig.1 Re-SG, firing of linear stapler (green load) along 34F orogastric bougie

Resorbable serosal-serosal running sutures were used to oversew the staple line, and the leak test was performed. The specimen was extracted from the abdomen by enlarging the 12-mm left upper quadrant trocar incision, which was later closed in layers. A drain was left in place along the staple line. No nasogastric tube was left in place. A methylene blue test was performed on the first postoperative day. If 
the test findings were negative, the patient started a liquid diet on the second postoperative day. The patient was discharged from the hospital on the fifth postoperative day, with the dietary restrictions of a strict pureed diet.

\subsubsection{DS}

For the DS, no effort was made to dissect the stomach itself, and the procedure was started with cholecystectomy. The first duodenum was encircled, just lateral to the gastroduodenal artery, and sectioned with a linear stapler blue load. The right colon was widely freed to provide more slack to the distal ileum because of the duodenoileostomy. The common and alimentary limbs were fashioned, measuring 100 and $150 \mathrm{~cm}$, respectively. Precise measurements were obtained by stretching the bowel along a $25-\mathrm{cm}$ tape. A semimechanical side-to-side ileoileostomy was performed between the alimentary and biliopancreatic limbs, with a final section of the alimentary loop close to this anastomosis. The alimentary limb was advanced in the direction of the sectioned duodenum. The duodenoileostomy was performed with manual running sutures in 1-layer of absorbable material. The mesenteric defect and Petersen's defect were closed with nonabsorbable sutures, and the leak test was performed. The gallbladder was extracted by enlarging the 12-mm left upper quadrant trocar incision, which was subsequently closed in layers. A drain was left in place near the duodenoileostomy. No nasogastric tube was left in place. A methylene blue test was performed on the first postoperative day. If the test findings were negative, the patient was allowed to start a liquid diet on the second postoperative day. Typically, the patient was discharged from the hospital on the fifth postoperative day, with no particular dietary restrictions.

\subsection{RESULTS}

At ISG, the mean weight and BMI was $127.7 \pm 31.4 \mathrm{~kg}$ (range 95-183), and $45.1 \pm 11.8$ $\mathrm{kg} / \mathrm{m}^{2}$ (range 32.9-68.9) for the re-SG group and 119.8 $\pm 20.9 \mathrm{~kg}$ (range 84-160) and $41.2 \pm 5.5 \mathrm{~kg} / \mathrm{m}^{2}$ (range $30-49.7$ ) for the DS group, respectively. At ISG, obesityrelated co-morbidities affected 4 patients in the re-SG group, including arterial hypertension in 4 and sleep apnea in 1. Obesity-related co-morbidities affected 5 patients in the DS group, including type 2 diabetes in 3, arterial hypertension in 3 , and sleep apnea in 1 . The mean interval between ISG and reoperation was $37.1 \pm 20.3$ months (range 9-53) for the re-SG group and 29.8 \pm 24.9 months (range 4-84) for the DS group. At revision, the mean weight, BMI, and \%EWL was $109.7 \pm 21 \mathrm{~kg}$ (range $88-146$ ), $38.9 \pm 8.7 \mathrm{~kg} / \mathrm{m}^{2}$ (range $30.4-55$ ), and $24.3 \pm 16.6 \%$ (range 3.6-56.9) for the re-SG group and 107.6 $\pm 19.6 \mathrm{~kg}$ (range 83-136), 36.9 \pm 4.2 $\mathrm{kg} / \mathrm{m}^{2}$ (range 30.4-45.9), and 19.5 $\pm 19.9 \%$ (range 32.4-50) for the DS group, respectively. Obesity-related co-morbidities affected 3 patients in the re-SG group (all arterial hypertension) and 4 patients in the DS group, including type 2 diabetes in 3 , arterial hypertension in 2 , and sleep apnea in 1 . The mean operative time was 
137.5 \pm 75.5 minutes (range 45-270) for the re-SG group and 152.6 \pm 54.3 minutes (range 90-270) for the DS group. All the patients in the DS group underwent cholecystectomy. No conversions to open surgery were required, and no mortality occurred. In the re-SG group, 1 patient developed a leak at the angle of His (14.2\%). In the DS group, 3 patients presented with early complications (15.7\%): abdominal bleeding in 1, duodenoileostomy leak in 1, and duodenoileostomy stenosis in 1 . The mean hospital stay was $11.5 \pm 20.5$ days (range 3-58) for the re-SG group and $4.7 \pm 2.7$ days (range 3-14) for the DS group, respectively. All patients were followed-up with office visits, with exception of 2 patients in the re-SG group who refused follow-up. The mean follow-up was $23.2 \pm 11.1$ months (range 13-38) for the re-SG group and 24.9 \pm 20.1 months (range 1-59) for the DS group. The mean weight, BMI, and \%EWL was $100 \pm 21.1 \mathrm{~kg}$ (range $74-132$ ), $35.3 \pm 8.3 \mathrm{~kg} / \mathrm{m}^{2}$ (range 27.8-49.7), and $43.7 \pm 24.9 \%$ (range 3.1-69.6) for the re-SG group, respectively (Fig.2).

\section{ISG to re-SG}

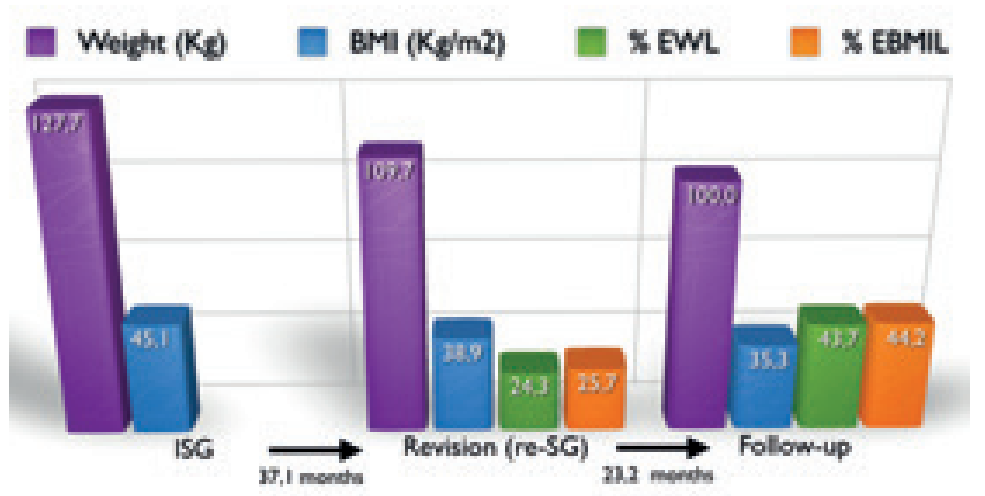

Fig.2 ISG to re-SG: comparison of weight, BMI, and \%EWL at ISG, at revision to reSG, and during follow-up

The mean weight, BMI, and \%EWL was $80.7 \pm 22.5 \mathrm{~kg}$ (range $37-120$ ), $27.3 \pm 5.2$ $\mathrm{kg} / \mathrm{m}^{2}$ (range 15.4-35.1), and 73.7 $\pm 27.7 \%$ (range 32.7-140) for the DS group, respectively (Fig.3). 


\section{ISG to DS}

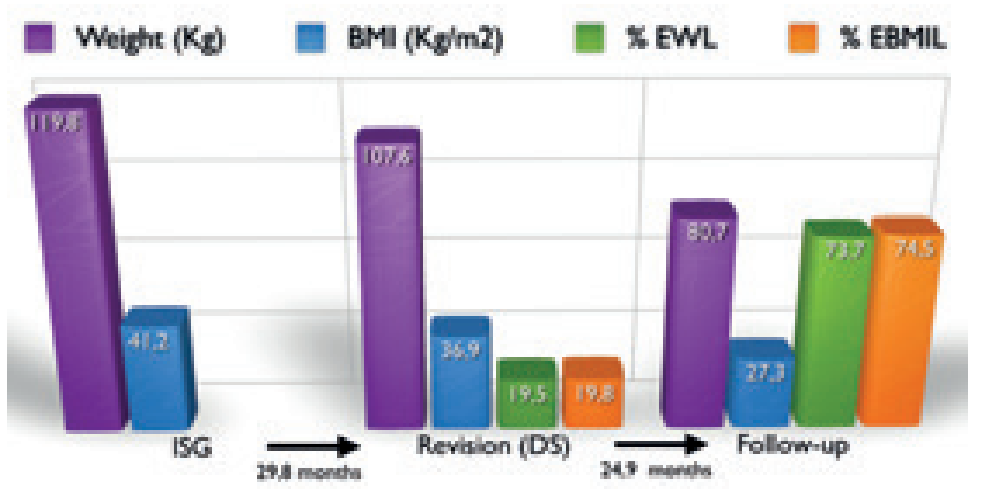

Fig.3 ISG to DS: comparison of weight, BMI, and \%EWL at ISG, at revision to DS, and during follow-up

Obesity-related co-morbidities had resolved in 1 patient $(33.3 \%)$ in the re-SG group and in 3 patients (75\%) in the DS group, including type 2 diabetes in 2, arterial hypertension in 2, and sleep apnea in 1 . During the follow-up period, 3 patients in the DS group (18.7\%) required surgery for late complications, including hypoproteinemia and diarrhea in 2 and a trocar-site ventral hernia in 1 . The first 2 patients were hospitalized at 16 and 17 months postoperatively, and treatment consisted of placement of a feeding jejunostomy tube. Together with adequate pharmacologic therapy after dis- charge, this approach was successful. The third patient underwent laparoscopic surgery for ventral hernia repair 7 months after the revision, without complications.

\subsection{DISCUSSION}

One of the greatest challenges of bariatric surgery is insufficient weight loss or weight regain, testifying to the failure of the chosen procedure. The reason for the failure must be thoroughly investigated. Because bariatric surgery candidates are at an increased risk of psychological diffi- culties, evidence has been growing that psychological issues play an essential role [12-14]. New dietary habits and patient adaptation to the new anatomic circuit are other fre- quent causes of insufficient weight loss and weight regain. Some investigators have advocated that failed ISG should be treated with RYGB $[15,16]$. However, in our department, RYGB has not been the treatment of choice as the corrective procedure for ISG, because, our experience with the latter treatment has shown the weight loss to be deceiving, with bloating a frequent and disturbing side effect. Therefore, we only perform RYGB after ISG in patients who complain of medication-resistant GERD. Only in the case of unsuccessful results with a proton pump inhibitor, together with poor weight 
loss, has conversion to RYGB been performed. Crookes [17] recently reported on 11 patients (100\%) who had undergone RYGB and were able to discontinue use of the proton pump inhibitor after conversion. In contrast, $3(42.8 \%)$ of 7 patients who had undergone DS were still dependent on the proton pump inhibitor after the revision [17]. Similarly, Langer et al. [18] reported a profound and immediate relief of reflux symptoms in 3 patients who had undergone ISG, with subsequent conversion to RYGB. However, when GERD is not present, psychological disorders, such as BED must be ruled out. Changes in BED have been correlated with changes in body weight, independent of the reported dietary intake and physical activity [19]. Because additional volume restriction might jeopardize the patient's psychological balance, the performance of a malabsorptive procedure (in our practice, DS) appears to be the only viable surgical option. In the absence of GERD and BED, changes in eating behavior should be evaluated. These changes are likely to have occurred at any point in the years after ISG. In the patients in the present series, our multidisciplinary obesity counseling focused on new alimentary habits (i.e., hyperphagia and polyphagia). Hyperphagia means volume eating (basically eating volumes that are too large) and polyphagia means eating meals too frequently. Alimentary behavior plays a significant role in the decision making for the primary procedure $[20,21]$. It is also our conviction that knowledge of this behavior is essential in the choice of the reoperative procedure. In the case of hyperphagia linked with a gastric volume issue, we have offered patients re-SG or another option is the placement of an adjustable gastric band [22]. If volume eating is not an issue, a new restrictive procedure would seem less appropriate, and a new approach is preferable. In addition to restriction, malabsorption is a proven effective method for achieving weight loss. It is for professionals such as nutritionists and bariatric dieticians, who are acquainted with the subject, to detect the subtle differences between the 2 eating behavior patterns (volume and frequency). The radiologist's evaluation in the multidisciplinary evaluation for insufficient weight loss or weight regain after ISG should focus on possible gastric dilation. When dilation is present, re-SG again would appear to be the logical option. Baltasar et al. [11], in 2006, first reported on 2 patients who had undergone re-SG for dilation of ISG, with subsequent increased successive weight loss. In our series, we did not find an evident preoperative dilation of the ISG on barium swallow testing; however, during surgical exploration, we did find sufficient space to place the linear staple next to the orogastric bougie. After placement of the orogastric bougie, in some patients, excessive redundancy was still found toward the antrum and, in some patients, in the upper part of the stomach tube. Thus, the barium swallow test does not seem completely appropriate to evaluate the status after ISG. The orogastric bougie used was the same for the primary and revisional procedure (34F). Our operative times were similar for re-SG and DS. This unexpected finding resulted because the addition of DS, in contrast to ISG, does not demand the timeconsuming freeing of the ISG from adhesions. In the case of re-SG, the gastric tube 
must be completely freed and checked well before stapling. Moreover, because we usually oversewed the staple line during re-SG, to both decrease operative bleeding and avoid postoperative leak development, the resulting operative time was quite similar to that for DS. In the present selected series of obese patients, we recorded 1 early gastric leak in the re-SG group. This complication has also been reported after ISG, with or without DS [23,24]. Logically, during ISG revisions, the risk factor would be greater and even more difficult to treat. This was demonstrated by our patient who required treatment for 58 days and 12 endoscopic stent placement. Recent data have shown that more conservative treatment of leak provides better results than reoperation, with no mortality overall [25]. Furthermore, it appears that very early placement of a covered metallic stent will substantially reduce the hospital length of stay, because patients are fed directly into the gut rather than intravenously, improving morbidity and allowing earlier hospital discharge without the need for an intravenous line [26]. In the DS group, 1 patient presented with bleeding from the greater omentum. This complication after ISG has been previously reported, with an incidence of 1.0-1.6\% [27]. Treatment should be laparoscopic lavage and drainage, such as for our patient, or blood transfusions, in the case of the hemodynamically stable patient. Two other patients presented with a complication at the duodenoileostomy. One developed a leak and one, stenosis. The incidence of leak at the duodenoileostomy has been reported to be $1.5-1.7 \%$ after a 1 -stage primary procedure $[28,29]$ and $33.3 \%$ after revisional procedures [30]. Conservative treatment can be attempted if the drain is well in place. In our patient, drainage appeared insufficient, and the patient was returned to the operating room for laparoscopic lavage and drainage. The complication of stenosis has previously been reported in 4 of 27 patients who had undergone second-stage DS [31]. Treatment should be endoscopic dilation, such as in our patient, who successfully benefited from a single endoscopic dilation at 1 month after the revision. During follow-up, we recorded greater weight loss after the DS procedure than after re-SG, with an achieved \%EWL of 73.7\%, similar to that reported after primary DS during the same follow-up period [29]. This obviously resulted from the addition of malabsorption, although sometimes at the cost of hypoproteinemia and diarrhea, which was experienced by 2 of our patients. Another patient in the DS group developed an occlusion owing to a trocar site ventral hernia. Although this is a nonspecific postlaparoscopic complication, in bariatric patients, this can become a critical issue because bowel resection of some length, especially if it involves the alimentary or common loop [32], can have morbid consequences. In terms of the obesity-related co-morbidities, for our patients who had undergone ISG, we achieved resolution in 1 patient in both groups before revision. After revision, more patients in the DS group than in the re-SG group had resolution of their co-morbidities, probably because of the greater weight loss achieved with DS. 


\subsection{CONCLUSION}

The results of the present study have shown that laparoscopic re-SG is feasible but carries the risk of fistula development, which is difficult to treat. Laparoscopic DS was also shown to be feasible but at the cost of not negligible complications, which are easier to manage than with re-SG. The efficacy appeared greater after DS than after re-SG.

\subsection{REFERENCES}

1. Johnston D, Dachtler J, Sue-Ling HM, King RF, Martin G. The Magenstrasse and Mill operation for morbid obesity. Obes Surg 2003;13:10-6

2. Marceau P, Hould FS, Simard S, et al. Biliopancreatic diversion with duodenal switch. World J Surg 1998;22:947-54

3. Hess DS, Hess DW. Biliopancreatic diversion with a duodenal switch. Obes Surg 1998;8:267-82

4. Deitel M, Crosby RD, Gagner M. The First International Consensus Summit for Sleeve Gastrectomy (SG), New York City, October 25-27, 2007. Obes Surg 2008;18:487-96

5. Gagner M, Deitel M, Kalberer TL, Erickson AL, Crosby RD. The Second International Consensus Summit for Sleeve Gastrectomy, March 19-21, 2009. Surg Obes Relat Dis 2009;5:476-85

6. Clinical Issues Committee of the ASMBS. Updated position statement on sleeve gastrectomy as a bariatric procedure. Surg Obes Relat Dis 2010;6:1-5

7. Burgos AM, Braghetto I, Csendes A, et al. Gastric leak after laparoscopic sleeve gastrectomy for obesity. Obes Surg 2009;19:1672-7

8. Dapri G, Cadière GB, Himpens J. Reinforcing the staple line during laparoscopic sleeve gastrectomy: prospective randomized clinical study comparing three different techniques. Obes Surg 2010;20:462-7

9. Dapri G, Cadière GB, Himpens J. Laparoscopic seromyotomy for long stenosis after sleeve gastrectomy with or without duodenal switch. Obes Surg 2009;19:495-9

10. Keidar A, Appelbaum L, Schweiger C, Elazary R, Baltasar A. Dilated upper sleeve can be associated with severe postoperative gastroesophageal dysmotility and reflux. Obes Surg 2010;20:140-7

11. Baltasar A, Serra C, Perez N, Bou R, Bengochea M. Re-sleeve gastrectomy. Obes Surg 2006;16:1535-8

12. Sarwer DB, Wadden TA, Fabricatore AN. Psychological and behavioral aspects of bariatric surgery. Obes Res 2005;13:639-48

13. Hsu LKG, Benotti PN, Dwyer J, et al. Nonsurgical factors that influence the outcome of bariatric surgery. Psychosom Med 1998;60:338-46

14. Sholtz S, Bidlake L, Morgan J, et al. Long-term outcomes following laparoscopic adjustable gastric banding: postoperative psychological sequelae predict outcome at 5 year follow-up. Obes Surg 2007;17:1220-5

15. Cottam D, Qureshi FG, Mattar SG, et al. Laparoscopic sleeve gastrectomy as an initial weight-loss procedure for high-risk patients with morbid obesity. Surg Endosc 2006;20:859-63

16. Han SM, Kim WW, Oh JH. Results of laparoscopic sleeve gastrec- tomy (LSG) at 1 year in morbidly obese Korean patients. Obes Surg 2005;15:1469-75

17. Crookes PF. Management of severe reflux after sleeve gastrectomy (abstract). Presented at the Second International Consensus Summit for Sleeve Gastrectomy, Miami Beach (FL), March 19-21, 2009

18. Langer FB, Bohdjalian A, Shakeri-Leidenmuhler S, Schoppmann SF, Zacherl J, Prager G. Conversion from sleeve gastrectomy to Roux-en-Y gastric bypass-indications and outcome. Obes Surg 2010;20:835-40 
19. Sherwood NE, Jeffery RW, Wing RR. Binge status as a predictor of weight loss treatment outcome. Int J Obes 1999;23:485-93

20. Busetto L, Segato G, De Marchi F, et al. Outcome predictors in morbidly obese recipients of an adjustable gastric band. Obes Surg 2002;12:83-92

21. Chevallier JM, Paita M, Rodde-Dunet MH, et al. Predictive factors of outcome after gastric banding: a nationwide survey on the role of center activity and patients' behavior. Ann Surg 2007;246:1034-9

22. Greenstein AJ, Vine AJ, Jacob PP. Video: when sleeve gastrectomy fails: adding a laparoscopic adjustable gastric band to increase restriction. Surg Endosc 2009;23:884

23. Stroh C, Birk D, Flade-Kuthe R, et al. Results of sleeve gastrectomy-data from a nationwide survey on bariatric surgery in Germany. Obes Surg 2009;19:632-40

24. Chen B, Kiriakopoulos A, Tsakayannis D, Wachtel MS, Linos D, Frezza EE. Reinforcement does not necessarily reduce the rate of staple line leaks after sleeve gastrectomy: a review of the literature and clinical experiences. Obes Surg 2009;19:166-72

25. Casella G, Soricelli E, Rizzello M, et al. Nonsurgical treatment of staple line leaks after laparoscopic sleeve gastrectomy. Obes Surg 2009;19:821-6

26. Kotzampassi K, Kolios G, Manousou P, et al. Oxidative stress due to anesthesia and surgical trauma: importance of early enteral nutrition. Mol Nutr Food Res 2009,53:770-9

27. Brethauer SA, Hammel JP, Schauer PR. Systematic review of sleeve gastrectomy as staging and primary bariatric procedure. Surg Obes Relat Dis 2009;5:469-75

28. Marceau P, Biron S, Hould FS, et al. Duodenal switch: long-term results. Obes Surg 2007;17:142130

29. Hess DS, Hess DW, Oakley RS. The biliopancreatic diversion with the duodenal switch: results beyond 10 years. Obes Surg 2005;15:408-416

30. Dapri G, Cadière GB, Himpens J. Laparoscopic conversion of adjustable gastric banding and vertical banded gastroplasty to duodenal switch. Surg Obes Relat Dis 2009;5:678-83

31. Silecchia G, Rizzello M, Casella G, Fioriti M, Soricelli E, Basso N. Two-stage laparoscopic biliopancreatic diversion with duodenal switch as treatment if high-risk super-obese patients: analysis of complications. Surg Endosc 2009;23:1032-7

32. Mitchell MT, Carabetta JM, Shah RN, O’Riordan MA, Gasparaitis AE, Alverdy JC. Duodenal switch gastric bypass surgery for morbid obesity: imaging of postsurgical anatomy and postoperative gastrointestinal complications. AJR Am J Roentgenol 2009;6:1576-80 


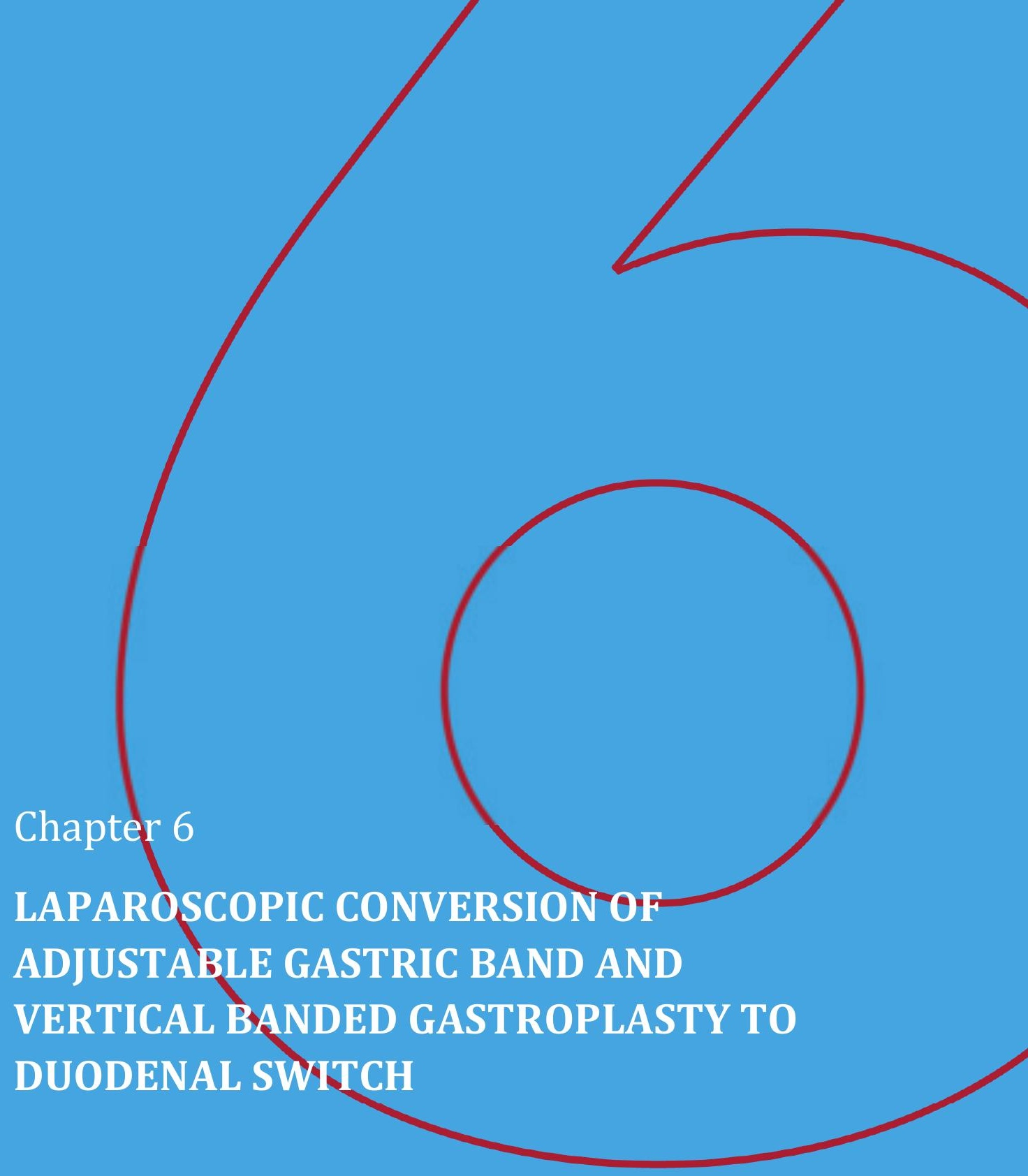

Dapri G, Cadière GB, Himpens J

Surgery for Obesity and Related Diseases 2009;5(6):678-683 



\subsection{ABSTRACT}

Background: The aim of this retrospective consecutive study was to evaluate the feasibility, safety, and efficacy of the conversion of laparoscopic adjustable gastric banding (LAGB) and open vertical banded gastroplasty (VBG) into duodenal switch (DS) by laparoscopy.

Patients and Methods: From November 2003 to February 2007, laparoscopic conversion into DS was performed in 1-step in 43 patients, 31 after LAGB and 12 after VBG. The reason for conversion was weight loss issues, such as insufficient excess weight loss (EWL) or weight regain. The mean interval from LAGB and VBG to conversion to the DS was $42.7 \pm 28.7$ months and $172.2 \pm 86.9$ months, respectively. The mean \%EWL at conversion was $8.3 \pm 19.3 \%$ after LAGB and $20.8 \pm 30 \%$ after VBG.

Results: The mean operative time was 205.8 \pm 44.8 minutes for LAGB and $210.9 \pm 53.7$ minutes for VBG. No conversions to open surgery occurred. One patient in the LAGB group died on the third postoperative day of sudden death syndrome, as shown by the postmortem examination. Major complications occurred in $6.4 \%$ of patients with LAGB (1 hemoperitoneum and 1 ileoileostomy leak) and in $50 \%$ with VBG (1 sleeve gastrectomy leak with subsequent duodenoileostomy leak, 3 duodenoileostomy leaks, 1 pancreatitis, and 1 respiratory insufficiency). The mean hospital stay was $5.5 \pm 5$ days for the LAGB group and $34.5 \pm 50.3$ days for the VBG group. After a mean follow-up of $28 \pm 15.7$ months for LAGB to DS and $43.5 \pm 6$ months for VBG to DS, reoperations for late complications were required in 6 patients $(20.6 \%)$ in the LAGB to DS group and in 5 patients $(62.5 \%)$ in the VBG to DS group. Three patients (25\%) died within 8 months after conversion of VBG. The 29 surviving patients (LAGB to DS) showed a mean \%EWL and percentage of excess body mass index loss of (\%EBMIL) 78.4 $\pm 24.9 \%$ and $77.8 \pm 23.7 \%$, respectively. The 8 surviving patients (VBG to DS) had a mean \%EWL and \%EBMIL of $85.1 \pm 20 \%$ and $85.8 \pm 18.7 \%$, respectively.

Conclusion: According to these results, laparoscopic conversion of LAGB to DS seems feasible and effective, despite the 1 death. However, in our hands, laparoscopic conversion of VBG to DS had an unacceptable rate of complications and deaths. 


\subsection{INTRODUCTION}

In the past century, the most common bariatric procedures have been restrictive procedures such as vertical banded gastroplasty (VBG) and laparoscopic adjustable gastric banding (LAGB). Malabsorptive procedures such as biliopancreatic diversion or duodenal switch (DS) have been less popular than the restrictive procedures, because they are technically more difficult to perform and require close patient follow-up [1-3]. Together with the rapid increase of patients undergoing surgery for morbid obesity, revisional surgery is becoming more common. Insufficient weight loss or weight regain after previous restrictive procedures is one of the challenges often confronting bariatric surgeons [4]. In addition to weight issues, other possible indications for revisional surgery include complications. Quite often, bariatric operations have their own typical complications. After LAGB, the appearance of gastroesophageal reflux disease (GERD), gastric erosion, band dilation, and tube-port problems have been reported [5-9]. After VBG, the development of GERD, band erosion, stomal stenosis, ulceration, and staple line rupture have been reported [5,10-13]. After LAGB, in addition to simple band removal [14], different options of conversion have been described, such as conversion to laparoscopic Roux-en-Y gastric bypass (LRYGB) [14-25], laparoscopic sleeve gastrectomy (LSG) $[14,26,27]$, or laparoscopic rebanding [14,28]. After VBG, the most frequently reported revisional surgery for whatever reason has been conversion to LRYGB $[29,30]$. Very few reports have described the technique and results of conversion from VBG [31-33] or LAGB [34-37] to duodenal switch (DS). The aim of the present retrospective consecutive study was to evaluate the feasibility, safety, and efficacy of laparoscopic conversion of LAGB and VBG to DS.

\subsection{PATIENTS AND METHODS}

From November 2003 to February 2007, 1-step laparoscopic conversion to DS was performed in 43 patients who had previously benefited from a restrictive procedure: 31 patients after LAGB ( 28 women and 3 men) and 12 patients after VBG (10 women and 2 men). In all patients but 2, 1 in each group, the reason for conversion to DS was weight loss issues, such as insufficient excess weight loss (EWL) or weight regain, after LAGB or VBG. Two patients with good weight loss underwent revision because of intractable GERD, persisting despite band deflation in 1 and incision of the Marlex mesh in the other. Unlike the LAGB group, all VBG patients had undergone laparotomy, and Marlex mesh had been used to reinforce the pouch outlet. The average interval between LAGB and VBG to conversion to DS was $42.7 \pm 28.7$ months (range 9-137) and $172.2 \pm 86.9$ months (range 46-261), respectively. At LAGB, the mean body mass index (BMI) was $45.4 \pm 6.3 \mathrm{~kg} / \mathrm{m}^{2}$ (range 35 58). At conversion, the mean BMI, \%EWL, and percentage of excess BMI loss (\%EBMIL) was $43.2 \pm 8.1 \mathrm{~kg} / \mathrm{m}^{2}$ (range 31-57), 8.3 $\pm 19.3 \%$ (range 27.5-67.1), and 
8.3 $\pm 19.9 \%$ (range 26.3-66.6), respectively. At VBG, the mean BMI was 47.8 \pm 7.1 $\mathrm{kg} / \mathrm{m}^{2}$ (range 41-67.7). At conversion, the mean BMI, \%EWL, and \%EBMIL was $41.5 \pm 6 \mathrm{~kg} / \mathrm{m} 2$ (range 35-51), 20.8 $\pm 30 \%$ (range 33.8-71.1), and 20 $\pm 29.9 \%$ (range 31.5-69.3), respectively. The average age at conversion from LAGB to DS and VBG to DS was $39.8 \pm 8.5$ years (range $24-57$ ) and $47.7 \pm 8.6$ years (range $30-55$ ), respectively. At conversion, 14 patients with LAGB had obesity-related co-morbidities, including arterial hypertension in 10, type 2 diabetes in 4, degenerative joint disease in 7, and sleep apnea in 1. Eight patients with VBG had co-morbidities including arterial hypertension in 4, type 2 diabetes in 2, degenerative joint disease in 3 , and sleep apnea in 2 . The statistical analysis consisted of studying the distributions of the parameters we collected using summary parameters: mean and standard deviation. No attempt was made to use performance hypothesis tests between the groups because the follow-up time in the present retrospective study was too different between the 2 groups ( $28 \pm 15.7$ months versus $43.5 \pm 6$ months).

\subsubsection{SURGICAL TECHNIQUE}

The patient was positioned supine with the legs apart and both arms in abduction. The surgeon stood between the patient's legs, with the camera person to the patient's right and the assistant to the patient's left. Six abdominal trocars were placed as follows: a $10-\mathrm{mm}$ trocar (for the $30^{\circ}$ optical system) $20 \mathrm{~cm}$ distal to the xiphoid process, a 5-mm trocar on the left anterior axillary line about $5 \mathrm{~cm}$ distal to the costal margin, a 12-mm trocar on the left mid-clavicular line between the first and second trocars, a 12-mm trocar on the right mid-clavicular line on the same horizontal line, a 5-mm trocar distal and to the left of the xiphoid process, and a 5$\mathrm{mm}$ trocar in the lower abdomen, to the left of the linea alba. Adhesiolysis between the abdominal wall and greater omentum and small bowel was performed to reach the left upper quadrant, followed by adhesiolysis between the left liver lobe and the stomach. The right hiatal pillar was systematically searched for by lysis of the adhesions along- side the lateral border of the caudate lobe. The left hiatal pillar was also dissected by freeing the greater curve from distally to proximally. After LAGB, the gastrogastric tunnel was sectioned. After VBG, the vertical staple line was well isolated and exposed over its entire length. The proximal limit of the antrum, about $6 \mathrm{~cm}$ cranial to the pylorus, was superficially scored, and the greater curvature was freed from the greater omentum using the Ligasure device (Covidien, New Haven, CT) or hook cautery, until the previously liberated left crus was reached. The stomach was transected by multiple firings of a linear stapler loaded with green cartridges (Covidien), with guidance of a 34F orogastric tube, which was positioned against the lesser curve. In patients with LAGB, the band was kept in place as a landmark for the more proximal staple firings. At the end of the gastric tubulization, the band was opened and retrieved. The fibrotic perigastric capsule at the site of the band was opened. Similar to the procedure in the patients with VBG, the firing of staplers was oriented toward the vertical staple line and the 
Marlex mesh. Once the Marlex mesh was reached, stapling was performed cephalad to the right of the staple line in the direction of the angle of His. Two converging seroserosal running sutures were used to buttress the staple line. Cholecystectomy was performed. The specimen, including the vertical staple line (if VBG) or the band (if LAGB), and the gallbladder were retrieved at the end of the procedure by enlarging the left upper quadrant 12 -mm trocar opening. The first part of the duodenum was encircled, just laterally to the gastroduodenal artery, and sectioned with a linear stapler using a blue load. The surgeon, camera person, and assistant moved to the patient's left. The right colon was widely freed to provide more slack to the distal ileum in view of the duodenoileostomy. The common and alimentary limbs were fashioned and measured to $100 \mathrm{~cm}$ and $150 \mathrm{~cm}$, respectively. Precise measurements were made by stretching the bowel along a $25-\mathrm{cm}$ tape. A semimechanical side-to-side ileoileostomy was performed between the alimentary and biliopancreatic limbs, with final sectioning of the alimentary loop close to this anastomosis. The mesenteric defect was closed using nonabsorbable pursestring suture. The alimentary limb was advanced in direction of the sectioned duodenum. The surgeon returned to between the patient's legs, the camera person to the patient's right, and the assistant to the patient's left. The duodenoileostomy was performed by manually suturing 1 layer of running suture of absorbable material. Petersen's defect was closed by nonabsorbable purse-string suture. The orogastric tube was advanced distally by the anesthesiologist until it reached the pylorus. A leak test was performed by air insufflation, keeping the duodenoileostomy under water. The specimens were retrieved and the enlarged left $12-\mathrm{mm}$ port site was closed in layers. The subcutaneous port was removed in the LAGB patients. A drain was left in the vicinity of the sleeve gastrectomy and the duodenoileostomy. A methylene blue test was performed on the first postoperative day. If negative, the patient was allowed to start a liquid diet on the second postoperative day. Typically, the patient was discharged from the hospital on the fifth postoperative day.

\section{$6.4 \quad$ RESULTS}

The mean operative time was 205.8 44.8 minutes (range 120-300) for the LAGB group and $210.9 \pm 53.7$ minutes (range 180-330) for the VBG group. No conversions to open surgery occurred. One patient after LAGB died on the third postoperative day of the sudden death syndrome as confirmed by the postmortem examination. Major complications occurred in 2 patients in the LAGB group (6.4\%). One patient presented with a hemoperitoneum that required second-look laparoscopy, and 1 patient developed a leak at the ileoileostomy, which was treated medically. After VBG, 6 patients (50\%) presented with major complications: 1 gastrocutaneous leak from the sleeve gastrec- tomy with a subsequent leak at the duodenoileostomy, 3 solitary leaks at the duodenoileostomy, 1 hemorrhagic pancreatitis, and 1 respiratory insufficiency (Tab.1). 


\begin{tabular}{|c|c|c|c|c|}
\hline Group & Easly complicantions & Patlients (u) & TrëLlment & Hesprital stay $(d)$ \\
\hline & Ileoileostomy leak & 1 & Conservative therapy & 14 \\
\hline \multirow[t]{3}{*}{ VBG to DS } & $\begin{array}{l}\text { Galstric leak and duodenoileostomy } \\
\text { leak }\end{array}$ & 1 & Endoscopic stent, tinal total gastrectomy & 149 \\
\hline & Duodenoileostomy leak & 3 & Laparoscopic revision, 2; laparoscopic subtotal gastrectomy, I & 8,11 , and 76 \\
\hline & Respiratory insulficiency & 1 & Conservative therapy & 15 \\
\hline
\end{tabular}

LAGB - laparoncopic adjustable gastric banding; DS - duodenal switch; VBG - vertical banded gastroplasty.

The patient presenting with a leak at the sleeve gastrectomy and duodenoileostomy was transferred to another hospital for placement of 2 endoscopic stents. Immediately after stent placement, the patient developed hemorrhagic shock. Total gastrectomy was performed by open access at the same hospital. The patient eventually died in our hospital 1 month later of multiple organ failure. Two patients with a duodenoileostomy leak were treated by laparoscopic revision and discharged after 8 and 11 days, respectively. One developed duodenoileostomy stenosis after 8 months. This stenosis was refractory to multiple endoscopic dilations and was finally treated by subtotal gastrectomy with gastroileostomy after 12 months. The third patient with a duodenoileostomy leak underwent reexploration after 5 days and underwent conversion to subtotal gastrectomy with gastroileostomy. This patient developed a gastroileostomy leak that was treated by placement of an endoscopic stent. At 7 months, the fistula was still present and increasingly symptomatic. The patient underwent laparoscopic re-exploration, and an unsuccessful attempt was made to close the fistula. The patient died 1 month later of, what on autopsy, appeared to be an abdominal compartment syndrome. The patient with hemorrhagic pancreatitis was checked laparoscopically on the fourth postoperative day and discharged 14 days later. The patient with respiratory insufficiency was treated medically and discharged on postoperative day 15 . Minor postoperative complications occurred in 2 patients in the LAGB group, who presented with a subcutaneous abscess at the trocar site, and in 1 patient in the VBG group, who presented with an intra-abdominal abscess that was successfully treated by percutaneous computed tomography-guided drainage. The mean hospital stay after conversion of LAGB to DS and VBG to DS was 5.5 \pm 5 days (range 3-28) and 34.5 \pm 50.3 days (range 4-149), respectively. One patient from each group, both foreigners, refused our follow-up. The remaining 29 surviving patients after LAGB and 8 surviving patients after VBG were followed up with office visits and telephone calls. In the LAGB to DS group, during a mean follow-up of 28 15.7 months (range 2-54), reoperations for late complications were required in 6 (20.6\%) of the 29 surviving patients (Tab.2). 


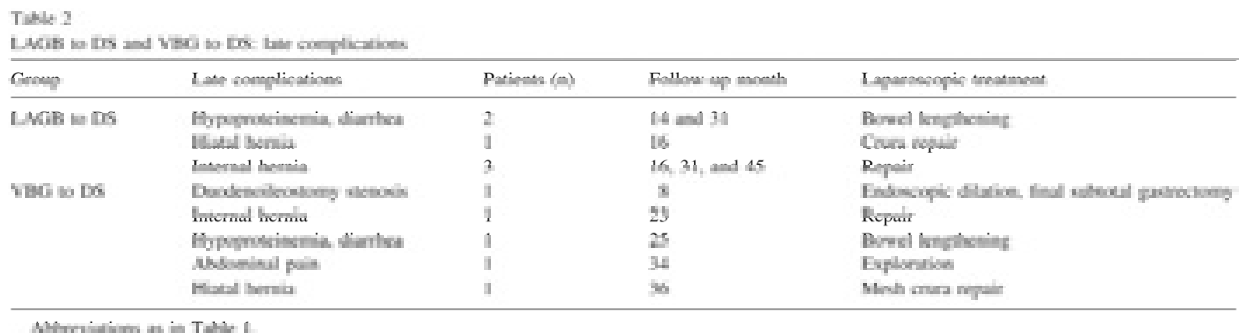

With the initial excess weight before LAGB as a reference, the mean \%EWL and $\%$ EBMIL was $78.4 \pm 24.9 \%$ (range $23.4-123.6$ ) and $77.8 \% \pm 23.7 \%$ (range 24126.6\%), respectively (Fig.1).

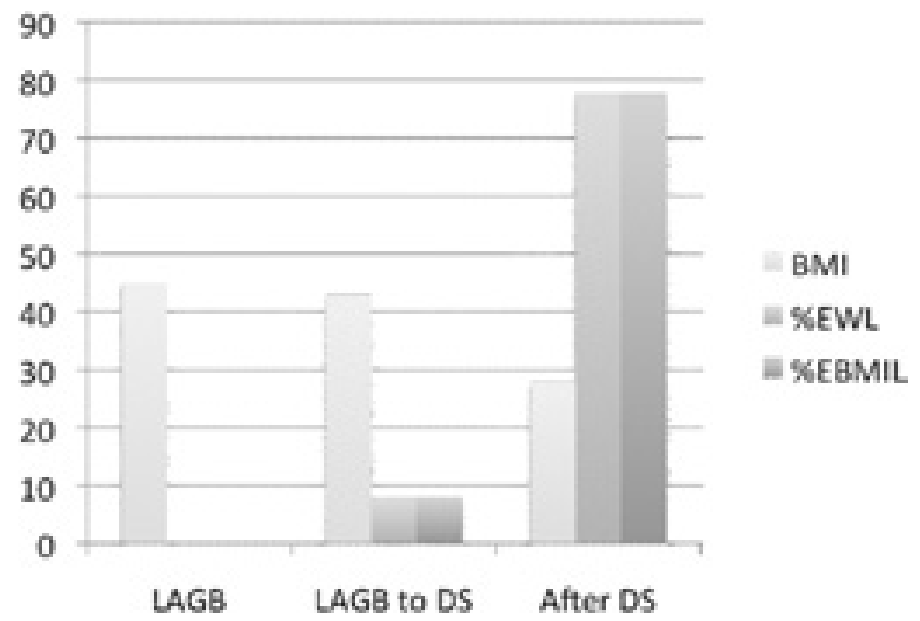

Fig.1 LAGB to DS: comparison of BMI, \%EWL, and \%EBMIL at restrictive procedure, at conversion, and during follow-up

In the VBG to DS group, during a mean follow-up of $43.5 \pm 6$ months (range $36-50$ ), reoperations for late complications were necessary in 5 (62.5\%) of 8 surviving patients (Tab.2). A third patient from this group died of a pulmonary embolism, confirmed at autopsy, 2 months after the procedure, for a mortality rate in this group of $25 \%$. With the initial excess weight before VBG as a reference, the mean $\%$ EWL and \%EBMIL was $85.1 \pm 20 \%$ (range $59-121.1$ ) and $85.8 \pm 18.7 \%$ (range 60.8-102), respectively (Fig.2). 


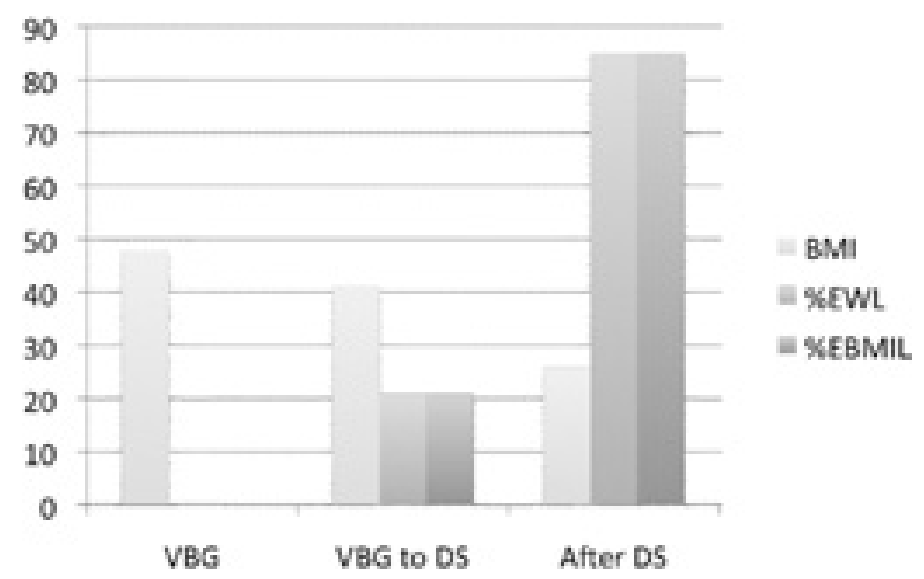

Fig.2 VBG to DS: comparison of BMI, \%EWL, and \%EBMIL at restrictive procedure, at conversion, and during follow-up

\subsection{DISCUSSION}

Failure of restrictive procedures can be managed by another, nonrestrictive, operation. The decision to reoperate should be made after multidisciplinary consultation among a psychologist, nutritionist, gastroenterologist, and surgeon. The patients in the present study had all had a compulsive eating disorder that persisted after undergoing a restrictive procedure, despite adequate counseling. In accordance with our algorithm, the restrictive procedure was converted to a malabsorptive one. The DS is a true malabsorptive procedure, in contrast to gastric bypass, which is a hybrid restrictive-malabsorptive operation [38]. This might explain why the DS has had better long-term results in terms of weight loss [1,2]. Revisional surgery is technically more demanding and time-consuming because of adhesions. Logically, open VBG induces more adhesions than LAGB. Dense adhesions quite often require conversion to open surgery, with rates up to $46.2-48 \%[17,39]$. In addition to the adhesions, the complexity of the DS construction itself results in a longer operative time. Our operative time was similar to that reported for open surgery [36], in which the conversion of LAGB to DS appeared longer than the conversion of LAGB to LRYGB, 239.7 a 55.8 minutes versus $135 \pm 26.7$ minutes, respectively. Revisional surgery is associated with an increased risk of leaks and complications [40], with an incidence of 29.6-41.7\% [41]. Moreover, increasing numbers of revisional surgeries in the same patient, after the first revision, increases the number of complications [41]. In our study, the morbidity and mortality were different after LAGB compared with after VBG. One patient in the LAGB group (3.2\%) died on the third postoperative day of sudden death syndrome, as confirmed by autopsy. Sudden death has occasionally been reported in published studies $[42,43]$. Prevention is difficult, because the only warning sign seems to be a subtle 
prolongation of the Q-T interval on electrocardiography. No leaks occurred at the site of the LSG in the LAGB to DS group, which seems to confirm that LSG can be performed safely after LAGB [26]. In the VBG group, 1 of the patients (8.3\%) presented with a leak at the site of LSG and shortly thereafter developed a leak at the duodenoileostomy. This patient was treated with endoscopic stents but eventually required total gastrectomy. The patient died 5 months after the conversion. Leaks at the place of the LSG after VBG have been well reported in published studies. Elazary et al. [44] reported on 2 patients (33.3\%) with postoperative gastric leak after this conversion. In our study, not only had all the patients undergone an open procedure, but they also had had reinforcement of the gastric pouch stoma by Marlex mesh. Marlex is known to induce severe adhesions [45], and dissecting this mesh from structures carries a high risk of complications [46]. Not surprisingly, in our series, 1 patient with a sleeve leak had the defect right at the intersection of the mesh and the staple line. The morbidity of the revision of VBG to LSG was high compared with the conversion of VBG to LRYGB [44], for which the incidence of leaks has varied from $0 \%$ to $12.2 \%$ [29,30]. We recorded a total incidence of $33.3 \%$ of leaks at the duodenoileostomy in the VBG group, much greater than after primary DS, for which leak rates of $1.5 \%$ [47] and $1.7 \%$ [48] have been reported $(1.8 \%$ in our hands). Acute pancreatitis (8.3\%), presumably due to duodenal isolation and sectioning, and postoperative respiratory insufficiency (8.3\%) occurred more often than after primary DS, for which the incidence has been reported to be $1.7 \%$ [48]. During a mean follow-up of 2 years, $20.6 \%$ of the surviving patients of DS after LAGB required reoperation for late complications compared with $62.5 \%$ of the surviving patients of DS after VBG, with a mean follow-up of almost 4 years. The late complications that occurred in our series were similar to those reported after primary DS and included hiatal hernia [49], excess diarrhea and protein malnutrition [2], internal hernia [50], and abdominal pain [51]. These results confirm the risk of developing these complications after DS as a primary procedure. In the DS after LAGB group, the \%EWL was almost $80 \%$ after a mean follow-up of 22 years, comparable to the data reported after primary DS in the same period [2]. This result was superior to the $28 \%$ reported at 1 year [37] and the result obtained by conversion of LAGB to LRYGB, for which a \%EWL of $52-59 \%$ was reported after 12 months $[16,20,22]$ and $62-70 \%$ after 18 months [22,36]. In the DS after VBG group, the \%EWL was $85 \%$ at almost 4 years, similar to that after primary DS [2]. Again, this result was better than that achieved with conversion of VBG to LRYGB, for which a $\% \mathrm{EWL}$ of $62 \%$ was reported at a follow-up shorter than 1 year [30].

\subsection{CONCLUSION}

According to these results, laparoscopic conversion of LAGB to DS seems feasible and effective, despite 1 death. In our experience, laparoscopic conversion of VBG to DS had an unacceptable rate of complications and deaths. 


\subsection{REFERENCES}

1. Marceau P, Biron S, Hould FS, et al. Duodenal switch: long-term results. Obes Surg 2007;17:142130

2. Hess DS, Hess DW, Oakley RS. The biliopancreatic diversion with the duodenal switch: results beyond 10 years. Obes Surg 2005;15:408-16

3. Marinari GM, Murelli F, Camerini G, et al. A 15-year evaluation of biliopancreatic diversion according to the Bariatric Analysis Reporting Outcome System (BAROS). Obes Surg 2004;14:325-8

4. Gagner M, Gumbs AA. Gastric banding: conversion to sleeve, bypass, or DS. Surg Endosc 2007;21:1931-5

5. Westling A, Ohrvall M, Gustavsson S. Roux-en-Y gastric bypass after previous unsuccessful gastric restrictive surgery. J Gastrointest Surg 2002;6:206-11

6. Suter M, Calmes JM, Paroz A, Giusti V. A 10-year experience with laparoscopic gastric banding for morbid obesity: high long-term complication and failure rates. Obes Surg 2006;16:829-35

7. Chevallier JM, Zinzindohoué F, Douard R, et al. Complications after laparoscopic adjustable gastric banding for morbid obesity: experience with 1000 patients over 7 years. Obes Surg 2004;14:40714

8. Weiner R, Blanco-Engert R, Weiner S, Matkowitz R, Schaefer L, Pomhoff I. Outcome after laparoscopic adjustable gastric banding-8 years' experience. Obes Surg 2003;13:427-34

9. DeMaria EJ, Sugerman HJ, Meador JG, et al. High failure rate after laparoscopic adjustable silicone gastric banding for the treatment of morbid obesity. Ann Surg 2001;233:809-18

10. MacLean LD, Rhode BM, Forse RA. Late results of vertical banded gastroplasty for morbid obesity. Surgery 1990;107:20-7

11. Sugerman HJ, Kellum JM Jr, DeMaria EJ, Reines HD. Conversion of failed or complicated vertical banded gastroplasty to gastric bypass in morbid obesity. Am J Surg 1996;171:263-9

12. van Gewert WG, van Wersch MM, Greve JW, Soeters PB. Revisional surgery after failed banded gastroplasty: restoration of vertical banded gastroplasty or conversion to gastric bypass. Obes Surg 1998;8:21-8

13. Balsiger BM, Murr MM, Mai J, Sarr MG. Gastroesophageal reflux after intact vertical banded gastroplasty: correction by conversion to Roux-en-Y gastric bypass. J Gastrointest Surg 2000;4:27681

14. Tucker 0, Sucandy I, Szomstein A, Rosenthal RJ. Revisional surgery after failed laparoscopic adjustable gastric banding. Surg Obes Relat Dis 2008;4:740-7

15. Sanchez H, Cabrera A, Cabrera K, et al. Laparoscopic Roux-en-Y gastric bypass as a revision procedure after restrictive bariatric surgery. Obes Surg 2008;18:1539-43

16. Langer FB, Bohdjalian A, Shakeri-Manesch S, et al. Inadequate weight loss vs secondary weight regain: laparoscopic conversion from gastric banding to Roux-en-Y gastric bypass. Obes Surg 2008;18:1381-6

17. Van Dessel E, Hubens G, Ruppett M, Balliu L, Weyler J, Vaneer- deweg W. Roux-en-Y gastric bypass as a re-do procedure for failed restrictive gastric surgery. Surg Endosc 2008;22:1014-8

18. te Riele WW, Sze YK, Wiezer MJ, van Ramshorst B. Conversion of failed laparoscopic gastric banding to gastric bypass as safe and effective as primary gastric bypass in morbidly obese patients. Surg Obes Relat Dis 2008;4:735-9

19. Spivak H, Beltran OR, Slavchev P, Wilson EB. Laparoscopic revision from LAP-BAND to gastric bypass. Surg Endosc 2007;21:1388-92

20. Van Wageningen B, Berends FJ, Van Ramshorst B, Janssen IF. Revision of failed laparoscopic adjustable gastric banding to Roux-en-Y gastric bypass. Obes Surg 2006;16:137-41

21. Calmes JM, Giusti V, Suter M. Re-operative laparoscopic Roux-en-Y gastric bypass: an experience with 49 cases. Obes Surg 2005;15:316-22

22. Mognol P, Chosidow D, Marmuse JP. Laparoscopic conversion of laparoscopic gastric banding to Roux-en-Y gastric bypass: a review of 70 patients. Obes Surg 2004;14:1349-53 
23. Weber M, Muller MK, Michel JM, et al. Laparoscopic Roux-en-Y gastric bypass, but not rebanding, should be proposed as rescue procedure for patients with failed laparoscopic gastric banding. Ann Surg 2003;238:827-34

24. Kothari SN, DeMaria EJ, Sugerman HJ, Kellum JM, Meador J, Wolfe L. Lap-band failures: conversion to gastric bypass and their preliminary outcomes. Surgery 2002;131:625-9

25. Gagner M, Gentileschi P, de Csepel J, et al. Laparoscopic reoperative bariatric surgery: experience from 27 consecutive patients. Obes Surg 2002;12:254-60

26. Dapri G, Cadière GB, Himpens J. Feasibility and technique of laparoscopic conversion of adjustable gastric banding to sleeve gastrectomy. Surg Obes Relat Dis 2009;5:72-6

27. Bernante $\mathrm{P}$, Foletto $\mathrm{M}$, Busetto $\mathrm{L}$, et al. Feasibility of laparoscopic sleeve gastrectomy as a revision procedure for prior laparoscopic gastric banding. Obes Surg 2006;16:1327-30

28. Muller MK, Attigah N, Wildi S, et al. High secondary failure rate of rebanding after failed gastric banding. Surg Endosc 2008;22:448-53

29. Marsk R, Jonas E, Gartzios H, et al. High revision after laparoscopic vertical banded gastroplasty. Surg Obes Relat Dis 2009;5:94-8

30. Mognol P, Chosidow D, Marmuse JP. Roux-en-Y gastric bypass after failed vertical banded gastroplasty. Obes Surg 2007;17:1431-4

31. Yashkov YI, Oppel TA, Shishlo LA, Vinnitsky LI. Improvement of weight loss and metabolic effects of vertical banded gastroplasty by an added duodenal switch procedure. Obes Surg 2001;11:635-9

32. Keshishian A, Zahriya K, Hartoonian T, Ayagian C. Duodenal switch is a safe operation for patients who have failed other bariatric operations. Obes Surg 2004;14:1187-92

33. Coakley BA, Deveney CW, Spight DH, et al. Revisional bariatric surgery for failed restrictive procedures. Surg Obes Relat Dis 2008;4:581-6

34. Wolnerhanssen BK, Peters T, Kern B, et al. Predictors of outcome in treatment of morbid obesity by laparoscopic adjustable gastric banding: results of a prospective study of 380 patients. Surg Obes Relat Dis 2008;4:500-6

35. Peterli R, Wolnerhanssen BK, Peters T, Kern B, Ackermann C, von Flue M. Prospective study of a two-stage operative concept in the treatment of morbid obesity: primary Lap-Band followed if needed by sleeve gastrectomy with duodenal switch. Obes Surg 2007;17:334-40

36. Topart P, Becouarn G, Ritz P. Biliopancreatic diversion with duodenal switch or gastric bypass for failed gastric banding: retrospective study from two institutions with preliminary results. Surg Obes Relat Dis 2007;3:521-5

37. Dolan K, Fielding G. Biliopancreatic diversion following failure of laparoscopic adjustable gastric banding. Surg Endosc 2004;18:60-3

38. Buchwald H. Evolution of bariatric procedures and selection algorithm. In: Buchwald H, Cowan GSM, Pories WJ, editors. Surgical management of obesity. Philadelphia: Saunders Elsevier; 2007, p. 147-57

39. Khaitan L, Van Sickle K, Gonzales R, Lin E, Ramshaw B, Smith CD. Laparoscopic revision of bariatric procedures: is it feasible? Am Surg 2005;71:6-12

40. Sugerman HJ, Wolper JL. Failed gastroplasty for morbid obesity: revised gastroplasty versus Roux-Y gastric bypass. Am J Surg 1984;148:331-6

41. Roller EJ, Provost DA. Revision of failed gastric restrictive operations to Roux-en-Y gastric bypass: impact of multiple prior bariatric operations on outcome. Obes Surg 2006;16:865-9

42. Wolnerhanssen BK, Langer I, Eriksson U, Schneider M. Sudden death after open gastric bypass surgery. Langenbecks Arch Surg 2009;394:573-7

43. Drenick EJ, Fisler JS. Sudden cardiac arrest in morbidly obese surgical patients unexplained after autopsy. Am J Surg 1988;155:720-6

44. Elazary R, Hazzan D, Appelbaum L, Rivkind AI, Keidar A. Feasi- bility of sleeve gastrectomy as a revision operation for failed silastic ring vertical gastroplasty. Obes Surg 2009;19:645-9

45. Stocked D, Granstrom L, Backman L, Dahlgren S. Inflammatory response to subcutaneously implanted Marlex and Gore-Tex in massively obese patients. Biomaterials 1992;13:261-3

46. Jamieson AC. Vertical banded gastroplasty. In: Buchwald H, Cowan GSM, Pories WJ, editors. Surgical management of obesity. Philadelphia: Saunders Elsevier; 2007, p. 167-76 
47. Hess DS, Hess DW. Biliopancreatic diversion with a duodenal switch. Obes Surg 1998;8:267-82

48. Marceau P, Hould FS, Simard S, et al. Biliopancreatic diversion with duodenal switch. World J Surg 1998;22:947-54

49. Parikh M, Gagner M. Laparoscopic hiatal hernia repair and repeat sleeve gastrectomy for gastroesophageal reflux disease after duodenal switch. Surg Obes Relat Dis 2008;4:73-5

50. Comeau E, Gagner M, Inabnet WB, Herron DM, Quinn TM, Pomp A. Symptomatic internal hernias after laparoscopic bariatric surgery. Surg Endosc 2005;19:34-9

51. Hamoui N, Chock B, Anthone GJ, Crookes PF. Revision of the duodenal switch: indications, technique, and outcomes. J Am Coll Surg 2007;204:603-8 



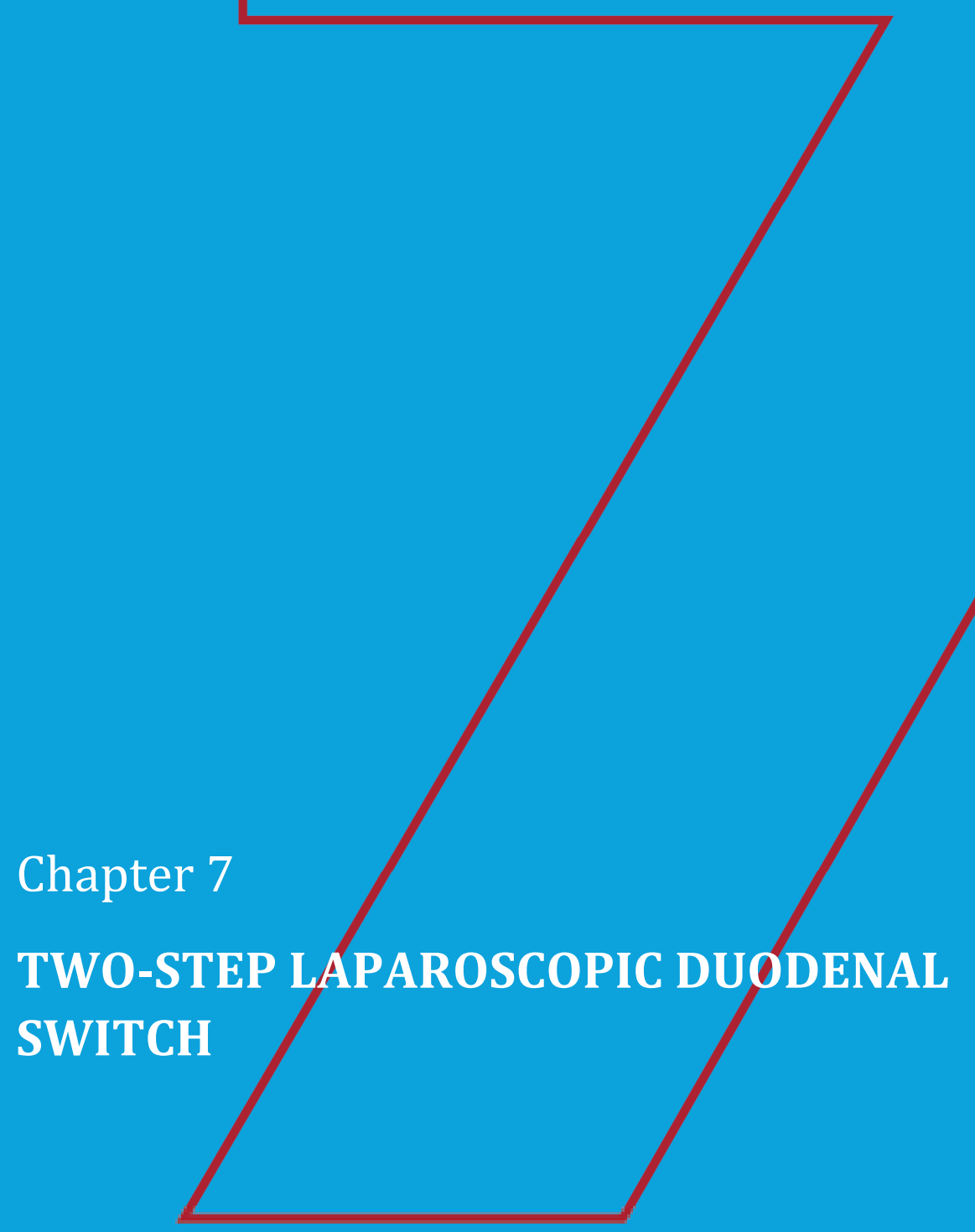

Dapri G, Cadière GB, Himpens J

Surgery for Obesity and Related Diseases 2011;7(6):703-708 



\subsection{ABSTRACT}

Background: Morbidity and mortality after bariatric surgery in superobese (body mass index $[\mathrm{BMI}]>50$ but $<60 \mathrm{~kg} / \mathrm{m}^{2}$ ) and super-superobese (BMI $>60$ $\mathrm{kg} / \mathrm{m}^{2}$ ) patients can allegedly be reduced by performing surgery in 2 steps. We report a retrospective study gathered from a prospective database for superobese and super-superobese patients who underwent laparoscopic biliopancreatic diversion/duodenal switch (LBPD/DS) after laparoscopic sleeve gastrectomy (LSG) as the first step.

Patients and Methods: From October 2004 to June 2010, 31 patients underwent LBPD/DS after LSG. The mean age was $45.8 \pm 10.1$ years (range 21-64). The mean interval between the 2 procedures was $13.9 \pm 8.4$ months (range 6-37). At LSG, the mean weight and BMI was $168.8 \pm 35.4 \mathrm{~kg}$ (range $127-255$ ) and $58.3 \pm 6.7 \mathrm{~kg} / \mathrm{m}^{2}$ (range 50-74.5). At LBPD/DS, the mean weight, BMI, and percentage of excess weight loss was $136.3 \pm 32.6 \mathrm{~kg}$ (range $92-220$ ), $47.1 \pm 7.2 \mathrm{~kg} / \mathrm{m}^{2}$ (range 37.8-64.3), and $31.6 \pm 12.2 \%$ (range -11.7 to +54.6 ). At LSG, 26 patients had 43 obesity comorbidities. Three co-morbidities (6.9\%) resolved in 3 patients before the second step of LBPD/DS was performed.

Results: The mean operative time was $175.5 \pm 60.6$ minutes (range $75-285$ ). There were no deaths or conversions to open surgery. Four patients had early complications ( 1 anastomotic leak, 1 small bowel perforation, 1 case of renal insufficiency, and 1 case of pneumonia). The mean hospital stay was $6.6 \pm 8$ days (range 3-35). All patients, with the exception of 3, were followed up for a mean of 28.8 \pm 21.4 months (range 4-71). At follow-up, the mean weight, BMI, and percentage of excess weight loss (compared with the pre-LSG weight) was $99.4 \pm 23.7 \mathrm{~kg}$ (range $62-150$ ), $34.5 \pm 5.8 \mathrm{~kg} / \mathrm{m}^{2}$ (range $24.9-46.3$ ), and $54.8 \pm 16 \%$ (range 18.984.8). A total of 22 obesity co-morbidities (51.1\%) resolved in 14 patients. Three patients presented with late complications (1 ventral hernia, 1 case of protein deficiency, 1 anastomotic stenosis).

Conclusion: In the treatment of superobese and super-superobese patients with 2-step LBPD/DS, we experienced no deaths and achieved acceptable morbidity, considering the high operative risk in this group. This procedure is effective for both weight loss and resolution of co-morbidities. 


\subsection{INTRODUCTION}

Obese patients with a body mass index (BMI) $>50 \mathrm{~kg} / \mathrm{m}^{2}$ or $>60 \mathrm{~kg} / \mathrm{m}^{2}$ are termed "superobese" (SO) and "super-superobese" (SSO), respectively. In general, SO and SSO patients are considered high-risk surgical candidates and are reported to have increased morbidity and mortality, even more than severely obese and morbidly obese patients [1-3]. Laparoscopy in bariatric surgery decreases the postoperative pain, parietal trauma, complication rates, and length of stay. Laparoscopic bariatric procedures have been shown to be safe, with low complication and 30-day mortality rates [4]. However, compared with the rates in morbidly obese patients, laparoscopic bariatric procedures in SO and SSO patients have been associated with significantly greater rates of complications, including the 30-day mortality rates. A variety of bariatric surgery procedures can be performed; however, laparoscopic Roux-en-Y gastric bypass (LRYGB) and laparoscopic biliopancreatic diversion/duodenal switch (LBPD/DS) are the only procedures that can be performed in 2 steps [5,6]. Two-step procedures are performed to decrease the postoperative morbidity and mortality. LBPD/DS consists of a restrictive procedure (sleeve gastrectomy [SG]) and a malabsorptive procedure (biliopancreatic diversion) [7,8]. Long-term follow-up data have shown a percentage of excess weight loss (\%EWL) of $75-76 \%$ at $12-15$ years $[9,10]$; however, strict follow-up is required to avoid the side effects due to the malabsorption. LBPD/DS remains an uncommon procedure because of the nutritional complications (e.g., anemia, hypoproteinemia, and bone demineralization). Furthermore, the technical complexity required to perform this surgery, especially by laparoscopy, also limits the use of this procedure. Laparoscopic SG (LSG) can be performed as a stand-alone procedure [11] or as a revision of a previous surgery, such as laparoscopic adjustable gastric banding [12], vertical banded gastroplasty [13], or LRYGB [14]. LSG is a multipurpose bariatric operation [15] that offers the option of a second procedure during follow-up. This is an important consideration because many SO patients remain in the SO or morbidly obese category even after bariatric surgery [16]. In the present retrospective study, we report our experience in treating SO and SSO patients using LBPD/DS after LSG as the first step.

\subsection{PATIENTS AND METHODS}

From October 2004 to June 2010, 31 patients (10 men and 21 women) underwent LBPD/DS after LSG. Their mean age was $45.8 \pm 10.1$ years (range 21-64). The chief inclusion criterion for the use of LSG as a first step was a BMI $>50 \mathrm{~kg} / \mathrm{m}^{2}$; patients with a history of bariatric surgery or a preoperative hiatal hernia were excluded. The exclusion criteria for performing LBPD/DS as a second step were a BMI $<35$ $\mathrm{kg} / \mathrm{m}^{2}$, the presence of SG dilation on barium swallow testing, and gastroesophageal reflux on gastroscopy. The mean interval between the 2 procedures was 
$13.9 \pm 8.4$ months (range 6-37). At LSG, the mean weight and BMI was $168.8 \pm 35.4$ $\mathrm{kg}$ (range $127-255$ ) and $58.3 \pm 6.7 \mathrm{~kg} / \mathrm{m}^{2}$ (range $50-74.5$ ), respectively. Of the 31 patients, 20 had a BMI of $50-60 \mathrm{~kg} / \mathrm{m}^{2}$ and 11 had a BMI $>60 \mathrm{~kg} / \mathrm{m}^{2}$. At LBPD/DS, the mean weight, BMI, and \%EWL was $136.3 \pm 32.6 \mathrm{~kg}$ (range 92-220), 47.1 \pm 7.2 $\mathrm{kg} / \mathrm{m}^{2}$ (range 37.8-64.3), and 31.6 $\pm 12.2 \%$ (range -11.7 to +54.6 ), respectively (Fig.1).

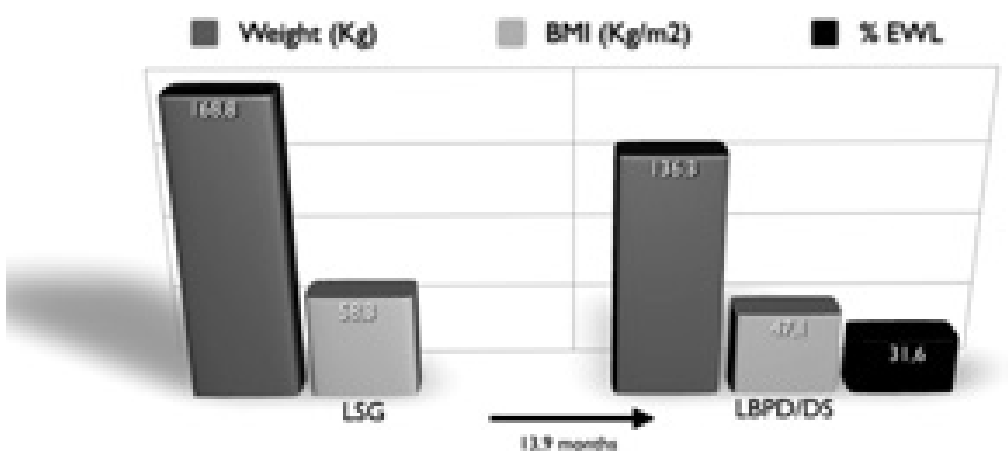

Fig.1 Comparison of weight, BMI, and \%EWL at LSG and LBPD/DS

At LSG, 26 patients had 43 obesity co-morbidities, and 3 (6.9\%) co-morbidities resolved in 3 patients before the second step of LBPD/DS (Tab.1).

Table 1

Modifications of obesity-related co-morbiditics: comparison amone

buselise, before second step of LBPDDS, and during follow-up

Co-morbidity Befoee L.SG Before LBPDDS After LBPDDS

(n) (n) (n)

\begin{tabular}{lrrr}
\hline Arterial bypertchsion & 16 & 16 & 9 \\
Type 2 diabetes & 11 & 10 & 4 \\
Slecp apnea & 6 & 5 & 2 \\
Joint pain & 10 & 9 & 3 \\
Total & 43 & 40 & 18
\end{tabular}

LSG - laparoscopic sleeve gastrestomy; LBPD/DS - laparoscopic biliogancreatic diversion/duodenal swich.

\subsubsection{SURGICAL TECHNIQUE}

First-step LSG was performed using a 34F orogastric bougie. The LBPD/DS procedure was initiated by inserting the $12-\mathrm{mm}$ trocar in the upper quadrant of the abdomen on the left midclavicular line using the Hasson technique. Five additional trocars were placed under view, usually near the same position as the first insertion. No efforts were made to dissect the stomach itself. The procedure began with cholecystectomy. The duodenum was subsequently encircled just lateral to the gastroduodenal artery and sectioned by linear stapler blue load. The right colon was freed to ensure more slack to the distal ileum because of the duodenoileo- 
stomy. The common and alimentary limbs were fashioned and measured at $100 \mathrm{~cm}$ and $150 \mathrm{~cm}$, respectively. The measurements were made by stretching the bowel along a $25-\mathrm{cm}$ tape. A semimechanical side-to-side ileoileostomy was performed between the alimentary and biliopancreatic limbs, with the final section of the alimentary loop close to this anastomosis. The duodenoileostomy was hand sewn, in 1 layer, using a running suture of absorbable material. The mesenteric defect and Petersen's defect were closed by pursestring sutures of nonabsorbable material. The orogastric tube was advanced by the anesthesiologist until it reached the pylorus. A leak test was used to check the duodenoileostomy. The gallbladder was extracted through the 12-mm trocar opening in the left upper quadrant, which was subsequently closed in layers. A drain was left near the duodenoileostomy. A peroral methylene blue test was performed on the first postoperative day, and, if negative, the patient was allowed to start a liquid diet on the second postoperative day. Typically, the patient was discharged from the hospital on the fifth postoperative day.

\subsection{RESULTS}

The mean operative time was $175.5 \pm 60.6$ minutes (range $75-285$ ). There were no deaths or conversions to open surgery. Four patients had early complications: 1 anastomotic leak, 1 small bowel perforation, 1 case of renal insufficiency, and 1 case of pneumonia. The mean hospital stay was 6.6 \pm 8 days (range 3-35). All patients, with the exception of 3 who refused our follow-up, were followed up for a mean of 28.8 \pm 21.4 months (range 4-71). At follow-up, the mean weight, BMI, and $\%$ EWL (compared with the pre-LSG weight) was $99.4 \pm 23.7 \mathrm{~kg}$ (range 62-150), $34.5 \pm 5.8 \mathrm{~kg} / \mathrm{m}^{2}$ (range 24.9-46.3), and $54.8 \pm 16 \%$ (range 18.9-84.8), respectively (Fig.2).

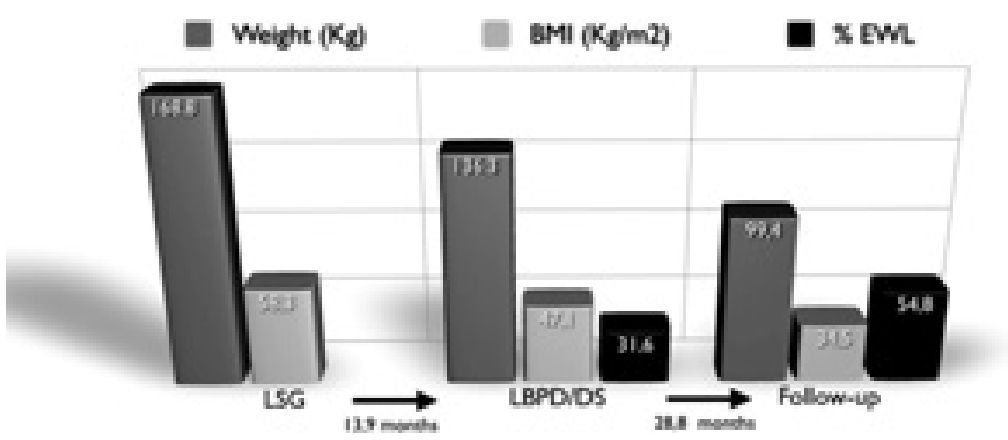

Fig.2. Comparison of weight, BMI, and \%EWL at LSG, LBPD/DS, and during follow-up 
A total of 22 obesity co-morbidities (51.1\%) resolved in 14 patients (Tab.1). Three patients presented with late complications ( 1 ventral hernia, 1 case of protein deficiency, and 1 anastomotic stenosis).

\subsection{DISCUSSION}

LBPD/DS has been reported to have a 38\% complication rate in patients with a BMI of $\geq 65 \mathrm{~kg} / \mathrm{m}^{2}$ compared with an $8 \%$ complication rate in patients with a BMI $<65 \mathrm{~kg} / \mathrm{m}^{2}$ [3]. From these results, LSG in SO or SSO patients was introduced as a first step before a definitive procedure, such as LBPD/DS or LRYGB [17]. The philosophy of performing LBPD/DS in 2 steps rests on the potential benefits for both patients and bariatric surgeons. From the patient's viewpoint, LSG offers the possibility of weight loss and overall improvements in, or even resolution of, obesityrelated co-morbidities, and some patients might not require a second bariatric procedure. That said, the second step is usually well tolerated with a smoother recovery. The interval between the first and second procedures allows time for psychological and physical improvements in the patient's health before additional surgery. From the surgeon's viewpoint, the severity of postoperative complications can be limited because the 2 procedures affect different parts of the digestive system, avoiding potentially challenging postoperative situations that are often difficult to manage [18]. Moreover, LBPD/DS can be performed more easily if weight loss has occurred after LSG, and the surgeon also has the potential to evaluate patient compliance during follow-up, including possible changes in eating behaviors. Because compliance with the postoperative regimen is an essential component of safety after LBPD/DS, this strategy allows one to select those patients for whom there is good evidence of treatment compliance. Considering the frequent development of de novo gastroesophageal reflux disease [19], with or without associated hiatal hernia [20], LBPD/DS can be replaced with the LRYGB procedure as the second step to mitigate this complication. In our department, we offered all SO or SSO patients the option of LBPD/DS as the second step. However, for patients in whom gastroesophageal reflux disease developed after LSG, we proposed LRYGB, in accordance with the published data [21,22]. This strategy was based on the data from Crookes et al. at the Consensus Summit [23], who reported that all 11 patients $(100 \%)$ who underwent LRYGB were able to discontinue proton pump inhibitors after conversion, but $3(42.8 \%)$ of 7 patients who had undergone LBPD/DS still required proton pump inhibitors after the revision. As a final consideration, in the case of SG dilation, we propose repeat SG. All these aspects reflect the absolute need for strict follow-up of patients with an obvious need for a workup before the second stage, including barium swallow testing, gastroscopy, and nutritional and psychological examinations, to better choose the subsequent

definitive procedure. We recorded a \%EWL of $31.6 \pm 12.2 \%$ after LSG and before LBPD/DS, with a BMI decrease of 11.2 points, similar to the decrease of 12.2 points 
previously reported for 2-step LBPD/DS [24]. Aside from surgery, other weight loss strategies can be used to improve the overall patient status before LBPD/DS. Huerta et al. [25] reported that the use of a low-calorie liquid diet $(<900 \mathrm{kcal} / \mathrm{d})$ and an exercise program can decrease the BMI by 12.7 points within 11 weeks. A second option for preoperative weight loss is the placement of an endoscopic intragastric balloon. In SO patients, this technique has resulted in a \%EWL of 7 $26.1 \%$ with a mean weight loss of 6-26.4 kg [26-28]. However, because the endoscopic intragastric balloon must be removed after 6 months, a significant risk exists of regaining weight [29]. One study comparing the endoscopic intragastric balloon and LSG in SO patients as a first stage procedure showed a decrease in BMI of 8 versus 16 points, with an achieved \%EWL of $24 \%$ versus 35\%, respectively [30]. In previous reports, the interval between the 2 steps varied from 9 to 27 months [24] to 12 months [21,31] and 15.8 months [32]. Also, the individual interests of the patient and surgeon must be considered in the search for the optimal interval. Our operative time was very close to the 158 minutes reported to perform LRYGB as a second step [17], and it decreased to within the range of 130 [32] to 201 minutes [24] required for second-step LBPD/DS. In the present series of 2step LBPD/DS, no conversions to open surgery were required, unlike the experience of other investigators [24,32]. Open conversions, however, have been reported to have an incidence of 3.4-13.9\% in 1-step LBPD/DS [33-35] and 0-9.5\% in 1-step LRYGB [36-38]. There is probably a substantial difference between the 2step and 1-step LBPD/DS. In our overall study design, therefore, we considered it important to prospectively decide to perform LSG as the first step, rather than making this decision perioperatively (e.g., in the case of respiratory problems, renal failure, or difficulty in accessing the duodenum) [35]. In our series, we recorded a total of 4 early complications (12.9\%): 1 anastomotic leak, 1 small bowel perforation, 1 case of renal insufficiency, and 1 case of pneumonia. Similar complications have been reported after single-step BPD/DS in patients of the same class of obesity [39], with a postoperative mortality rate of 7.8\% (SSO) and $0 \%$ (SO or morbidly obese). Although our mortality rate was nil, mortality rates of $0-2.5 \%$ $[3,33,34]$ and $0-4.7 \%[16,33,34,36,38,40]$ have been reported in 1-step LBPD/DS and 1-step LRYGB, respectively, for SO and SSO patients. However, our early complication rate was between the previously reported range of $6.7 \%$ [32] to $29.6 \%$ [24] for 2-step LBPD/DS. Similar data were also reported after 1-step LBPD/DS, but the complication rates in those studies ranged from $24 \%$ to $45.9 \%$ $[3,33,35,41]$, and in 1-step LRYGB, the complication rate was of $2.5-32.2 \%$ $[16,33,36-38,40]$. Our length of stay data reflect the policy of discharging the patient before the end of 1 week, except in the case of complications; for example, 1 of our patients had a lengthened hospital stay, similar to the experience of other investigators [32]. In contrast to previous reports [24,32], none of our patients required a reoperation in the early postoperative period. However, 1 of our patients $(3.5 \%)$ required a feeding jejunostomy tube for protein deficiency after 7 
months, and another required reoperation to repair a ventral hernia after 12 months. A third patient presented with stenosis at the duodenoileostomy at 10 months that resolved after 1 session of endoscopic dilation. In terms of weight loss, with a mean follow-up of $28.8 \pm 21.4$ months, we achieved a $\% \mathrm{EWL}$ of $54.8 \pm 16 \%$. This represents a 20.3-point improvement compared with the results obtained after LSG alone. These data represent the plateau of the weight loss curve after the initial greater weight loss [10]. These data might appear rather low compared with those from reports for both 1-step and 2-step LBPD/DS [3,32-34,42]. These findings closely resemble the post-LRYGB reports for SO and SSO patients $[16,33,34,37,38,40]$. Obesity-related co-morbidities have been reported to improve or resolve after the first step of LSG, followed by continued improvement after conversion to LRYGB [21,43]. Similarly, Silecchia et al. [44] reported improvements and cure of co-morbidities 18 months after LSG as a first step, with cure rates of $62.5 \%$ for arterial hypertension, $76.9 \%$ for type 2 diabetes, and $56.2 \%$ for sleep apnea. Our data did not confirm these results, but they did speak to the effect of second step LBPD/DS, after which the number of resolved co-morbidities increased from 3 to 22. Arterial hypertension was resolved in 43.7\%, type 2 diabetes in $63.6 \%$, sleep apnea in $66.6 \%$, and joint pain in $70 \%$ of our patients. Finally, the second-step LBPD/DS in SO and SSO patients had a comparable effect on comorbidities as in previous 1-step reports [9].

\subsection{CONCLUSION}

In the treatment of SO and SSO patients with 2-step LBPD/DS, we experienced no deaths and obtained acceptable morbidity considering the high operative risk in this group. This procedure is effective in terms of weight loss and the resolution of co-morbidities.

\subsection{REFERENCES}

1. Livingston EH, Huerta S, Arthur D, Lee S, De Schields S, Heber D. Male gender is a predictor of morbidity and age a predictor of mortality for patients undergoing gastric bypass surgery. Ann Surg 2002;236:576-82

2. Buchwald H, Consensus Conference Panel. Bariatric surgery for morbid obesity: health implications for patients, health professionals, and third-party payers. J Am Coll Surg 2005;200:593-604

3. Ren CJ, Patterson E, Gagner M. Early results of laparoscopic biliopancreatic diversion with duodenal switch: a case series of 40 consecutive patients. Obes Surg 2000;10:514-23

4. Kakarla VR, Nandipati K, Lalla M, Castro A, Merola S. Are laparoscopic bariatric procedures safe in superobese $\left(B M I>50 \mathrm{~kg} / \mathrm{m}^{2}\right.$ ) patients? An NSQIP data analysis. Surg Obes Relat Dis 2011;7:4528

5. Nguyen NT, Longoria M, Gelfand DV, Sabio A, Wilson SE. Staged laparoscopic Roux-en-Y: a novel two-stage bariatric operation as an alternative in the super-obese with massively enlarged liver. Obes Surg 2005;15:1077-81 
6. Gagner M, Matteotti M. Laparoscopic biliopancreatic diversion with duodenal switch. Surg Clin North Am 2005;85:141-9

7. Hess DS, Hess DW. Biliopancreatic diversion with a duodenal switch. Obes Surg 1998;8:267-82

8. Marceau P, Hould FS, Simard S, et al. Biliopancreatic diversion with duodenal switch. World J Surg 1998;22:947-54

9. Hess DS, Hess DW, Oakley RS. The biliopancreatic diversion with the duodenal switch: results beyond 10 years. Obes Surg 2005;15:408-16

10. Biertho L, Biron S, Hould FS, Lebel S, Marceau S, Marceau P. Is biliopancreatic diversion with duodenal switch indicated for patients with body mass index $<50 \mathrm{~kg} / \mathrm{m}^{2}$ ? Surg Obes Relat Dis 2010;6:508-15

11. Bohdjalian A, Langer FB, Shakeri-Leidenmühler S, et al. Sleeve gastrectomy as sole and definitive bariatric procedure: 5-year results for weight loss and ghrelin. Obes Surg 2010;20:535-40

12. Dapri G, Cadière GB, Himpens J. Feasibility and technique of laparoscopic conversion of adjustable gastric banding to sleeve gastrectomy. Surg Obes Relat Dis 2009;5:72-6

13. Iannelli A, Schneck AS, Ragot E, et al. Laparoscopic sleeve gastrectomy as revisional procedure for failed gastric banding and vertical banded gastroplasty. Obes Surg 2009;19:1216-20

14. Dapri G, Cadière GB, Himpens J. Laparoscopic conversion of Roux-en-Y gastric bypass to sleeve gastrectomy as first step of duodenal switch: technique and preliminary outcomes. Obes Surg 2011;21:517-23

15. Baltasar A, Serra C, Pérez N, Bou R, Bengochea M, Ferri L. Laparoscopic sleeve gastrectomy: a multi-purpose bariatric operation. Obes Surg 2005;15:1124-8

16. Suter M, Calmes JM, Paroz A, Romy S, Giusti V. Results of Roux-en-Y gastric bypass in morbidly obese vs superobese patients: similar body weight loss, correction of comorbidities, and improvement of quality of life. Arch Surg 2009;144:312-8

17. Regan JP, Inabnet WB, Gagner M, Pomp A. Early experience with two-stage laparoscopic Roux-enY gastric bypass as an alternative in the super-super obese patient. Obes Surg 2003;13:861-4

18. Almogy G, Crookes PF, Anthone GJ. Longitudinal gastrectomy as a treatment for the high-risk super-obese patient. Obes Surg 2004;14:492-7

19. Himpens J, Dobbeleir G, Peeters G. Long-term results of laparoscopic sleeve gastrectomy for obesity. Ann Surg 2010;252:319-24

20. Parikh M, Gagner M. Laparoscopic hiatal hernia repair and repeat sleeve gastrectomy for gastroesophageal reflux disease after duodenal switch. Surg Obes Relat Dis 2008;4:73-5

21. Cottam D, Qureshi FG, Mattar SG, et al. Laparoscopic sleeve gastrectomy as an initial weight-loss procedure for high-risk patients with morbid obesity. Surg Endosc 2006;20:859-63

22. Langer FB, Bohdjalian A, Shakeri-Leidenmühler S, Schoppmann SF, Zacherl J, Prager G. Conversion from sleeve gastrectomy to Roux-en-Y gastric bypass-indications and outcome. Obes Surg 2010;20:835-40

23. Gagner M, Deitel M, Kalberer TL, Erickson AL, Crosby RD. The second International Consensus Summit for Sleeve Gastrectomy, March 19-21, 2009. Surg Obes Relat Dis 2009;5:476-85

24. Silecchia G, Rizzello M, Casella G, Fioriti M, Soricelli E, Basso N. Two-stage laparoscopic biliopancreatic diversion with duodenal switch as treatment of high-risk super-obese patients: analysis of complications. Surg Endosc 2009;23:1032-7

25. Huerta S, Li Z, Anthony T, Livingston EH. Feasibility of a supervised inpatient low-calorie diet program for massive weight loss prior to RYGB in superobese patients. Obes Surg 2010;20:17380

26. Alfalah H, Philippe B, Ghazal F, et al. Intragastric balloon for pre-operative weight reduction in candidates for laparoscopic gastric bypass with massive obesity. Obes Surg 2006;16:147-50

27. Busetto L, Segato G, De Luca M, et al. Preoperative weight loss by intragastric balloon in superobese patients treated with laparoscopic gastric banding: a case-control study. Obes Surg 2004; $14: 671-6$

28. Weiner R, Gutberlet H, Bockhorn H. Preparation of extremely obese patients for laparoscopic gastric banding by gastric-balloon therapy. Obes Surg 1999;9:261-4 
29. Genco A, Cipriano M, Materia A, et al. Laparoscopic sleeve gastrectomy versus intragastric balloon: a case-control study. Surg Endosc 2009;23:1849-53

30. Milone L, Strong V, Gagner M. Laparoscopic sleeve gastrectomy is superior to endoscopic intragastric balloon as a first stage procedure for super-obese patients (BMI $>$ or $=50 \mathrm{~kg} / \mathrm{m}^{2}$ ). Obes Surg 2005;15:612-7

31. Gagner M, Gumbs AA, Milone L, Yung E, Goldenberg L, Pomp A. Laparoscopic sleeve gastrectomy for the super-super-obese (body mass index $>60 \mathrm{~kg} / \mathrm{m}^{2}$ ). Surg Today 2008;38:399-403

32. Iannelli A, Schneck AS, Dahman M, Negri C, Gugenheim J. Two-step laparoscopic duodenal switch for superobesity: a feasibility study. Surg Endosc 2009;23:2385-9

33. Søvik TT, Taha 0, Aasheim ET, et al. Randomized clinical trial of laparoscopic gastric bypass versus laparoscopic duodenal switch for superobesity. Br J Surg 2010;97:160-6

34. Prachand VN, DaVee RT, Alverdy JC. Duodenal switch provides superior weight loss in the superobese (BMI $\geq 50 \mathrm{~kg} / \mathrm{m}^{2}$ ) compared with gastric bypass. Ann Surg 2006;244:611-9

35. Topart P, Becouarn G, Ritz P. Should biliopancreatic diversion with duodenal switch be done as single-stage procedure in patients with $\mathrm{BMI}>$ or $=50 \mathrm{~kg} / \mathrm{m}^{2}$ ? Surg Obes Relat Dis 2010;6:59-63

36. Dresel A, Kuhn JA, McCarty TM. Laparoscopic Roux-en-Y gastric bypass in morbidly obese and super morbidly obese patients. Am J Surg 2004;187:230-2

37. Parikh MS, Shen R, Weiner M, Siegel N, Ren CJ. Laparoscopic bariatric surgery in super-obese patients (BMI > 50) is safe and effective: a review of 332 patients. Obes Surg 2005;15:858-63

38. Artuso D, Wayne M, Kaul A, Bairamian M, Teixeira J, Cerabona T. Extremely high body mass index is not a contraindication to laparoscopic gastric bypass. Obes Surg 2004;14:750-4

39. Fazylov RM, Savel RH, Horovitz JH, et al. Association of super-superobesity and male gender with elevated mortality in patients undergoing the duodenal switch procedure. Obes Surg 2005;15:618-23

40. Raftopoulos I, Ercole J, Udekwu AO, Luketich JD, Courcoulas AP. Outcomes of Roux-en-Y gastric bypass stratified by a body mass index of $70 \mathrm{~kg} / \mathrm{m}^{2}$ : a comparative analysis of 825 procedures. J Gastrointest Surg 2005;9:44-52

41. Buchwald H, Kellogg TA, Leslie DB, Ikramuddin S. Duodenal switch operative mortality and morbidity are not impacted by body mass index. Ann Surg 2008;248:541-8

42. Anthone GJ, Lord RVN, DeMeester TR, Crookes PF. The duodenal switch operation for the treatment of morbid obesity. Ann Surg 2003;238:618-28

43. Yang 00, Loi K, Liew V, Talbot M, Jorgensen J. Staged laparoscopic sleeve gastrectomy followed by Roux-en-Y gastric bypass for morbidly obese patients: a risk reduction strategy. Obes Surg 2008;18:1575-80

44. Silecchia G, Boru C, Pecchia A, et al. Effectiveness of laparoscopic sleeve gastrectomy (first stage of biliopancreatic diversion with duodenal switch) on co-morbidities in super-obese high-risk patients. Obes Surg 2006;16:1138-44 



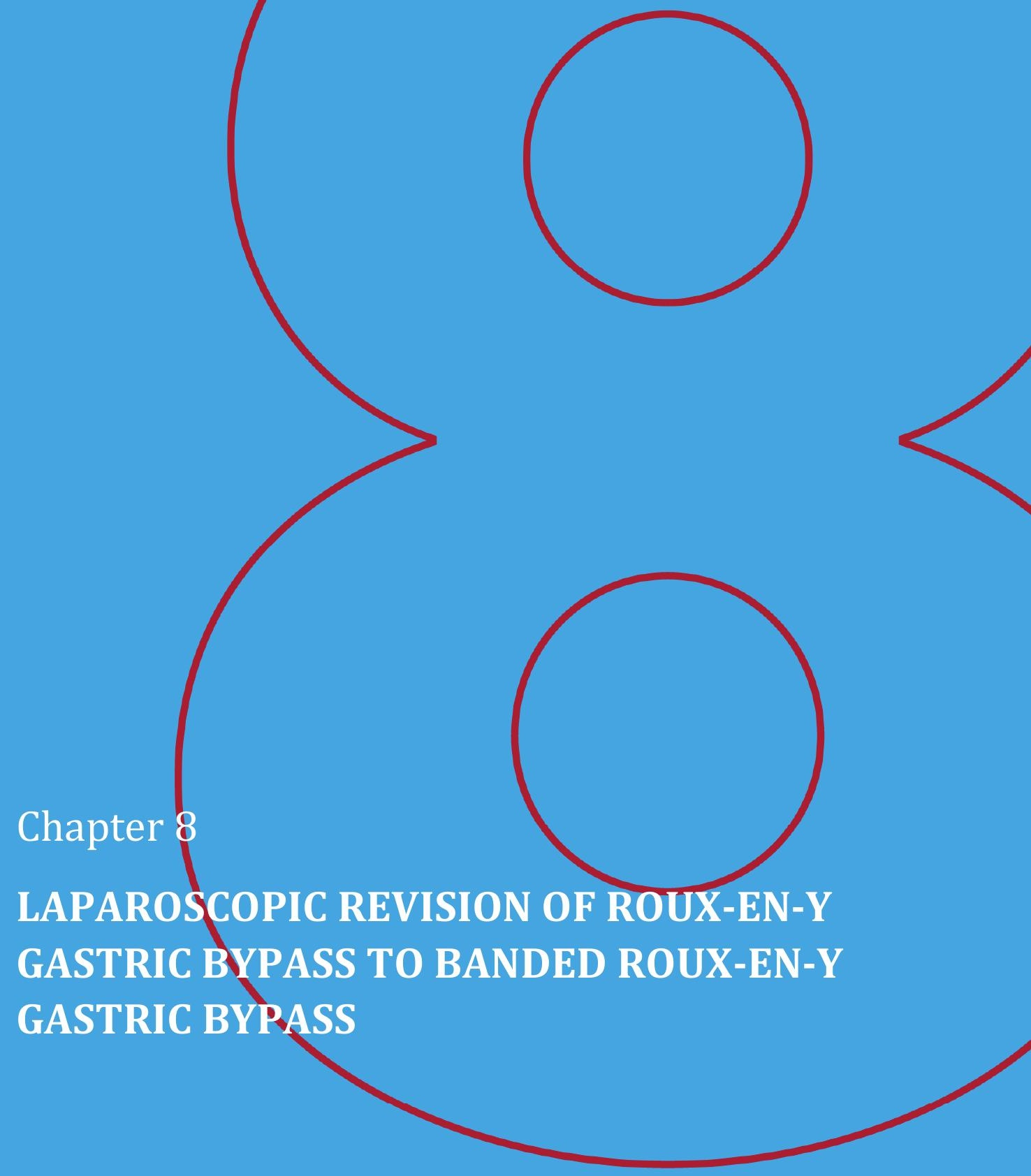

Dapri G, Cadière GB, Himpens J

Obesity Surgery 2009;19(5):650-654 



\subsection{ABSTRACT}

Background: Roux-en-Y gastric bypass (RYGB) is presently one of the most popular surgical procedures for obesity. One of the possible long-term problems is weight regain, usually after a period of successful weight loss. Weight regain after RYGB can be due to new eating habits, like sweet-eating or grazing, or volume eating because of impaired restriction. This paper reports our experience in patients who presented weight regain after laparoscopic RYGB, because of new appearance of volume eating or hyperphagia, treated by the laparoscopic placement of a nonadjustable silicone ring around the gastric pouch.

Patients and Methods: From July 2004 to November 2007, six patients affected by weight regain due to hyperphagic behavior, benefited from revision of RYGB consisting of the placement of a non-adjustable silicone ring loosely encircling the stomach part. Mean weight and body mass index (BMI) at the time of RYGB were $105.0 \pm 12.3 \mathrm{~kg}$ and $36.3 \pm 3.0 \mathrm{~kg} / \mathrm{m}^{2}$, respectively, and all patients suffered from obesity-related co-morbidities. After a mean time from RYGB of $26.0 \pm 14.2$ months, patients presented a weight regain of $4.7 \pm 3.4 \mathrm{~kg}$ compared with their minimal weight, with a final mean weight, BMI, and percentage of excess weight loss (\%EWL) at the time of the silicone ring of $86.0 \pm 13.1 \mathrm{~kg}, 29.5 \pm 3.9 \mathrm{~kg} / \mathrm{m}^{2}$, and $47.0 \pm 24.7 \%$, respectively. Preoperative evaluation for each patient included history and physical examination, nutritional and psychiatric evaluation, laboratory tests, and barium swallow check. Outcome measures included evaluation of the Roux-en-Y construction, operative time, postoperative morbidity and mortality, and weight loss in terms of absolute weight loss, BMI, and \%EWL.

Results: Any modification of the digestive circuit was evidenced. Mean operative time was $82.5 \pm 18.3 \mathrm{~min}$. No operative mortality and no conversion to open surgery were achieved. No postoperative complications were achieved. Mean hospital stay was $2.6 \pm 1.5$ days. After a mean follow-up of $14.0 \pm 9.2$ months, the six patients presented a mean weight loss of $9.1 \pm 2.4 \mathrm{~kg}$, with a final mean weight, BMI, and $\% E W L$ of $76.8 \pm 13.7 \mathrm{~kg}, 26.4 \pm 4.2 \mathrm{~kg} / \mathrm{m}^{2}$, and $70.4 \pm 30.4 \%$, respectively. Difference in term of \%EWL before and after revision (23.4 \pm 5.7 ) is statistically significant $(\mathrm{p}<0.05)$. There have been no erosions or slippage of the ring during this follow-up.

Conclusion: One of the possible causes of weight regain after RYGB is the new eating behavior of the patient, one of which is hyperphagia. Treatment of this condition can be the placement of a non-adjustable silicone ring loosely fitted around the gastric pouch, which contributes to improved weight loss. 


\subsection{INTRODUCTION}

Since its description in open surgery in 1966 [1] and by laparoscopy in 1994 [2], Roux-en-Y gastric bypass (RYGB) has become one of the most popular surgical procedures for obesity [3]. In the literature, reports on long-term results (over 10 years) are relatively rare [4-6]. One of the possible long-term complications is the problem of weight regain, usually after a period of successful weight loss. Weight regain after RYGB can be due to increased volume intake from gastric pouch dilation, gastro-jejunostomy dilation, or presence of gastro-gastric fistula. It can also be caused by inadequate length of the alimentary limb resulting in reduced malabsorption, and by changes in eating behavior (sweet-eating, grazing or polyphagia, and volume eating or hyperphagia). Dilation of the gastric pouch and of the gastrojejunostomy can actually be treated by the application of the endoluminal devices, such as StomaphyX (Endogastric Solutions, Redmond, WA, USA) [7,8], Endocinch (C.R. BARD, Murray Hill, NJ, USA) [9], Spiderman (Ethicon Endosurgery, Cincinnati, OH, USA) [10], and g-prox (USGI Medical) [11,12]. Also attempts to close gastrogastric fistulas by endoluminal means was tried, but it remained essentially unsuccessful with remaining open fistula in $75 \%$ of the cases after 1 year [13]. Finally lengthening of the alimentary limb by conversion to distal RYGB seems to result in unacceptable malnutrition $[14,15]$. Change of the patient's alimentary behavior remains an extremely difficult aspect in the case of weight regain after laparoscopic RYGB. Some patients bypass the intention of the procedure by eating sweets because they are no longer affected by the dumping syndrome and others by eating too frequently, becoming grazers (polyphagia). Due to these dietary flaws, patients can increase their caloric uptake and consequently gain weight. In the case of weight regain caused by volume eating or hyperphagia, a possible treatment can be offered by surgical revision aiming at restoring restriction, hence a non- adjustable silicone ring can be loosely fitted around the gastric pouch, as reported for more than 17 years by Dr. Mal Fobi in the procedure of banded RYGB [16]. This paper reports our experience in patients submitted to RYGB, presenting weight regain due to hyperphagia. Treatment was the laparoscopic placement of a nonadjustable silicone ring around the gastric pouch.

\subsection{PATIENTS AND METHODS}

From July 2004 to November 2007, six patients (all females) underwent consecutively revision of RYGB consisting of placement of the non-adjustable silicone ring (Bariatric Solution, Kaltenbach, Switzerland) around the gastric pouch. The indi cat ion was new hyperphagic behavior with resulting weight regain. The mean age at the time of the revision was $37.8 \pm 11.2$ years. Mean weight and body mass index (BMI) at the time of RYGB were $105.0 \pm 12.3 \mathrm{~kg}$ and $36.3 \pm 3.0 \mathrm{~kg} / \mathrm{m}^{2}$ respectively, and all patients suffered from obesity-related co-morbidities (six HTA, one degen- 
erative joint disease). RYGB had been performed in three of patients as conversion from a previous adjustable gastric banding (AGB) (two) or vertical banded gastroplasty (one). After a mean time from RYGB of $26.0 \pm 14.2$ months, all six patients achieved a weight regain of $4.7 \pm 3.4 \mathrm{~kg}$ compared to their lowest weight, with a final mean weight, BMI, and percentage of excess weight loss (\%EWL) at the time of silicone ring of $86.0 \pm 13.1 \mathrm{~kg}, 29.5 \pm 3.9 \mathrm{~kg} / \mathrm{m}^{2}$, and $47.0 \pm 24.7 \%$, respectively. Preoperative evaluation for each patient included history and physical examination, nutritional and psychiatric evaluation, laboratory tests, and barium swallow check. Surgeon discussed the surgical options with each patient, mentioning the limited literature data regarding the use of a non-adjustable silicone ring or AGB as treatment for weight regain after RYGB. Outcome measures included evaluation of the Roux-en-Y construction, operative time, postoperative morbidity and mortality, weight loss in terms of absolute weight loss, BMI, and \%EWL. Statistical analysis was mainly descriptive; observed distributions are reported using summary parameters: mean and standard deviation for each variable analyzed (all variables being continuous). Distributions of \%EWL were compared before and after the ring's insertion using exact Wilcoxon signed-ranks test.

\subsubsection{SURGICAL TECHNIQUE}

Abdominal insufflation pressure was set at $15 \mathrm{mmHg}$. Five trocars were used and placed as follows: a $10-\mathrm{mm}$ trocar $20 \mathrm{~cm}$ below the xyphoid process for the $30^{\circ}$ angled laparoscope, a 5-mm trocar on the left anterior axillary line, a 12-mm trocar on the left mid-clavicular line between the first and the second trocars, a $5-\mathrm{mm}$ trocar on the right mid-clavicular line, and a 5-mm trocar below the xyphoid process. Adhesiolysis between the liver, gastric pouch, and gastrojejunostomy was performed with the hook electrocautery, until clear identification of these structures was obtained. The anatomy of the RYGB and the alimentary loop length were checked. The gastrojejunostomy was located, and carefully freed from the gastric remnant avoiding any devascularization. The vertical part of the gastric pouch was separated from the gastric remnant and from the greater omentum and freed from the left crus. A tunnel was fashioned from medially to laterally through the lesser sac dorsal to the gastric pouch, just cranial to the gastrojejunostomy level. The circumference of the gastric pouch at the level of the tunnel was measured and a silicone non-stretchable radiopaque ring was selected. The ring was introduced into the abdomen through the 12-mm trocar (Fig.1) and passed through the tunnel, thus cranial to the level of the gastrojejunostomy (Fig.2). 


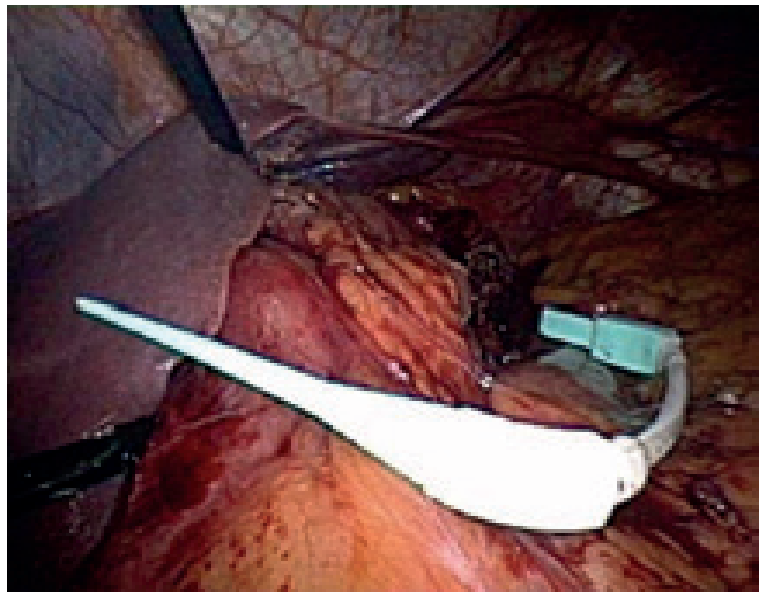

Fig.1 Non-adjustable silicone ring

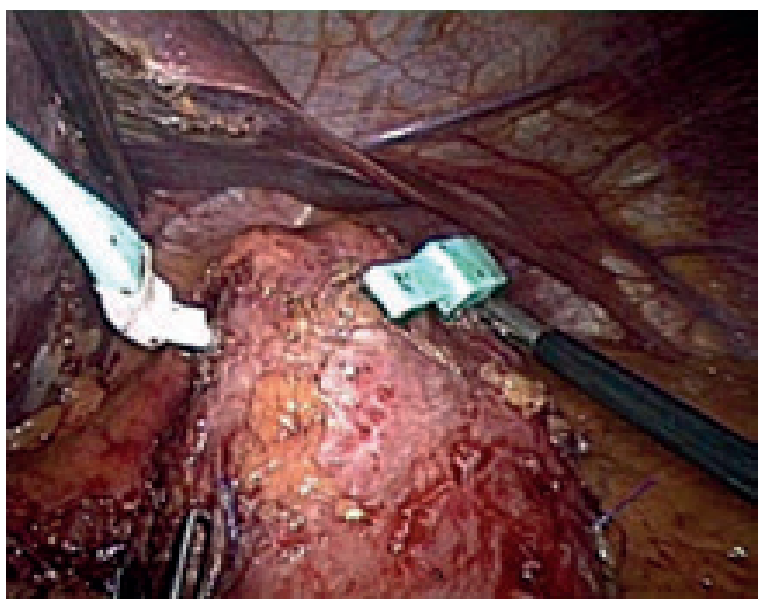

Fig.2 Placement of the non-adjustable silicone ring around the gastric pouch

The protective latch covers of the ring were retrieved and the ring was gently autolocked. Finally, the ring was fixed to the gastric pouch by resorbable sutures (Vicryl 2/0) (Figs.3 and 4). 


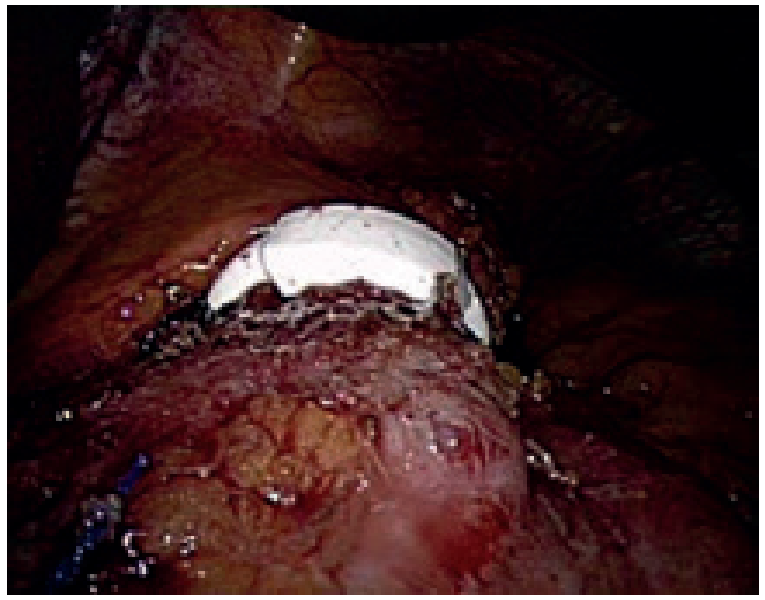

Fig.3 Final view of the procedure

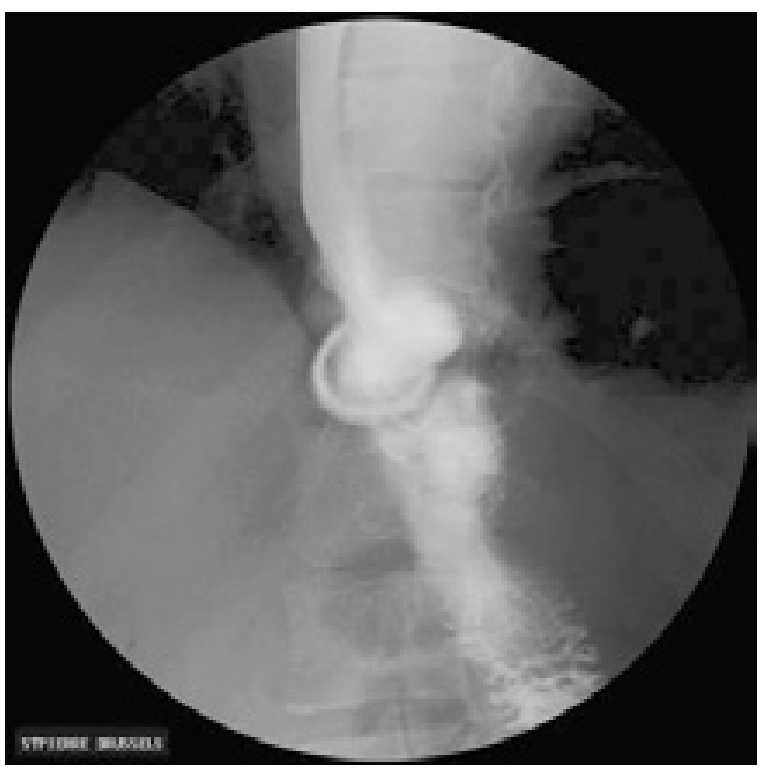

Fig.4 Upper gastrointestinal gastrografin swallow on first postoperative day

\subsection{RESULTS}

Barium swallow did not evidence any gastric pouch dilation. RYGB had been performed, in six patients, with an antecolic antegastric construction, and in one with a retrocolic antegastric technique; in all cases, the alimentary limb appeared to measure $150 \mathrm{~cm}$. A silicone ring of $6.5 \mathrm{~cm}$ was elected in two patients and of $7 \mathrm{~cm}$ in the remaining four. Mean operative time was $82.5 \pm 18.3 \mathrm{~min}$. There were no 
operative mortality and conversion to open surgery. No postoperative complications were achieved. Mean hospital stay was $2.6 \pm 1.5$ days. After a mean follow-up of $14.0 \pm 9.2$ months, the six patients presented a mean weight loss of $9.1 \pm 2.4 \mathrm{~kg}$, with a final mean weight, BMI, and \%EWL of $76.8 \pm 13.7 \mathrm{~kg}, 26.4 \pm 4.2 \mathrm{~kg} / \mathrm{m}^{2}$, and $70.4 \pm 30.4 \%$, respectively (Fig.5).

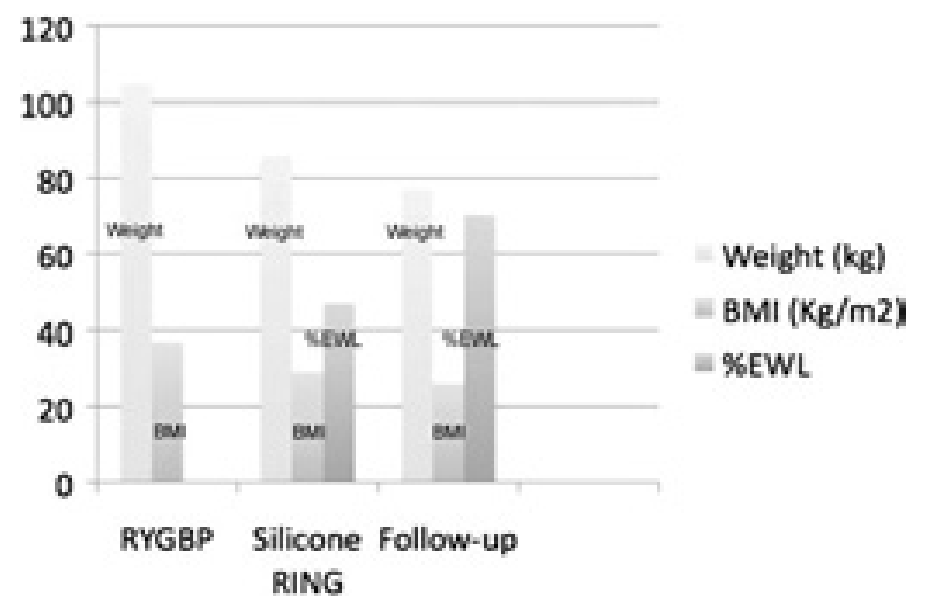

Fig.5 A comparison of weight loss, BMI, and \%EWL after the ring revision

Difference in term of \%EWL before and after the ring's insertion (23.4 \pm 5.7$)$ is statistically significant $(\mathrm{p}<0.05)$. No erosions or slippage of the silicone ring has been observed during this follow-up.

\subsection{DISCUSSION}

Different causes can contribute to weight regain after RYGB. One of them is new eating behavior, characterized by volume eating or hyperphagia. Nutritional counseling can be advised in order to reduce weight with a prescribed diet [17], but more often than not will fail in the classically poorly compliant bariatric patient. In some patients, restriction fades with time, which allows the patients to consume larger meals, becoming hyperphagic. Trying to obtain a new restriction with a ring around the gastric pouch seems a reasonable option. The idea of the placement of a non-adjustable silicone ring in patients already submitted to RYGB, stems from the Fobi technique in banded RYGB $[16,18]$. Superior results of the banded RYGB versus standard RYGB, in terms of \%EWL at 3 years, 73.4\% versus $57.7 \%$ [19], can support the option to band a RYGB as a second procedure in the case of insufficient weight loss or weight regain. Banding can be achieved by placement of an AGB around the gastric pouch by laparoscopy [20,21] or by open access [22]. As Bessler et al. recently presented, 22 patients submitted to AGB after RYGB, had a mean 
$\%$ EWL at $1,2,3,4$, and 5 years respectively of $29 \%, 43.5 \%, 51 \%, 33 \%$, and $34 \%$ [23]. Gobble et al., using a similar technique, reported a mean \%EWL of $20.8 \pm 16.9 \%$ after a mean of $13.2 \pm 10.3$ months in 11 patients [21]. Chin et al. confirmed a mean \%EWL of $24.3 \%$ at 1 year in 8 patients and $48.7 \%$ at 2 years in 5 patients [22]. These encouraging results are similar to ours during a similar followup period. In our series, however, the band we used was not adjustable. We believe this constitutes a significant difference. The circumference of the silicone ring which we placed was chosen between 6.5 and $7.0 \mathrm{~cm}$, in order to surround the gastric pouch in a loose manner. Whereas the AGB is supposed to be adjusted until 'optimal restriction' is achieved [20-23], the non-adjustable silicone ring does not constrict the pouch, but rather reduces the compliance of the latter, interrupting the propulsive wave aiming for evacuating the food bolus. The diameter of the band that we used varied between 2.7 and $2.9 \mathrm{~cm}$. Since the ring was placed in a strictly perigastric position, it is likely to be less restrictive than an even noninflated AGB, because the latter is placed around substantially more tissue with the pars flaccida technique [24] (inner diameter in a non-inflated low pressure band is $\sim 2.9 \mathrm{~cm}$ ). The loose non-adjustable silicone band causes slower emptying of the pouch into the alimentary loop. Proof for this can be found in patients who suffer from symptomatic postprandial hypoglycemia and who significantly benefit from placement of a silicone ring through slower gastric emptying [25]. Possible complications related to the use of AGB or non-adjustable silicone ring are erosion and slippage of the device, as reported with the standard procedure of AGB [26] or banded RYGB [27]. In our series and in others' [20-23], there was no evidence of either of these complications. The suture-fixation of the ring to the pouch, as described here, could contribute to reducing the incidence of the slippage. Despite the small size of our patient sample and the short follow-up, our results seem to demonstrate the safety and efficacy of placement of a non-adjustable silicone ring as a rescue operation for weight regain in patients who experience volume increase after laparoscopic RYGB.

\subsection{REFERENCES}

1. Mason EE, Ito C. Gastric bypass in obesity. Surg Clin North Am 1967;47:1345-51

2. Wittgrove AC, Clark GW, Tremblay LJ. Laparoscopic gastric bypass, Roux-en-Y: preliminary report of five cases. Obes Surg 1994;4:353-7

3. DeMaria EJ, Schauer PP, Patterson E, et al. The optimal surgical management of the superobese patients: the debate. Surg Innov 2005;12:107-21

4. Pories W, Swanson M, MacDonald K. Who would have thought it ? An operation proves to be the most effective therapy for adult-onset diabetes mellitus. Ann Surg 1995;22:39-50

5. Jones K. Experience with Roux-en-Y gastric bypass, and commentary on current trends. Obes Surg 2000;10:183-5

6. White S, Brooks E, Jurikova L, et al. Long-term outcomes after gastric bypass. Obes Surg 2005;15:155-63 
7. Himpens J, Cremer M, Cadière GB, et al. Use of a new endoluminal device in the transoral endoscopic surgical procedure for the treatment of weight regain after Roux-en-Y gastric bypass. Presented at the Annual Meeting of the Society of American Gastrointestinal and Endoscopic Surgeons (SAGES), April 18-22, 2007, Dallas TX (US)

8. Mikami DJ, Needleman B, Happel L, et al. Natural orifice surgery: initial US experience utilizing the StomaphyX device to reduce gastric pouches after Roux-en-Y gastric bypass. Presented at the 11th World Congress of Endoscopic Surgery (WCES), September 2-5, 2008, Yokohama (Japan)

9. Thompson CC, Slattery J, Bundga ME, et al. Peroral endoscopic reduction of dilated gastrojejunal anastomosis after Roux-en-Y gastric bypass: a possible new option for patients with weight regain. Surg Endosc 2006;20:1744-8

10. Torquati A, Kernodle SS, Kaiser JI, Attwell AR. Transoral revision of dilated gastro-jejunostomy anastomosis after gastric bypass surgery. Abstract Surg Obes Relat Dis 2008;4:306

11. Mullady DK, Lautz DB, Thompson CC. Treatment of weight regain following gastric bypass surgery using a novel endoscopic device: technical feasibility and early outcomes in twenty patients. Poster at the Annual Meeting of the Digestive Disease Week (DDW), May 17-22, 2008, San Diego CA (US)

12. Herron DM, Birkett DH, Thompson CC, et al. Gastric bypass pouch and stoma reduction using a transoral endoscopic anchor placement system: a feasibility study. Surg Endosc 2008;22:1093-9

13. Thompson CC. Techniques of stenting for leaks and gastro-gastric fistulae. Presented at the Annual Meeting of the American Society for Metabolic and Bariatric Surgery (ASMBS), June 15-20, 2008, Washington DC (US)

14. Fobi MAL, Lee H, Igwe D Jr, et al. Revision of failed gastric bypass to distal Roux-en-Y gastric bypass: a review of 65 cases. Obes Surg 2001;11:190-5

15. Sugerman HJ, Kellum JM, De Maria EJ. Conversion of proximal to distal gastric bypass for failed gastric bypass for superobesity. J Gastrointest Surg 1997;1:517-25

16. Fobi MAL. Why the operation I prefer is silastic ring vertical gastric bypass. Obes Surg 1991;1:423-6

17. Faria SL, de Oliveira Kelly E, Lins RD, Faria OP. Nutritional management of weight regain after bariatric surgery. Obes Surg 2010;20:135-9

18. Fobi MAL. Placement of the GaBP ring system in the banded gastric bypass operation. Obes Surg 2005;15:1196-1201

19. Bessler M, Daud A, Kim T, et al. Prospective randomized trial of banded versus nonbanded gastric bypass for the super obese: early results. Surg Obes Relat Dis 2007;3:480-5

20. Bessler M, Doud A, DiGiorgi MF, et al. Adjustable gastric banding as a revisional baraitric procedure after failed gastric bypass. Obes Surg 2005;15:1443-8

21. Gobble RM, Parikh MS, Greives MR, et al. Gastric banding as a salvage procedure for patients with weight loss failure after Roux-en-Y gastric bypass. Surg Endosc 2008;22:1019-22

22. Chin PL, Ali M, Francis K, LePort PC. Adjustable gastric band placed around gastric bypass pouch as revision operation for failed gastric bypass. Surg Obes Relat Dis 2009;5:38-42

23. Bessler M, Daud A, Inabnet WB, Schrope B. Adjustable gastric banding as a revisional bariatric procedure after failed gastric bypass-intermediate results. Abstract Surg Obes Relat Dis 2008;4:310

24. O'Brien PE, Dixon JB, Laurie C, et al. A prospective randomized trial of placement of the laparoscopic adjustable gastric band: comparison of the perigastric and pars flaccida pathways. Obes Surg 2005;15:820-6

25. Z'graggen K, Guweidhi A, Steffen R, et al. Severe recurrent hypoglycemia after gastric bypass surgery. Obes Surg 2008;18:981-8

26. Silecchia G, Bacci V, Bacci S, et al. Reoperation after laparoscopic adjustable gastric banding: analysis of a cohort of 500 patients with long-term follow-up. Surg Obes Relat Dis 2008;4:430-6

27. Fobi MAL, Lee H, Igwe D, et al. Band erosion: incidenceetiology, management and outcome after banded vertical gastric bypass. Obes Surg 2001;11:699-707 



\subsection{ABSTRACT}

Background: Weight regain after Roux-en-Y gastric bypass (RYGB) is one of the possible complications bariatric surgeons are confronted with. An option for enhancing weight loss is the conversion of RYGB into distal RYGB (DRYGB), which is a malabsorptive procedure. We report the technical strategy and the preliminary outcomes of conversion of RYGB to DRYGB by laparoscopy.

Patients and Methods: Between April 2005 and November 2009, 7 patients benefited from laparoscopic conversion of RYGB to DRYGB for weight regain mainly due to a new dietary behavior, namely, polyphagia (eating too frequent meals). At the time of RYGB, the mean weight and BMI was $120.5 \pm 26.4 \mathrm{~kg}$ and $43.2 \pm 6.7$ $\mathrm{kg} / \mathrm{m}^{2}$, respectively. Five patients suffered of obesity-related comorbidities. Mean interval time between RYGB and conversion was $41 \pm 15.9$ months. At the time of conversion, the mean weight, BMI, \% excess weight loss were $100.7 \pm 19.8 \mathrm{~kg}$, $36.1 \pm 4.8 \mathrm{~kg} / \mathrm{m}^{2}$, and $33.7 \pm 12.1 \%$, respectively. Obesity-related comorbidities at that time affected 4 patients.

Results: Mean operative time was $122.1 \pm 34$ minutes. There were no conversions to open surgery and no mortality. Postoperatively, 1 patient suffered of a bleeding. Mean hospital stay was $4.7 \pm 2.5$ days. After a mean follow-up of $19 \pm 23.7$ months, the mean weight, BMI, and \% excess weight loss was $82.5 \pm 19.7 \mathrm{~kg}$, $29.5 \pm 5.3 \mathrm{~kg} / \mathrm{m}^{2}$, and $57.6 \pm 8.1 \%$, respectively. Obesity-related comorbidities remained unchanged after the conversion in the 4 patients. One patient required a surgical reoperation for internal hernia.

Conclusion: Conversion of RYGB to DRYGB for weight regain can safely be performed by laparoscopy, with satisfactory early results. 


\section{$9.2 \quad$ INTRODUCTION}

Roux-en-Y gastric bypass (RYGB) is a common procedure for morbid obesity, and midterm excess weight loss (EWL) is reported to be 43-68.1\% [1-3]. Weight regain is one of the possible long-term complications. Possible causes of weight regain after RYGB can be related to technical failures as gastric pouch dilation, gastrojejunal anastomosis dilation, and development of gastro-gastric fistula. More often than not, weight regain depends on new dietary behavior of the patient. Treatment will take into account the cause of weight regain, with consequent proposal of revisional surgery by laparoscopy [4,5] or endoluminal [6-9]. As with other bariatric procedures, patients after RYGB frequently develop new dietary habits as hyperphagia, polyphagia, or sweet eating. In presence of hyperphagia (volume eating or eating too large meals), treatment can consist in increasing the restriction compartment, by placing around the gastric pouch an adjustable gastric band [10-12] or a nonadjustable ring [13]. In the presence of polyphagia (eating too frequent meals or grazing), a conversion to malabsorptive procedures can be proposed [14]. In case of increased caloric intake by sweet eating, a conversion to malabsorptive procedures such as duodenal switch (DS) could be proposed as well [15]. Obviously, the nutritionist's counseling constitutes an important part of the multidisciplinary consultation, since mental disorders, such as binge eating and night eating disorders, must be ruled out. Consequently, it is our attitude, in absence of mental disorders [16], to offer conversion to distal RYGB (DRYGB) in patients with RYGB presenting weight regain due to a new polyphagia diet. In this retrospective study we report the technical strategy and the preliminary outcomes of the conversion of RYGB to DRYGB by laparoscopy, in a selected group of patients presenting weight regain due to de novo polyphagia behavior.

\subsection{PATIENTS AND METHODS}

Between April 2005 and November 2009, 7 patients (5 females and 2 males) benefited from laparoscopic conversion of RYGB to DRYGB. The patients were informed of the new digestive circuit, of main advantage in term of weight loss and disadvantages in term of increased flatulence, bloating, and frequency of bowel movements. Reason of conversion was weight regain, predominantly due to a new dietary behavior, such as polyphagia, diagnosed at the nutritionist's counseling. The psychologist's counseling ruled out mental disorders. The rest of the multidisciplinary consultation (gastroenterologist and radiologist) performing preoperative gastroscopy and barium swallow excluded technical causes for weight regain. At the time of RYGB, the mean weight and BMI was $120.5 \pm 26.4 \mathrm{~kg}$ (range 87-161) and $43.2 \pm 6.7 \mathrm{~kg} / \mathrm{m}^{2}$ (range 33.2-52.4), respectively. Obesity-related comorbidities affected 5 out of 7 patients, including arterial hypertension (2), type 2 diabetes (2), sleep apnea (2), and degenerative joint diseases (1). Mean age at the time of con- 
version was $51.8 \pm 11.2$ years (range 38-71). Mean interval time between RYGB and conversion was $41 \pm 15.9$ months (range 22-66). In this interval time, the extreme achieved weight, BMI, and \%EWL was $91.1 \pm 18.2 \mathrm{~kg}$ (range 67-115), 34.4 \pm 6.1 $\mathrm{kg} / \mathrm{m}^{2}$ (range 25.5-43.8), and $49.1 \pm 14.5 \%$ (range 24.3-66.6), respectively. At the time of conversion, the mean weight, BMI, and \%EWL were $100.7 \pm 19.8 \mathrm{~kg}$ (range $75-129$ ), $36.1 \pm 4.8 \mathrm{~kg} / \mathrm{m}^{2}$ (range 28.6-44.6), and $33.7 \pm 12.1 \%$ (range 12.1-46.1), respectively. Four out of 7 patients suffered from obesity-related comorbidities, including arterial hypertension (1), type 2 diabetes (1), sleep apnea (1), and degenerative joint diseases (1). The main objective of our study was to describe the feasibility of our technique by laparoscopy and to document whether the conversion we used might lead to some success in terms stopping weight regain and reinducing further weight loss. Our sample size was small preventing us to carry out any statistical inference. We therefore used descriptive statistical methods. We reported frequency tabulations for categorical variables and mean and standard deviation as summary parameters of the observed distributions of continuous covariables or outcomes. The main criteria of evaluation was the \%EWL calculated on the basis of the initial weight before the procedure of RYGB. The ideal weight for evaluation of \%EWL was set at a BMI of $22 \mathrm{~kg} / \mathrm{m}^{2}$. We also reported graphical representations of means of continuous outcomes during the first follow-up period and the second follow-up period.

\subsubsection{SURGICAL TECHNIQUE}

The patient was positioned supine with the legs apart and with both arms in abduction (French position). The surgeon stood between the patient's legs, the camera-person to the patient's right, and the assistant to the patient's left. The procedure started with the insertion in the abdomen of the first 12-mm trocar using the Hasson technique on the left upper quadrant midclavicular line. Three additional trocars were placed under view, usually at the same position as in the original surgery: a $10-\mathrm{mm}$ trocar some $20 \mathrm{~cm}$ below the xyphoid process, a $5-\mathrm{mm}$ trocar on the right midclavicular line on the same horizontal line, and a 5 -mm trocar just distal to the xyphoid process (Fig.1).

The procedure started by identification of the gastrojejunostomy, after adhesiolysis between the abdominal wall and Roux limb, and between the left liver lobe and the gastrojejunostomy. Once the anastomosis identified, the Roux limb was measured precisely by stretching the bowel along a $25-\mathrm{cm}$ tape. The jejunojejunostomy came into view and each limb was marked at this level using 3 differently colored stitches, to identify the Roux, the biliary, and the common limbs. The Roux limb proximal to the jejunojejunostomy was sectioned by a firing of a linear stapler blue load (EndoGIA; Covidien, New Haven, CT) (Fig.2a). 


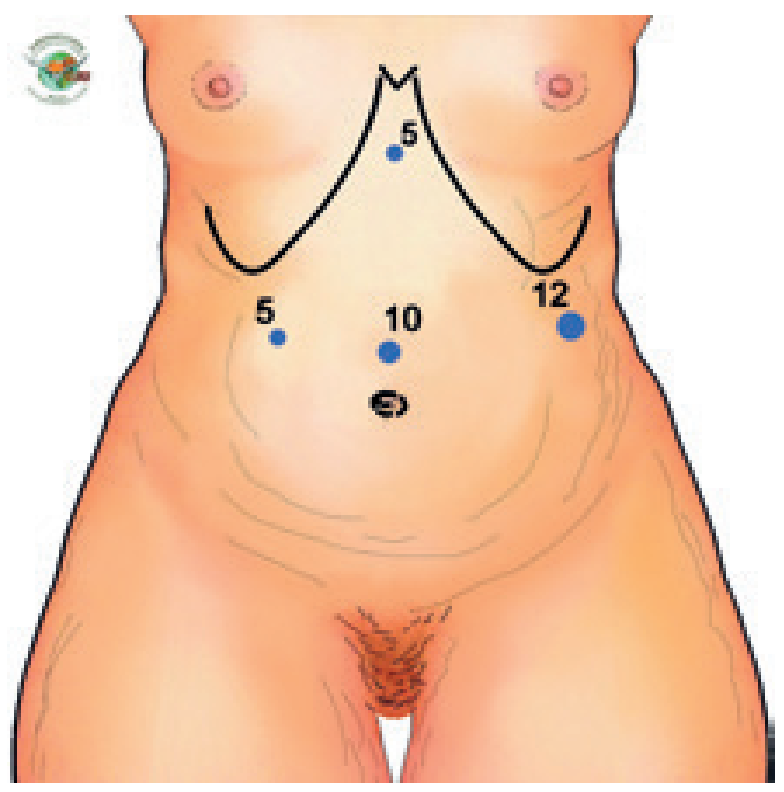

Fig.1 Placement of the abdominal trocars
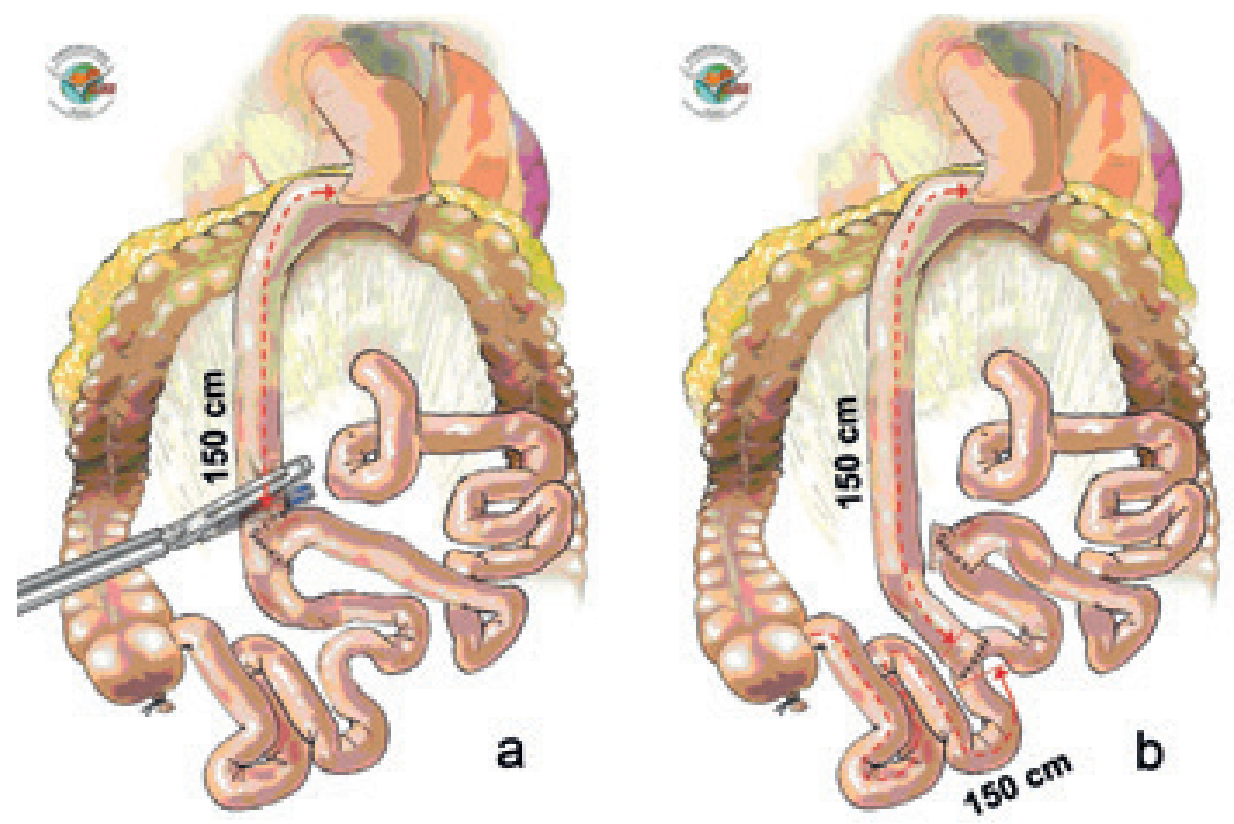

Fig.2 Schematic illustration of the conversion of RYGB to DRYGB: transposition of the distal end of Roux limb (a) so as to reach a total of $300 \mathrm{~cm}$ including the previous Roux limb and the new common limb (b)

The patient, camera-person, and assistant now moved to the patient's left. The ileocaecal valve was identified and the small bowel measured so as to reach a total 
of $300 \mathrm{~cm}$, including the previous Roux limb. At that level, a new side-to-side linear mechanical jejunojejunostomy (one firing of linear stapler white load and two 2/0 polydiaxone running sutures for the openings closure) was performed between the Roux and the new common limbs (Fig.2b).

The newly created mesenteric defect was closed by a nonabsorbable purse string suture (1 polypropylene). Cholecystectomy was performed as well, and the gallbladder retrieved by the left $12-\mathrm{mm}$ upper quadrant trocar. The latter was closed in layers. The patient was allowed to a liquid diet on the first postoperative day, and typically was discharged from the hospital with a protein-rich diet.

\subsection{RESULTS}

Peroperatively the Roux limb length appeared to measure exactly $150 \mathrm{~cm}$, except in 1 patient where it was $110 \mathrm{~cm}$. Gallbladder was still present at the time of the revision in 3 out of 7 patients; hence, cholecystectomy was performed in these latter patients. The internal hernia sites were systematically closed in all patients. Mean operative time was 122.1 \pm 34 minutes (range 90-180). There were no conversions to open surgery, and no mortality. During the postoperative course, 1 patient (14.2\%) suffered a significant abdominal bleeding, treated by blood transfusions. Mean hospital stay was $4.7 \pm 2.5$ days (range 2-10). All patients were followed-up by office visits, with complete blood test, including albumin and protein level. After a mean follow-up of $19 \pm 23.7$ months (range 2-56), the mean weight, BMI, and \%EWL was $82.5 \pm 19.7 \mathrm{~kg}$ (range $52-105$ ), $29.5 \pm 5.3 \mathrm{~kg} / \mathrm{m}^{2}$ (range 19.8 37.2 ), and $57.6 \pm 8.1 \%$ (range $50-120.6$ ), respectively (Fig.3).

\section{RYGB to DRYGB}

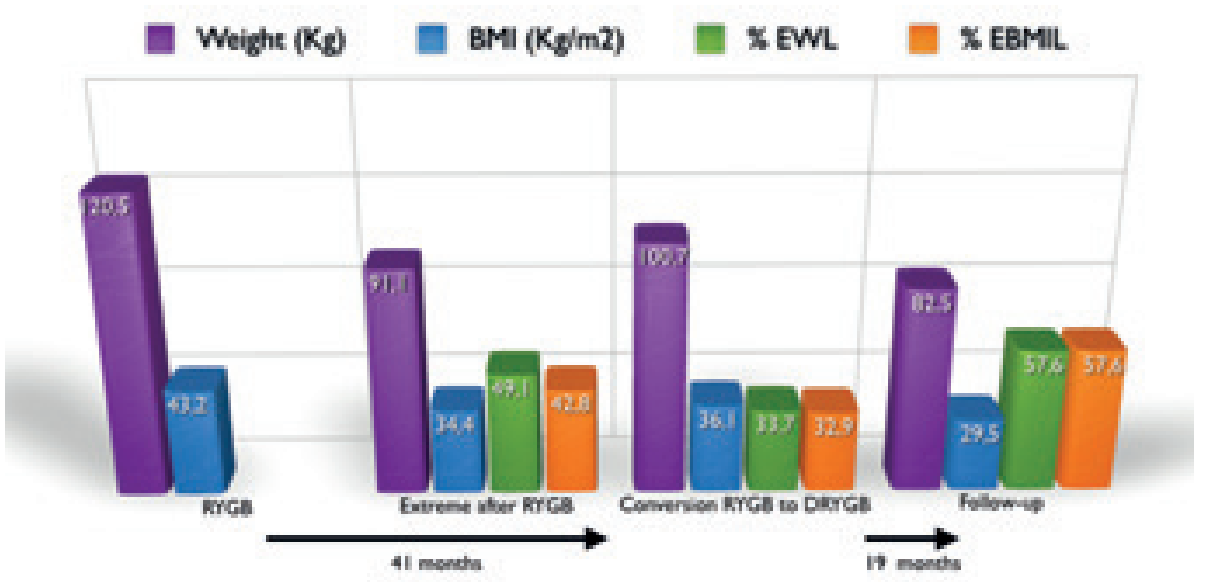

Fig.3 Comparison of weight, BMI, and \% excess weight loss (\%EWL) at RYGB, at extreme values before the conversion to DRYGB, at the conversion, and at follow-up (mean values) 
No protein malnutrition or hepatic function failures were evidenced during this follow-up time, but all patients referred an increased flatulence and frequency of bowel movements. Frequency bowel movement was mostly influenced by the dietary, increasing with fat-rich diet. Obesity- related comorbidities affecting the 4 patients before the conversion remained unchanged during this follow-up time. One patient (14.2\%) presented a late complication consisting of intestinal occlusion due to internal hernia, which required surgical reoperation.

\subsection{DISCUSSION}

Provided mental disorders were ruled out, patients submitted to RYGB presenting weight regain due to new eating behavior such as polyphagia can benefit from conversion to DRYGB. The procedure of DRYGB was first reported to induce better weight loss than the standard RYGB in super-obese patients, in a randomized trial [17]. The same authors also reported the conversion of RYGB to DRYGB for failures in superobese patients, and achieved a \%EWL of $67 \pm 5 \%$ and $69 \pm 5 \%$ at follow-up of 3 and 5 years, respectively [18]. In this latter study, in 22 patients the revision included creation of a Roux limb of $145 \mathrm{~cm}$ and a common limb of $150 \mathrm{~cm}$, whereas in 5 patients Roux limb of $200 \mathrm{~cm}$ and common limb of $50 \mathrm{~cm}$ were created. The reason of lengthening of the common limb in 22 out of 27 patients was mainly based on the development of severe protein-calorie malnutrition during follow-up. In our department we adopted a similar technique as reported by Sugerman et al. [18]. We created a total Roux and common limbs length of $300 \mathrm{~cm}$. In our study, enrolling a smaller number of patients, we recorded a \%EWL of $57.6 \pm 8.1 \%$ at a mean follow-up of $19 \pm 23.7$ months, which is quite similar to that reported of $61 \pm 4 \%$ at 1 year by Sugerman et al. [18]. A similar revision with quite similar digestive construction was also reported by Fobi et al. [19], who revisioned 65 patients from RYGB to DRYGB. The authors reported a decrease of BMI from 41.8 to $34.6 \mathrm{~kg} / \mathrm{m}^{2}$ after more than 1 year of follow-up. This is higher than our mean BMI of $29.5 \pm 5.3 \mathrm{~kg} / \mathrm{m}^{2}$, but this must be weighed against BMI level at the time of the conversion, and take into account the small series of our patients. Obviously, the increased weight loss after the revision is related to the addition of a malabsorptive process, which, on the other hand, can lead to protein malnutrition as late complication. Both Sugerman et al. [18] and Fobi et al. [19] reported late protein malnutrition, in $4(18.1 \%)$ and 15 patients (23.2\%), respectively. Furthermore, Brolin et al. corroborated these findings later [14]. Our follow-up time is one of the major weak aspects of the article, and could explain way in this limited time we did not record any proteins deficiency. On the other hand, other side effects, such as increased flatulence and frequency of bowel movements, were achieved in our patients. Interesting seems the increase of frequency bowel movement mostly related to the dietary type, especially fat-rich diet as it usually occurs in patients with other malabsorptive procedures as biliopancreatic diversion or DS. Techni- 
cally speaking, it is our strategy to start by a limited adhesiolysis in the left upper quadrant, just sufficient to obtain vision of the proximal end of the Roux limb and gastro-jejunostomy, so as not to jeopardize the vascularization of this area. Then, the Roux limb is measured precisely allowing exact measurement of the new entire length of active bowel of $300 \mathrm{~cm}$. It is mandatory to be able to recognize all three components at all times during surgery. This is the reason for placing different colored stitches on the loops of the three components at the jejunojejunostomy (distal end of the Roux limb, distal end of biliary limb, and proximal end of the old common limb). Placement of the marked stitches is extremely helpful because the measurement of the new common limb and the new jejunojejunostomy are performed using a different position of the surgeons (at the patient's left), which leads to confusion. The distal end of the Roux limb has to be sectioned close to the jejunojejunostomy, taking care to avoid stenosis. Finally, it is mandatory to close the new mesenteric defect, which is usually large and sometimes appears difficult to close, if exposure is not sufficient. Our operative time highly depends on the sometimes lengthy adhesiolysis, but overall it is the measurement of the Roux and the new common limbs, which take the most time. Moreover, time to perform cholecystectomy, where it is present, has to be counted as well. We recommend performing cholecystectomy during this type of revision, because in $50 \%$ of the patients submitted to DRYGB, another revision was necessary for the development of cholecystitis [18]. In our study we recorded only one early complication as bleeding, which was medically treated. Consequently, hospital stay was longer in this latter patient. Usually, however, since the procedure involves just the dismanteling of the jejunojejunostomy and the manufacturing of a new anastomosis in another segment of the small bowel, the hospital stay is kept short. Anyway, other possible early complications, such as leaks, small bowel obstruction, or wound infection, can contribute to quite longer hospital stay [19]. Obesity-related comorbidities, affecting 4 out of our 7 patients at the time of the revision, remained unchanged during this follow-up, which is remarkable considering the satisfactory weight loss. In this selected series of patients, we registered one late complication. Six months after the revision, the patient presented an intestinal occlusion due to internal hernia, which required a resection of the biliary limb by open surgery. This complication, well reported after the procedure of primary RYGB [20], could become very dangerous in this category of patients, especially when the bowel resection includes the common or Roux limbs length, which are critical. Moreover, these data confirm that despite closure of the defect, as it was for our patient, the risk of the defect to open always persists [21]. In conclusion, conversion of RYGB to DRYGB for weight regain can safely be performed by laparoscopy, with satisfactory early results. 


\subsection{REFERENCES}

1. Pories W, Swanson M, MacDonald K. Who would have thought it? An operation to be the most effective therapy for adult-onset diabetes mellitus. Ann Surg 1995;222:339-50

2. Jones K. Experience with the Roux-en-Y gastric bypass, and commentary on current trends. Obes Surg 2000;10:183-5

3. Christou NV, Look D, MacLean LD. Weight gain after short- and long-limb gastric bypass in patients followed for longer than 10 years. Ann Surg 2006;244:734-40

4. Gagner M, Gentileschi P, de Csepel J, Kini S, Patterson E, Inabnet WB, Herron D, Pomp A. Laparoscopic reoperative bariatric surgery: Experience from 27 consecutive patients. Obes Surg 2002;12:254-60

5. Gumbs AA, Pomp A, Gagner M. Revisional bariatric surgery for inadequate weight loss. Obes Surg 2007;17:1137-45

6. Thompson CC, Slattery J, Bundga ME, Lautz DB. Peroral endoscopic reduction of dilated gastrojejunal anastomosis after Roux-en-Y gastric bypass: A possible new option for patients with weight regain. Surg Endosc 2006;20:1744-8

7. Mullady DK, Lautz DB, Thompson CC. Treatment of weight regain after gastric bypass surgery when using a new endoscopic platform: Initial experience and early outcomes (with video). Gastrointest Endosc 2009;70:440-4

8. Ryou M, Mullady DK, Lautz DB, Thompson CC. Pilot study evaluating technical feasibility and early outcomes of second-generation endosurgical platform for treatment of weight regain after gastric bypass surgery. Surg Obes Relat Dis 2009;5:450-4

9. Mikami D, Needleman B, Narula V, Durant J, Melvin WS. Natural orifice surgery: Initial US experience utilizing the StomaphyX device to reduce gastric pouches after Roux-en-Y gastric bypass. Surg Endosc 2010;24:223-8

10. Bessler M, Daud A, Digiorgi MF, Inabnet WB, Schrope B, Olivero-Rivera L, Davis D. Adjustable gastric banding as revisional bariatric procedure after failed gastric bypass-Intermediate results. Surg Obes Relat Dis 2010;6:31-5

11. Gobble RM, Parikh MS, Greives MR, Ren CJ, Fielding GA. Gastric banding as a savage procedure for patients with weight loss failure after Roux-en-Y gastric bypass. Surg Endosc 2008;22:1019-22

12. Chin PL, Ali M, Francis K, LePort PC. Adjustable gastric band placed around gastric bypass pouch as revision operation for failed gastric bypass. Surg Obes relat Dis 2009;5:38-42

13. Dapri G, Cadie`re GB, Himpens J. Laparoscopic placement of non-adjustable silicone ring for weight regain after Roux- en-Y gastric bypass. Obes Surg 2009;19:650-4

14. Brolin RE, LaMarca LB, Kenler HA, Cody RP. Malabsorptive gastric bypass in patients with superobesity. J Gastrointest Surg 2002;6:195-205

15. Dapri G, Cadière GB, Himpens J. Laparoscopic conversion of Roux-en-Y gastric bypass to sleeve gastrectomy as first step of duodenal switch: technique and preliminary and preliminary outcomes. Obes Surg 2011;21:517-23

16. Dapri G, Himpens J, Cadie` re GB. Laparoscopic conversion of Roux-en-Y gastric bypass to biliopancreatic diversion. Surg Endosc 2010;24:1490-3

17. Sugerman HJ, Kellum JM, Rothrock MK, et al. Proximal vs. distal gastric bypass in the superobese patient: A randomized study. Poster presentation at the Society for Surgery of the Alimentary Tract, Boston, MS, April 17, 1993

18. Sugerman HJ, Kellum JM, DeMaria EJ. Conversion of proximal to distal gastric bypass for failed gastric bypass for superobesity. J Gastrointest Surg 1997;6:517-25

19. Fobi M, Lee H, Igwe D, Jr., Felahy B, James E, Stanczyk M, Tambi J, Eyong P. Revision of failed gastric bypass to distal Roux-en-Y gastric bypass: A review of 65 cases. Obes Surg 2001;11:190-5

20. Carucci LR, Turner MA, Shaylor SD. Internal hernia following Roux-en-Y gastric bypass surgery for morbid obesity: Evaluation of radiographic findings at small-bowel examination. Radiology 2009;251:762-70

21. Ahmed AR, Rickards G, Husain S, Johnson J, Boss T, O’Malley W. Trends in internal hernia incidence after laparoscopic Roux-en-Y gastric bypass. Obes Surg 2007;17:1563-6 


\section{Chapter 10}

\section{LAPAROSCOPIC CONVERSION OF ROUX- EN-Y GASTRIC BYPASS TO SLEEVE GASTRECTOMY AS FIRST STEP OF DUODENAL SWITCH}

Dapri G, Cadière GB, Himpens J

Obesity Surgery 2011;21(4):517-523 



\subsection{ABSTRACT}

Background: Weight loss issues are one of the problems that can affect patients after undergoing bariatric surgery. We report the feasibility, safety and preliminary outcomes of laparoscopic conversion of Roux-en-Y gastric bypass (RYGB) to sleeve gastrectomy (SG), as a first step of duodenal switch (DS), for insufficient weight loss or weight regain.

Patients and Methods: Between August 2007 and November 2009, four patients benefited from laparoscopic conversion for insufficient weight loss or weight regain, mainly due to a new dietary behaviour such as sweet eating. At the time of RYGB, the mean weight and body mass index (BMI) was $118.5 \pm 32.8 \mathrm{~kg}$ and $43.2 \pm 8$ $\mathrm{kg} / \mathrm{m}^{2}$, respectively. The mean interval time between RYGB and conversion to $\mathrm{SG}$ was $36.7 \pm 15.6$ months. At the time of conversion, the mean weight, BMI, $\%$ excess weight loss (\%EWL) and \% excess BMI loss (\%EBMIL) was 101.7 $\pm 24.7 \mathrm{~kg}$, $37.3 \pm 6.6 \mathrm{~kg} / \mathrm{m}^{2}, 27.5 \pm 11.8 \%$ and $26.5 \pm 12 \%$, respectively. The procedure involved the dismantling of both anastomosis, performance of SG before restoration of gastric continuity, and new small bowel anastomosis.

Results: Mean operative time was $233.7 \pm 46.4 \mathrm{~min}$. There were no conversions to open surgery and no mortality. One patient developed a gastric fistula. Mean hospital stay was $20.2 \pm 17.9$ days. After a mean follow-up of $11 \pm 12.8$ months, the mean weight, BMI, \%EWL and \%EBMIL was $81 \pm 12.1 \mathrm{~kg}, 30.3 \pm 5.1 \mathrm{~kg} / \mathrm{m}^{2}$, $59.3 \pm 31.5 \%$ and $42.3 \pm 34.5 \%$, respectively. During follow-up, one patient underwent the second step of DS.

Conclusion: Laparoscopic conversion of RYGB to SG is feasible and safe despite the development of gastric fistula. Weight loss is increased, leaving the patients in better conditions to undergo the second step of DS. 


\subsection{INTRODUCTION}

Laparoscopic Roux-en-Y gastric bypass (RYGB) is one of the most common bariatric procedures performed, and is reported to offer at mid-term a \% excess weight loss (\%EWL) of 43-68.1 \% [1-3]. Laparoscopic sleeve gastrectomy (SG) is actually becoming a popular procedure for morbid obesity [4,5], achieving a \%EWL of $48.5 \pm 8.7 \%$ after the first 4 years [5]. \%EWL after duodenal switch (DS) is reported to be of $68.9 \%$ after more than 10 years [6]. Weight loss issues (either too much weight or too little weight loss) or weight regain after initial successful weight loss, are a few of the negative aspects that can affect patients after undergoing bariatric surgery. Weight regain after RYGB can be related to technical failures or to new dietary behaviour. Technical causes of weight regain can be gastric pouch dilation, gastrojejunostomy dilation and development of gastro-gastric fistula. Patients who undergo RYGB frequently develop new alimentary habits like hyperphagia, polyphagia or sweet eating. Hyperphagia, which means volume eating (eating too large meals), will logically be treated by increasing restriction by placement of an adjustable gastric band [7-9], or a non-adjustable ring [10] around the gastric pouch. Polyphagia, which means grazing (eating too frequent meals), can logically be treated by conversion of RYGB to a malabsorptive procedure like distal RYGB (DRYGB), or DS performed in two steps. A new mixed alimentary behaviour, characterized by grossly increased caloric intake, will be treated by conversion to SG, leaving the probability of adding a significant malabsorption consequent by the second step of DS. The authors report the feasibility, safety and preliminary outcomes of laparoscopic conversion of RYGB to SG, performed as a first step of DS, for insufficient weight loss or weight regain mainly related to a new sweet-eating behaviour.

\subsection{PATIENTS AND METHODS}

Between August 2007 and November 2009, four patients (all females) benefited from laparoscopic conversion of RYGB to SG. Their mean age was $42 \pm 14.7$ (range 26-56) years. Multidisciplinary consultation, involving psychological counseling, gastroscopy and barium swallow, permitted us to rule out mental disorders (as binge eating or night eating) as well as technical failures. In addition, the nutritionist's counseling reported a new eating pattern, namely, sweet-eating. At the time of RYGB, the mean weight and body mass index (BMI) was $118.5 \pm 32.8 \mathrm{~kg}$ (range 90152 ) and $43.2 \pm 8 \mathrm{~kg} / \mathrm{m}^{2}$ (range 35-52), respectively. Two patients suffered from obesity-related co-morbidities (one from arterial hypertension and one from type 2 diabetes mellitus). The mean interval time between RYGB and conversion to SG was $36.7 \pm 15.6$ (range 17-55) months. In this interval, the extreme achieved weight, BMI, \%EWL, \% excess BMI loss (\%EBMIL) was 90.7 $\pm 32.4 \mathrm{~kg}$ (range 53130 ), $33.2 \pm 7 \mathrm{~kg} / \mathrm{m}^{2}$ (range 20.5-44), 52.9 $\pm 43.2 \%$ (range 15.5-111.7) and 
$52.5 \pm 43.4 \%$ (range 15.3-111.5), respectively. At the time of conversion, the mean weight, BMI, \%EWL and \%EBMIL was $101.7 \pm 24.7 \mathrm{~kg}$ (range 80-130), 37.3 \pm 6.6 $\mathrm{kg} / \mathrm{m}^{2}$ (range 31-44), 27.5 $\pm 11.8 \%$ (range 15.5-41.8) and $26.5 \pm 12 \%$ (range 15.341.6), respectively. The obesity-related co-morbidities were resolved in both patients. The main objective of our study was to describe the feasibility of our technique, and to document whether the conversion we used might lead to tangible effects in terms of stopping weight regain and reinducing further weight loss. Due to our study design, which features a small series of cases, we used descriptive statistical methods. We reported frequency tabulations for categorical variables and mean and standard deviation as summary parameters of the observed distributions of continuous covariables or outcomes. The main criteria of evaluation were $\% \mathrm{EWL}$ and \%EBMIL calculated on the basis of the initial weight before RYGB. The ideal weight for evaluation of \%EWL and \%EBMIL was set at a BMI of 22 $\mathrm{kg} / \mathrm{m}^{2}$. We also provide graphical representations of means of continuous outcomes after the first follow-up period and the second follow-up period. Due to the narrative nature of the study and its extremely limited sample size, no inferential statistical analysis was carried out.

\subsubsection{SURGICAL TECHNIQUE}

The patient was positioned supine with the legs and both arms in abduction (French position). The surgeon stood between the patient's legs, the person holding the camera was to the patient's right and the assistant to the patient's left. The procedure started by inserting the first 12-mm trocar, using the Hasson technique, on the mid-clavicular line in the left upper quadrant. Four additional trocars were placed under direct intraperitoneal view, usually at the same position as for the original surgery: a 5-mm trocar on the left anterior axillary line at $5 \mathrm{~cm}$ distal to the costal margin, a $10-\mathrm{mm}$ trocar at some $20 \mathrm{~cm}$ below the xyphoid process, a 12$\mathrm{mm}$ trocar on the right mid-clavicular line on the same horizontal line, and a 5-mm trocar just distal to the xyphoid process. The alimentary loop was identified, and adhesions between the parietal peritoneal sheet and the greater omentum and/or small bowel, and between the left liver lobe and the gastrojejunostomy were severed (great care was taken to prevent damage to the hepatic capsule). At this stage, both the diaphragmatic crura were clearly identified and separated from the esophagus. In case of crural diastasis or incipient hernia, hiatoplasty was performed by passing one or two figure-of-eight sutures with 1 polypropylene. The gastric remnant was separated from the adhesions with the gastric pouch and gastrojejunostomy by stapling. Green loads were used (EndoGIA, Covidien, New Haven, CT, USA) considering tissue thickness. The gastric pouch was sectioned by a firing of linear stapler green load, just proximal to the anastomosis in healthy tissue, and extreme care was taken not to devascularize the little stomach pouch, since it usually survives on just one or two branches of the left gastric artery (Fig.1). 


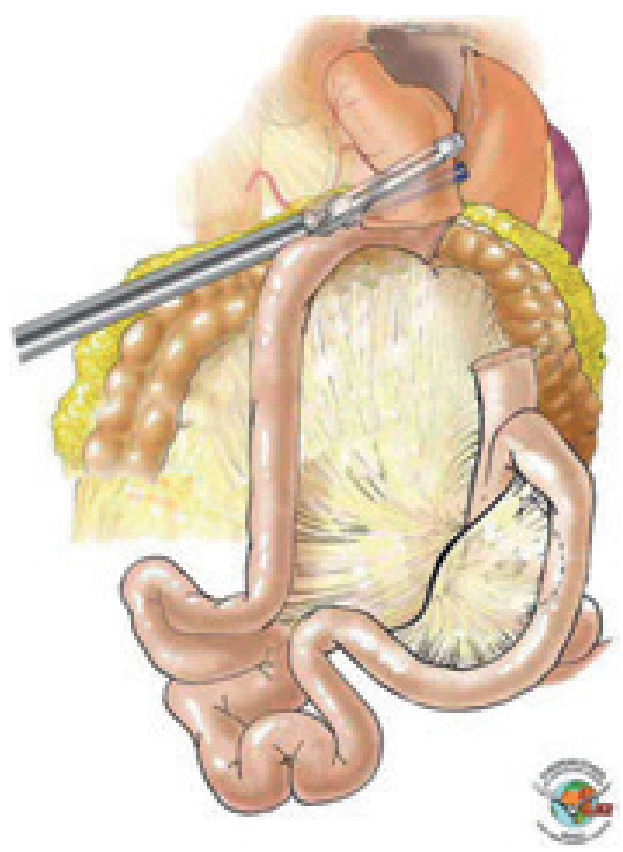

Fig.1 Dismantling of the previous gastrojejunostomy on the gastric side

The fundus of the gastric remnant was subsequently freed from top to bottom along the greater curvature, down to the level of the body of the stomach. At this level, the body of the gastric remnant was transected from lateral to medial by firings (usually two) of linear stapler green load (Fig.2).

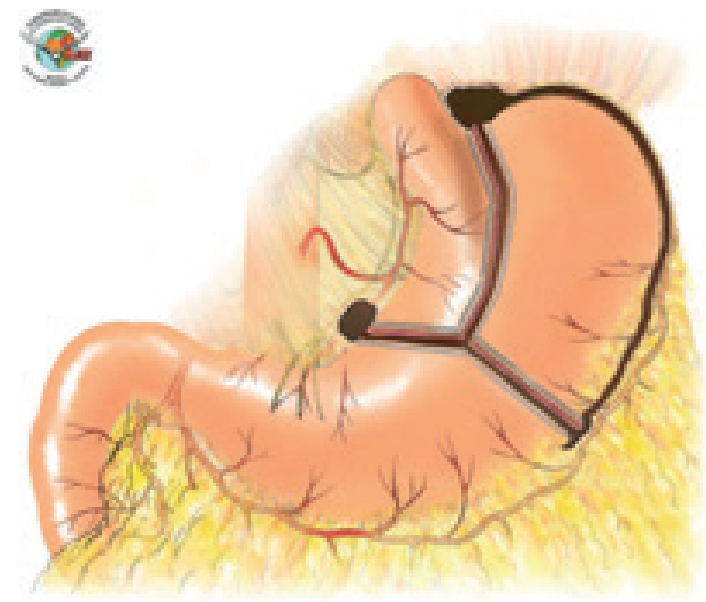

Fig.2 Fundectomy of the gastric remnant 
The gastric pouch was opened on its posterior side, and the remaining upper pole of gastric remnant on its anterior side (Fig.3),

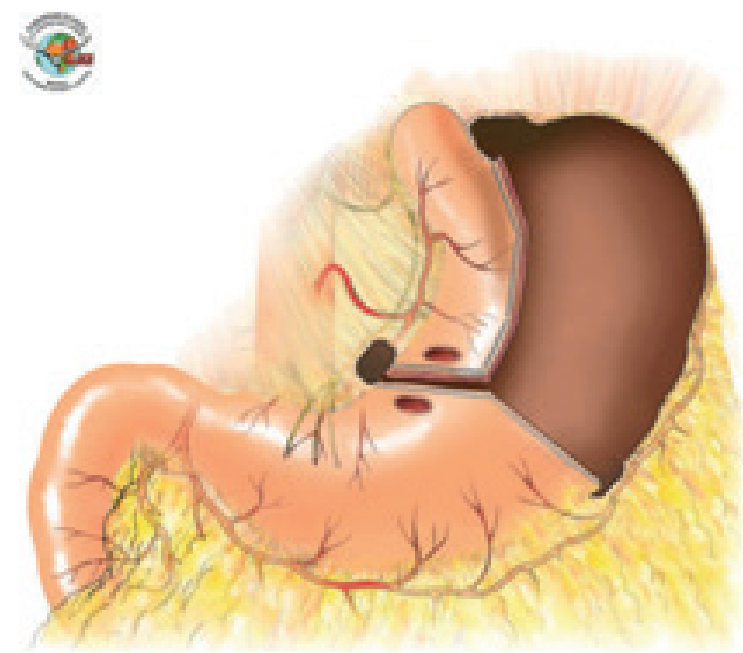

Fig.3 Opening of the gastric pouch and gastric remnant to accommodate the orogastric bougie

in order to accommodate a 34-Fr orogastric bougie, pushed down at this time by the anesthesiologist. The orogastric bougie was advanced towards the pylorus, permitting us to complete the SG, by stapling the antrum with multiple firings of linear stapler green load alongside the tube (Fig.4).

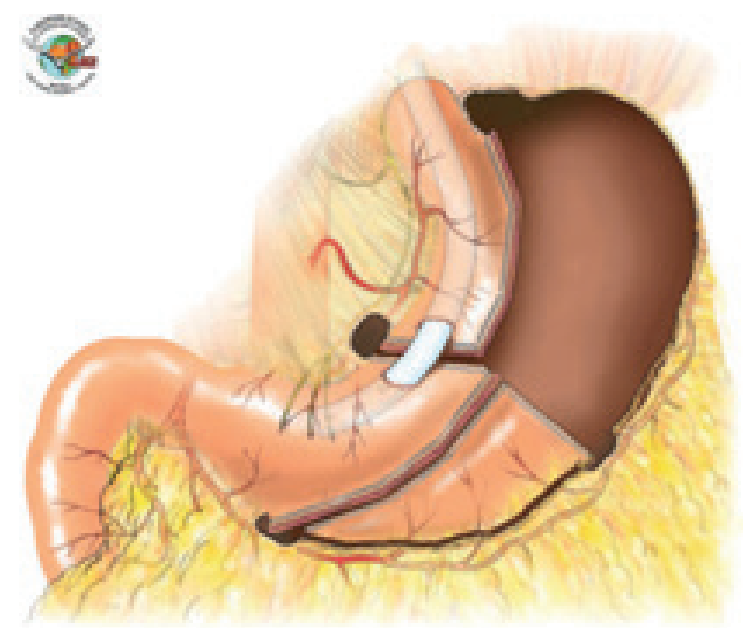

Fig.4 Resection of the gastric antrum to complete sleeve gastrectomy, after placement of an orogastric bougie and before the restoration of the gastric continuity 
After this step, the continuity of the stomach was established by a manual gastrogastrostomy between the gastric pouch and the gastric remnant, performed by two 1 polydiaxone (PDS) running sutures (Fig.5).

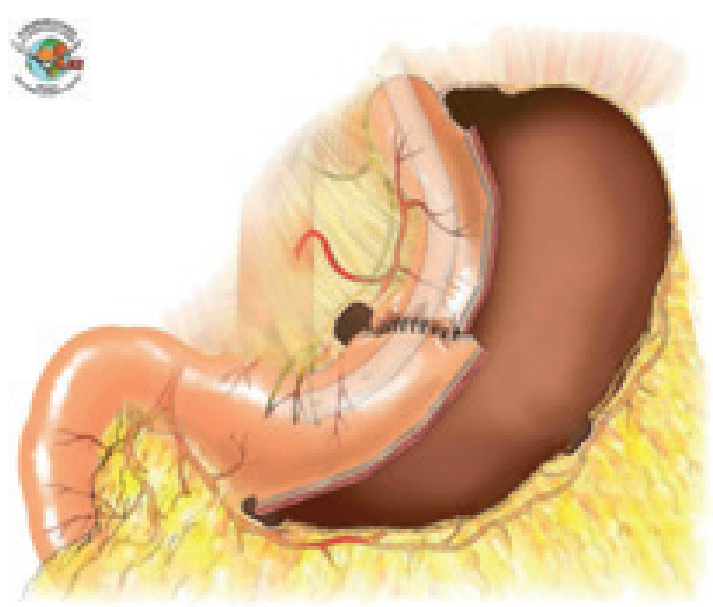

Fig.5 Restoration of the gastric continuity through a manual gastrogastrostomy between the gastric pouch and the gastric remnant

The jejunojejunostomy was localized and the alimentary, biliary and common limbs were identified. The anastomosis was dismantled by firings of linear stapler blue load, in an attempt to duplicate the original staple line and certainly not to impinge on the distal end of the alimentary limb (Fig.6).

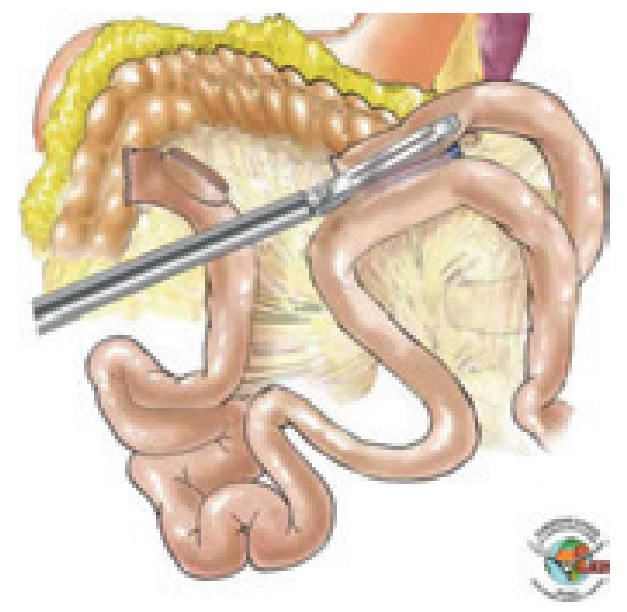

Fig.6 Dismantling of the previous jejunojejunostomy (more on the biliary limb) 
A linear stapler white load anastomosed the proximal end of the alimentary limb and the distal end of the biliary limb, and the enterotomy was closed by two $2 / 0$ PDS running sutures. The blind loop of the biliary and alimentary limbs was resected after completion of the new jejunojejunostomy (Fig.7).

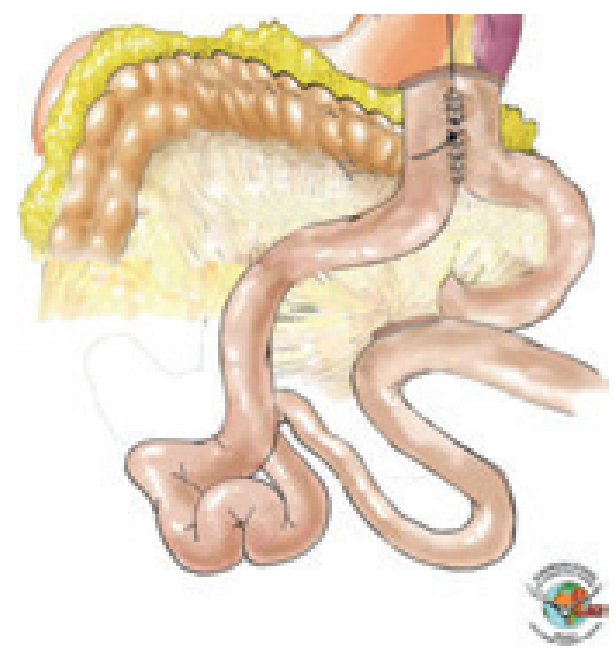

Fig.7 Restoration of the small bowel continuity through a new jejunojejunostomy, performed between the previous alimentary proximal end and the previous biliary distal end

The mesenteric window, created at the time of RYGB, was closed using purse string of 1 polypropylene, thereby re-establishing the original anatomy. The gastrointestinal continuity was checked by insufflation of compressed air through the orogastric bougie. Two drains were left in the abdominal cavity near the gastrogastrostomy and the body of the stomach. The specimen was retrieved from the abdomen by enlarging the left 12-mm upper quadrant trocar, which was subsequently closed in layers. A methylene blue swallow was realized on the first postoperative day, and if negative a liquid diet was started on the second postoperative day. The patient was discharged on a pureed diet on the fifth postoperative day, and a normal diet was started at the $3^{\text {rd }}$ postoperative month.

\subsection{RESULTS}

The mean operative time was $233.7 \pm 46.4$ min (range 195-300). There were no conversions to open surgery and no mortality. In all patients, gastric continuity was fashioned with a manual anastomosis and small bowel continuity with a sideto-side linear mechanical. One patient (25\%) developed a fistula at the site of the gastrogastrostomy. Mean hospital stay was $20.2 \pm 17.9$ days (range 5-40). All patients were followed up by office visits, and after a mean follow-up of $11 \pm 12.8$ 
(range 3-30) months, the mean weight, BMI, \%EWL and \%EBMIL was $81 \pm 12.1 \mathrm{~kg}$ (range 63-90), 30.3 $\pm 5.1 \mathrm{~kg} / \mathrm{m}^{2}$ (range $24.5-37$ ), $59.3 \pm 31.5 \%$ (range $12.9-82.3$ ) and $42.3 \pm 34.5 \%$ (range 6.2-80.7), respectively (Fig.8). During this follow-up, one patient underwent the second step of DS.

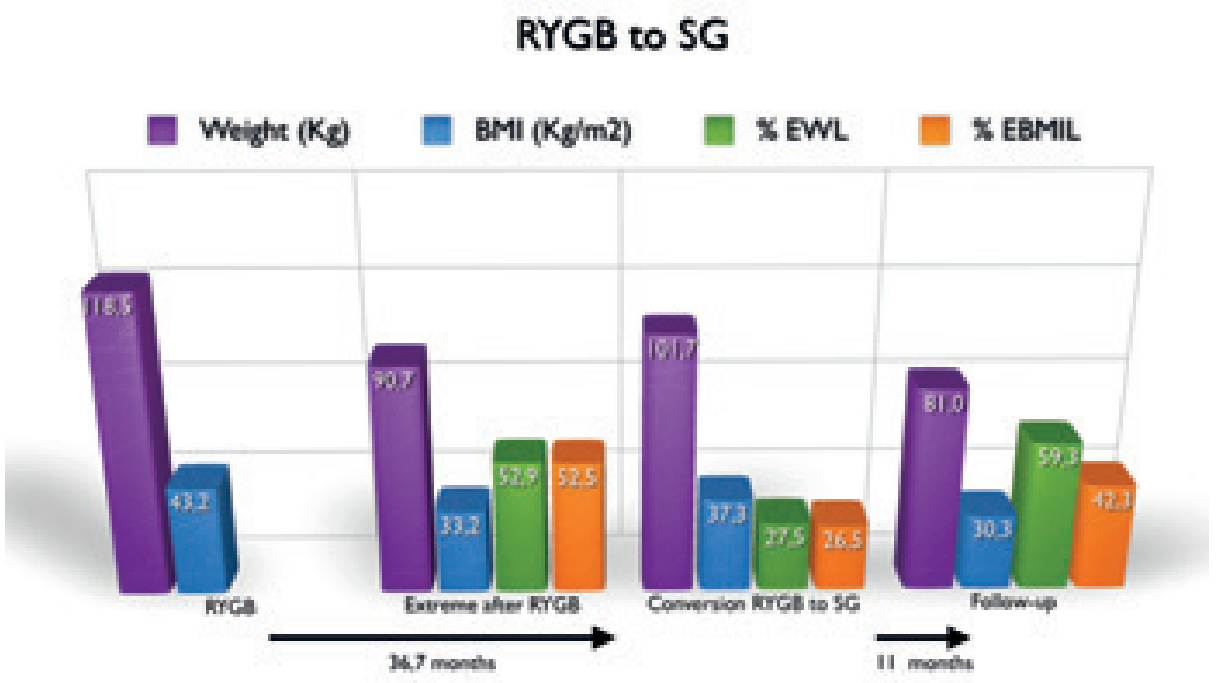

Fig.8 Comparison of weight, BMI, \%EWL, \%EBMIL at RYGB, at extreme values before the conversion to $\mathrm{SG}$, at the conversion to $\mathrm{SG}$, and at followup (mean values)

\subsection{DISCUSSION}

Obese patients are strongly encouraged to undergo follow-up by multidisciplinary counseling, involving psychologist, nutritionist and surgeon. In the years after surgery, patients often deny a newly developed eating behaviour. In case of insufficient weight loss or weight regain, the culprit is, more often than not, abuse of sweets. Patients with RYGB consuming large amount of fast carbohydrates can initially be confronted with dumping syndrome, which is considered helpful in an effort to lose weight [11]. This symptom, if at all present, usually disappears with time because of body adjustment. Abuse of sweets can be confirmed in laboratory findings with increased levels of cholesterol, especially LDL cholesterol [12] and nonalcoholic fatty liver disease [13]. Patients with this new behaviour will no be longer deterred from eating sugars, but usually become clinically symptomatic (fatigue, drowsiness, neurologic symptoms). The first treatment for this condition is obviously trying to correct the unhealthy dietary change, but if these measures do not suffice, medical treatment with insulin-modulating agents like acarbose or glyclaside should be tried. Surgical options are aiming at delaying gastric pouch emptying like placement of the Fobi ring around the gastric pouch [14] or gastric 
pouch restriction by endolumenal approach [15]. The treatment of sugar consumption-linked symptoms is essential since this behaviour can bring the patients at risk of developing conditions caused by excessive insulin production or improved insulin sensitivity [16]. In extreme cases, this latter condition can lead to symptomatic hyper-insulinemic hypoglycemia [17], or in contrast, because of combustion of insulin stocks, to insulinopenic diabetes. Finally, the hyperinsulinemic status is reported to possibly evolves into beta-cell hyperplasia [18] and even nesidioblastoma [19]. Hence, patients with RYGB presenting insufficient weight loss or weight regain mainly due to a new sweet eating pattern who do not respond to dietary and medical treatment, need to undergo another operation. A valuable option is to convert the procedure of RYGB to a restrictive procedure, which does not bypass the duodenum [20,21]. Symptomatic dumping syndrome without postprandial hypoglycemia needs to be approached differently. This condition has to be treated by dietary efforts in close consultation with a nutritionist, and medical treatment with serotonin antagonists or somatostatin analogs can be attempted. In case of unsuccessful results and/or persisting symptomatic dumping syndrome, surgical procedures aiming at delaying gastric pouch emptying $[14,15]$ or conversion of RYGB to the original anatomy can be proposed [22]. This latter option is obviously associated to the risk of weight regain, which again can be resolved with the next malabsorptive procedure. It is our belief that during revision of RYGB to $\mathrm{SG}$, the sequence of the different steps performed for the restoration of the gastric continuity is critical. The gastric pouch and gastrojejunostomy have to be exposed completely, in preparation for the gastrogastrostomy. In order to perform SG satisfactorily, the gastric remnant needs be resected at the level of the fundus and body, as well as at the antrum after the placement of the orogastric bougie towards the pylorus. These steps allow performing a narrow SG, similar to SG performed as a primary bariatric procedure. We prefer to fashion the gastrogastrostomy manually, because linear anastomosis can be difficult when the size of the pouch is small, and circular anastomosis can be complicated by stenosis as reported in $25 \%$ of patients [23]. Early complications such as fistula and stenosis at the gastrogastrostomy due to ischemia, remain a constant worry. One of our patients developed a gastric fistula, probably related to poor vascularization of the gastric pouch. Hence, it is mandatory to maximally preserve the upper branches of the left gastric artery at the cranial part of the lesser curve. Our patient developed a low output leak, and with consequent conservative treatment, healing was achieved after 40 days. In case of high output leak, the preferred treatment would have been placement of endoscopic stent [24]. However in case of unstable and septic patients, laparoscopic lavage and drainage will be required. In contrast to Parikh et al. [23], we did not record complications as stenosis during follow-up in this selected series of patients. Hospital stay for our patients is longer than reported elsewhere [23], which reflects early complications like gastric fistula in one of our patients. Operative time obviously depends on the time spent to perform the necessary adhesioly- 
sis in the different steps of the resection of the gastric remnant and the restoration of gastric continuity. In case of too dense adhesions, a conversion to open surgery may be preferable [23]. Small bowel restoration appears to demand significantly less time than the other steps. This can explain why our mean operative time approaches more the $255 \mathrm{~min}$ reported in one-step DS, than the total of $303 \mathrm{~min}$ achieved in the two-step DS [23]. In this limited series of patients, substantial weight loss followed the conversion to SG. This is most likely due to the enhanced gastric restriction. In our four patients we recorded, in the same mean follow-up time of 11 months, a mean \%EWL of 59.3\%. This is higher than the $57.4 \%$ reported in the four patients who underwent two-step DS, but lower than the $68.7 \%$ reported in six patients who underwent one-step DS [23]. It is our policy to perform the conversion of RYGB to DS in two steps, not only to reduce morbidity and mortality $[25,26]$, but also because we adhere to the Scopinaro's principle of not combining restriction and malabsorption at the same time [27,28]. During follow-up, one of our patients (25\%) already has benefited from the second step of DS. After a follow-up of 14 months after DS, the patient experienced a weight loss of $20 \mathrm{~kg}$, and a BMI decrease to $27.3 \mathrm{~kg} / \mathrm{m}^{2}$. Obviously, the increased weight loss with DS is related to the malabsorptive process, which is more important than with RYGB $[29,30]$. In conclusion, laparoscopic conversion of RYGB to SG is feasible and safe. The appearance of gastric fistula is a definite risk. Weight loss is increased, which leaves the patients in better conditions to undergo the second step of DS.

\subsection{REFERENCES}

1. Pories W, Swanson M, MacDonald K. Who would have thought it? An operation to be the most effective therapy for adult-onset diabetes mellitus. Ann Surg 1995;222:339-50

2. Jones K. Experience with the Roux-en-Y gastric bypass, and commentary on current trends. Obes Surg 2000;10:183-5

3. Christou NV, Look D, MacLean LD. Weight gain after short- and long-limb gastric bypass in patients followed for longer than 10 years. Ann Surg 2006;244:734-40

4. Deitel M, Crosby RD, Gagner M. The first international consensus summit for sleeve gastrectomy (SG), New York City, October 25-27, 2007. Obes Surg 2008;18:487-96

5. Gagner M, Deitel M, Kalberer TL, Erickson AL, Crosby RD. The second international consensus summit for sleeve gastrectomy, March 19-21, 2009. Surg Obes Relat Dis 2009;5:476-85

6. Marceau P, Biron S, Hould FS, et al. Duodenal switch: long-term results. Obes Surg 2007;17:142130

7. Bessler M, Daud A, Digiorgi MF, et al. Adjustable gastric banding as revisional bariatric procedure after failed gastric bypass-intermediate results. Surg Obes Relat Dis 2010;6:31-5

8. Gobble RM, Parikh MS, Greives MR, Ren CJ, Fielding GA. Gastric banding as a savage procedure for patients with weight loss failure after Roux-en-Y gastric bypass. Surg Endosc 2008;22:1019-22

9. Chin PL, Ali M, Francis K, LePort PC. Adjustable gastric band placed around gastric bypass pouch as revision operation for failed gastric bypass. Surg Obes Relat Dis 2009;5:38-42

10. Dapri G, Cadière GB, Himpens J. Laparoscopic placement of non-adjustable silicone ring for weight regain after Roux-en-Y gastric bypass. Obes Surg 2009;19:650-4 
11. Sugerman HJ, Londrey GL, Kellum JM, et al. Weight loss with vertical banded gastroplasty and Roux-en-Y gastric bypass for morbid obesity with selective versus random assignment. Am J Surg 1989;157:93-102

12. Enjoji M, Nakamuta M. Is the control of dietary cholesterol intake sufficiently effective to ameliorate nonalcoholic fatty liver disease? World J Gastroenterol 2010;21:800-3

13. de Piano A, Tock L, Carnier J, et al. The role of nutritional profile in the orexigenic neuropeptide secretion in nonalcoholic fatty liver disease obese adolescents. Eur J Gastroenterol Hepatol 2010;22:557-63

14. Z'graggen K, Guweidhi A, Steffen R, et al. Severe recurrent hypoglicemia after gastric bypass. Obes Surg 2008;18:981-8

15. Fernandez-Esparrach G, Lautz DB, Thompson CC. Peroral endoscopic anastomotic reduction improves intractable dumping syndrome in Roux-en-Y gastric bypass patients. Surg Obes Relat Dis 2010;6:36-40

16. Bikman BT, Zheng D, Pories WJ, et al. Mechanism for improved insulin sensitivity after gastric bypass surgery. J Clin Endocrinol Metab 2008;93:4656-63

17. Bantle JP, Ikramuddin S, Kellogg TA, Buchwald H. Hyper-insulinemic hypoglycemia developing late after gastric bypass. Obes Surg 2007;17:592-4

18. Patti ME, McMahon G, Mun EC, et al. Severe hypoglycemia post-gastric bypass requiring partial pancreatectomy: evidence for inappropriate insulin secretion and pancreatic islet hyperplasia. Diabetologia 2005;48:2236-40

19. Service GJ, Thompson GB, Service FJ, Andrews JC, Collazo-Clavell ML, Lloyd RV. Hyperinsulinemic hypoglycemia with nesidioblastosis after gastric-bypass surgery. N Engl J Med 2005;353:249-54

20. Dirksen C, Hansen DL, Madsbad S, et al. Postprandial diabetic glucose tolerance is normalized by gastric bypass feeding as opposed to gastric feeding and is associated with exaggerated GLP-1 secretion: a case report. Diab Care 2010;33:375-7

21. McLaughlin T, Peck M, Holst J, Deacon C. Reversible hyper-insulinemic hypoglycemia after gastric bypass: a consequence of altered nutrient delivery. J Clin Endocrinol Metab 2010;95:1851-5

22. Dapri G, Cadière GB, Himpens J. Laparoscopic reconversion of Roux-en-Y gastric bypass to original anatomy: technique and preliminary outcomes. Obes Surg 2011;21:1289-5

23. Parikh M, Pomp A, Gagner M. Laparoscopic conversion of failed gastric bypass to duodenal switch: technical considerations and preliminary outcomes. Surg Obes Relat Dis 2007;3:611-8

24. Thaler K. Treatment of leaks and other bariatric complications with endoluminal stents. J Gastrointest Surg 2009;13:1567-9

25. Silecchia G, Boru C, Pecchi a A, et al . Effectiveness of laparoscopic sleeve gastrectomy (first stage of biliopancreatic diversion with duodenal switch) on co-morbidities in super-obese high-risk patients. Obes Surg 2006;16:1138-44

26. Iannelli A, Schneck AS, Dahman M, Negri C, Gugenheim J. Two- step laparoscopic duodenal switch for superobesity: a feasibility study. Surg Endosc 2009;23:2385-9

27. Scopinaro N, Adami GF, Marinari GM, Traverso E, Papadia F, Camerini G. Biliopancreatic diversion: two decades of experience. In: Deitel M, Cowan GSM, editors. Update: surgery for the morbidly obese patient. Toronto: FD-Communications Inc.; 2000. p. 227-58

28. Scopinaro N, Adami GF, Marinari GM, et al. Biliopancreatic diversion. World J Surg 1998;22:93646

29. Sovik TT, Taha 0, Aasheim ET, et al. Randomized clinical trial of laparoscopic gastric bypass versus laparoscopic duodenal switch for superobesity. Br J Surg 2010;97:160-6

30. Prachand VN, Davee RT, Alverdy JC. Duodenal switch provides superior weight loss in the superobese $\left(\mathrm{BMI}>\right.$ or $=50 \mathrm{~kg} / \mathrm{m}^{2}$ ) compared with gastric bypass. Ann Surg 2006;244:611-9 



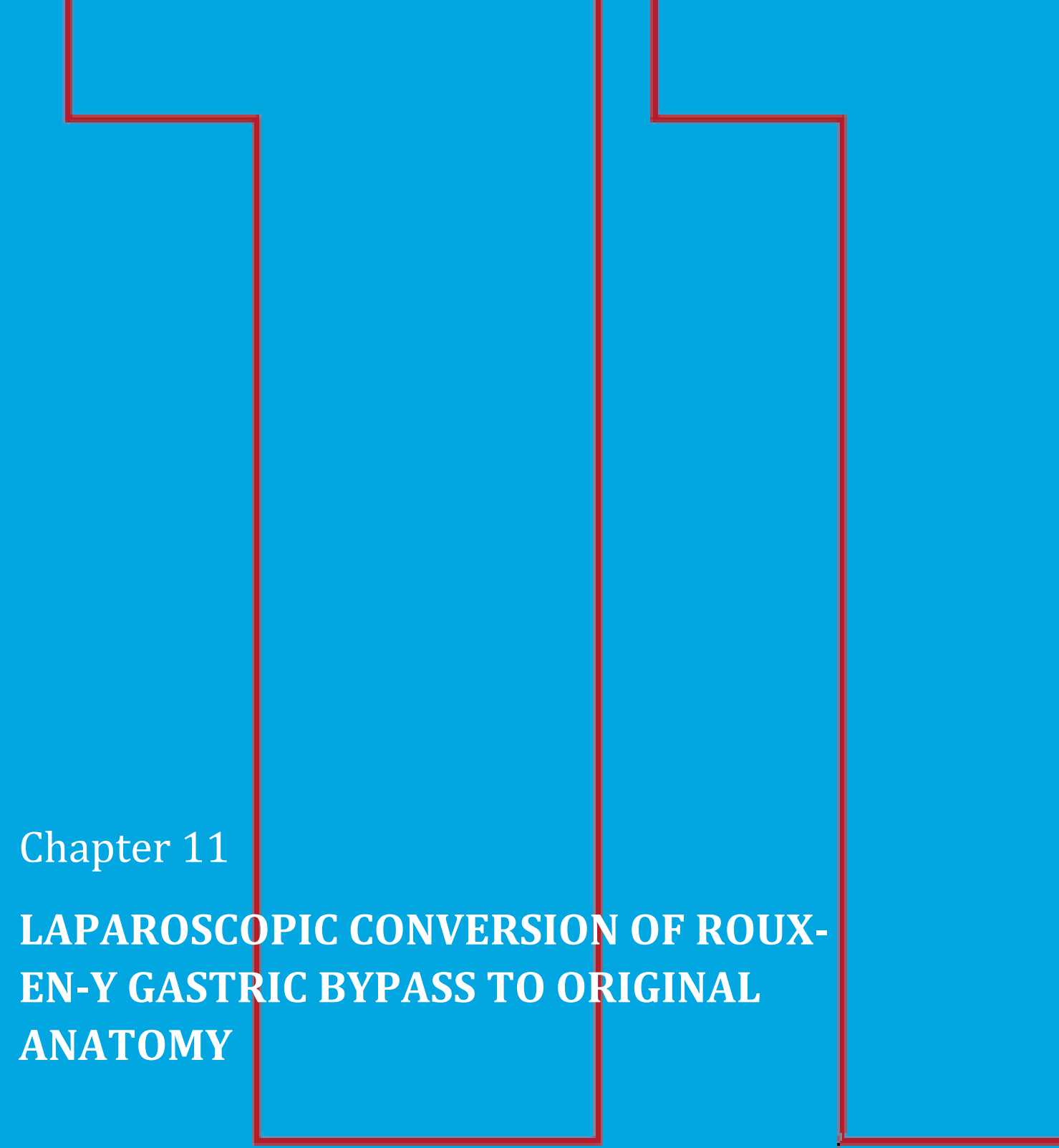

Dapri G, Cadière GB, Himpens J

Obesity Surgery 2011;21(8):1289-1295 



\subsection{ABSTRACT}

Background: Laparoscopic Roux-en-Y gastric bypass (RYGB) is one of the most common bariatric procedures performed. Dumping syndrome, intolerance to RYGB-induced restriction, and weight loss issues are possible problems bariatric surgeons are confronted with. This study reports the feasibility, safety, and outcomes of laparoscopic reconversion of RYGB to original anatomy (OA) as treatment of these complications.

Patients and Methods: Between January 2005 and April 2008, eight patients benefited from laparoscopic reconversion of RYGB to OA. Reason was dumping syndrome without postprandial hypoglycemia (three), intolerance to RYGBinduced restriction (three), too much (one) and too little weight loss (one). Mean weight and body mass index (BMI) at RYGB were $104.7 \pm 19.3 \mathrm{~kg}$ and $38.7 \pm 6 \mathrm{~kg} / \mathrm{m}^{2}$, respectively. Four patients suffered of obesity co-morbidities. Mean time between RYGB and reconversion was $21 \pm 18.8$ months. Mean weight, BMI, and \% excess weight loss at reconversion was $66.8 \pm 21.7 \mathrm{~kg}, 20.1 \pm 7 \mathrm{~kg} / \mathrm{m}^{2}$, and $23.7 \pm 55 \%$, respectively. The procedure involved dismantling both gastrojejunostomy and jejunojejunostomy, reanastomosing gastric pouch to gastric remnant, and proximal alimentary limb end to distal biliary limb end.

Results: Mean operative time was $132.2 \pm 29.5 \mathrm{~min}$. There were no conversions to open surgery and no early complications. Gastrogastrostomy was performed manually (four) and by linear stapler (four), and jejunojejunostomy by linear stapler (eight). Mean hospital stay was $7.7 \pm 3.5$ days. After a mean follow-up of $18.3 \pm 9.2$ months, two patients continued to further lose weight, two patients maintained the same weight, and four patients presented weight regain. Gastroesophageal reflux disease appeared in three patients.

Conclusion: Laparoscopic reconversion of RYGB to OA is feasible and safe. Dumping syndrome and intolerance to RYGB-induced restriction are resolved. The anatomy remains one of the aspects besides nutritional and psychological factors in cases of reconversion for weight issues. 


\subsection{INTRODUCTION}

Roux-en-Y gastric bypass (RYGB) and adjustable gastric banding are actually the two most commonly bariatric procedures performed. The procedure of RYGB leads to a \% excess weight loss (\%EWL) reported at medium term of 43-68.1\% [1-3], with improvement of almost all conditions related to obesity [4]. However, this procedure needs a multidisciplinary follow-up because it may lead to some serious problems. One problem associated with RYGB is dumping syndrome, which is clinically characterized by postprandial sweating, flushing, dizziness, weakness, tachycardia, palpitations, diaphoresis, and lassitude. This can be attributed to the rapid entrance of hyperosmotic foods to the jejunum which, according to one hypothesis, causes a fall in blood volume and significant sympathetic stimulation from various pressoreceptors [5]. It is also related to the effect of hyperosmolar fluid on the argentaffin cells in the small intestinal mucosa, causing release of vasoactive serotonin and vasomotor effects. A third explanation of the syndrome is hypoglycemia provoked by excessive intake of rapid sugars or foods with high glycemic index, which because increased insulin sensitivity induces abrupt glucose fluctuations in the blood [6]. In bariatric surgery the dumping syndrome has been considered as a beneficial feature because patients learned to avoid calorie-dense foods and ate less at one time [7]. Despite adequate dietary counseling (small meals, little carbohydrates), patients with RYGB still can fail to comply with restriction caused by the procedure, with subsequent excessive dumping, vomiting episodes, and abdominal pain. Another possible problem in patients after RYGB is related to weight loss, either too much or too little. The precise mechanisms whereby RYGB achieves sustained weight loss remain unknown, but many of the changes in gastrointestinal hormones, adipokines, and cytokines as well as in hypothalamic neuropeptides and neurotransmitters resemble the changes observed in cachexia rat model [8]. Hence, in humans, RYGB triggers a catabolic state responsible for loss of appetite and prolonged body weight reduction. The opposite situation of unsuccessful weight loss after RYGB can occur with poor dietary compliance, resulting in high caloric intake. This study reports the feasibility, safety, and outcomes of laparoscopic reconversion of RYGB to original anatomy (OA) in patients presenting complications as dumping syndrome, intolerance to dietary restriction due to procedure, and weight loss issues.

\subsection{PATIENTS AND METHODS}

Between January 2005 and April 2008, eight patients (all females) previously submitted to laparoscopic RYGB benefitted from laparoscopic reconversion to OA. Mean age was $44 \pm 12.4$ years (range $24-59$ ). RYGB was performed in all the patients with an alimentary limb of $150 \mathrm{~cm}$, in an antecolic antegastric position. Reason of reconversion was exaggerated dumping syndrome without postprandial 
hypoglycemia (three), intolerance to RYGB-induced restriction (three), too much weight loss (one), and too little weight loss (one) (Tab.1).

Table I Reason of reconversion of RYGB to OA

\begin{tabular}{ll}
\hline Number & Reason of reconversion \\
\hline 1 & Inolelerance to RYGB-inducod nestriction \\
2 & Too little weight loss \\
3 & Dumping syndrome \\
4 & Intolerance to RYGB-induced restriction \\
5 & Dumping syndrome \\
6 & Dumping syndrome \\
7 & Too much weight loss \\
8 & Intolerance to RYGB-induced restriction \\
\hline
\end{tabular}

Mean weight and body mass index (BMI) at the time of RYGB were $104.7 \pm 19.3 \mathrm{~kg}$ (range 73-131) and $38.7 \pm 6 \mathrm{~kg} / \mathrm{m}^{2}$ (range 30-46), respectively. Four patients suffered of obesity-related co-morbidities. Mean interval time between RYGB and reconversion to $\mathrm{OA}$ was $21 \pm 18.8$ months (range 7-60). Mean weight, BMI, and $\% E W L$ at the time of the reconversion were $66.8 \pm 21.7 \mathrm{~kg}$ (range 48-110), 20.1 \pm 7 $\mathrm{kg} / \mathrm{m}^{2}$ (range 16.6-38), and 23.7 $\pm 55 \%$ (range 0-122.3), respectively. Multidisciplinary consultation, involving nutritionist's and psychologist's counseling, blood tests, gastroscopy, and barium swallow, permitted to rule out the presence of technical failures of the Roux-en-Y construction in all the patients and to exclude the presence of hyperinsulinemic hypoglycemia in three patients with dumping syndrome. In these patients, the lab work failed to show fasting hypoglycemia, elevating insulin and C-peptide levels and cholesterol values within acceptable limits. One patient suffered of a dietary behavior (sweet eating), and OA was offered as first stage for a subsequent new bariatric procedure, in accordance with the patient's preference. Four other patients were psychologically labeled as loss of control. Our study had a main objective to describe our experience with the reconversion technique; therefore, our analysis was descriptive in nature and we did not have, at study start, formulated any formal hypothesis test to conduct and we did not perform any a priori sample size estimation. Furthermore, despite 3 years of accrual, sample size remained limited and our analysis used only descriptive methods. We used as main criteria of evaluation the \%EWL, which was defined as the relative reduction of the weight in excess, the weight in excess being calculated on the basis of an ideal weight corresponding to a BMI of $22 \mathrm{~kg} / \mathrm{m}^{2}$. The reference weight for the calculation of \%EWL is the weight before the procedure of RYGB. For categorical variables, we reported frequencies and for continuous variables, we used mean and standard deviation as position summary parameter and dispersion summary parameter, respectively. 


\subsubsection{SURGICAL TECHNIQUE}

The patient was positioned supine with the legs and with both arms in abduction (French position). The surgeon stood between the patient's legs, the person holding the camera was to the patient's right and the assistant to the patient's left. The procedure started with the insertion in the abdomen of the first 12-mm trocar, using the Hasson technique, on the left upper quadrant mid-clavicular line. Four additional trocars were placed under view, usually at the same position as the original surgery, mostly without any further dissection: a 5-mm trocar on the left anterior axillary line at $5 \mathrm{~cm}$ distal to the costal margin, a $10-\mathrm{mm}$ trocar at some 20 $\mathrm{cm}$ below the xyphoid process, a 12-mm trocar on the right mid-clavicular line on the same horizontal line, and a 5-mm trocar just distal to the xyphoid process. The alimentary loop was identified and the adhesions between the peritoneal sheet and greater omentum and/or small bowel, and between the left liver lobe and the gastrojejunostomy were severed, trying not to damage the hepatic capsule. The stomach was sectioned by a firing of linear stapler green load (EndoGIA, Covidien, New Haven, CT, USA) just proximal to the anastomosis, in healthy tissue, care being taken not to devascularize the little stomach pouch, which usually survives on one or two branches of the left gastric artery (Fig.1).

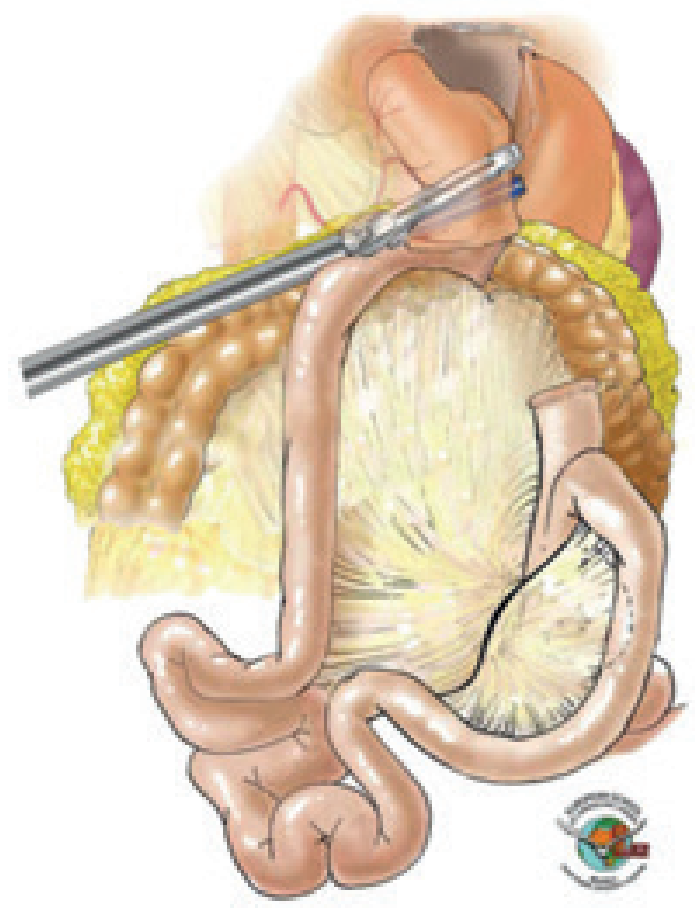

Fig.1 Dismantling of the previous gastrojejunostomy on the gastric side 
Subsequent dissection of the gastric remnant was kept minimal just sufficiently so as to allow linear stapler or manual suturing technique. The linear stapled gastrogastrostomy was performed with one firing of blue load, and introduction openings were closed with two 1 polydiaxone (PDS) running sutures. The manual gastrogastrostomy was fashioned in one layer using two 1 PDS running sutures (Fig.2).

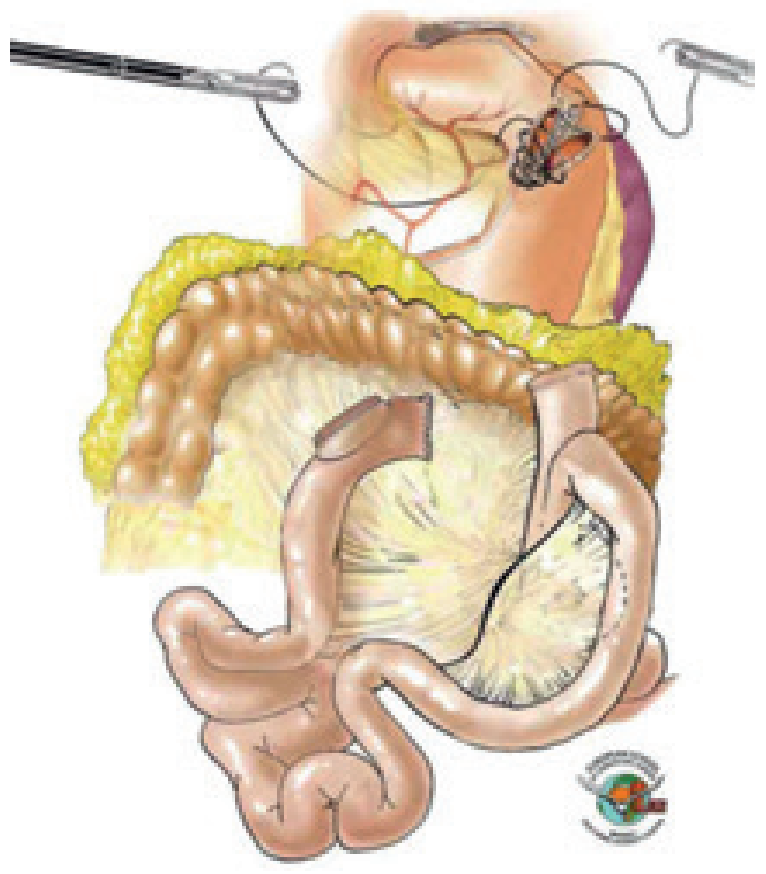

Fig.2 Restoration of the gastric continuity through a manual gastrogastrostomy between the gastric pouch and the gastric remnant

The jejunojejunostomy was localized and the three components (alimentary, biliary, and common limbs) were identified. The anastomosis was dismantled by firings of linear stapler blue load, more of which were required on the distal end of the biliary limb than of the distal end of the alimentary limb (Fig.3).

The proximal end of the alimentary limb and the distal end of the biliary limb were then anastomosed by a linear stapler white load, and the enterotomy was closed by two 2/0 PDS running sutures (Fig.4). 


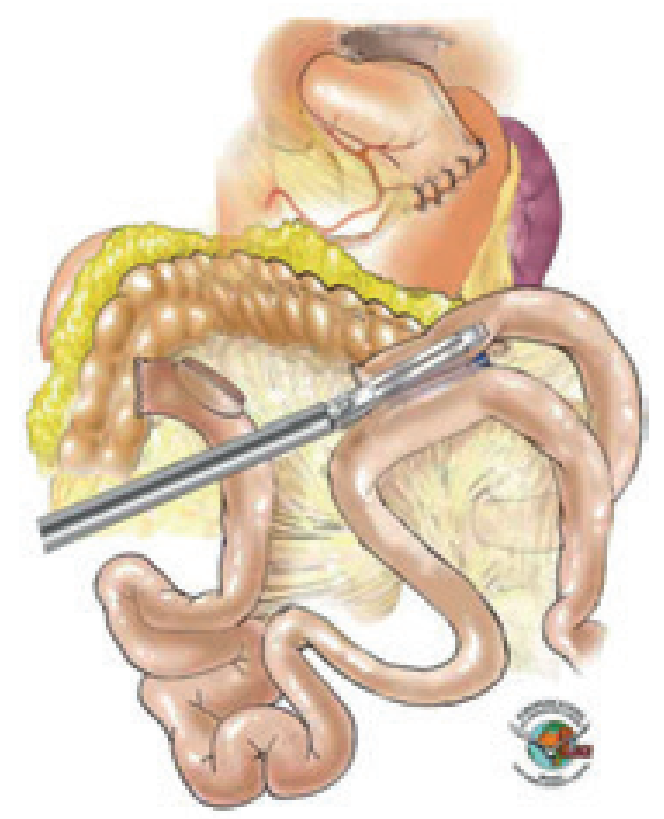

Fig.3 Dismantling of the previous jejunojejunostomy (more on the biliary limb)

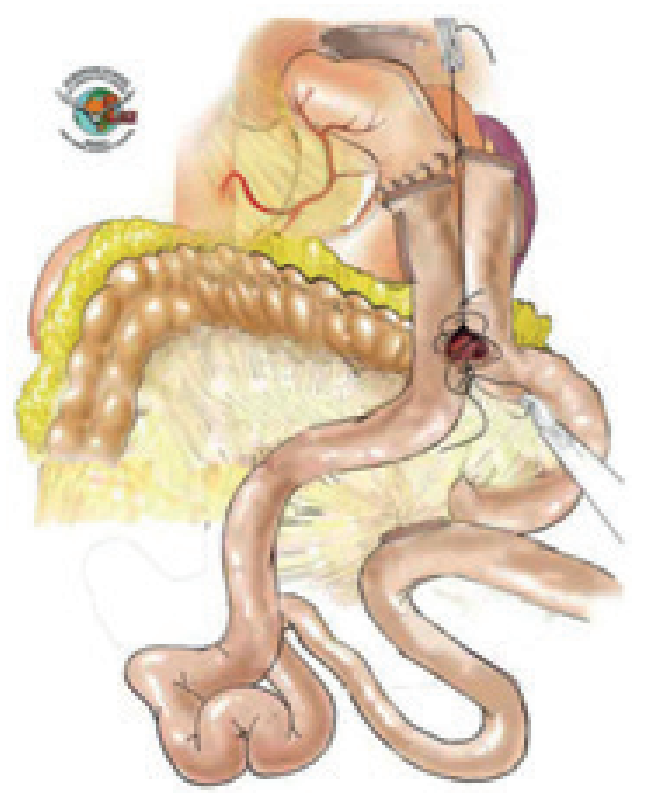

Fig.4 Restoration of the small bowel continuity through a new jejunojejunostomy, performed between the previous alimentary proximal end, and the previous biliary distal end 
The blind loop of these latter both limbs was resected after the jejunojejunostomy (Fig.5).

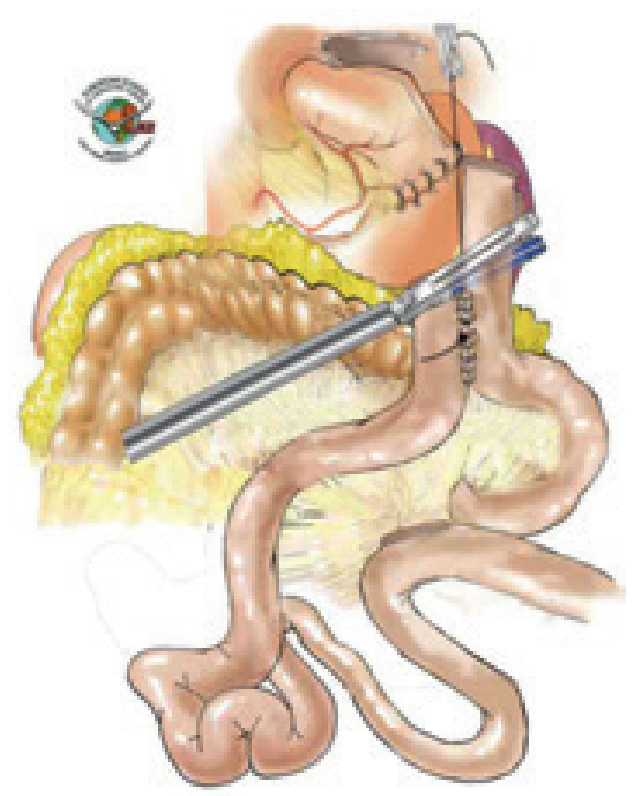

Fig.5 Sectioning at the new jejunojejunostomy of both extremities of previous alimentary proximal end, and previous biliary distal end

The mesenteric window, created at the time of RYGB, was closed hereby reestablishing the $\mathrm{OA}$, using a non-absorbable purse string suture (1polypropylene). The gastrointestinal continuity was checked by insufflation of compressed air through the orogastric bougie. A drain was left in the abdominal cavity near the gastrogastrostomy. The specimen wasretrieved from the abdomen by enlarging the left 12$\mathrm{mm}$ upper quadrant trocar, which was subsequently closed in layers. A methylene blue swallow was realized on the first postoperative day, and if negative a liquid diet was started on second postoperative day. The patient was usually discharged on a pureed diet on the fifth postoperative day, and a normal diet was started after the first office visit at the fourth postoperative week.

\subsection{RESULTS}

Mean operative time was 132.2 \pm 29.5 min (range 95-180). There were no conversions to open surgery, no mortality and no early complications. Gastrogastrostomy was performed manually (four) and by linear stapler (four) and jejunojejunostomy 
by linear stapler in all patients. Mean hospital stay was $7.7 \pm 3.5$ days (range 5-13) (Tab.2).

Table 2 Type of gastrogastrostomy and cutcomes

\begin{tabular}{llcc}
\hline Number & Gastrogastrostony & $\begin{array}{c}\text { Operative } \\
\text { time (min) }\end{array}$ & $\begin{array}{c}\text { Hospital } \\
\text { stay (days) }\end{array}$ \\
\hline 1 & Linear stapler & 120 & 5 \\
2 & Manual & 120 & 5 \\
3 & Manual & 95 & 5 \\
4 & Linear stapler & 120 & 6 \\
5 & Manual & 165 & 5 \\
6 & Linear stapler & 180 & 12 \\
7 & Manual & 108 & 11 \\
8 & Linear stapler & 150 & 13 \\
Mean & & 132.2 & 7.7 \\
SD & & 29.5 & 3.5 \\
\hline
\end{tabular}

All patients were followed up by office visits, and after a mean follow-up of $18.3 \pm 9.2$ months (range 7-36), two patients $(25 \%)$ continued to lose weight (13 and $35 \mathrm{~kg}$ ), with a drop in BMI to 27 and $25.5 \mathrm{~kg} / \mathrm{m}^{2}$, respectively; two patients (25\%) maintained the same weight as at the time of reconversion; and four patients (50\%) presented a mean weight regain of $20.2 \pm 8.8 \mathrm{~kg}$ (range 7-32), with a mean increased BMI to $28 \pm 0.7 \mathrm{~kg} / \mathrm{m}^{2}$ (range 25-31.5) (Tab.3). During this followup time, appearance of gastroesophageal reflux disease (GERD) was recorded in three out of eight patients (37.5\%).

\begin{tabular}{|c|c|c|c|c|c|c|c|c|c|c|c|}
\hline \multirow[t]{2}{*}{ Number } & \multicolumn{2}{|l|}{ RYCo } & \multirow{2}{*}{$\begin{array}{l}\text { rins afer } \\
\text { Rrycill } \\
\text { (movethd) }\end{array}$} & \multicolumn{3}{|c|}{ Rrowevernion } & \multirow{2}{*}{$\begin{array}{l}\text { Thims affer resocronise } \\
\text { (moniths) }\end{array}$} & \multicolumn{3}{|c|}{ Followesp } & \\
\hline & $\begin{array}{l}\text { Weights } \\
\text { (kg) }\end{array}$ & $\begin{array}{l}\mathrm{BMI} \alpha_{\mathrm{f}} \\
\left.\mathrm{m}^{2}\right)\end{array}$ & & $\begin{array}{l}\text { astiplu } \\
\text { (agi) }\end{array}$ & $\begin{array}{l}\text { Butl } \mathrm{k}= \\
\left.\mathrm{m}^{2}\right)\end{array}$ & $\begin{array}{l}\text { \& } \\
\text { EWI. }\end{array}$ & & $\begin{array}{l}\text { ustiple } \\
\text { (ag) }\end{array}$ & $\begin{array}{l}\text { Bull } k \text { te } \\
\left.\mathrm{m}^{2}\right)\end{array}$ & $\begin{array}{l}\% \\
\text { EW1. }\end{array}$ & \\
\hline 3 & 110 & 46 & 7 & 64 & 27 & 978 & 36 & 64 & 27 & $\mathrm{se7}$ & Sexls \\
\hline 4 & 100 & 4 & 7 & $\alpha Z$ & 27.5 & 745 & 8 & $\mathrm{WI}$ & 27.5 & 745 & Sebic \\
\hline 5 & 104 & 20 & 14 & 51 & 19 & 1152 & 24 & 83 & 315 & 456 & $\uparrow$ \\
\hline 6 & 73 & 30 & 38 & 55 & 23 & 90 & 19 & 70 & 29.5 & 15 & 1 \\
\hline 7 & 130 & 48 & 60 & 5 & 166 & 1223 & 13 & 73 & 26 & 833 & 7 \\
\hline
\end{tabular}




\subsection{DISCUSSION}

In our department, we have performed the first laparoscopic reconversion of RYGB to OA in 2005 [9]. Since that time the RYGB, usually considered as permanent, has been demonstrated to be reversible at least anatomically. Possible problems related to RYGB like dumping syndrome must in first instance be treated by multidisciplinary counseling. Patients presenting dumping syndrome after RYGB usually benefit from dietary measures and experience significant improvement of the symptoms [10]. Kellogg et al. observed that after a low-carbohydrate diet, patients demonstrated very little change in plasma glucose and only a modest increase in serum insulin, with at least some improvement of the symptoms [11]. However, some cases are refractory to diet measures and medical treatments with serotonin antagonists or somatostatin analogs can be attempted $[10,12,13]$. Evidence exists that slowing down the clearance of foods from the gastric pouch may be efficient in the treatment of these conditions. Z'graggen et al. placed a silastic ring or adjustable gastric band around the gastric pouch and obtained an improvement of hypoglycemic episodes [14]. Alternatively, endoscopic techniques using StomaphyX (Endogastric Solution, Palo Alto, CA, USA) or Endocinch devices (Bard, Covington, GA, USA) [15] can be proposed with encouraging results. A last surgical option is the reconversion of RYGB to OA [9]. A different strategy is proposed for patients with postprandial hyperinsulinemic hypoglycemia associated or not to dumping syndrome. Firstly, the ill dietary behavior has to be corrected and medical therapy with insulin-modulating agents like acarbose or glyclaside can be attempted. Surgical treatment options can be to delay gastric pouch emptying by adding restriction, or reconversion to OA. This latter option is obviously associated to the risk of weight regain, which can be resolved with the next malabsorptive procedure. There is no question that these less aggressive methods should be attempted before possible pancreatic lesions are investigated $[16,17]$. Technically, it is our policy to perform minimal dissection in order to respect general vascularization. Our strategy is to minimally free the gastrojejunostomy, which avoids jeopardizing the vascularization of the gastric pouch in view of its transection. This is important since this latter part survives on only one or two branches of the left gastric artery located at the lesser curvature. The gastrogastrostomy that might forward the only limiting factor is the possible traction between the gastric pouch and the gastric remnant. Again for vascularity reasons, dissection should be kept minimal, just sufficient for the fundus to reach the gastric pouch without traction. The anastomosis is performed using the linear stapler technique. Sometimes, however, the gastric pouch is a micropouch which does not accommodate the insertion of linear stapler; hence, a manual anastomosis is preferred. The gastrogastrostomy is performed on a 34-Fr orogastric bougie, which can be considered a safe diameter. Sutures used for gastrogastrostomy are reabsorbable and thick (1 PDS) so as not to cut through the gastric tissue. In this series we did not use the circular stapler 
technique, as reported by other authors [18], because we prefer to maintain intact the rest of the stomach (gastric remnant), which has to be reanastomosed. The jejunojejunostomy is usually found without effort, thanks to its antecolic position. However, when a transmesocolic route had been performed, dissection of the alimentary limb is far more extensive and a longer portion of the loop may need to be sacrificed because of ischemia. Moreover, there is the risk of ischemia to the transverse colon, which is yet another argument in favor of the antecolic position, besides the risk of postoperative obstruction $[19,20]$. Correct dismantling of the jejunojejunostomy consists of sectioning the bowel on the biliary loop side rather than the alimentary one, in order to respect the integrity of the alimentary and common loops. The mesenteric window between the new enteral anastomosis, which is the consequence of the mesenteric transection-all be it small-created at the original construction of RYGB, has to be closed. One should resist the tentation to overly dissect the gastroesophageal junction, in an effort to isolate the gastric pouch and the gastric remnant, since this area is sensitive to surgical dissection especially in reoperations. Severance of all the adhesions in this area could induce GERD, as seen in three of our patients. Indeed, unlike after band gastroplasty the long-time strain on the lower esophageal sphincter (LES) [21], caused by the hyperpression, is likely to provoke irreversible damage to the LES, RYGB should not have created such situations, since it is a low pressure system. Hence, GERD encountered in three of our patients was probably caused by overzealous dissection at the time of the revision. Two of our patients never recovered a normal weight and actually continued to lose weight after the procedure. This can be explained by the refeeding syndrome $[22,23]$. In order to avoid this syndrome, it is probably preferable to do the reconversion in staged procedures. First, a feeding gastrostomy is performed, followed by very careful and slowly increasing enteral feedings over the normal anatomical route. Reconversion is only performed when weight regain has been clearly initiated. Preoperative nasoenteral feedings are much more difficult to handle and are less effective since the use of the normal anatomical pathway, including the antrum and the duodenum, is essential in absorbing vitamins and minerals. Surprisingly, one of these two patients with excessive weight loss after reconversion had presented too little weight loss after the procedure of RYGB. This patient with a sweet-eating behavior at preoperative workup was offered OA as first stage for a subsequent new bariatric procedure, in accordance with the patient's preference. During follow-up after reconversion, the patient presented a surprising weight loss, probably because of fear for having to undergo a new bariatric procedure. New surgery was therefore not proposed. Similarly, the two patients who remained at a stable weight after reconversion allegedly have fear to having to undergo a new bariatric procedure, which to them had proven to be very uncomfortable. The four patients presenting weight regain after reconversion were patients evidenced with loss of control at psychologist's consultation. Longer follow-up will need to confirm the partial or total regain weight. This again high- 
lights the need of a multidisciplinary approach before all bariatric surgery and the necessity to tailor the bariatric procedure to the personality of the patients. Our patients probably were candidate for a malabsorptive procedure as biliopancreatic diversion than a mixed procedure as RYGB, which can still be a viable option because all the upper parts of the stomach are in place and of the very few adhesions after the laparoscopic procedures. The operative time recorded in this small series of reversal procedures appeared acceptable, but tight adhesions from other previous abdominal surgeries can be factors of time-consuming factors. The relatively long hospital stay was never caused by physical complications, but rather had to do with the psychological complexity of the patients. Indeed, it is mandatory not to neglect the psychological impact of the reconversion, which should be accounted for already in the preoperative period [24]. Finally, despite the fact that after these reversal procedures patients are anatomically restored, it would be presumptuous to think that the preoperative integrity can be re-achieved. In conclusion, laparoscopic reconversion of RYGB to OA is feasible and safe. This procedure in patients with RYGB abolishes the presence of dumping syndrome without postprandial hypoglycemia and intolerance to RYGB-induced restriction. The anatomy remains one of the aspects besides nutritional and psychological factors in cases of reconversion for weight issues. Special care in limited dissection around the low esophageal sphincter could be useful in avoiding GERD.

\subsection{REFERENCES}

1. Pories W, Swanson M, MacDonald K. Who would have thought it? An operation to be the most effective therapy for adult-onset diabetes mellitus. Ann Surg 1995;222:339-50

2. Jones K. Experience with the Roux-en-Y gastric bypass, and commentary on current trends. Obes Surg 2000;10:183-5

3. Christou NV, Look D, MacLean LD. Weight gain after short- and long-limb gastric bypass in patients followed for longer than 10 years. Ann Surg 2006;244:734-40

4. Buchwald H, Avidor Y, Braunwald E, et al. Bariatric surgery: a systematic review and metaanalysis. JAMA 2004;292:1724-37

5. Matthews DH, Lawrence Jr W, Poppell JW, et al. Change in effective volume during experimental dumping syndrome. Surgery 1960;48:185-94

6. Bikman BT, Zheng D, Pories WJ, et al. Mechanism for improved insulin sensitivity after gastric bypass surgery. J Clin Endocrinol Metab 2008;93:4656-63

7. Deitel M. The change in the dumping syndrome concept. Obes Surg 2008;18:1622-4

8. Guijarro A, Kirchner H, Meguid MM. Catabolic effects of gastric bypass in a diet-induced obese rat model. Curr Opin Clin Nutr Metab Care 2006;9:423-35

9. Himpens J, Dapri G, Cadière GB. Laparoscopic conversion of the gastric bypass into a normal anatomy. Obes Surg 2006;16:908-12

10. Ukleja A. Dumping syndrome: pathophysiology and treatment. Nutr Clin Pract 2005;20:517-25

11. Kellogg TA, Bantle JP, Leslie DB, et al. Postgastric bypass hyperinsulinemic hypoglycemia syndrome: characterization and response to a modified diet. Surg Obes Relat Dis 2008;4:492-9

12. Johnson LP, Sloop RD, Jesseph JE, et al. Serotonin antagonists in experimental and clinical "dumping". Ann Surg 1962;156:537-49

13. Peskin GW, Miller LD. The use of serotonin antagonists in postgastrectomy syndromes. Am J Surg 1965;109:7-13 
14. Z'graggen K, Guweidhi A, Steffen R, et al. Severe recurrent hypoglycemia after gastric bypass. Obes Surg 2008;18:981-8

15. Fernandez-Esparrach G, Lautz DB, Thompson CC. Peroral endoscopic anastomotic reduction improves intractable dumping syndrome in Roux-en-Y gastric bypass patients. Surg Obes Relat Dis 2010;6:36-40

16. Service GJ, Thompson GB, Service FJ, Andrews JC, Collazo-Clavell ML, Lloyd RV. Hyperinsulinemic hypoglycemia with nesidioblastosis after gastric-bypass surgery. N Engl J Med 2005;353:249-54

17. Patti ME, McMahon G, Mun EC, et al. Severe hypoglycemia post-gastric bypass requiring partial pancreatectomy: evidence for inappropriate insulin secretion and pancreatic islet hyperplasia. Diabetologia 2005;48:2236-40

18. Parikh M, Pomp A, Gagner M. Laparoscopic conversion of failed gastric bypass to duodenal switch: technical considerations and preliminary outcomes. Surg Obes Relat Dis 2007;3:611-8

19. Escalona A, Devaud N, Perez G, et al. Antecolic versus retrocolic alimentary limb in laparoscopic Roux-en-Y gastric bypass: a comparative study. Surg Obes Relat Dis 2007;4:423-7

20. Champion JK, Williams M. Small bowel obstruction and internal hernias after laparoscopic Rouxen-Y gastric bypass. Obes Surg 2003;13:596-600

21. Klaus A, Gruber I, Wetscher G, et al. Prevalent esophageal body motility disorders underlie aggravation of GERD symptoms in morbidly obese patients following adjustable gastric banding. Arch Surg 2006;141:247-51

22. Korbonits M, Blaine D, Elia M, Powell-Tuck J. Metabolic and hormonal changes during the refeeding period of prolonged fasting. Eur J Endocrinol 2007;157:157-66

23. Gariballa S. Refeeding syndrome: a potentially fatal condition but remains under diagnosed and under treated. Nutrition 2008;24:604-6

24. Rutledge T, Groesz LM, Savu M. Psychiatric factors and weight loss patterns following gastric bypass surgery in a veteran population. Obes Surg 2011;21:29-35 


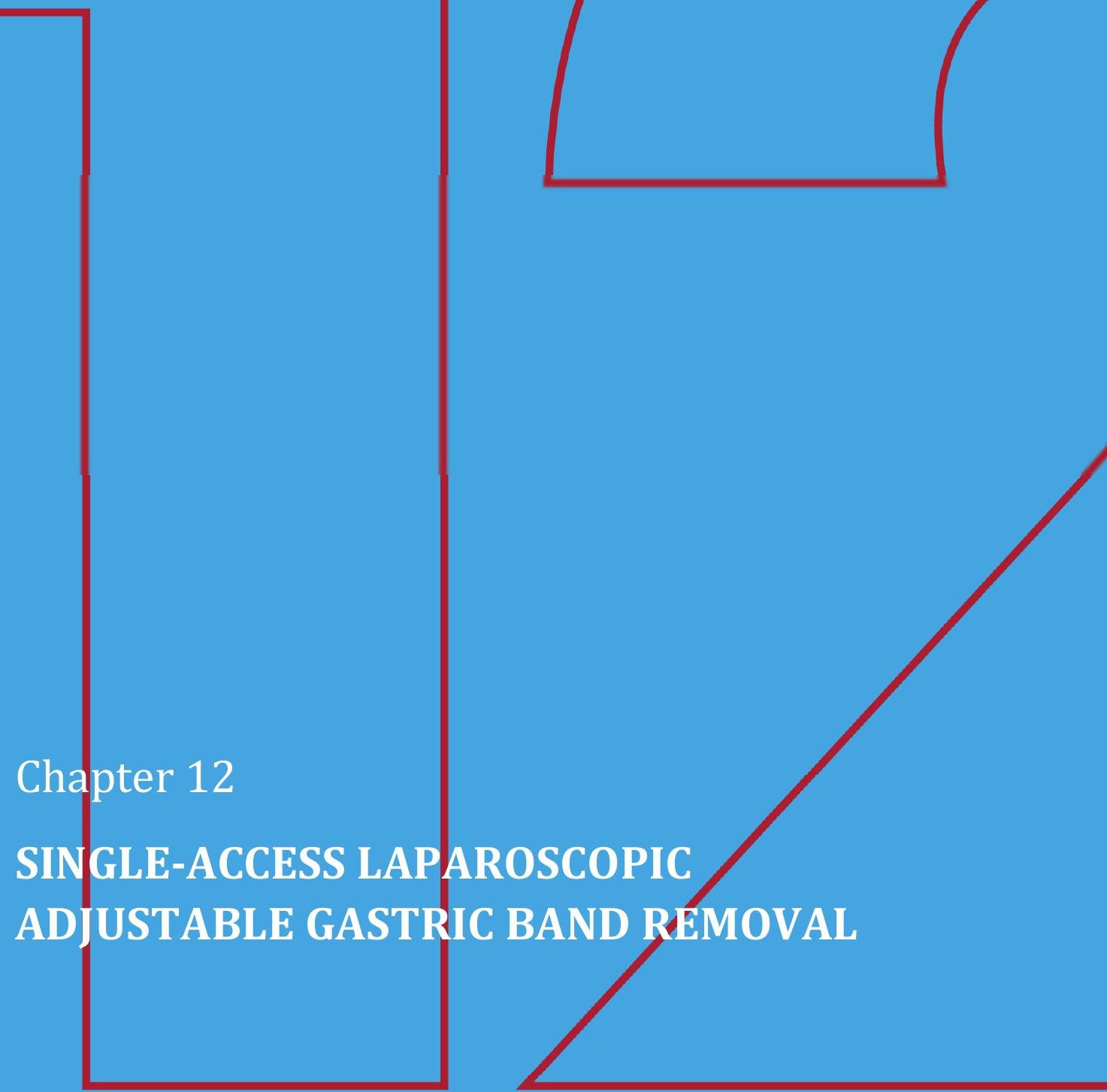

Dapri G, El Mourad H, Mathonet P, Delaporte A, Himpens J, Cadière GB, Greve JW

Obesity Surgery 2013;23(2):272-276 



\subsection{ABSTRACT}

Background: Single-access laparoscopy (SAL) has gained significant interest in recent years. Potential benefits, beyond cosmetic outcomes, could be reduction of abdominal trauma, decreased risk of incisional hernia and diminished postoperative pain. Technique and initial experience in patients submitted to laparoscopic adjustable gastric band removal (LAGBR) through SAL is reported here.

Patients and Methods: Between December 2009 and March 2012, 14 patients (9 females, 5 males) underwent LAGBR through SAL. Indications for operation were band-intolerance (11), pouch dilatation (2) and insufficient weight loss (1). The mean age was $40.3 \pm 9.1$ years (range 26-57), and the mean interval time between LAGB placement and removal was $94.7 \pm 41.9$ months (range 37-157). The mean weight and the mean body mass index at the time of LAGBR were $89.3 \pm 17.6$ $\mathrm{kg}$ (range $65-119$ ) and $30.6 \pm 4.5 \mathrm{~kg} / \mathrm{m}^{2}$ (range 25.3-36.7), respectively. Technically, the previous port site scar was used as the single-access site to the abdominal cavity. An 11-mm reusable trocar was adopted for a $10-\mathrm{mm}$ regular scope, besides curved reusable instruments.

Results: No patients required conversion to open surgery and none necessitated additional trocars. The mean laparoscopic time was 24.6 \pm 7.9 minutes (range 13-37), and the mean final scar length was $3.6 \pm 0.3 \mathrm{~cm}$ (range 3-4). Two patients experienced early postoperative complications. The mean hospital stay was $1.3 \pm 1.1$ days (range 1-5). The mean follow-up time was of $18 \pm 9.8$ months (range 330 ), and there were no late complications.

Conclusion: LAGBR can be safely performed through SAL. Thanks to this technique, the laparoscopic working triangulation is established as well as the ergonomic positions of the surgeon. Due the use of only reusable material, the cost of this SAL remains similar to mulriport laparoscopy. 


\subsection{INTRODUCTION}

Open bariatric surgery can be performed with relatively low morbidity and mortality rates, but wound-related postoperative complications remain a significant problem. Wound infection occurs in as many as $25 \%$ of morbidly obese patients treated, and incisional hernia develops in as many as $16.7 \%$ of patients $[1,2]$. With the advent of laparoscopy, these complications have been reduced. Other advantages to laparoscopy include less postoperative pain, a shorter length of hospitalisation and faster recovery [3]. Single-incision, single-port, single-site or singleaccess laparoscopy (SAL) was first described in 1992 [4]. After more than 20 years, thanks to the advent of Natural Orifices Transluminal Endoscopic Surgery (NOTES), and a desire for improved cosmetic outcomes, SAL has gained significant interest. Since 2008, the first SAL bariatric procedures have been described like LAGB [5], sleeve gastrectomy (SG) [6], Roux-en-Y gastric bypass [7] and biliopancreatic diversion [8]. Along with improved cosmetic results, SAL may decrease abdominal trauma (trocar fascial-peritoneal punture, bleeding, hematoma formation, visceral injury, local nerve irritation), postoperative pain and incidence of incisional hernia. The main technical difficulties during SAL are the lack of triangulation inside the abdomen, the clashing of the instrument tips and crossing of the surgeon's hands externally. Furthermore, one of the essential laparoscopic rules, to keep the surgeon's two effectors at a right angle with the optical system at the bisector of this angle [9], is frequently lost. The use of curved instruments allows for classic laparoscopic triangulation inside and outside the abdomen (Fig.1a-c).
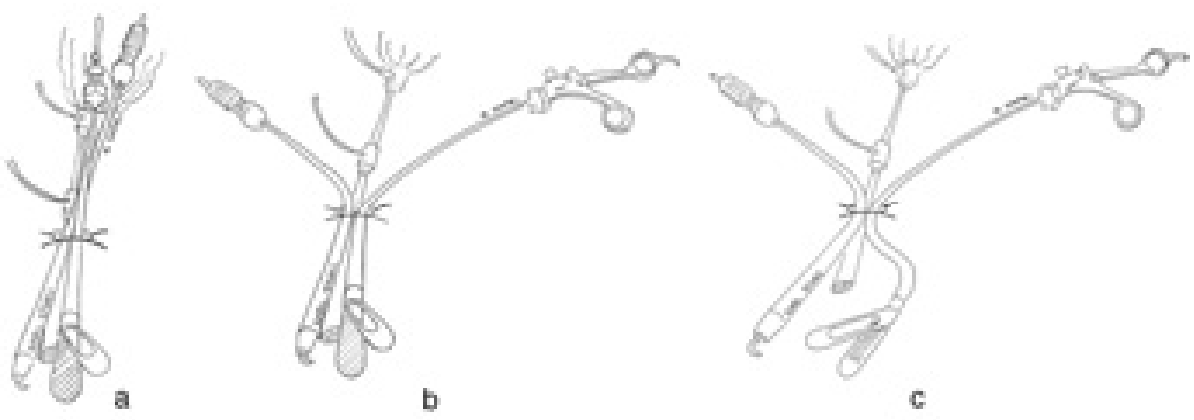

Fig.1a-c: The straight classic laparoscopic instruments (a) are curved outside the access (b) and inside the abdomen (c) to permit the establishment of the conventional laparoscopic triangulation

\subsection{PATIENTS AND METHODS}

Between December 2009 and March 2012, 14 patients (9 females, 5 males) underwent laparoscopic adjustable gastric band removal (LAGBR) using SAL. Indications for operation were band-intolerance (11), pouch dilatation (2) and insuffi- 
cient weight loss (1). The mean age was $40.3 \pm 9.1$ years (range 26-57), and the mean interval time between LAGB placement and removal was $94.7 \pm 41.9$ months (range 37-157). At the time of LAGBR, the mean weight was $89.3 \pm 17.6 \mathrm{~kg}$ (range $65-119$ ), and the mean body mass index was $30.6 \pm 4.5 \mathrm{~kg} / \mathrm{m}^{2}$ (range $25.3-36.7$ ).

\subsubsection{SURGICAL TECHNIQUE}

The patient was placed in a supine position with the arms alongside the body and the legs abducted. The surgeon stood between the patient's legs with the camera assistant to the patient's left. The subcutaneous port was identified and the previous port site scar was incised sufficiently to expose and remove the port. The peritoneal cavity was entered using the "open laparoscopy technique" with a fascia opening of $1 \mathrm{~cm}$. Purse-string sutures using one polydiaxone (PDS) and one polyglactine (Vicryl) were placed in the superficial and deep muscular fascia, respectively. A reusable $11-\mathrm{mm}$ trocar was used for a $10-\mathrm{mm}, 30^{\circ}$ angled, rigid and standard length scope. Curved reusable instruments (Karl Storz - Endoskope, Tuttlingen, Germany) were inserted into the abdomen through the same incision without trocars by following the curves on the shaft and forming a $45^{\circ}$ angle with the abdominal wall plane.

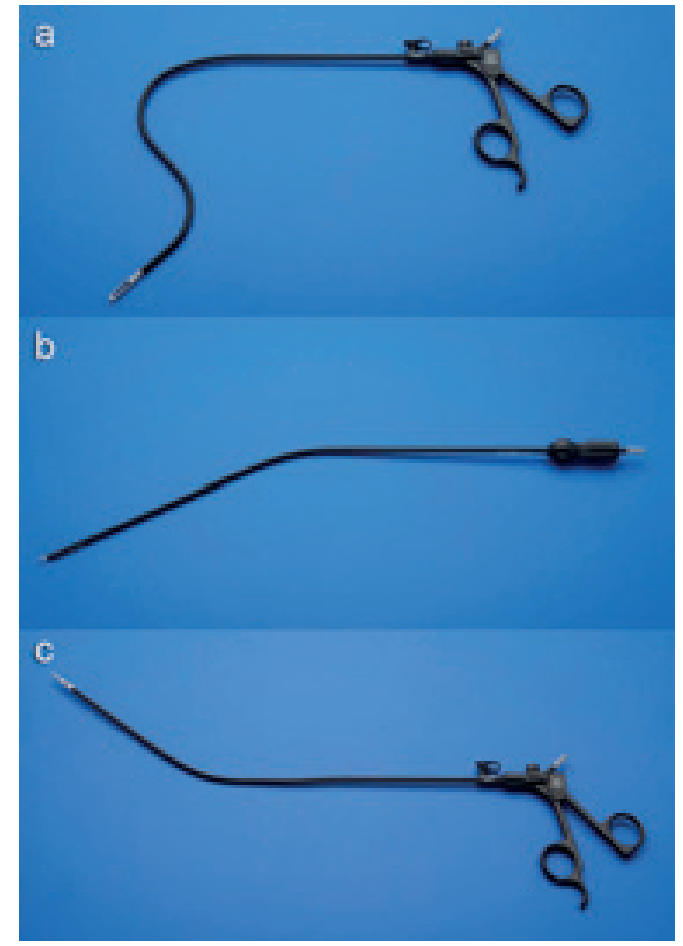

Fig.2a-c: DAPRI curved reusable instruments: grasping forceps I (a), coagulating hook (b), scissors (c) (source: Karl Storz Endoskope, Tuttlingen, Germany) 
The curved grasping forceps I (Fig.2a) was advanced through a different fascial window outside of the purse-string suture (10 o'clock position), which was created using the wire of a 5-mm trocar. Other instruments, including a curved coagulating hook (Fig.2b), curved scissors (Fig.2c) and a curved suction device, were introduced alongside the 11-mm trocar and inside the purse-string sutures $(3$ o'clock position) (Fig.3).

\section{Patient head}

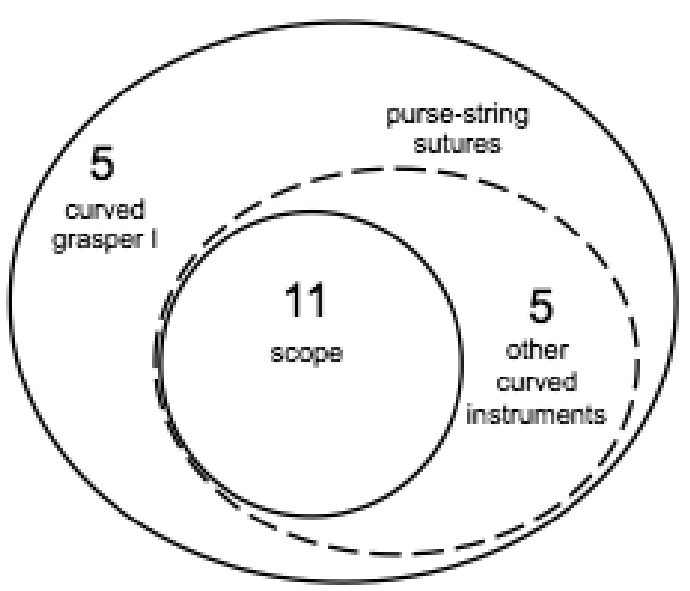

Fig.3: Single-access site: placement of purse-string sutures, 11-mm reusable trocar and curved reusable instruments

The sutures were adjusted to maintain a tight seal around the 5-mm tools and the 11-mm trocar. The sutures were loosened only to permit instrument exchange or to evacuate the smoke generated from the dissection. The band was identified by following the tubing and was dissected off of the left lobe of the liver. Internal triangulation was established (Fig.4a), which allowed the surgeon to work in ergonomic positions similar to multiport laparoscopy (Fig.4b). 


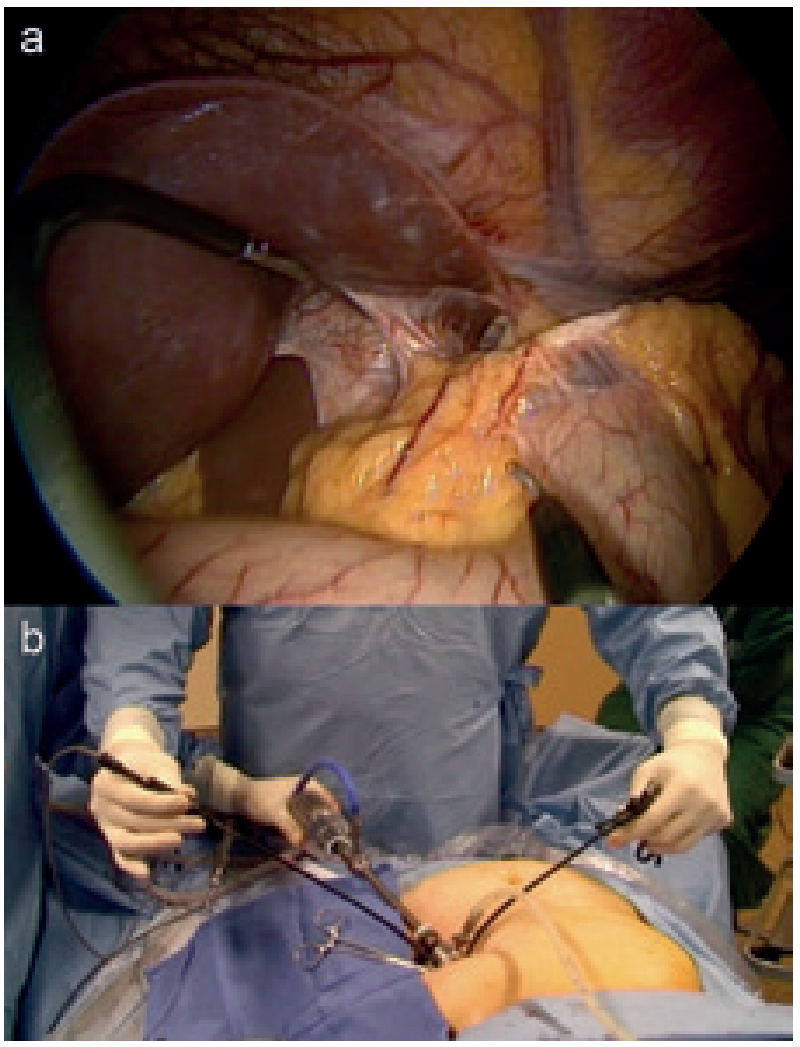

Fig.4a,b: Intracorporeal working triangulation (a) and external surgeon's ergonomy (b)

After sufficiently detaching the band from the stomach, the band was cut, pulled away from the gastric surface and removed from the abdomen through the singleaccess site. The instruments were removed under direct vision and the pursestring sutures were tied. Supplementary absorbable sutures were placed to reinforce the access site and to close the separate opening for the grasper. The final scar length varied depending on the diameter of the previous subcutaneous port.

\subsection{RESULTS}

No patient required conversion to open surgery or additional trocars. The mean total operative time (between skin incision and closure of the fascia) was $55.9 \pm 21.6$ minutes (range 34-120), and the mean laparoscopic time (between beginning of pneumoperitoneum and removal of the instruments and trocars) was 24.6 \pm 7.9 minutes (range 13-37). The mean blood loss was $6.1 \pm 5.8 \mathrm{~mL}$ (range 020 ), and the mean final scar length was $3.6 \pm 0.3 \mathrm{~cm}$ (range 3-4). Two patients developed early postoperative complications (1 pleural effusion, 1 subcutaneous 
abscess). The mean hospital stay was $1.3 \pm 1.1$ days (range 1-5). At a mean followup of 18 \pm 9.8 months (range 3-30), no late complications were observed. Nine patients gained a mean weight of $14.5 \pm 11.7 \mathrm{~kg}$ (range 2-39), one patient remained with a stale weight, one patient continued to lose weight and the remaining three patients refused follow-up.

\subsection{DISCUSSION}

SAL has mainly been described through the original umbilical scar, which is considered an embryologic orifice and keeps good cosmesis [10]. For patients who have had previous LAGB, the improved cosmetic outcomes with SAL are less of an issue because these patients already present with three to ten cutaneous scars. Other potential advantages, such as reduced abdominal trauma (trocar fascialperitoneal puncture, bleeding, hematoma formation, visceral injury, local nerve irritation), less postoperative pain and lower risk of incisional hernia, are significant because these patients will likely undergo another bariatric procedure. Increasing the number of trocars can contribute to the development of incisional hernias [11]. The scar covering the subcutaneous port can be used as the singleaccess site for the procedure. As subcutaneous ports have different diameters, the final scar length will depend on the size of the port. Every patient treated in our series had their subcutaneous port located in the left upper quadrant. Nevertheless, this procedure can also be applied for patients who have their port located more medially. For patients with ports above the xiphoid process or in other abdominal areas, the access site for SAL will be chosen among the previous scars, preferably in the left-sided upper quadrant. In the technique described here, no disposable ports specifically designed for SAL were used. Instead, we used an 11$\mathrm{mm}$ trocar and curved instruments. We utilised purse-string sutures in the abdominal fascia to maintain sufficient pneumoperitoneum and to minimise air leak. A purse-string suture allows the surgeon to insert instruments into the abdomen, parallel to the 11-mm trocar, using his or her dominant hand. Furthermore, because the instrument held by the surgeon's non-dominant hand (grasper) does not change during the procedure, it is inserted through a separate window outside of the purse-string sutures. A thick and sliding stitch, such as PDS 1 suture, is chosen for closure of the superficial abdominal fascia. Vicryl 1 suture is used for closure of the deep abdominal fascia. The purse-string sutures have to be adjusted to maintain pneumoperitoneum during the procedure and enlarged only to permit the exchange of instruments or to evacuate the smoke generated by the dissection. The curved grasping forceps I has two curves. The first curve is at the level of the abdominal incision, which avoids the unintentional contact between the grasper's handle and the camera assistant's hand. The second curve is inside the abdomen and establishes the working triangulation with the other curved tools. The other curved instruments (coagulating hook, scissors, suction device) are similar in 
shape, but have only one curve. They are designed to avoid the collision between the surgeon's hand and assistant's hand outside of the access site. These curved instruments allow the surgeon to work ergonomically during SAL, without clashing of instrument tips or crossing of the surgeon's hands (Fig.4a,b). All curved instruments must be introduced and removed from the abdominal cavity by following the curves of the instruments and maintaining a $45^{\circ}$ angle with respect to the abdominal wall. Operative field's exposure during SAL remains one of the main drawbacks. When SAL is applied to bariatric surgery, exposure to the hiatal region is problematic. The classic Nathanson liver retractor can be inserted through the single-access site or through a different skin puncture [12]. Other available options include the use of percutaneous diaphragmatic crura sutures [13], percutaneous transhepatic sutures [7], a non-puncturing penrose drain with endohernia stapler [14], a penrose drain [15], a bulldog clamp with a hook retractor [16], a magneticassisted grasper [17] and placement of a subcostal Veress needle [18]. In our technique, we use the distal curve of the grasper for the dissection and for exposure to the hiatal region (Fig.4a). SAL has been reported to increase the cost of the procedure [19], mainly because of the use of specific disposable port devices and instruments. We adopted a procedure that can be performed without the use of disposable equipment, which should make the cost of SAL similar to multiport laparoscopy. No patients in this study required insertion of additional trocars. The need for additional trocars has been reported in SAL with an incidence of $4.5-13 \%$ during LAGB [20-24] and 4-66.6\% during SG [6,25-28]. We consider insertion of one or more trocars not as a failure of SAL, but rather as a technique of reduced port laparoscopic surgery [29]. Similarly, Galvani et al. [30] compared single- and dual incision LAGB, and had a $0 \%$ of conversion rate in the last 19 patients treated. We reported a mean difference of 31.3 minutes between the total and laparoscopic time. This interval time can be explained by the time needed to remove the port, to obtain access to the peritoneal cavity through the "open laparoscopy technique", and to close the access site, taking care of the different fascial opening for the grasper. Our laparoscopic time was not dependant on the learning curve, unlike the literature data [6,21]. Although no perioperative complications were registered, two patients developed postoperative complications. One patient developed a pleural effusion, was successfully treated by chest physiotherapy and was discharged on postoperative day 5 . A second patient developed a subcutaneous infection at the access site. This infection was probably due to a port problem rather than laparoscopic single-access site [31]. At a mean follow-up of 1.5 years, no patients presented with complications related to the laparoscopic procedure. No patient developed an incisional hernia at clinical follow-up. However, longer follow-up is needed to make firm conclusions. Finally, there are several limitations to this study. First, this is a single surgeon experience. Therefore, the patient population suffers from selection bias. Most patients refused the procedure and preferred another bariatric procedure. Second, the evaluation of the postoperative pain, 
which is the most significant short-term outcome, is not included in this study. In a comparison between SAL and multiport laparoscopic LAGB, Raman et al. [32] reported a significant difference in analgesic use during the immediate postoperative period after SAL. Patel et al. [22] reported a visual analogue scale score of 2.5 out of 10 (range 0-7) at 24 hours following SAL. Similarly, in another comparison between SAL and multiport laparoscopic SG, Saber et al. [33] reported a significantly reduced pain score in the SAL group. Other authors have found significantly less pain after the $1^{\text {st }}[25]$ and the $8^{\text {th }}[34]$ postoperative hours following SAL.

\subsection{CONCLUSIONS}

LAGBR can be safely performed using SAL. Thanks to this technique, the laparoscopic working triangulation is established as well as the ergonomic positions of the surgeon. Due the use of only reusable material, the cost of this SAL remains similar to multiport laparoscopy.

\subsection{REFERENCES}

1. See C, Carter PL, Elliott D, et al. An institutional experience with laparoscopic gastric bypass complications seen in the first year compared with open gastric bypass complications during the same period. Am J Surg 2002;183:533-8

2. Balsinger BM, Kennedy FP, Abu-Ledbeh HS, et al. Prospective evaluation of Roux-en-Y gastric bypass as primary operation for medically complicated obesity. Mayo Clin Proc 2000;75:673-80

3. Nguyen NT, Wolfe BM, Open versus laparoscopic bariatric surgery. In Buchwald H, Cowan GSM, Pories W (eds), Surgical Management of Obesity, Saunders Elsevier, 2007, chapter 33, pp 287-90

4. Pelosi MA, Pelosi MA III. Laparoscopic appendectomy using a single umbilical puncture. J Reprod Med 1992;37:588-94

5. Nguyen NT, Hinojosa MW, Smith BR, Reavis KM. Single laparoscopic incision transabdominal (SLIT) surgery - adjustable gastric banding: a novel minimally invasive surgical approach. Obes Surg 2008;18:1628-31

6. Saber AA, Elgamal MH, Itawi EA, Rao AJ. Single incision laparoscopic sleeve gastrectomy (SILS): a novel technique. Obes Surg 2008;18:1338-42

7. Huang CK, Houng JY, Chiang CJ, Chen YS, Lee PH. Single incision transumbilical laparoscopic Roux-en-Y gastric bypass: a first case report. Obes Surg 2009;19:1711-5

8. Tacchino RM, Greco F, Matera D. Single-incision laparoscopic biliopancreatic diversion. Surg Obes Relat Dis 2010;6:444-5

9. Hanna GB, Drew T, Clinch P, Hunter B, Cuschieri A. Computer-controlled endoscopic performance assessment system. Surg Endosc 1998;12:997-1000

10. Desai MM, Stein R, Rao P, et al. Embryonic natural orifice transumbilical endoscopic surgery (ENOTES) for advanced reconstruction: initial experience. Urology 2009;73:182-7

11. Helgstrand F, Rosenberg J, Bisgaard T. Trocar site hernia after laparoscopic surgery: a qualitative systematic review. Hernia 2011;15:113-21

12. Saber AA, El-Ghazaly TH, Dewoolkar AV. Single-incision laparoscopic bariatric surgery: a comprehensive review. Surg Obes Relat Dis 2010;6:575-82

13. Tacchino RM, Greco F, Matera D. Laparoscopic gastric banding without visible scar: a short series with intraumbilical SILS. Obes Surg 2010;20:236-9 
14. Huang CK, Lo CH, Asim SK, Houng JY, Huang SF. A novel technique for liver retraction in laparoscopic bariatric surgery. Obes Surg 2011;21:676-9

15. Hamzaoglu I, Karahasanoglu T, Aytac E, Karatas A, Baca B. Transumbilical totally laparoscopic single-port Nissen fundoplication: a new method of liver retraction: the Istanbul technique. J Gastrointest Surg 2010;14:1035-9

16. Galvani CA, Choh M, Gorodner MV. Single-incision sleeve gastrectomy using a novel technique for liver retraction. JSLS 2010;14:228-33

17. Morales-Conde S, Dominguez G, Canete Gomez J, et al. Magnetic-assisted single-port sleeve gastrectomy. Surg Innov 2011 Dec 4 (Epub ahead of print)

18. Gianni S, De Luca M, Oscar B, et al. Veress needle: a simple liver retraction technique for lap band positioning in (single incision laparoscopic technique) SILS. Obes Surg 2012;22:190-1

19. Ahmed I, Paraskeva P. A clinical review of single-incision laparoscopic surgery. Surgeon 2011;9:341-51

20. Teixeira J, McGill K, Koshy N, McGinty, Todd G. Laparoscopic single-site surgery for placement of adjustable gastric band - a series of 22 cases. Surg Obes Relat Dis 2010;6:41-5

21. Koh CE, Martin DJ, Cavallucci DJ, Becerril-Martinez G, Taylor CJ. On the road to single-site laparoscopic adjustable gastric banding: lessons learned from 60 cases. Surg Endosc 2011;25:947-53

22. Patel AG, Murgatroyd B, Ashton WD. Single incision laparoscopic adjustable gastric banding: 111 cases. Surg Obes Relat Dis 2012 (in press)

23. Keidar A, Shussman N, Elazary R, Rivkind AI, Mintz Y. Right-sided upper abdomen single-incision laparoscopic gastric banding. Obes Surg 2010;20:757-60

24. Nguyen NT, Slone J, Reavis K. Comparison study of conventional laparoscopic gastric banding versus laparoendoscopic single site gastric banding. Surg Obes Relat Dis 2010;6:503-7

25. Park K, Afthinos JN, Lee D, Koshy N, McGinty JJ, Teixeira JA. Single port sleeve gastrectomy: strategic use of technology to re-establish fundamental tenets of multiport laparoscopy. Surg Obes Relat Dis 2012;8:450-7

26. Delgado S, Ibarzabal A, Adelsdorfer C, et al. Transumbilical single-port sleeve gastrectomy: initial experience and comparative study. Surg Endosc 2012;26:1247-53

27. Pourcher G, Di Giuro G, Lafosse T, Lainas P, Naveau S, Dagher I. Routine single-port sleeve gastrectomy: a study of 60 consecutive patients. Surg Obes Relat Dis 2012 Mar 8 (Epub ahead of print)

28. Alevizos L, Lirici MM. Laparo-endoscopic single-site sleeve gastrectomy: results from a preliminary series of selected patients. Minim Invasive Ther Allied Technol 2012;21:40-5

29. Lee WJ, Chen JC, Yao WC, Taou JJ, Lee YC, Ser KH. Transumbilical 2-site laparoscopic Roux-en-Y gastric bypass: initial results of 100 cases and comparison with traditional laparoscopic technique. Surg Obes Relat Dis 2012;8:208-13

30. Galvani CA, Gallo AS, Gorodner MV. Single-incision and dual-incision laparoscopic adjustable gastric band: evaluation of initial experience. Surg Obes Relat Dis 2012;8:194-200

31. Keidar A, Carmon E, Szold A, Abu-Abeid S. Port complications following laparoscopic adjustable gastric banding for morbid obesity. Obes Surg 2005;15:361-5

32. Raman SR, Franco D, Holover S, Gaber S. Does transumbilical single incision laparoscopic adjustable gastric banding result in decreased pain medicine use? A case-matched study. Surg Obes Relat Dis 2011;7:129-33

33. Saber AA, El-Ghazaly TH, Dewoolkar AV, Slayton SA. Single-incision sleeve gastrectomy versus conventional multiport laparoscopic sleeve gastrectomy: technical considerations and strategic modifications. Surg Obes Relat Dis 2010;6;658-64

34. Lakdawala MA, Muda NH, Goel S, Bhasker A. Single-incision sleeve gastrectomy versus conventional laparoscopic sleeve gastrectomy - a randomised pilot study. Obes Surg 2011;21:1664-70 



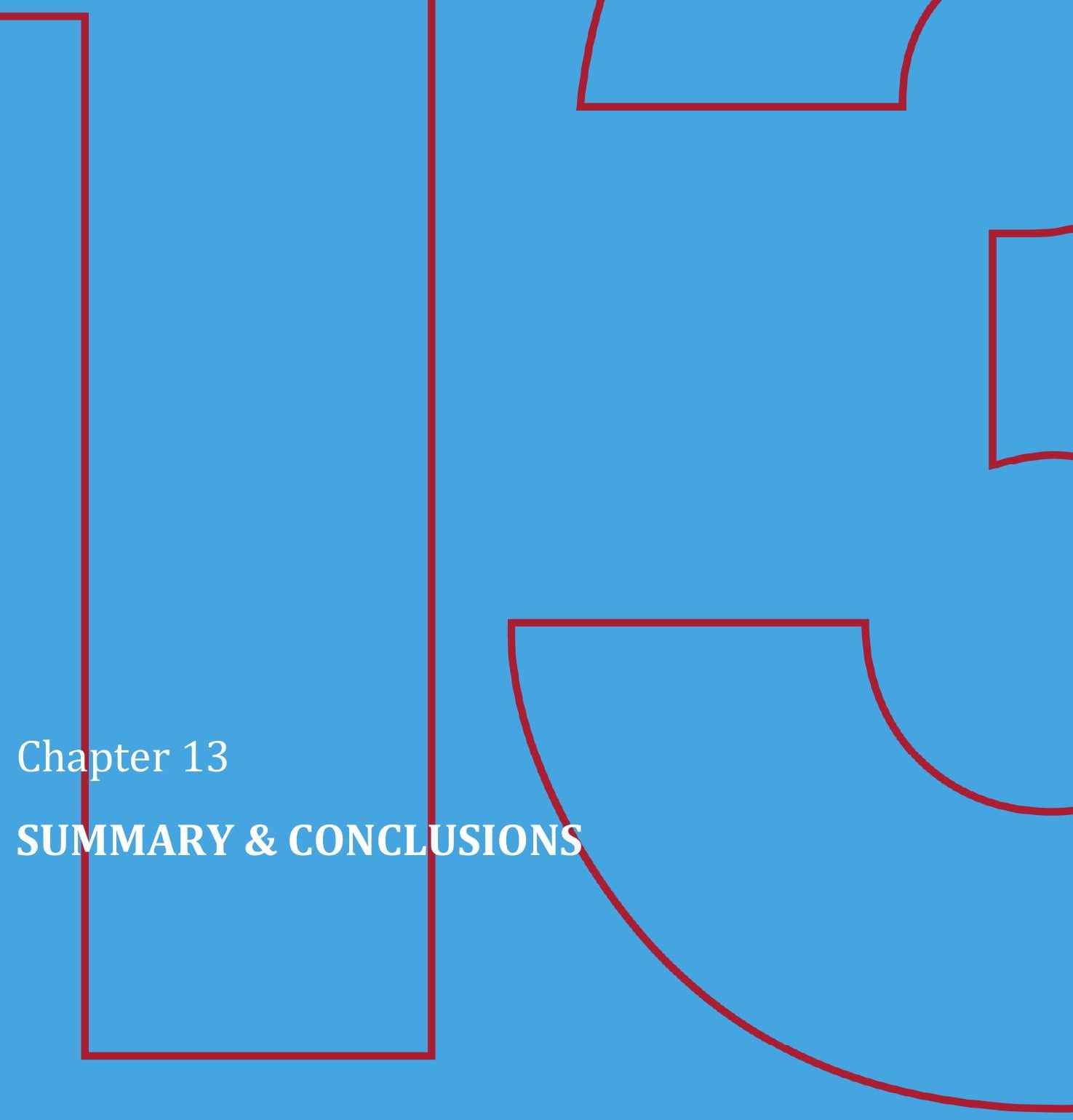





\subsection{SUMMARY}

This thesis can be divided in four main sections. The first section, chapters 2-3, discusses some technical aspects of the performance of laparoscopic sleeve gastrectomy (SG).

The second section, chapters 4-7, describes the various laparoscopic conversions performed in patients with previous restrictive procedures, such as laparoscopic adjustable gastric banding (LAGB), vertical banded gastroplasty (VBG) and SG.

The third section, chapters 8-11, describes the different laparoscopic conversions performed in patients after Roux-en-Y gastric bypass (RYGB).

The fourth section, chapter 12 , reports the evolution of conventional laparoscopy toward the performance of bariatric surgery not through a multitrocar technique but rather through a single-incision or single-access laparoscopy.

\section{Chapter 2. Randomized Study Comparing Two Techniques for Laparoscopic Sleeve} Gastrectomy (SG)

The procedure of SG has gained interest in the last decade. The most commonly used technique is to first devascularize the greater curvature from the antrum to the fundus and then to section the stomach using firings of a linear stapler after having placed an orogastric tube as the calibrator. This technique is also called the "lateral-to-medial approach".

Another possible SG technique consists of opening the lesser sac at the antrum and sectioning the stomach first, guided by an orogastric bougie placed endoscopically. The greater curvature is devascularized after creation of the SG. This technique is also called the "medial-to-lateral approach".

In this randomized study, these two laparoscopic SG methods were compared prospectively. Essentially, the technical steps of the dissection of the angle of His, of the tissue tension during the last firing of the stapler, and prevention of potential postoperative leaks at this area were evaluated and compared between the two techniques. The dissection of the stomach close to the angle of His was found to be more easily performed during the "medial-to-lateral approach", and this results is most likely due to the angle of His being freed from top to bottom and viceversa, thus permitting the introduction of the stapler and overall sectioning of the stomach without any undue tension. Analysis of the results did not show statistically significant differences in terms of operative time, perioperative bleeding, the number of cartridges used, hospital stay or weight loss.

The conclusions of the study confirmed no significant difference between the "medial-to-lateral approach" and the "lateral-to-medial approach". 
Chapter 3. Randomized Study in Laparoscopic Sleeve Gastrectomy (SG) Comparing the Reinforcement of the Staple Line

The SG procedure can be associated with crucial perioperative and postoperative complications. During surgery, the hemorrhage of the staple line is a frequent problem encountered by bariatric surgeons. In the postoperative period, a gastric leak is one of the most difficult complications to manage. The gastric leak usually occurs at the upper part of the SG in the area of the previous angle of His.

In this randomized study, three different techniques of managing the staple line during laparoscopic SG were compared prospectively. The techniques included no staple line reinforcement, buttressing the staple line with Gore Seamguard ${ }^{\circledR}$ (Gore Seamguard ${ }^{\circledR}$; W.L. Gore \& Associates, Inc, Flagstaff, AZ), and staple line suturing.

The results of the study showed that the operative time to perform stomach sectioning appeared to be statistically significant lower in the group with no staple line reinforcement. This result was most likely related to the fact that a simple stapler had just sectioned the stomach. Buttressing the staple line with Gore Seamguard ${ }^{\circledR}$ demonstrated statistically significant lower blood loss along the staple line, but at an increased procedure cost due to the material used. No statistically significant differences were found among the groups in terms of the number of linear stapler cartridges used or the occurrence of postoperative complications, such as gastric leaks.

In conclusion, the staple line can be managed safely during laparoscopic SG using all three techniques analyzed, thus achieving both a significantly reduced operative time with no staple line reinforcement and reduced blood loss with the use of buttressing material.

\section{Chapter 4. Laparoscopic Conversion of Adjustable Gastric Band (LAGB) to Sleeve Gastrectomy (SG)}

The choice of the conversion of LAGB to another bariatric procedure remains challenging and primarily depends on the surgeon's personal experience and philosophy.

The conversion to SG in one step involves the removal of LAGB and the tubulization of the stomach to create a SG. One of the immediate possible complications that can occur with this surgery is the development of a gastric leak at the region of the previous LAGB due to gastric sectioning in a fibrotic area.

This type of conversion can be desirable in patients with a behavior history of volume eating before the LAGB procedure and in whom the weight loss failure could be attributed to poor food choices and poor compliance to the strenuous follow-up needed for a successful LAGB operation.

In this retrospective study, 27 patients submitted to laparoscopic conversion of LAGB to SG were analyzed after a mean follow-up of 1.5 years. The results of the study showed an increased mean weight loss of $17.2 \mathrm{~kg}$, an increased mean \% ex- 
cess weight loss (EWL) of 16.7 points, and a decreased mean body mass index (BMI) of 4.4 points.

Patients presenting with obesity-related co-morbidities at the time of the conversion showed a resolution of those co-morbidities in $41.6 \%$ of cases.

In this preliminary experience, no conversion to open surgery, postoperative gastric leak or mortality was recorded.

The mean operative time to perform this conversion by laparoscopy was 2 hours.

In conclusion, laparoscopic conversion of LAGB to SG is feasible and safe.

Chapter 5. Laparoscopic Revision of Sleeve Gastrectomy (SG): Re-Sleeve (re-SG) versus Duodenal Switch (DS)

Patients submitted to SG can present during follow-up with problems of weight regain or insufficient weight loss. Weight loss issues are usually the result of inappropriate dietary habits adopted by the patient after SG. Problems can be hyperphagia (i.e. volume eating) or polyphagia (i.e. eating meals too frequently).

In this study, the treatment of these inappropriate alimentary behaviors was evaluated. Patients with hyperphagia after SG were submitted to re-SG, and patients with polyphagia after SG were converted to duodenal switch (DS).

This retrospective study included 26 patients; 7 patients submitted to laparoscopic re-SG, and 19 patients submitted to laparoscopic DS. The results were reviewed after a mean follow-up of 2 years.

After re-SG, patients had a mean weight loss of $9.7 \mathrm{~kg}$, with a decreased mean BMI of 3.6 points and an increased mean \%EWL of 19.4 points. After DS, patients achieved a mean weight loss of $26.9 \mathrm{~kg}$, with a decreased mean BMI of 9.6 points and an increased mean \%EWL of 54.2 points. The superior results of DS are related to the addition of malabsorption, but sometimes at the cost of serious side effects such as hypoproteinemia and diarrhea.

The obesity-related co-morbidities were resolved in accordance with the weight loss that was achieved.

The mean operative time to perform these two laparoscopic procedures was similar and close to 2.5 hours. The differing results were most likely related to difficulties in the performance of re-SG caused by adhesions and to the complexity of DS, which is a more complex procedure that is performed in different abdominal quadrants.

In this study, there were no conversions to open surgery or postoperative mortalities, but there was a significant postoperative morbidity due to leaks in both groups.

In conclusion, laparoscopic revisions by re-SG or DS of patients with previous SG and weight loss issues (due to inappropriate dietary habits) are feasible as long as the patients do not present with gastroesophageal reflux. In cases with gastroesophageal reflux, a laparoscopic conversion to RYGB is preferred. 
Chapter 6. Laparoscopic Conversion of Adjustable Gastric Band (LAGB) and Vertical Banded Gastroplasty (VBG) to Duodenal Switch (DS)

Patients with previous LAGB or VBG can present with weight loss issues such as insufficient weight loss or weight regain due to compulsive eating disorders persisting after both restrictive procedures or due to mechanical failure of the technique (band slippage, high band position, VBG opening stapling).

The aim of this retrospective study was to evaluate the selected patients treated by laparoscopic conversion to DS in one-step. This conversion includes two surgical phases. The first phase is the stomach section to perform SG together with the removal of the previous LAGB or with the transection of the previous VBG (and residual of ring or mesh). The second phase is the connection of the SG to the small bowel (through the duodenum) to create malabsorption. In this way, the procedure of laparoscopic DS is performed.

The laparoscopic conversion was realized in a mean operative time of 3.5 hours.

Forty-three patients were analyzed after a mean follow-up of 2.3 years: 31 patients with LAGB and 12 patients with VBG. The revision resulted in a mean $\%$ EWL of 70.1 points (LAGB) or 64.3 points (VBG). This result was mainly obtained by the addition of malabsorption with DS.

Unfortunately, the mortality and postoperative morbidity were too high after this laparoscopic conversion. After LAGB, one patient died suddenly postoperatively (negative autopsy), and major early complications were recorded in $6.4 \%$ of patients. After VBG, $50 \%$ of patients presented with major early complications, and 3 patients died outside the hospital during the follow-up period.

The conclusion of this analysis was to abandon this type of revision. In patients with VBG, a laparoscopic conversion to distal RYGB is now preferred, and in patients with LAGB, a two-step procedure with SG and LAGB removal, followed by the $2^{\text {nd }}$ step of DS (after a designated interval of time) is preferred.

\section{Chapter 7. Two-step Laparoscopic Duodenal Switch (DS)}

Because it is composed by a restrictive and a malabsorptive component, the DS, can be offered in two steps with a designated interval of time between the two procedures. Furthermore, this procedure must be performed in two steps for super-obese and super super-obese patients because of a proven reduced incidence of complications and mortality.

In this retrospective study, the total experience of two-step laparoscopic DS for the treatment of super-obese and super super-obese patients was evaluated. A total of 31 patients were submitted to the $2^{\text {nd }}$ step of DS after a mean interval time of 1.1 years after SG. These patients were evaluated at a mean follow-up of 2.4 years. The second step (malabsorptive procedure) increased the mean weight loss by $36.9 \mathrm{~kg}$ and reduced the mean BMI by 12.6 points. 
No conversions to open surgery or postoperative deaths were registered, but complication rates of $12.9 \%$ in the early postoperative course and $10.7 \%$ during follow-up were observed.

After the $2^{\text {nd }}$ step of DS, $51.1 \%$ of the obesity-related comorbidities were resolved.

The $2^{\text {nd }}$ step of laparoscopic DS was performed in a mean operative time of 3 hours.

Currently, super-obese and super super-obese patients are treated by two step DS with the exception of the appearance of gastric dilation or gastroesophageal reflux after the $1^{\text {st }}$ step of SG. In cases of gastric dilation or gastroesophageal reflux, patients will be revised, and laparoscopic re-SG or conversion to laparoscopic RYGB, respectively, will be proposed.

\section{Chapter 8. Laparoscopic Revision of Roux-en-Y Gastric Bypass (RYGB) to Banded $R Y G B$}

Patients submitted to RYGB can present during follow-up with weight regain or insufficient weight loss. Weight loss issues can be the result of technical aspects such as pouch or stoma dilatation, gastro-gastric fistulae or inappropriate alimentary behavior.

In this retrospective study, a group of 6 patients was evaluated; the patients presented with either weight regain after RYGB, mainly associated with hyperphagia, or volume eating. Treatment consisted of the laparoscopic placement of a non-adjustable silicone ring around the gastric pouch. The aim of this procedure is to increase the volume restriction.

The procedure can be performed in a mean operative time of 1.3 hours.

After a mean follow-up of 1.1 years, an increased mean weight loss of $9.2 \mathrm{~kg}$ and \%EWL of 23.4 points were achieved, as well as a decrease of 3.1 points in the mean BMI.

There was no postoperative morbidity or mortality and, during the follow-up period, no erosions or slippage of the ring were observed.

In conclusion, patients with RYGB and weight loss issues related to the alimentary behavior of hyperphagia can be treated by the placement of a band around the gastric pouch.

\section{Chapter 9. Laparoscopic Conversion of Roux-en-Y Gastric Bypass to Distal RYGB} In patients with RYGB, weight loss issues not related to technical aspects but rather to a dietary habit such as polyphagia can be treated by laparoscopic conversion of standard RYGB to distal RYGB. Polyphagia includes mainly grazing or eating meals too frequently. The new procedure results in malabsorption and can be compared to the other malabsorptive procedures described (biliopancreatic diversion and DS). 
The laparoscopic revision consists of the dismantling of the previous jejunojejunostomy and the transposition of the alimentary bowel loop more distally on the common loop to reach a sum of $300 \mathrm{~cm}$ between the previous alimentary limb (usually $150 \mathrm{~cm}$ ) and the new common limb $(150 \mathrm{~cm}$ ). The new jejunojejunostomy will be performed at this level, closer to the ileocecal valve. Obviously, patients undergoing this surgical revision must be informed of its potential for increased flatulance, frequent bowel movements due to malabsorption and deficiencies of micronutrients and proteins.

This bariatric revision can be performed in a mean operative time of 2 hours.

In this retrospective study, 7 patients were evaluated and followed-up for a mean time of 1.5 years. These patients increased their mean weight loss by $38 \mathrm{~kg}$ and increased their mean \%EWL by 23.9 points; they also decreased their mean BMI by 13.7 points. In this limited follow-up period, no protein malnutrition or hepatic failures were observed.

In conclusion, this type of bariatric revision should be considered in patients with RYGB presenting weight loss issues mainly associated with polyphagia.

Chapter 10. Laparoscopic Conversion of Roux-en-Y Gastric Bypass (RYGB) to Sleeve Gastrectomy (SG) as First Step of Duodenal Switch (DS)

A nutritionist and a psychologist must evaluate patients presenting weight loss issues not related to technical aspects. If insufficient weight loss or weight regain after RYGB is mainly related to a new mixed alimentary behavior characterized by a grossly increased caloric intake, the laparoscopic conversion of RYGB into a SG can be proposed. In general, SG should be considered the $1^{\text {st }}$ step to a successive malabsorptive procedure such as DS rather than stand-alone surgery.

This laparoscopic conversion involves the dismantling of both the gastrojejunostomy and jejunojejunostomy of the previous RYGB and then the realization of SG after restoring gastric continuity. Finally, small bowel continuity must be restored.

This laparoscopic conversion can be performed in a mean operative time of 3.8 hours.

The presented series consisted of 4 patients who were analyzed after a mean follow-up of 11 months. The patients achieved a mean weight loss of $20.7 \mathrm{~kg}$ and a mean \%EWL of 15.8 points, as well as a decrease of 7 points in mean BMI.

There were no conversions to open surgery and no mortalities. One patient developed a postoperative fistula at the location of restored gastric continuity.

During follow-up, one patient had already been submitted to the $2^{\text {nd }}$ step of DS.

In conclusion, this bariatric revision is feasible and can be proposed to selected patients presenting weight loss issues after RYGB. 
Chapter 11. Laparoscopic Conversion of Roux-en-Y Gastric Bypass (RYGB) to Original Anatomy (OA)

After RYGB, severe problems can be encountered, such as dumping syndrome without postprandial hypoglycemia, intolerance to RYGB-induced restriction, and excessive weight loss.

In dumping syndrome resistant to dietary measures and medical therapy (serotonin antagonists, somatostatin analogs), a band on the gastric pouch or endoscopic restriction using various devices can be useful to slow down the clearance of foods from the gastric pouch and to improve symptoms. When these options are not successful, restoration to the original anatomy $(\mathrm{OA})$ can be considered.

Intolerance to RYGB-induced restriction or too much weight loss can be treated with this conversion as well, but the risk of weight regain during follow-up or the appearance of gastroesophageal reflux must be considered.

Laparoscopic conversion to $\mathrm{OA}$ involves dismantling both the gastrojejunostomy and jejunojejunostomy and creating a new anastomosis between the gastric pouch and the gastric remnant, as well as between the proximal alimentary limb and the proximal biliary limb.

Conversion to $\mathrm{OA}$ can also be considered as a bridge to performing a malabsorptive procedure such as DS in two steps. SG after OA is performed first, and then, after a designated interval of time, the malabsorptive procedure of DS is performed as the $2^{\text {nd }}$ step.

This laparoscopic conversion can be performed in a mean operative time of 2.2 hours.

In this retrospective study, 8 patients submitting to the laparoscopic conversion of RYGB to OA were analyzed. After a mean follow-up of 1.5 years, $50 \%$ of the patients presented weight regain, $25 \%$ of the patients maintained a stable weight, and the remaining 25\% continued losing weight. During this follow-up, gastroesophageal reflux appeared de-novo in three out of eight patients (37.5\%).

In conclusion, the laparoscopic conversion of RYGB to OA is feasible in patients presenting severe problems, such as dumping syndrome, intolerance to RYGBinduced restriction, and weight loss issues, but in general it results in weight regain.

Chapter 12. Single-Access Laparoscopic Adjustable Gastric Band (LAGB) Removal Single-incision laparoscopic surgery (SILS) has recently gained interest mainly to improve cosmetic outcomes but also to reduce abdominal trauma, incisional hernia formation and postoperative pain.

In patient candidates to remove the LAGB, the subcutaneous port must be removed as well. Hence, this scar can be used as the main and single-access site to the abdominal cavity.

In this retrospective study, the preliminary experience of LAGB removal through SILS was reported. The subcutaneous port-site scar was used as the sin- 
gle-access-site to the abdomen, and an 11-mm trocar (for a 10-mm scope) and curved reusable instruments were inserted through the same incision.

There are several advantages of this particular technique. Surgeons work during the entire procedure in an ergonomic position with flexed arms, reaching a working triangulation inside the abdomen. The cost of the procedure is not different from multitrocar laparoscopy because all of the materials are reusable. The procedure can be performed in a mean operative time of less than 1 hour.

In conclusion, patients can benefit from the same procedure of conventional laparoscopy with less abdominal trocars, which most likely will lead to fewer trocar-related complications, such as bleeding, pain, infection and trocar-site hernia.

\subsection{CONCLUSIONS}

Obesity surgery is a rapidly evolving surgical procedure that has become common practice since the introduction of laparoscopic minimally invasive approach. With this approach the image is magnified, the operative field exposure is better, the trauma and postoperative pain are less, the hospital stay and convalescence are reduced, and the patient outcome is improved.

Initially, many existing techniques have been adapted to the minimally invasive approach and applied in patients often without any substantial research. However, more and more new techniques are being tested in a randomized fashion before clinical implementation.

The first part of and the last part of this thesis are focusing on the evaluation of new surgical procedures such as laparoscopic sleeve gastrectomy (SG) and more recently single incision laparoscopic surgery (SILS). Laparoscopic SG can be mainly performed through two different techniques and to control perioperative and postoperative complications, the staple line can be managed in different methods.

SILS consists into perform laparoscopic procedures through a single incision instead of three, five or more incisions, to reduce trauma, postoperative pain and abdominal wall infections and improved the cosmetic outcomes. All bariatric procedures realized by conventional laparoscopy are feasible to be performed through SILS. A future investigation will be the evaluation of revisional bariatric surgery performed through SILS and the application of the robot to the SILS.

Considering the high number of bariatric procedures performed annually, the request of revisional surgery is increasing as well and revisional procedures are feasible to be performed by laparoscopy, achieving the different advantages of minimally invasive approach.

The second part of this thesis is focusing on the evaluation of patients with previous gastric restrictions, like gastric banding, vertical gastroplasty or SG, undergoing to new bariatric procedures with the adjunction of also malabsorption.

Patients with previous mixed procedures, like gastric bypass, submitted to new bariatric operations are considered in the third part of this thesis. 
During revisional bariatric surgery, more than during primary surgery, the selection of the appropriate procedure for each patient appears fundamental and it mainly comes from the analysis of the multidisciplinary counseling between dietician, psychologist, internist and surgeon.

Finally, a supplementary benefit for obese patients undergoing to laparoscopic surgery will be offered by the improvement of the operative rooms with more confortable tables, more magnified views, smaller diameter of staplers and more dedicated bariatric instrument set. 



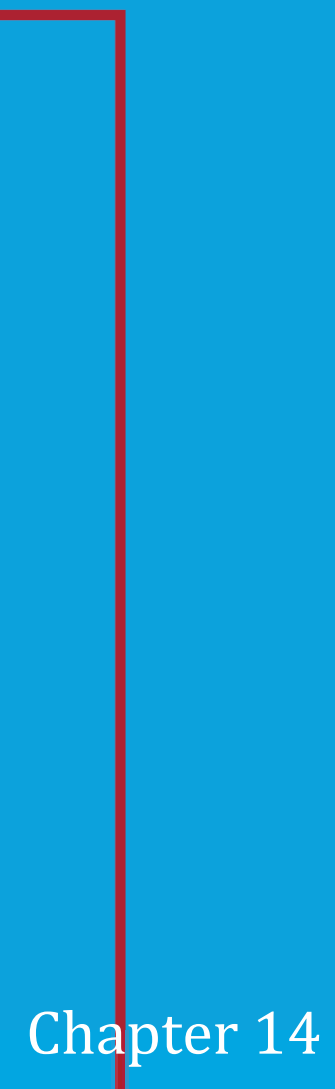

SAMENVATTING \& CONCLUSIE 



\subsection{SAMENVATTING}

Deze thesis kan verdeeld worden in vier delen. In het eerste deel, bestaande uit hoofdstukken 2 en 3, bespreken we sommige technische aspecten van een laparoscopische sleeve gastrectomie (SG).

In het tweede deel, bestaande uit hoofdstukken 4 en 7, beschrijven we de verscheidene laparoscopische conversies bij patiënten met voorafgaande restrictieve ingrepen, zoals laparoscopische adjustable gastric banding (LAGB) en vertical banded gastroplastie (VBG) en SG.

In het derde deel, bestaande uit hoofdstukken 8 en 11, beschrijven we de verschillende conversies die worden uitgevoerd na een Roux-en-Y gastric bypass (RYGB).

In het vierde deel, bestaande uit hoofdstuk 12, beschrijven we de evolutie van conventionele laparoscopie voor bariatrische heelkunde en dit via één enkele incisie of enkele-toegang en niet via verschillende trocars.

\section{Hoofdstuk 2. Gerandomiseerde Studie voor de Vergelijking van Twee Technieken voor Laparoscopische Sleeve Gastrectomie (SG)}

De SG heeft aan interesse gewonnen in de laatste 10 jaar. De meest gebruikte techniek is om eerst de curvatura major te devascularizeren van het antrum tot de fundus om vervolgens lineaire nietjes te plaatsen met een orogastrische sonde als calibratie. Deze techniek wordt ook de « lateraal-tot-mediale aanpak » genoemd.

Een andere mogelijke SG techniek bestaat er in te beginnen aan de curvatura minor ter hoogte van het antrum met een orogastrische sonde, via endoscopie geplaatst, als calibratie. De curvatura major wordt gedevasulariseerd na de creatie van de SG. Deze techniek wordt ook de "mediaal-tot-laterale aanpak" genoemd.

In deze gerandomiseerde prospectieve studie werden deze twee laparoscopische technieken vergeleken. De technische aspecten van de dissectie van de hoek van His, van de weefselspanning tijdens de laatste plaatsing van de nietjes en de preventie van eventuele postoperatieve lekken werden geëvalueerd en vergeleken tussen de twee technieken. De dissectie van de maag dicht bij de hoek van His werd gemakkelijker uitgevoerd bij de "mediaal-tot-laterale aanpak". Dit resultaat is waarschijnlijk doordat de hoek van His wordt vrijgemaakt van boven naar beneden en omgekeerd, zodoende kunnen de nietjes geplaatst worden zonder spanning op de maag uit te voeren.

De analyse van de resultaten toonde geen statistische verschillen aan qua operatieduur, perioperatieve bloeding, het aantal gebruikte nietjes, de duur van de hospitalisatie of qua gewichtsverlies.

De conclusie van de studie bevestigde dat er geen significant verschil is tussen de "mediaal-tot-laterale aanpak" en de "lateraal-tot-mediale aanpak". 
Hoofdstuk 3. Gerandomiseerde Studie in Laparoscopische Sleeve Gastrectomie (SG) ter Vergelijking van de Versterking van de Nietjeslijn

De SG procedure kan geassocieerd zijn met zware perioperatieve en postoperatieve complicaties. Tijdens heelkunde is een hemorragie ter hoogte van de nietjeslijn een courant probleem voor de bariatrische chirurg. In de postoperatieve periode is een lek ter hoogte van de maag één van de moeilijkste complicaties om te behandelen. Een lekkage gebeurt meestal in het bovenste deel van de SG in het gebied waar voorheen de hoek van His was.

In deze gerandomiseerde studie werden prospectief drie verschillende technieken voor het managen van de nietjeslijn vergeleken. De technieken waren: geen versterking van de nietjeslijn, versterking van de nietjeslijn met een Gore Seamguard ${ }^{\circledR}$ (Gore Seamguard ${ }^{\circledR}$; W.L. Gore \& Associates, Inc, Flagstaff, AZ) en een hechting van de nietjeslijn.

De resultaten van deze studie toonden aan dat de operatieve tijd om de maag te verkleinen significant kleiner was in de groep zonder versterking van de nietjeslijn. Dit resultaat was hoogstwaarschijnlijk te danken aan het feit dat één enkele nietjeslijn werd gebruikt. Versterking van de nietjeslijn met Gore Seamguard ${ }^{\circledR}$ toonde een statistisch significant verminderd bloedverlies ter hoogte van de nietjeslijn aan, maar een verhoogde kost door het gebruikte materiaal. Geen statistisch significante verschillen werden tussen de groepen gevonden qua verbruik van aantal nietjes of het optreden van postoperatieve complicaties zoals lekkages.

Ter besluit kan de nietjeslijn veilig worden gemanaged tijdens laparoscopische SG, gebruik makende van de drie geanaliseerde technieken.

Men kan een significant verminderde operatieduur waarnemen zonder versterking van de nietjeslijn en verminderd bloedverlies met het gebruik van materiaal om de nietjeslijn te verstevigen.

\section{Hoofdstuk 4. Laparoscopische Conversie van een Laparoscopische Adjustable Gastric Banding (LAGB) naar een Sleeve Gastrectomie (SG)}

De keuze voor een conversie van een LAGB naar een andere bariatrische ingreep blijft een uitdaging en hangt hoofdzakelijk af van de persoonlijke ervaring en overtuiging van de chirurg.

De conversie van een SG in één stap bevat het wegnemen van de LAGB en het tubuliseren van de maag om een SG te creëren. Eén van de mogelijke complicaties die kunnen optreden is een lek ter hoogte van de weggenomen LAGB, door een dissectie in fibrotisch weefsel.

Dit type conversie kan wenselijk zijn bij patiënten met een voorgeschiedenis van volume-eten voor de LAGB en bij wie het gebrek aan gewichtsverlies te wijten kan zijn aan foute voedingskeuzes en een slechte compliantie aan de follow-up die nodig zijn voor het slagen van een LAGB.

In deze retrospectieve studie werden 27 patiënten die een laparoscopische conversie van een LAGB naar een SG ondergingen geanalyseerd na een gemiddelde 
follow-up van 1.5 jaar. De resultaten van deze studie toonden een verhoogd gemiddeld gewichtsverlies van $17.2 \mathrm{~kg}$, een verhoogd gemiddeld \% overgewichtsverlies (\%EWL) van 16.7 punten en een vermindering van de body mass index (BMI) met 4.4 punten aan.

Patiënten die obesitas-gelinkte comorbiditeiten hadden ten tijde van de conversie vertoonden een verdwijning van deze in $41.6 \%$ van de gevallen.

In deze preliminaire studie werden geen conversies naar open heelkunde, postoperatieve lekkages of mortaliteit gevonden.

De gemiddelde operatieve tijd om deze conversie uit te voeren was 2 uur.

In conclusie is laparoscopische conversie van een LAGB naar een SG doenbaar en veilig.

Hoofdstuk 5. Laparoscopische Revisie van een Sleeve Gastrectomie (SG): Re-Sleeve (re-SG) versus Duodenale Switch (DS)

Patiënten die een SG ondergingen kunnen tijdens hun follow-up problemen ondervinden met gewichtstoename of onvoldoende gewichtsverlies. Problemen met gewichtsverlies zijn meestal het resultaat van onaangepaste voedingspatronen na de SG. Problemen als hyperfagie (volume-eten) of polyfagie (te frekwent eten) kunnen voorkomen.

In deze studie werd de behandeling van dit onaangepast voedingsgedrag geevalueerd. Patiënten met hyperfagie na een SG ondergingen een re-SG en patiënten met polyfagie na een SG ondergingen een DS.

Deze retrospectieve studie bevatte 26 patiënten; 7 patiënten met een laparoscopische re-SG en 19 patiënten met een laparoscopische DS. De resultaten werden bekeken na een gemiddelde follow-up van 2 jaar.

$\mathrm{Na}$ een re-SG hadden patiënten een gemiddeld gewichtsverlies van $9.7 \mathrm{~kg}$, met een gemiddelde BMI-daling van 3.6 punten en een gemiddeld overgewichtsverlies van 19.4 punten. Na een DS bereikten patiënten een gemiddeld gewichtsverlies van $26.9 \mathrm{~kg}$ met een gemiddelde BMI-daling van 9.6 punten en een gemiddeld overgewichtsverlies (\%EWL) van 54.2 punten. De betere resultaten met een DS zijn te wijten aan de toevoeging van een malabsorptie, maar soms zijn er ernstige neveneffecten zoals een hypoproteïnemie en diarree.

De comorbiditeiten door obesitas werden opgelost in overeenstemming met het gewichtsverlies.

De gemiddelde operatieve tijd om deze twee laparoscopische ingrepen uit te voeren was gelijkaardig en ongeveer 2.5 uur. Het verschil in resultaten was hoogstwaarschijnlijk door problemen in de uitvoering van een re-SG veroorzaakt door adhesies en door de complexiteit van een DS, hetgeen een meer complexe ingreep is die wordt uitgevoerd in verschillende abdominale kwadranten.

In deze studie waren er geen conversies naar open heelkunde noch postoperative mortaliteit, maar er was wel een significante postoperatieve morbiditeit door lekkages in beide groepen. 
In conclusie zijn laparoscopische revisies door re-SG of DS bij patiënten met voorgaande SG met gewichtsverliesproblemen (door onaangepaste voedingsgewoonten) mogelijk zolang de patiënten geen gastroesophageale reflux hebben. In gevallen met gastroesophageale reflux is de uitvoering van een laparoscopische conversie naar een RYGB aangewezen.

\section{Hoofdstuk 6. Laparoscopische Conversie van een Adjustable Gastric Banding (LAGB) en een Vertical Banded Gastroplasty (VBG) naar een Duodenal Switch (DS)}

Patiënten met een voorgaande LAGB of een VBG kunnen onvoldoende gewichtsverlies hebben of een gewichtstoename door compulsieve eetstoornissen die persisteren na restrictieve ingrepen of door mechanisch falen van een techniek (verglijden van de maagband, hoge bandpositie, VBG nietjesopening).

Het doel van deze retrospectieve studie was om de geselecteerde patiënten te evalueren bij de laparoscopische conversie van een DS in één stap. Deze conversie bevat twee heelkundige fases. De eerste fase is de sectie van de maag om de SG uit te voeren, waarbij men gelijktijdig de voorgaande LAGB wegneemt of waarbij men gelijktijdig de sectie van de voorgaande VBG uitvoert (en de residuele ring of band). De tweede fase is de aanhechting van de SG aan de dunne darm (door het duodenum) om een malabsorptie te creëren. Op deze manier wordt de laparoscopische DS procedure uitgevoerd.

De laparoscopische conversie werd uitgevoerd in een gemiddelde operatieduur van 3.5 uur.

43 patiënten werden geanalyseerd na een gemiddelde follow-up van 2.3 jaar: 31 patiënten met een LAGB en 12 patiënten met een VGB. De revisie had tot resultaat dat er een overgewichtsverlies (\%EWL) van 70.1 punten (LAGB) of 64.3 punten (VBG) werd genoteerd. Dit resultaat werd voornamelijk behaald door de toevoeging van een malabsorptie bij een DS.

Spijtig genoeg waren de mortaliteit en postoperatieve morbiditeit te hoog na deze laparoscopische conversies. Na LAGB overleed 1 patiënt plots in de postoperatieve periode (negatieve lijkschouwing) en majeure vroege complicaties werden gevonden in $6.4 \%$ van de patiënten. Na VBG hadden $50 \%$ van de patënten majeure vroege complicaties en 3 patënten overleden buiten het ziekenhuis tijdens hun follow-up periode.

De conclusie van deze analyse was om dit soort revisie niet meer uit te voeren. Bij patiënten met een VBG wordt nu een laparoscopische conversie naar een distale RYGB verkozen en bij patiënten met een LAGB wordt een twee-stapsprocedure met een SG en LAGB verwijdering uitgevoerd, gevolgd door een tweede stap van een DS (na een vooropgestelde tijd). 
Hoofdstuk 7. Twee-staps Laparoscopische Duodenale Switch (DS)

Omdat deze bestaat uit een restrictieve en een malabsorbatieve component kan de DS in twee stappen worden uitgevoerd met een vooropgestelde tijd tussen de twee ingrepen. Daarenboven dient deze ingreep in twee stappen te worden uitgevoerd voor super-obesen en super super-obesen door de bewezen verminderde incidentie van complicaties en mortaliteit.

In deze retrospectieve studie werd de twee-staps laparoscopische DS voor de behandeling van super-obesen en super super-obesen geëvalueerd. Een totaal aantal van 31 patiënten ondergingen de tweede stap van een DS na een gemiddelde van 1.1 jaar na een SG. Deze patiënten werden geëvalueerd na een gemiddelde follow-up van 2.4 jaar. De tweede stap (malabsorbatieve procedure) verhoogde het gemiddelde gewichtsverlies met $36.9 \mathrm{~kg}$ en verminderde de BMI met 12.6 punten. Geen conversies naar open heelkunde noch postoperatieve overlijdens werden geregistreerd, maar complicatieratio's van $12.9 \%$ in het vroege postoperatieve verloop en $10.7 \%$ tijdens follow-up werden geobserveerd.

Na de tweede stap van de DS waren $51.1 \%$ van de obesitas gerelateerde comorbiditeiten opgelost.

De tweede stap van de laparoscopische DS werd uitgevoerd in een gemiddelde operatietijd van 3 uur. Heden worden super-obesen en super super-obesen behandeld met een twee-staps DS met uitzondering van patiënten met een maagdilatatie of gastroesophageale reflux na de eerste stap van de SG. In gevallen van maagdilatatie of gastroesophageale reflux zullen patiënten worden hernomen en laparoscopische re-SG of een conversie naar een laparoscopische RYGB zal voorgesteld worden.

Hoofdstuk 8. Laparoscopische Revisie van een Roux-en-Y Gastric Bypass (RYGB) naar een Banded RYGB

Patiënten die een RYGB ondergingen kunnen tijdens hun follow-up een gewichtstoename of een onvoldoende gewichtsverlies ondervinden. Gewichtsverliesproblemen kunnen het resultaat zijn van technische aspecten zoals verwijding van de maag of stomadilatatie, gastro-gastrische fistels of onaangepaste voedingsgewoonten.

In deze retrospectieve studie werd een groep van 6 patiënten geëvalueerd met een nieuwe gewichtstoename na een RYGB, voornamelijk geassocieerd met een hyperfagie of volume-eten. De behandeling bestond uit de laparoscopische plaatsing van een niet-aanpasbare siliconering rond de maag. Het doel van deze ingreep is de volumerestrictie te laten toenemen.

De procedure kan uitgevoerd worden in een gemiddelde operatietijd van 1.3 uur.

Na een gemiddelde follow-up van 1.1 jaar werd een gewichtsverlies van $9.2 \mathrm{~kg}$ en een overgewichtsverlies (\%EWL) van 23.4 punten waargenomen. Eveneens was er een afname van 3.1 punten in de gemiddelde BMI. 
Er was geen postoperative morbiditeit of mortaliteit en tijdens de follow-up periode werden geen erosies of verplaatsingen van de ring waargenomen.

In conclusie kunen patiënten met een RYGB met gewichtsverliesproblemen door hun voedingspatroon of hyperfagie behandeld worden door banding van de maag.

Hoofdstuk 9. Laparoscopische Conversie van een Roux-en-Y Gastric Bypass (RYGB) naar een Distale RYGB

Bij patiënten met een RYGB kunnen gewichtsverliesproblemen die niet voortkomen uit technische aspecten, maar eerder door voedingsgewoonten worden veroorzaakt zoals polyfagie, worden behandeld door een laparoscopische conversie van een standaard RYGB naar een distale RYGB. Polyfagie betreft voornamelijk het te frekwent eten. De nieuwe ingreep resulteert in een malabsorptie en kan vergeleken worden met andere malabsorbatieve ingrepen (biliopancreatische diversie en DS).

De laparoscopische revisie omvat een losmaking van de voorgaande jejunostomie en een distale transpositie van de alimentaire darmlus naar de gemeenschappelijke lus om $300 \mathrm{~cm}$ tussen de voorgaande alimentaire tak (meestal 150 $\mathrm{cm})$ en de gemeenschappelijke tak $(150 \mathrm{~cm})$ te bereiken. De nieuwe jejunostomie zal worden uitgevoerd op dit niveau, dichter bij de ileocaecale klep. Uiteraard dienen patiënten die deze heelkundige ingreep gaan ondergaan geïnformeerd worden over een verhoogd risico op flatulentie, frekwente darmbewegingen door malabsorptie en deficiënties in micronutriënten en proteïnen.

Deze bariatrische herziening kan uitgevoerd worden in een gemiddelde operatietijd van 2 uur.

In deze retrospectieve studie werden 7 patiënten geëvalueerd en opgevolgd voor een gemiddelde duur van 1.5 jaar. Deze patiënten verhoogden hun gemiddeld gewichtsverlies met $38 \mathrm{~kg}$ en verhoogden hun overgewichtsverlies (\%EWL) met 23.9 punten. Evenals verminderden ze hun gemiddelde BMI met 13.7 punten. Tijdens deze gelimiteerde follow-up periode werden geen proteïnemalnutritie of leverfalen geobserveerd.

In conclusie zou dit type bariatrische revisie moeten overwogen worden bij patiënten die gewichtsverliesproblemen ondervinden hoofdzakelijk door polyfagie.

Hoofdstuk 10. Laparoscopische Conversie van een Roux-en-Y Gastric Bypass (RYGB) naar een Sleeve Gastrectomie (SG) als eerste stap naar een Duodenal Switch (DS)

Een nutritionist en een psycholoog dienen patiënten te evalueren met gewichtsverliesproblemen die niet voortkomen uit technische aspecten. Indien onvoldoende gewichtsverlies of gewichtstoename na een RYGB hoofdzakelijk voortkomen uit een gemengd voedingspatroon gekarakteriseerd door een sterk verhoogde calorie- 
inname, kan men een laparoscopische conversie van een RYGB naar een SG voorstellen. In het algemeen dient een SG aanzien te worden als een eerste stap naar een daaropvolgende malabsorptieve ingreep zoals een DS in tegenstelling tot een stand-alone heelkunde.

Deze laparoscopische ingreep omvat het losmaken van zowel de gastrojejunostomie als de jejunojejunostomie van de voorafgaande RYGB en de daaropvolgende SG na het herstellen van de maagcontinuïteit. Uiteindelijk dient de dunne darmcontinuïteit te worden hersteld.

Deze laparoscopische ingreep kan uitgevoerd worden in een gemiddelde operatietijd van 3.8 uur.

De gepresenteerde data omvatte 4 patiënten die werden geanalyseerd na een gemiddelde opvolging van 11 maanden. De patiënten bereikten een gemiddeld gewichtsverlies van $20.7 \mathrm{~kg}$ en een gemiddeld overgewichtsverlies (\%EWL) van 15.8 punten; evenals een vermindering van hun gemiddelde BMI met 7 punten.

Er waren geen conversies naar open heelkunde noch mortaliteiten. Eén patient ontwikkelde een postoperatieve fistel op de plaats van de herstelde maagcontinuïteit.

Tijdens de follow-up had één patient de tweede stap van de DS al ondergaan. In conclusie is deze bariatrische herziening uitvoerbaar en kan ze worden voorgesteld aan geselecteerde patiënten die gewichtsverliesproblemen ondervinden na een RYGB.

Hoofdstuk 11. Laparoscopsiche Conversie van een Roux-en-Y Gastric Bypass (RYGB) naar de Oorspronkelijke Anatomie (OA)

$\mathrm{Na}$ een RYGB kunnen zich ernstige problemen voordoen, zoals het dumping syndroom zonder postprandiale hypoglycemie, intolerantie voor de RYGB-geïnduceerd restrictie en overmatig gewichtsverlies.

Bij het dumping syndroom dat niet beantwoordt aan voedingsmaatregelen en medische behandeling (serotonine antagonisten, somatostatine analogen), kan er een banding van de maag worden uitgevoerd of een endoscopische restrictie die gebruik maakt van verscheidene hulpmiddelen om de maaglediging te vertragen en om symptomen te verbeteren. Indien dit niet helpt kan men een conversie naar de originele anatomie (OA) voorstellen.

Intolerantie voor de RYGB-geïnduceerde restrictie, evenals een te groot gewichtsverlies kan met deze conversie worden behandeld. Een te grote gewichtstoename tijdens opvolging zowel als het verschijnen van gastroesophageale reflux dient in overweging te worden genomen.

Laparoscopische conversie naar OA omvat het losmaken van de gastrojejunostomie en de jejunojejunostomie en het creëren van een nieuwe anastomose tussen de maagzak en het restant van de maag, zowel als tussen de proximale alimentaire tak en de proximale biliaire tak. 
Conversie naar OA kan eveneens worden overwogen als een overgang naar het uitvoeren van een malabsorptieve procedure zoals een DS in twee stappen. SG na OA wordt eerst uitgevoerd, waar na een vooropgestelde tijd de malabsorptieve procedure van een DS wordt gedaan.

Deze laparoscopische conversie kan uitgevoerd worden in een gemiddelde operatietijd van 2.2 uur.

In deze retrospectieve studie werden 8 patiënten die een conversie van een laparoscopische RYGB naar OA ondergingen geanalyseerd. $\mathrm{Na}$ een gemiddelde follow-up van 1.5 jaar hadden $50 \%$ van de patiënten een gewichtstoename, $25 \%$ van de patiënten hadden een stabiel gewicht en de overige $25 \%$ bleven gewicht verliezen. Tijdens deze follow-up hadden drie van de acht (37.5\%) patiënten een de novo gastroesophageale reflux.

Ter conclusie is de laparoscopische conversie van een RYGB naar OA uitvoerbaar bij patiënten met ernstige problemen zoals dumping syndroom, intolerantie van een RYGB-geïnduceerde restrictie en gewichtsverliesproblemen, maar het vertaalt zich meestal in een nieuwe gewichtstoename.

\section{Hoofdstuk 12. Single-Access Laparoscopische Adjustable Gastric Band (LAGB) wegname}

Single-incision laparoscopic surgery (SILS) heeft aan interesse gewonnen, voornamelijk om de esthestische resultaten te verbeteren, maar eveneens om abdominaal trauma, incisionele herniavorming en postoperatieve pijn te verminderen.

Bij patiënten die zich presenteren voor een wegname van een LAGB dient het subcutane reservoir ook te worden weggenomen. Dit litteken kan dus worden gebruikt als voornaamste en enige toegang tot de abdominale caviteit.

In deze retrospectieve studie werden de preliminaire resultaten met de wegname van een LAGB via SILS getoond. Het litteken van het subcutane reservoir werd gebruikt als enige toegang en een 11- mm trocar (voor een 10-mm scoop) en gebogen herbruikbare instrumenten werden ingebracht door dezelfde incisie.

Er zijn verscheidene voordelen van deze techniek. Chirurgen werken gedurende de gehele ingreep in een ergonomische houding met gebogen armen, terwijl ze via een werkende triangulatie kunnen werken in het abdomen. De kostprijs van deze procedure is niet verschillend van een multitrocar laparoscopie aangezien alle materiaal herbruikbaar is. De ingreep kan uitgevoerd worden in een gemiddelde operatietijd van minder dan 1 uur.

Ter besluit kunnen patiënten van dezelfde procedure als met conventionele laparoscopie genieten met minder abdominale trocars, wat hoogstwaarschijnlijk minder trocar-gelinkte complicaties zoals bloeding, pijn, infectie en hernia tot gevolg zullen hebben. 


\subsection{CONCLUSIE}

Obesitasheelkunde is een snel evoluerende tak van de geneeskunde sinds de introductie van de minimaal invasieve laporoscopie. Met deze aanpak wordt het beeld vergroot, het zicht op het operatieveld verbeterd, de postoperatieve pijn en trauma verminderd, de hospitalisatieduur en revalidatie verkort en de patiëntenoutcome verbeterd.

Initieel werden vele bestaande technieken aangepast aan de minimaal invasieve aanpak en dit werd bij patiënten gebruikt zonder voorafgaand onderzoek. $\mathrm{Nu}$ daarentegen worden meer en meer nieuwe technieken op een gerandomiseerde manier onderzocht en getest voor hun klinische implementatie.

Het eerste en het laatste deel van deze thesis handelen over de evaluatie van nieuwe heelkundige ingrepen zoals de laparoscopische sleeve gastrectomie (SG) en meer recent de ontwikkeling van de enkele-toegang laparoscopie (single incision laparoscopic surgery of SILS). Laparoscopische SG kan hoofdzakelijk uitgevoerd worden via twee verschillende technieken en om peri-en postoperatieve complicaties te verminderen kan de nietjeslijn op verschillende manieren worden uitgevoerd.

SILS bestaat er in laparoscopische procedures uit te voeren via één enkele incisie in tegenstelling tot drie, vijf of meerdere incisies en dit om trauma, postoperatieve pijn en abdominale wandinfecties te verminderen en om esthetische resultaten te verbeteren. Alle bariatrsiche ingrepen die via conventionele laparoscopie worden uitgevoerd kunnen worden gedaan via SILS. Verder onderzoek zal de evaluatie zijn van revisies in de bariatrische heelkunde via SILS en het gebruik van de robot voor SILS.

Aangezien het grote aantal bariatrische procedures die jaarlijks worden uitgevoerd, wordt de vraag naar revisionele heelkunde groter. Nieuwe ingrepen kunnen worden uitgevoerd via laparoscopie en dit brengt de verschillende voordelen van de minimaal-invasieve aanpak met zich mee.

Het tweede deel van deze thesis handelt over de evaluatie van patiënten met voorafgaande restrictieve ingrepen, zoals een maagband, vertikale gastroplastie of SG die vervolgens een nieuwe bijkomende malabsorptieve bariatrische ingreep ondergaan.

Het derde deel van deze thesis handelt over patiënten die voorafgaand gemengde ingrepen zoals een gastric bypass ondergingen en die daarna een nieuwe bariatrische ingreep ondergaan.

Tijdens revisionele bariatrische heelkunde dient men, meer dan tijdens de eerste ingreep, de aangepaste ingreep voor elke patiënt te kiezen en dit gebeurt best in een multidisciplinair team met een voedingsdeskundige, een psycholoog, een internist en een chirurg.

Tenslotte zal men naar de toekomst toe meer voorzieningen treffen voor obese patiënten die een laparoscopische ingreep ondergaan door de verbetering van 
operatiezalen met meer comfortabele tafels, meer vergrote beelden, kleinere nietjes en instrumenten die speciaal worden ontworpen voor bariatrische heelkunde. 


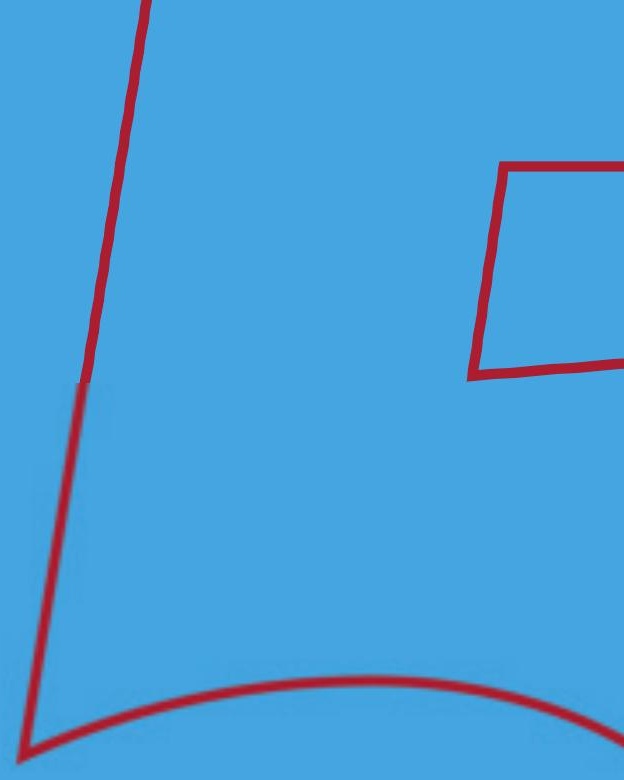

Chapter 15

RIASSUNTO \& CONCLUSIONI

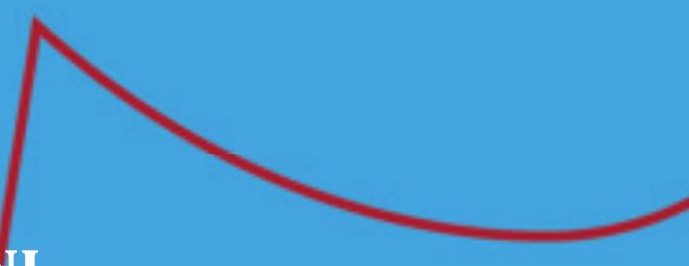





\subsection{RIASSUNTO}

Questa tesi puo' essere divisa in 4 sezioni principali. La prima sezione, capitoli 23 , discute alcuni aspetti tecnici per la realizzazione della gastrectomia sleeve laparoscopica (SG).

La seconda sezione, capitoli 4-7, descrive le varie conversioni laparoscopiche realizzate in pazienti con precedenti procedure restrittive, come l'anello gastrico aggiustabile laparoscopico (LAGB), la gastroplastica verticale (VBG) e la SG.

La terza sezione, capitoli 8-11, descrive le differenti conversioni laparoscopiche realizzate in pazienti dopo bypass gastrico Roux-en-Y (RYGB).

La quarta sezione, capitolo 12, riporta l'evoluzione della laparoscopia convenzionale verso la realizzazione della chirurgia bariatrica non attraverso la tecnica multitrocart ma piuttosto attraverso una singola incisione o un singolo accesso laparoscopico.

\section{Capitolo 2. Studio Randomizzato Paragonante Due Tecniche per la Gastrectomia Sleeve (SG) Laparoscopica}

La procedura di SG ha guadagnato interesse nell'ultima decade. La piu' comune tecnica usata consiste nella devascolarizzazione della grande curvatura dello stomaco, dall'atrio fino al fondo gastrico, e poi nella sezione dello stomaco usando linee di agrafes e seguendo un tubo orogastrico come tutore. Questa tecnica e' anche chiamata l' "approccio da laterale a mediale".

Un'altra possibile tecnica di SG consiste nell'apertura della retrocavita' degli epiploon a livello dell'atrio e nella sezione dello stomaco per primo, lungo un tubo orogastrico spinto endoscopicamente. La grande curvatura dello stomaco viene devascolarizzata dopo la creazione della SG. Questa tecnica e' anche chiamata l' "approccio da mediale a laterale".

In questo studio randomizzato, questi due metodi di SG laparoscopica sono stati paragonati in maniera prospettica. Essenzialmente, gli step tecnici di dissezione dell'angolo di His, della tensione del tessuto durante l'ultima linea di agrafes, della prevenzione della potenziale perforazione postoperatoria in questa area sono stati valutati e paragonati tra le due tecniche. La dissezione dello stomaco vicino all'angolo di His e' stata trovata piu' facile da realizzare durante l' "approccio da mediale a laterale", e questo risultato e' piuttosto dovuto alla liberazione dell'angolo di His dall'alto verso il basso e viceversa, che permette l'introduzione della suturatrice e soprattutto la sezione dello stomaco senza alcuna tensione. L'analisi dei risultati non ha dimostrato differenze statisticamente significative per quanto riguarda il tempo operatorio, il sanguinamento perioperatorio, il numero di agraphes usate, la degenza ospedaliera o la perdita di peso.

Le conclusioni dello studio hanno confermato la differenza non significativa tra l' "approccio da mediale a laterale" e l' "approccio da laterale a mediale". 


\section{Capitolo 3. Studio Randomizzato di Gastrectomia Sleeve (SG) Laparoscopica Paragonante il Rinforzo della Linea di Sutura}

La procedura di SG puo' essere associata a importanti complicanze perioperatorie e postoperatorie. Durante la chirurgia, l'emorragia della linea di sutura e' un frequente problema incontrato dai chirurghi bariatrici. Nel periodo postoperatorio, la perforazione gastrica e' una delle piu' difficili complicanze da trattare. La perforazione gastrica occorre di solito nella parte alta della SG, nell'area del precedente angolo di His.

In questo studio randomizzato, tre differenti tecniche di trattamento della linea di sutura durante SG laparoscopica sono state paragonate in maniera prospettica. Le tecniche includono il non rinforzo della linea di sutura, l'utilizzo sulla linea di sutura del Gore Seamguard ${ }^{\circledR}$ (Gore Seamguard ${ }^{\circledR}$; W.L. Gore \& Associates, Inc, Flagstaff, AZ), e il rinforzo con filo della linea di sutura.

I risultati dello studio hanno dimostrato che il tempo operatorio per realizzare la sezione dello stomaco appare essere statisticamente siginificativo piu' basso nel gruppo del non rinforzo della linea di sutura. Questo risultato e' associato semplicemente al fatto che una semplice suturatrice ha sezionato lo stomaco. L'utilizzo del Gore Seamguard ${ }^{\circledR}$ sulla linea di sutura ha dimostrato una perdita di sangue dalla linea di sutura statisticamente significativa piu' bassa, ma un aumento del costo della procedura dovuto al materiale usato. Nessuna differenza statisticamente significativa e' stata trovata tra i gruppi per quanto riguarda il numero di agrafes utilizzate o l'occorrenza delle complicanze postoperatorie, come le perforazioni gastriche.

In conclusione, la linea di sutura puo' essere trattata con sicurezza durante la SG laparoscopica usando tutte e tre le tecniche analizzate, raggiungendo un significativo ridotto tempo operatorio con il non rinforzo della linea di sutura e una ridotta perdita di sangue dalla linea di sutura con l'utilizzo del Gore Seamguard ${ }^{\circledR}$.

\section{Capitolo 4. Conversione Laparoscopica di Anello Gastrico Aggiustabile (LAGB) a Gastrectomia Sleeve (SG)}

La scelta di conversione di LAGB in un'altra procedura bariatrica rimane difficile e primariamente dipende dall'esperienza personale del chirurgo e dalla sua filosofia.

La conversione in SG in uno step unico interessa la rimozione del LAGB e la tubulizzazione dello stomaco per creare la SG. Una delle immediate possibili complicanze che possono occorrere con questa chirurgia e' lo sviluppo della perforazione gastrica nell'area del precedente LAGB, dovuta alla sezione gastrica in un'area fibrotica.

Questo tipo di conversione puo' essere indicato in pazienti con un storia di comportamento alimentare tipo grandi mangiatori prima della procedura di LAGB e in quelli dove il fallimento della perdita di peso potrebbe essere dovuta alla povera scelta di alimenti e alle poche visite di controllo da parte del paziente, fattori considerati necessari per il successo dell'intervento di LAGB. 
In questo studio retrospettivo, 27 pazienti sottoposti a conversione laparoscopica da LAGB a SG sono stati analizzati dopo un follow-up medio di 1.5 anni. I risultati dello studio hanno dimostrato un aumento medio di perdita di peso di $17.2 \mathrm{~kg}$, un aumento medio della \% dell'eccesso della perdita di peso (EWL) di 16.7 punti, e una riduzione media dell'indice di massa corporea (BMI) di 4.4 punti.

I pazienti che presentavono malattie associate all'obesita' al momento della conversione hanno dimostrato una risoluzione di queste malattie in $41.6 \%$ dei casi.

In questa esperienza preliminare, non e' stata riscontrata nessuna conversione in chirurgia aperta, perforazione gastrica postoperatoria o mortalita'.

Il tempo operatorio medio per realizzare questa conversione in laparoscopia $\mathrm{e}^{\prime}$ stato di 2 ore.

In conclusione, la conversione laparoscopica di LAGB a SG e' fattibile e sicura.

Capitolo 5. Revisione Laparoscopica di Gastrectomia Sleeve (SG): Re-Sleeve (re-SG) verso Switch Duodenale (DS)

Pazienti sottoposti a SG possono presentare durante il follow-up problemi di ripresa di peso o insufficiente perdita di peso. I problemi di perdita di peso sono di solito il risultato di abitudini di dieta inappropriate, adottate dal paziente dopo SG. I problemi possono essere di iperfagia (es. grandi mangiatori) o polifagia (es. pasti piccoli e frequenti).

In questo studio, e' stato valutato il trattamento di questi comportamenti alimentari inappropriati. Pazienti con iperfagia dopo SG sono stati sottomessi a re-SG, e pazienti con polifagia dopo SG sono stati convertiti a switch duodenale (DS).

Questo studio retrospettivo ha incluso 26 pazienti: 7 pazienti sottoposti a reSG laparoscopico, e 19 pazienti sottoposti a DS laparoscopico. I risultati sono stati rivisti dopo un follow-up medio di 2 anni.

Dopo re-SG, i pazienti hanno avuto una perdita di peso media di $9.7 \mathrm{~kg}$, con una riduzione media di BMI di 3.6 punti e un aumento medio di \%EWL di 19.4 punti. Dopo DS, i pazienti hanno registrato una pedita di peso media di $26.9 \mathrm{~kg}$, con una riduzione media di BMI di 9.6 punti e un aumento medio di \%EWL di 54.2 punti. I risultati superiori di DS sono dovuti all'aggiunta di malassorbimento, che qualche volta e' a associata all'apparizione di effetti collaterali come ipoproteinemia e diarrea.

Le malattie associate all'obesita' sono state risolte grazie alla perdita di peso registrata dai pazienti.

Il tempo operatorio medio per realizzare queste due procedure laparoscopiche e' risultato simile e di circa 2.5 ore. I risultati differenti furono piuttosto correlati alla difficolta' di realizzazione del re-SG, causata dalle aderenze e alla complessita' di realizzazione del DS, che e' una procedura piu' complessa perche' interessa differenti quadranti addominali. 
In questo studio, non ci furono conversioni in chirurgia aperta o mortalita' postoperatoria, ma c'e stata una significativa morbidita' postoperatoria dovuta alle perforazioni gastriche registrate in entrambi i gruppi.

In conclusione, le revisioni laparoscopiche di re-SG o DS in pazienti con precedente SG e con problemi di perdita di peso (dovuta a inappropriate abitudini alimentari) sono fattibili fino a quando i pazienti non presentano un reflusso gastroesofageo. In casi di reflusso gastroesofageo, una conversione laparoscopica in RYGB e' preferita.

\section{Capitolo 6. Conversione Laparoscopica di Anello Gastrico Aggiustabile (LAGB) e Gastroplastica Verticale (VBG) a Switch Duodenale (DS)}

Pazienti con precedenti LAGB o VBG possono presentare problemi di perdita di peso come insufficiente perdita di peso o ripresa di peso dovuti a disordini alimentari compulsivi presenti dopo entrambi gli interventi o dovuti a fallimenti tecnici degli interventi subiti (scivolamento dell'anello, posizione alta dell'anello, aperture delle agrafes del VBG).

Lo scopo di questo studio retrospettivo e' stato di valutare pazienti selezionati trattati mediante conversione laparoscopica in DS in un unico step. Questa conversione interessa due fasi chirurgiche. La prima fase e' la sezione dello stomaco per realizzare la SG insieme alla rimozione del precedente LAGB o alla sezione della precedente VBG (e dell'anello o benda residua). La seconda fase e' l'unione della SG al piccolo intestino (attraverso il duodeno) per creare il malassorbimento. In questa maniera la procedura di DS laparoscopica e' realizzata.

La conversione laparoscopica e' stata realizzata in un tempo operatorio medio di 3.5 ore.

Quarantatre pazienti sono stati analizzati dopo un follow-up medio di 2.3 anni: 31 pazienti con LAGB e 12 pazienti con VBG. La revisione e' risultata in una media di \%EWL di 70.1 punti (LAGB) o 64.3 punti (VBG). Questo risultato e' stato principalmente ottenuto dall'aggiunta del malassorbimento con DS.

Sfortunatamente la mortalita' e morbidita' postoperatoria sono state troppo alte dopo questa conversione laparoscopica. Dopo LAGB, un paziente e' morto improvvisamente nel postoperatorio (autopsia negativa), e complicanze precoci maggiori sono state registrate in $6.4 \%$ dei pazienti. Dopo VBG, $50 \%$ dei pazienti hanno presentato complicanze precoci maggiori, e 3 pazienti sono morti durante il periodo di follow-up, dopo la loro dimissione dall'ospedale.

La conclusione di questa analisi e' stata di abbandonare questo tipo di revisione. In pazienti con VBG, una conversione laparoscopica in RYGB distale e' ora preferita, e in pazienti con LAGB, una procedura in due step con SG e rimozione di LAGB, seguita dal secondo step di DS (dopo un appropriato intervallo di tempo) e' preferita. 
Capitolo 7. Switch Duodenale (DS) Laparoscopico in Due Step

Il DS puo' essere realizzato in due step, con un appropriato intervallo di tempo fra le due procedure, grazie al fatto di essere composto da una componente restrittiva e una malassorbitiva. Per di piu', questa procedura deve essere realizzata in due step per i pazienti super-obesi e super super-obesi perche' e' stata provata la ridotta incidenza di complicanze postoperatorie e mortalita'.

In questo studio retrospettivo, e' stata valutata l'esperienza totale del DS laparoscopico in due step per il trattamento di pazienti super-obesi e super superobesi. Un totale di 31 pazienti sono stati sottoposti al secondo step di DS dopo SG, dopo un intervallo di tempo medio di 1.1 anni. Questi pazienti sono stati valutati dopo un follow-up medio di 2.4 anni. Il secondo step (processo malassorbitivo) ha aumentato la perdita di peso media di $36.9 \mathrm{~kg}$ e ridotto il BMI medio di 12.6 punti. Nessuna conversione a chirurgia aperta o morte postoperatoria sono state registrate, ma sono state osservate una complicanza del $12.9 \%$ nel decorso postoperatorio precoce e del $10.7 \%$ durante il follow-up.

Dopo il secondo step di DS, 51.1\% delle malattie associate alla obesita' sono state risolte.

Il secondo step di DS laparoscopico e' stato realizzato in un tempo operatorio medio di 3 ore.

Attualmente, i pazienti super-obesi e super super-obesi sono trattati con il DS in due step all'eccezione dell'apparizione della dilatazione gastrica o reflusso gastroesofageo dopo primo step di SG. In casi di dilatazione gastrica o reflusso gastroesofageo, i pazienti sono revisionati e una re-SG laparoscopica o conversione a RYGB laparoscopica, e' rispettivamente proposta.

Capitolo 8. Revisione Laparoscopica di Bypass Gastrico Roux-en-Y (RYGB) a RYGB con Bendaggio

Pazienti sottoposti a RYGB possono presentare durante il follow-up una ripresa di peso o un'insufficiente perdita di peso. Problemi di perdita di peso possono risultare da aspetti tecnici come una dilatazione della tasca gastrica o dell'anastomosi, la presenza di fistola gastro-gastrica o un inappropriato comportamento alimentario.

In questo studio retrospettivo, un gruppo di 6 pazienti e' stato valutato; i pazienti presentavono o una ripresa di peso dopo RYGB, principalmente associata a iperfagia, o erano grossi mangiatori. Il trattamento e' consistito nel posizionare un anello di silicone non regolabile intorno alla tasca gastrica per via laparoscopica. Lo scopo di questa procedura e' stato di aumentare la restrizione del volume gastrico.

La procedura puo' essere realizzata in un tempo operatorio medio di 1.3 ore.

Dopo un follow-up medio di 1.1 anni, e' stato raggiunto un aumento della perdita di peso media di $9.2 \mathrm{~kg}$ e di \%EWL di 23.4 punti, e una riduzione media di BMI di 3.1 punti. 
Non c'e' stata nessuna morbidita' o mortalita' postoperatoria e, durante il periodo di follow-up, nessuna erosione o scivolamento dell'anello sono state osservate.

In conclusione, pazienti con RYGB e problemi di peso associati a un comportamento alimentario di iperfagia possono essere trattati con il posizionamento di anello non regolabile intorno alla tasca gastrica.

\section{Capitolo 9. Conversione Laparoscopica di Bypass Gastrico Roux-en-Y (RYGB) a RYGB Distale}

In pazienti con RYGB, problemi di perdita di peso non associati a aspetti tecnici ma piuttosto a abitudini alimentari come polifagia possono essere trattati con la conversione laparoscopica del RYGB standard a RYGB distale. Polifagia include principalmente il mangiare piccoli pasti frequentemente. La nuova procedura risulta in un processo di malassorbimento e puo' essere paragonata alle altre procedure malassorbitive descritte (diversione biliopancreatica e DS).

La revisione laparoscopica consiste nella sezione della precedente digiunodigiunostomia e nella transposizione dell'ansa intestinale alimentare piu' distalmente sull'ansa intestinale comune per raggiungere una somma di $300 \mathrm{~cm}$ tra la precedente ansa alimentare (di solito $150 \mathrm{~cm}$ ) e la nuova ansa comune $(150 \mathrm{~cm}$ ). La nuova digiunodigiunostomia sara' realizzata a questo punto, e piu' vicino alla valvola ileocecale. Ovviamente, pazienti sottoposti a questa revisione chirurgica devono essere informati del potenziale aumento di flatulenza, frequenti movimenti intestinali dovuti al malassorbimento e deficit di micronutrienti e proteine.

Questa revisione bariatrica puo' essere realizzata in un tempo operatorio medio di 2 ore.

In questo studio retrospettivo, 7 pazienti sono stati valutati e seguiti nel follow-up per un tempo medio di 1.5 anni. Questi pazienti hanno aumentato la loro perdita di peso media di $38 \mathrm{~kg}$ e aumentato il loro \%EWL medio di 23.9 punti; hanno anche diminuito il loro BMI medio di 13.7 punti. In questo limitato periodo di follow-up, nessuna malnutrizione proteica o disfunzionamento epatico e' stato osservata.

In conclusione, questo tipo di revisione bariatrica dovrebbe essere considerata in pazienti con RYGB presentanti problemi di perdita di peso principalmente associati a polifagia.

Capitolo 10. Conversione Laparoscopica di Bypass Gastrico Roux-en-Y (RYGB) a Gastrectomia Sleeve (SG) come Primo Step di Switch Duodenale (DS)

Pazienti presentanti problemi di perdita di peso non associata ad aspetti tecnici devono essere valutati da un nutrizionista e da uno psicologo. Se l'insufficienza di perdita di peso o ripresa di peso dopo RYGB e' principalmente associata a un nuovo comportamento alimentario misto caratterizzato da aumento di cibo calorico, la conversione laparoscopica di RYGB a SG puo' essere proposta. In generale, 
la SG dovrebbe essere considerata come primo step del successivo procedimento malassorbitivo come DS piuttosto che la chirurgia di SG da sola.

Questa conversione laparoscopica interessa la sezione di entrambe gastrodigiunostomia e digiunodigiunostomia del precedente RYGB e la realizzazione della SG dopo aver restaurato la continuita' gastrica. Alla fine, la conitinuita' del piccolo intestino deve essere realizzata.

Questa conversione laparoscopica puo' essere realizzata in un tempo operatorio medio di 3.8 ore.

La presente serie consiste di 4 pazienti che furono analizzati dopo un follow-up medio di 11 mesi. I pazienti hanno raggiunto una perdita di peso media di $20.7 \mathrm{~kg}$ e un \%EWL medio di 15.8 punti, cosi' come una riduzione di 7 punti di BMI medio.

Non ci sono state conversioni in chirurgia aperta e nessuna mortalita'. Un paziente ha sviluppato una fistola postoperatoria nell'area della restaurata continuita' gastrica.

Durante il periodo di follow-up, un paziente e' stato gia' sottoposto al secondo step di DS.

In conclusione, questa revisione bariatrica e' fattibile e puo' essere proposta a pazienti selezionati presentanti problemi di perdita di peso dopo RYGB.

Capitolo 11. Conversione Laparoscopica di Bypass Gastrico Roux-en-Y (RYGB) a Anatomia Originale (OA)

Dopo RYGB, parecchi problemi possono succedere come la sindrome di dumping senza ipoglicemia postprandiale, l'intolleranza all'indotta restrizione dal bypass, e l'eccessiva perdita di peso.

Difronte a una sindrome di dumping, resistente alle misure dietetiche e alla terapia medica (antagonisti della serotonina, analoghi della somatostatina), un bendaggio della tasca gastrica o una restrizione endoscopica usando vari endoscopi possono essere utili per diminuire lo svuotamento dei cibi dalla tasca gastrica e migliorare i sintomi. Quando queste opzioni non risultano di successo, la ristorazione dell'anatomia originale $(\mathrm{OA})$ puo' essere considerata.

L'intolleranza alla restrizione indotta dal bypass o l'eccessiva perdita di peso puo' esssere trattata con questa conversione, ma il rischio della ripresa di peso durante il follow-up o l'apparizione di reflusso gastroesofageo devono essere considerate.

La conversione laparoscopica a OA coinvolge la sezione di entrambe gastrodigiunostomia e digiunodigiunostomia e crea una nuova anastomosi tra la tasca gastrica e lo stomaco residuo, cosi' come tra l'ansa intestinale prossimale alimentare e l'ansa intestinale prossimale biliare.

La conversione a OA puo' anche essere considerata come un ponte per realizzare una procedura malassorbitiva come il DS in due step. La SG dopo OA e' realizzata per prima, e poi, dopo un appropriato tempo di intervallo, la procedura malassorbitiva di DS e' realizzata come secondo step. 
Questa conversione laparoscopica puo' essere realizzata in un tempo operatorio medio di 2.2 ore.

In questo studio retrospettivo, sono stati analizzati 8 pazienti sottoposti a conversione laparoscopica di RYGB a OA. Dopo un follow-up medio di 1.5 anni, 50\% dei pazienti hanno presentato una ripresa di peso, $25 \%$ dei pazienti hanno mantenuto un peso stabile, e il rimanente $25 \%$ ha continuato a perdere peso. Durante questo follow-up, il reflusso gastroesofageo e' apparso come de-novo in tre degli otto pazienti (37.5\%).

In conclusione, la conversione laparoscopica di RYGB a OA e' fattibile in pazienti presentanti problemi severi, come la sindrome di dumping, l'intolleranza all'indotta restrizione dal bypass e problemi di perdita di peso, ma in generale risulta in una ripresa di peso.

Capitolo 12. Rimozione di Anello Gastrico Aggiustabile (LAGB) con un Solo Accesso Laparoscopico

La chirurgia laparoscopica con una sola incisione (SILS) ha recentemente guadagnato interesse principalmente per la migliorata cosmesi, ma anche per la riduzione del trauma addominale, della formazione di ernia incisionale e del dolore postoperatorio.

Nei pazienti candidati a rimozione di LAGB, il port sottocutaneo deve essere rimosso. Pertanto, questa cicatrice puo' essere usata come il principale e il solo accesso alla cavita' addominale.

In questo studio retrospettivo e' stata riportata l'esperienza preliminare di rimozione di LAGB mediante SILS. La cicatrice del port sottocutaneo e' stata usata come il solo accesso all'addome, e un trocart da 11-mm (per un'ottica da 10-mm), assieme agli strumenti curvi reutilizzabili sono stati inseriti attraverso la stessa incisione.

Ci sono parecchi vantaggi legati a questa particolare tecnica. I chirurghi lavorano durante l'intera procedura in una posizione ergonomica con le braccia flesse e con la triangolazione di lavoro della laparoscopia all'interno dell'addome. Il costo della procedura non e' differente dalla laparoscopia multitrocart perche' tutti i materiali sono reutilizzabili. La procedura puo' essere realizzata in un tempo operatorio medio di meno di un'ora.

In conclusione, i pazienti possono beneficiare della stessa procedura realizzata con la laparoscopia convenzionale ma con ridotto numero di trocart addominali, e probabilmente meno complicanze assocate ai trocart stessi, come sanguinamento, dolore, infezione, e ernia su trocart.

\subsection{CONCLUSIONI}

La chirurgia dell'obesita' e' una procedura chirurgica in rapida evoluzione che e' divenuta pratica comune grazie all'avvento dell'approccio mini-invasivo laparo- 
scopico. Con questo approccio l'immagine e' magnificata, l'esposizione del campo operatorio e' migliore, il trauma e il dolore postoperatorio sono minori, la degenza ospedaliera e la convalescenza sono ridotte, e il futuro del paziente e' migliorato.

Inizialmente, molte tecniche esistenti sono state adottate con l'approccio miniinvasivo e applicate in pazienti spesso senza alcuna sostanziale ricerca. Comunque, sempre piu' nuove tecniche sono state testate in maniera randomizzata prima dell'utilizzo clinico.

La prima parte e l'ultima parte di questa tesi focalizzano la valutazione delle nuove procedure chirurgiche come la gastrectomia sleeve laparoscopica (SG) e piu' recentemente la chirurgica laparoscopica con una sola incisione (SILS). La SG laparoscopica puo' essere principalmente realizzata attraverso due differenti tecniche e la linea di sutura puo' essere trattata in metodi differenti per controllare le complicanze peroperatorie e postoperatorie.

La SILS consiste nel realizzare procedure laparoscopiche attraverso una singola incisione invece di tre, cinque o piu' incisioni, affinche' il trauma, il dolore postoperatorio e le infezioni della parete addominale siano ridotte e l'estetica migliorata. Tutte le procedure bariatriche realizzate in laparoscopia convenzionale sono possibili attraverso la SILS. Una investigazione futura sara' la valutazione della chirurgia bariatrica di revisione realizzata attraverso la SILS e l'applicazione del robot alla SILS.

Considerato l'elevato numero di procedure bariatriche realizzate annualmente, la richiesta di chirurgia di revisione sta aumentando e le procedure di revisione possono essere realizzate in laparoscopia, acquisendo i differenti vantaggi dell'approccio mini-invasivo.

La seconda parte di questa tesi focalizza la valutazione dei pazienti con precedente restrizione gastrica, come il bendaggio gastrico, la gastroplastica verticale $o$ la SG, sottoposti a nuove procedure bariatriche di anche unione a malassorbimento.

I pazienti con precedenti procedure miste, come il bypass gastrico, sottoposti a nuove operazioni bariatriche sono considerati nella terza parte di questa tesi.

Durante la chirurgia bariatrica di revisione, ancor piu' che durante la chirurgia primaria, la selezione dell'appropriata procedura per ogni paziente appare fondamentale e principalmente deriva dall'analisi della consulenza multispecialistica tra dietista, psicologo, internista e chirurgo.

Alla fine, un beneficio supplementare per i pazienti obesi sottoposti a chirurgia laparoscopica sara' offerto dal miglioramento delle sale operatorie con tavoli piu' confortevoli, visioni piu' magnificate, stapler con diametro piu' piccolo e set di strumenti bariatrici piu' dedicati. 

Chapter 16 ADDENDUM 



\subsection{ACKNOWLEDGMENTS}

This thesis is completely dedicated to my mother ("la mamma"), who supported me during these years with force, courage and dedication. I'm happy to offer her this work, which globally summaries the last 9 years passed in Belgium.

I have to thank Prof. dr. Guy-Bernard Cadière and Prof. dr. Jacques Himpens for their teaching laparoscopy in operative theatre and contemporary have permitted me to do this research.

These publications have been composed thanks to the help of Mrs Christine D'Haese, who provided me of each patient's history, and of Mr. Léon Cadière, who contacted the patients during follow-up. I take also the opportunity to thank Mrs Marianne Paesmans, who always gave me the statistical support, and Dr Els Pastijn, who helped me with the Dutch chapter.

Reason of the discussion of the thesis in Maastricht University brought me to visit Prof. dr. Jan Willem Greve, who kindly revised the work done and accepted my proposition to discuss the thesis in this prestigious University. There are no words to thank all his work, time reserved to me and patience to meet me during the last years. Without him, this thesis would not be defended today!

A special thank is addressed to Prof. dr. J.G. Maessen, Prof. dr. L.P.S. Stassen, Prof. dr. P.B. Soeters, Prof. dr. R. Weiner and Dr. R. Schouten for their scientific analysis and presence during the public defense. 


\subsection{CURRICULUM VITAE}

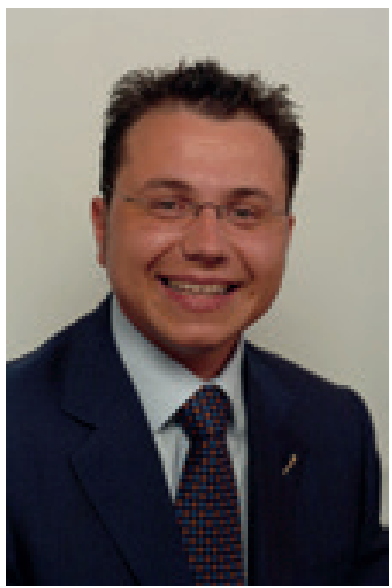

\section{Giovanni Dapri,}

born in Treviglio (Bergamo), Italy on May 6, 1975

Education, Training \& Positions

1994-2000: Medical School at the University of Milan, Italy

2000-2006: Residency in General Surgery at the University of Milan, Italy

2006-2012: Résident Surgeon at the Department of Gastrointestinal Surgery, Saint-Pierre University Hospital, Brussels, Belgium

1998: Internship at the Department of Surgery of the University of California San Diego, San Diego CA, US (Chief: Pr. A.R.Moossa)

1999: Internship at the Department of Surgery of the University of Washington School of Medicine, Seattle WA, US (Chief: Pr. C.A.Pellegrini)

2002: Fellowship at the Service of Digestive and Hepatobiliary Surgery, Princess Grace Hospital, Monaco, Principaute of Monaco (Chief: Pr. C.Huguet)

2004-2006: Fellowship at the Department of Gastrointestinal Surgery, European School of Laparoscopic Surgery, Saint-Pierre University Hospital, Brussels, Belgium (Director and Chief: Pr. G.B.Cadière)

\section{Currently}

- Chef de Clinique Adjoint at the Department of Gastrointestinal Surgery, SaintPierre University Hospital, Brussels, Belgium

- Secretary of the European School of Laparoscopic Surgery, Saint-Pierre University Hospital, Brussels, Belgium 
- Course Co-Chair of "Single Access Laparoscopic Surgery Workshop", "Laparoscopic Bariatric Surgery Workshop", "Laparoscopic Colorectal Surgery Workshop", "Laparoscopic Hernia Repair Surgery", and "General Laparoscopic Surgery Course" at the European School of Laparoscopic Surgery, Saint-Pierre University Hospital, Brussels, Belgium

- Personal realization of more than 2000 laparoscopic procedures (more than 500 by single access laparoscopy)

\section{Academic Experiences}

\section{Author and Co-author}

- 84 scientific papers on reviewed and no-reviewed Journals

- 44 book chapters

- Brochure+DVD: First Single-Portal Laparoscopic Surgery Using Curved and Reusable Instruments (2010)

- Brochure+DVD: First Single-Portal Access Using Curved Instruments for Laparoscopic Appendectomy and Cholecystectomy (2009)

- Book+DVDs: Atlas of Laparoscopic Obesity Surgery (2007)

- 4 DVDs of Laparoscopic Surgery:

- Minimal Invasive Esophagectomy and Gastrectomy for Tumor

- Laparoscopic Colorectal Surgery

- Laparoscopic Hernia Repair

- Use of Bioabsorbable Staple Line Reinforcement in Digestive and Obesity Surgery

\section{International and National Congress participations}

- 307 oral presentations

- 134 abstracts published

- 36 session moderator

- 61 LIVE surgeries

- 17 lab instructor

\section{Award Congress Session}

- 19th Annual Congress of European Association for Endoscopic Surgery (EAES) (June 17 2011, Turin, Italy)

- 16th Annual Congress of European Association for Endoscopic Surgery (EAES) (June 13 2008, Stockholm, Sweden)

- 109 e Congrès Français de Chirurgie (AFC), session International Club of Young Laparoscopic Surgeons (ICYLS) (October 3 2007, Paris, France)

- 108e Congrès Français de Chirurgie (AFC) (October 3 2006, Paris, France)

- 14th Annual Congress of European Association for Endoscopic Surgery (EAES) (September 14 2006, Berlin, Germany) 
- 9th Annual Meeting of European Society of Surgery (ESS) (November 12 2005, Vienna, Austria)

- 107e Congrès Français de Chirurgie (AFC) (September 30 2005, Paris, France)

- 13th Annual Congress of European Association for Endoscopic Surgery (EAES) (Juin 3 2005, Venice, Italy)

- MISCJU 2008 Award for Technical and Scientific Research (October 17-18 2008, Caceres, Spain)

- WCES Young Investigators Award (YIA) at 11th World Congress of Endoscopic Surgery (September 2-6 2008, Yokohama, Japan)

- European Association for Endoscopic Surgery (EAES) Educational Grant at 10th World Congress of Endoscopic Surgery (September 13-16 2006, Berlin, Germany)

\section{Development}

- Set for Single Access Laparoscopic Surgery according to DAPRI:

- curved grasping forceps I

- curved grasping forceps II

- curved grasping forceps III

- curved grasping forceps IV

- curved dissecting and coagulating electrode

- curved scissors

- curved bipolar grasper

- curved bipolar scissors

- curved dissecting forceps

- curved needle holder I

- curved needle holder II

\section{Member of Editorial Board Journal}

- Surgical Innovation

- World Journal of Gastrointestinal Surgery

- World Journal of Gastrointestinal Endoscopy

- World Journal of Diabetes

- World Journal of Surgical Procedures

- Abdominal Wall Repair Journal

- Global Journal of Surgery

- Interventional Oncology Society Journal

- Journal of Thoracic Disease

- Case Reports in Surgery

- WebmedCentral plus

- Obésité - Springer Verlag France

- European Journal of Coelio-Surgery - Le Journal de Coelio-Chirurgie

- Medical Instrumentation 


\section{Member of Society Committee}

- American College of Surgeons (ACS) for "Video-based Education"

- Society of American Gastrointestinal and Endoscopic Surgeons (SAGES) for "Guidelines", "Bariatric", "Flex Endoscopy" and "Research"

- American Society for Metabolic and Bariatric Surgery (ASMBS) for "International Development"

- International Federation for the Surgery of Obesity (IFSO) for "New Technologies"

- European Association for Endoscopic Surgery (EAES) for "Technology"

\section{Member of Faculty Courses}

- Institut de Recherche contre les Cancers de l'Appareil Digestif (IRCAD, Strasbourg, France)

- International Institut of Endoscopic Surgery (LapSurg Insitut, Sao Paulo, Brasil)

- Minimally Invasive Surgical Centre (MISC-ASIA, Singapore)

- Cuschieri Skills Centre (Dundee, Scotland)

- Co-Founder of Strategic Laparoscopy for Improved Cosmesis (SLIC) group (www.slicsurgery.com)

\section{Member of Society}

- Fellow American College of Surgeons (FACS)

- Fellow American Society for Metabolic and Bariatric Surgery (FASMBS)

- Honorary Fellow Philippine Association of Laparoscopic and Endoscopic Surgeons (HonPALES)

- Honorary Member Sociedade Portoguese de Cirurgia Minimamente Invasiva (HonSPCMIN)

- Honorary Member Bulgarian Society of Surgery (HonBSS)

- Foreign Member Sociedad de Cirujanos Generales del Peru (SCGP)

- Society of American Gastrointestinal and Endoscopic Surgeons (SAGES)

- European Association for Endoscopic Surgery (EAES)

- International Federation for Surgery of Obesity (IFSO)

- Belgian Section of Obesity \& Metabolic Surgery (BeSOMS)

- Belgian Group for Endoscopic Surgery (BGES)

- Association Française de Chirurgie (AFC)

- International Club of Young Laparoscopic Surgeons (ICYLS)

- International Society of Surgery (ISS) 


\subsection{BIBLIOGRAPHY}

SUPRAPUBIC SINGLE-INCISION LAPAROSCOPIC RIGHT HEMICOLECTOMY WITH INTRACORPOREAL ANASTOMOSIS

Dapri G, Carandina S, Mathonet P, Himpens J, Cadière GB

Surg Innov 2013 Jan 15 (Epub ahead of print)

SINGLE-ACCESS LAPAROSCOPIC PRIMARY AND INCISIONAL PROSTHETIC HERNIA REPAIR: FIRST 50 PATIENTS

Dapri G, Bruyns J, Paesmans M, Himpens J, Cadière GB

Hernia 2013 Jan 6 (Epub ahead of print)

SINGLE-ACCESS LAPAROSCOPIC ADJUSTABLE GASTRIC BAND REMOVAL: TECHNIQUE AND INITIAL EXPERIENCE

Dapri G, El Mourad H, Mathonet P, Delaporte A, Himpens J, Cadière GB, Greve JW Obes Surg 2013; 23(2): 272-6

INITIAL EXPERIENCE IN SINGLE-INCISION TRANSUMBILICAL LAPAROSCOPIC LIVER RESECTION: INDICATIONS, POTENTIAL BENEFITS AND LIMITATIONS

Dapri G, DiMarco L, Cadière GB, Donckier V

HPB Surg 2012; 2012: 921973

SINGLE-ACCESS TRANSUMBILICAL LAPAROSCOPIC UNROOFING OF A GIANT HEPATIC CYST USING REUSABLE INSTRUMENTS

Dapri G, Barabino M, Carnevali P, Surdeanu I, Himpens J, Cadière GB, Donckier V JSLS 2012; 16(2): 296-300

COMMENT JE FAIS ? L'OESOPHAGECTOMIE SELON IVOR LEWIS

Cadière GB, Himpens J, Dapri G

Le Jour de Coelio-Chir 2012 Septembre; 83: 39-46

APPROCHE MINIMALE INVASIVE DE L'OESOPHAGECTOMIE. RESULTATS SUR 50 PATIENTS. COMMENT JE FAIS ? L'OESOPHAGECTOMIE SELON IVOR LEWIS

Marcelis Q, Himpens J, Dapri G, Mathonet P, Cadière GB

Le Jour de Coelio-Chir 2012 Septembre; 83: 23-30

LAPAROSCOPIC CHOLECYSTECTOMY WITH STRAIGHT INSTRUMENTS THROUGH ONE INCISION: A REPORT FROM JAMAICA

Cawich SO, Albert M, Mohanty SK, Dapri G

Int J Surg 2012; 28(4). DOI: 10.5580/2c68 
CONSENSUS STATEMENT OF THE CONSORTIUM FOR LESS CHOLECYSTECTOMY

Ross S, Rosemurgy A, Albrink M, Choung E, Dapri G, Gallagher S, Hernandez J, Horgan S, Kelley W, Kia M, Marks J, Martinez J, Mintz Y, Oleynikov D, Pryor A, Rattner D, Rivas H, Roberts K, Rubach E, Schwaitzberg S, Swanstrom L, Sweeney J, Wilson E, Zemon $\mathrm{H}$, Zundel $\mathrm{N}$

Surg Endosc 2012; 26(10): 2711-6

COMMENT JE REALISE LE GASTRIC BYPASS

Cadière GB, Himpens J, Dapri G

Le Jour de Coelio-Chir 2012 Juin; 82: 41-8

SPECIALLY DESIGNED CURVED INSTRUMENTS FOR SINGLE-ACCESS LAPAROSCOPY: 2.5-YEAR EXPERIENCE IN 265 PATIENTS

\section{Dapri G}

Minim Invasive Ther Allied Technol 2012; 21(1): 31-9

TRANSUMBILICAL SINGLE-ACCESS LAPAROSCOPIC PERFORATED GASTRIC ULCER REPAIR

Dapri G, El Mourad H, Himpens J, Evola G, Marsili L, Cadière GB

Surg Innov 2012;19(2):130-3

TRAIL BLAZING BARIATRIC SURGERY DEVICES. SEWING MACHINES FOR OVERSTITCHING, PLEATING, CLIPPING, AND MORE

\section{Dapri G}

European Hospital Journal October 2011; 20(5): 6

SUPEROBESE AND SUPER-SUPEROBESE PATIENTS: 2-STEP LAPAROSCOPIC DUODENAL SWITCH

Dapri G, Cadière GB, Himpens J

Surg Obes Relat Dis 2011; 7(6): 703-8

SINGLE-ACCESS TRANSUMBILICAL LAPAROSCOPIC SPLENECTOMY USING CURVED REUSABLE INSTRUMENTS

Dapri G, Bron D, Himpens J, Casali L, Carnevali P, Koustas P, Cadière GB

Surg Endosc 2011; 25(10): 3419-22

LONG-TERM OUTCOMES OF LAPAROSCOPIC ADJUSTABLE GASTRIC BANDING Himpens J, Cadière GB, Bazi M, Vouche M, Cadière B, Dapri G

Arch Surg 2011; 146(7): 802-7 
LAPAROSCOPIC RECONVERSION OF ROUX-EN-Y GASTRIC BYPASS TO ORIGINAL ANATOMY: TECHNIQUE AND PRELIMINARY OUTCOMES

Dapri G, Cadière GB, Himpens J

Obes Surg 2011; 21(8): 1289-95

ARE LAPAROSCOPIC GASTRIC BYPASS AFTER GASTROPLASTY AND PRIMARY LAPAROSCOPIC GASTRIC BYPASS SIMILAR IN TERMS OF RESULTS ?

Cadière GB, Himpens J, Bazi M, Cadière B, Vouche M, Capelluto E, Dapri G

Obes Surg 2011; 21(6): 692-8

LAPAROSCOPIC CONVERSION OF ROUX-EN-Y GASTRIC BYPASS TO SLEEVE GASTRECTOMY AS FIRST STEP OF DUODENAL SWITCH: TECHNIQUE AND PRELIMINARY OUTCOMES

Dapri G, Cadière GB, Himpens J

Obes Surg 2011; 21(4): 517-23

SINGLE-ACCESS TRANSUMBILICAL LAPAROSCOPIC APPENDECTOMY AND CHOLECYSTECTOMY USING NEW CURVED REUSABLE INSTRUMENTS: A PYLOT FEASIBILITY STUDY

Dapri G, Casali L, Dumont H, Van der Goot L, Herrandou L, Pastijn E, Sosnowski M, Himpens J, Cadière GB

Surg Endosc 2011; 25(4): 1325-32

LAPAROSCOPIC CONVERSION OF ROUX-EN-Y GASTRIC BYPASS TO DISTAL GASTRIC BYPASS FOR WEIGHT REGAIN

Dapri G, Cadière GB, Himpens J

J Laparoendosc Adv Surg Tech A 2011; 21(1): 19-23

THORACOSCOPIC ESOPHAGECTOMY IN PRONE POSITION

Cadière GB, Dapri G, Himpens J, Rajan A

Ann Surg Oncol 2011; 18: 838

SINGLE-ACCESS TRANSUMBILICAL DIAGNOSTIC LAPAROSCOPY FOR PANCREATIC RUMOR USING CURVED AND REUSABLE INSTRUMENTS

Dapri G, Carnevali P, Himpens J, Bianchi P, Opocher E, Montorsi M, Cadière GB Ann Surg Oncol 2011; 18: 628

SINGLE-ACCESS TRANSUMBILICAL LAPAROSCOPIC NISSEN FUNDOPLICATION PERFORMED WITH NEW CURVED REUSABLE INSTRUMENTS

Dapri G, Bruyns J, Himpens J, Cadière GB

Surg Innov 2011; 18(1): 61-5 
LAPAROSCOPIC REPEAT SLEEVE GASTRECTOMY VERSUS DUODENAL SWITCH AFTER ISOLATED SLEEVE GASTRECTOMY FOR OBESITY

Dapri G, Cadière GB, Himpens J

Surg Obes Relat Dis 2011; 7(1): 38-44

SINGLE INCISION TRANSUMBILICAL LAPARO-ENDOSCOPIC GASTRIC BENIGN TUMOR RESECTION

Dapri G, Ntounda R, Himpens J, Carnevali P, Scomersi S, Cadière GB

Ann Surg Oncol 2011; 18: 191

SINGLE-ACCESS LAPAROSCOPIC SURGERY USING NEW CURVED REUSABLE INSTRUMENTS: INITIAL HUNDRED PATIENTS

Dapri G, Casali L, Bruyns J, Himpens J, Cadière GB

Surg Technol Int 2010; 20: 21-35

NOUVELLES FRONTIERES DE LA CHIRURGIE BARIATRIQUE: CHIRURGIE ENDOLUMINALE ET LAPAROSCOPIE PAR UNE SEULE INCISION.

Dapri G, Himpens J, Cadière GB

Obes 2010; 5: 59-66

SINGLE ACCESS LAPAROSCOPIC SURGERY: COMPLEMENTARY OR ALTERNATIVE TO NOTES ?

\section{Dapri G}

WJGS 2010; 2(6): 207-9

LAPAROSCOPIC CONVERSION OF ADJUSTABLE GASTRIC BANDING TO SLEEVE GASTRECTOMY: A FEASIBILITY STUDY

Himpens J, De Schepper M, Dapri G

Surg Laparosc Endosc Percutan Tech 2010; 20(3): 162-5

LAPAROSCOPIC CONVERSION OF ROUX-EN-Y GASTRIC BYPASS TO BILIOPANCREATIC DIVERSION

Dapri G, Himpens J, Cadière GB

Surg Endosc 2010; 24(6): 1490-3

IVOR LEWIS ESOPHAGECTOMY WITH MANUAL ESOGASTRIC ANASTOMOSIS BY THORACOSCOPY IN PRONE POSITION AND LAPAROSCOPY

Cadière GB, Dapri G, Himpens J, Fodderie L, Rajan A

Surg Endosc 2010; 24(6): 1482-5 
Y A-T-IL UNE DIFFERENCE ENTRE LES RESULTATS DU BYPASS GASTRIQUE PAR LAPAROSCOPIE EN PREMIERE INTENTION ET LE BYPASS GASTRIQUE APRES GASTROPLASTIE ?

Bazi M, Cadière B, Vouche M, Capelluto E, Dapri G, Himpens J, Cadière GB

Le Jour de Coelio-Chir 2010 Juin; 74: 40-5

RESULTATS DU SUIVI DE L'ANNEAU GASTRIQUE AJUSTABLE PAR LAPAROSCOPIE APRES PLUS DE 12 ANS

Vouche M, Cadière B, Bazi M, Himpens J, Dapri G, Cadière GB

Le Jour de Coelio-Chir 2010 Juin; 74: 11-5

REINFORCING THE STAPLE LINE DURING LAPAROSCOPIC SLEEVE GASTRECTOMY: PROSPECTIVE RANDOMIZED CLINICAL STUDY COMPARING THREE DIFFERENT TECHNIQUES

Dapri G, Cadière GB, Himpens J

Obes Surg 2010; 20(4): 462-7

LAPAROSCOPIC TOTAL GASTRECTOMY AND D2 LYMPHADENECTOMY

Dapri G, Himpens J, Cadière GB

Ann Surg Oncol 2010; 17: 1605

APPENDICECTOMIE ET CHOLECYSTECTOMIE PAR LAPAROSCOPIE A TRAVERS UNE SEULE INCISION OMBELICALE: NOUVEAUX INSTRUMENTS COURBES ET REUTILISABLES.

Dapri G, Casali L, Capelluto E, Lipski D, Bruyns J, Himpens J, Cadière GB

Le Jour de Coelio-Chir 2010 Mars; 73: 14-20

+ Revista Portuguesa de Cirurgia II Serie, N.13, Junho 2010, 13-18

ENUCLEATION OF A LEIOMYOMA OF THE MID-ESOPHAGUS THROUGH A RIGHT THORACOSCOPY WITH THE PATIENT IN PRONE POSITION

Dapri G, Himpens J, Ntounda R, Alard S, Derepeer E, Cadière GB

Surg Endosc 2010; 24(1): 215-8

LAPAROSCOPIC CONVERSION OF ADJUSTABLE GASTRIC BANDING AND VERTICAL BANDED GASTROPLASTY TO DUODENAL SWITCH

Dapri G, Cadière GB, Himpens J

Surg Obes Relat Dis 2009; 5(6): 678-83

TREATMENT OF LEAKS AFTER SLEEVE GASTRECTOMY

Himpens J, Dapri G, Cadière GB

Bariatric Times 2009; 6(9): 12-3 
L'OESOPHAGECTOMIE SELON LA TECHNIQUE D'IVOR LEWIS PAR LAPAROSCOPIE ET THORACOSCOPIE EN POSITION VENTRALE

Cadière GB, Dapri G, Himpens J, Fodderie L, Cadière B, Rajan A

Le Jour de Coelio-Chir 2009 Septembre; 71: 34-8

LAPAROSCOPIC TRANSGASTRIC ACCESS TO THE COMMON BILE DUCT

AFTER ROUX-EN-Y GASTRIC BYPASS

Dapri G, Himpens J, Buset M, Vasilikostas G, Ntounda R, Cadière GB

Surg Endosc 2009; 23(7): 1646-8

LAPAROSCOPIC PLACEMENT OF A NON ADJUSTABLE SILICONE RING FOR WEIGHT REGAIN AFTER ROUX-EN-Y GASTRIC BYPASS

Dapri G, Cadière GB, Himpens J

Obes Surg 2009; 19(5): 650-4

DUODENAL DUPLICATION CYST IN AN ADULT: FIRST SIMULTANEOUS LAPAROSCOPIC AND ENDOSCOPIC SURGERY

Jiménez M, Cadière GB, Dapri G, Vasilikostas G, Bruyns J, Capelluto E

J Laparoendosc Adv Surg Tech A 2009; 19(2): 207-10

LAPAROSCOPIC SEROMYOTOMY FOR LONG STENOSIS AFTER SLEEVE GASTRECTOMY WITH OR WITHOUT DUODENAL SWITCH

Dapri G, Cadière GB, Himpens J

Obes Surg 2009; 19(4): 495-9

FEASIBILITY AND TECHNIQUE OF LAPAROSCOPIC CONVERSION OF ADJUSTABLE GASTRIC BANDING TO SLEEVE GASTRECTOMY

Dapri G, Cadière GB, Himpens J

Surg Obes Relat Dis 2009; 5(1): 72-6

A BOERHAAVE'S SYNDROME DIAGNOSIS TREATED BY THORACOSCOPY IN PRONE POSITION

Dapri G, Dumont H, Roman A, Stevens E, Himpens J, Cadière GB

Minerva Chir 2008; 63(3): 237-40

LAPAROSCOPIC RESTORATION OF GASTROINTESTINAL CONTINUITY AFTER DUODENAL SWITCH

Dapri G, Cadière GB, Himpens J

Surg Obes Relat Dis 2008; 4(3): 451-4 
COMPLETELY STAPLE-FREE HAND-SEWN LAPAROSCOPIC ANASTOMOSIS IN COLORECTAL SURGERY

Lipski D, Dapri G, Himpens J

J Lap Adv Surg Tech 2008; 18(2): 282-5

MINIMALLY INVASIVE ESOPHAGECTOMY FOR CANCER: LAPAROSCOPIC TRANSHIATAL APPROACH OR THORACOSCOPY IN PRONE POSITION FOLLOWED BY LAPAROSCOPY?

Dapri G, Himpens J, Cadière GB

Surg Endosc 2008; 22(4): 1060-9

TRAITEMENT PAR THORACOSCOPIE EN POSITION VENTRALE D'UNE RUPTURE SPONTANEE DU BAS OESOPHAGE

Dapri G, Dumont H, Roman A, Stevens E, Scomersi S, Calligaris L, Lipski S, Himpens J, Cadière GB

Le Jour de Coelio-Chir 2008 Mars; 65: 31-4

ROLE OF LAPAROSCOPY IN THE MANAGEMENT OF VISCERAL INJURIES FOLLOWING ABDOMINAL STAB WOUNDS

Dapri G, Himpens J, Lipski D, Bruyns J, Capelluto E, Stevens E, Roman A, Hainaux B, Germay 0 , Cadière GB

J Lap Adv Surg Tech 2007; 17(6): 713-8

LAPAROSCOPIC TRANSHIATAL ESOPHAGO-GASTRECTOMY AFTER CORROSIVE INJURY

Dapri G, Himpens J, Mouchart A, Ntounda R, Claus M, Dechamps Ph, Hainaux B, Kefif R, Germay 0, Cadière GB

Surg Endosc 2007; 21(12): 2322-5

A PROSPECTIVE RANDOMIZED STUDY BETWEEN TWO DIFFERENT TECHNIQUES OF LAPAROSCOPIC SLEEVE GASTRECTOMY

Dapri G, Vaz C, Cadière GB, Himpens J

Obes Surg 2007; 17(11): 1435-41

TUMEURS INTRAGASTRIQUES: RESECTION PAR VOIE LAPAROSCOPIQUE ET ENDOSCOPIQUE

Dapri G, Ntounda R, Jimenez Fuertes M, Vasilikostas G, Scomersi S, Capelluto E, Lipski D, Andrianne $S$, Buset $M$, Himpens J, Cadière GB

Le Jour de Coelio-Chir 2007 Septembre; 63: 40-5 
SLEEVE GASTRECTOMIE PAR LAPAROSCOPIE

Cadière GB, Dapri G, Himpens J

J Chir 2007; 144(4): 313-7

SLEEVE GASTRECTOMIE PAR LAPAROSCOPIE: ETUDE PROSPECTIVE RANDOMISEE ENTRE DEUX TECHNIQUES DIFFERENTES

Himpens J, Dapri G, Vaz C, Bouillon I, Cadière GB

Le Jour de Coelio-Chir 2007 Juin; 62: 42-8

SURGICAL TECHNIQUE AND COMPLICATIONS DURING LAPAROSCOPIC REPAIR OF DIAPHRAGMATIC HERNIAS

Dapri G, Himpens J, Hainaux B, Roman A, Stevens E, Capelluto E, Germay O, Cadière $\mathrm{GB}$

Hernia 2007; 11(2): 179-83

BRULURE CAUSTIQUE EXTENSIVE DE L'OESOPHAGE ET DE L'ESTOMAC. A PROPOS D'UN CAS.

Dapri G, Himpens J, Mouchart A, Ntounda R, Capelluto E, Claus M, Dechamps Ph, Hainaux B, Kefif R, Lipski D, Germay O, Cadière GB

Le Jour de Coelio-Chir 2006 Décembre; 60: 37-43

ENDOLUMINAL FUNDOPLICATION (ELF) - EVOLUTION OF ESOPHYXTM, A NEW SURGICAL DEVICE FOR TRANSORAL SURGERY

Cadière GB, Rajan A, Rqibate M, Germay O, Dapri G, Himpens J, Gawlicka AK

Minimally Invasive Therapy and Allied Technology 2006; 15(6): 348-55

A PROSPECTIVE RANDOMIZED STUDY BETWEEN LAPAROSCOPIC GASTRIC BANDING AND LAPAROSCOPIC GASTRIC SLEEVE : RESULTS AFTER 1 AND 3 YEARS

Himpens J, Dapri G, Cadière GB

Obes Surg 2006; 16(11): 1450-6

THORACOSCOPIC AND LAPAROSCOPIC OESOPHAGECTOMY IMPROVES THE QUALITY OF EXTENDED LYMPHADENECTOMY

Cadière GB, Torres R, Dapri G, Capelluto E, Himpens J, Hainaux B

Surg Endosc 2006; 20(8): 1308-9

OESOPHAGECTOMIE PAR THORACOSCOPIE EN POSITION VENTRALE, LAPAROSCOPIE ET CERVICOTOMIE

Cadière GB, Himpens J, Dapri G

J Chir 2006; 143(4): 237-42 
LAPAROSCOPIC CONVERSION OF THE GASTRIC BYPASS INTO A NORMAL ANATOMY

Himpens J, Dapri G, Cadière GB

Obes Surg 2006; 16(7): 908-13

ESOPHAGETOMY BY THORACOSCOPY WITH PATIENT IN PRONE POSITION, LAPAROSCOPY AND CERVICOTOMY (TECHNIQUE)

Cadière GB, Dapri G, Capelluto E, Himpens J

European Surgery - Acta Chirurgica Austriaca 2006; 38(3): 164-70

CONVERSION DU BYPASS GASTRIQUE EN ANATOMIE NORMALE PAR LAPAROSCOPIE

Dapri G, Himpens J, Cadière GB

Le Jour de Coelio-Chir 2006 Juin; 58: 38-42

ROBOT-ASSISTED THORACOSCOPIC ESOPHAGECTOMY WITH PATIENT IN PRONE POSITION

Dapri G, Himpens J, Cadière GB

J Lap Adv Surg Tech 2006; 16(3): 278-85

NOUVELLE TECHNIQUE DU TRAITEMENT PAR VOIE ENDOSCOPIQUE DU REFLUX GASTRO-OESOPHAGIEN : LA FUNDOPLICATURE ENDOLUMINALE

Cadière GB, Rajan A, Dapri G, Rqibate M, Germay 0, Himpens J

Le Jour de Coelio-Chir 2006 Mars; 57: 14-9

TRAITEMENT DES HERNIES DE LARREY PAR LAPAROSCOPIE

Dapri G, Hainaux B, Roman A, Stevens E, Capelluto E, Germay O, Himpens J, Cadière $G B$

Le Jour de Coelio-Chir 2006 Mars; 57: 62-8

ENTIRELY THORACOSCOPIC PNEUMONECTOMY USING THE PRONE POSITION: A NEW TECHNIQUE

Cadière GB, Himpens J, Torres R, Dapri G, Bosschaerts T, Karler C

Surg Endosc 2005; 19(9): 1282-3

PLAIES ABOMINALES PAR ARME BLANCHE : DIAGNOSTIC ET TRAITEMENT PAR LAPAROSCOPIE

Dapri G, Lipski D, Bruyns J, Stevens E, Roman A, Devriendt V, Hainaux B, Capelluto E, Germay 0 , Himpens J, Cadière GB

Le Jour de Coelio-Chir 2005 Septembre; 55: 51-6 
COMPARAISON ENTRE LES RÉSULTATS DU BYPASS GASTRIQUE EN PREMIÈRE INTENTION ET APRÈS UNE GASTROPLASTIE

Rqibate O, Himpens J, Dapri G, Ntounda R, Gaudissart Q, Capelluto E, Cadière GB Le Jour de Coelio-Chir 2005 Septembre; 55: 23-30

LAPAROSKOPISCHE MAGENBYPASSCHIRURGIE

Cadière GB, Himpens J, Dapri G

Der Chirurg 2005; 76(7): 668-77

SWITCH DUODÉNAL PAR LAPAROSCOPIE : CODIFICATION DE LA TECHNIQUE APRÈS UNE EXPÉRIENCE DE 340 CAS

Himpens J, Cadière GB, Dapri G

Le Jour de Coelio-Chir 2005 Juin; 54: 11-22

LOCAL ANAESTHESIA FOR STAPLED PROLAPSECTOMY IN DAY-SURGERY: RESULTS OF A PROSPECTIVE TRIAL

Mariani P, Arrigoni G, Quartierini G, Dapri G, Leone S, Barabino M, Opocher E Dis Colon Rectum 2005; 48(7): 1447-50

LAPAROSCOPIC LEFT LATERAL HEPATIC LOBECTOMY FOR METASTATIC COLORECTAL TUMOR

Cadière GB, Torres R, Dapri G, Capelluto E, Himpens J

Surg Endosc 2005; 19(1): 152

CODIFICATION DES DIFFÉRENTES TECHNIQUE DU BYPASS GASTRIQUE APRÈS UNE EXPÉRIENCE DE PLUS DE 1000 CAS

Dapri G, Himpens J, Capelluto E, Rqibate 0, Germay 0, Cadière GB Le Jour de Coelio-Chir 2004 Décembre; 52: 37-45

INTRAOPERATIVE BILIARY TREE EVALUATION DURING LAPAROSCOPIC CHOLECYSTECTOMY

Santambrogio R, Opocher E, Bianchi P, Dapri G, Costa M, Montorsi M

Osp Ital Chir 2004; 10(6): 571-5

PNEUMONECTOMIE GAUCHE RÉALISÉE ENTIÈREMENT PAR THORACOSCOPIE EN POSITION VENTRAL. A PROPOS D'UNE OBSERVATION.

Cadière GB, Torres R, Dapri G, Capelluto E, Bosschaerts T, Himpens J

Le Jour de Coelio-Chir 2004 Sep; 51: 11-5

HISTORICAL SHAPE OF "EMPIERREMENT" OF THE COMMON BILE DUCT

Dapri G, Nardi F, Gavelli A, Ambrosiani A, Marmorale A, Huguet C

Chirurgia 2004; 17(4): 133-5 
LA CALCOLOSI DEL COLEDOCO: IL TRATTAMENTO CHIRURGICO RESTA SEMPRE VALIDO

Nardi F, Gavelli A, Dapri G, Huguet C

Minerva Chirurgica 2004; 59(1): 17-21

HEPATOBILIARY CYSTADENOMA : DIAGNOSTIC UNCERTAINTY

Barabino M, Leone S, Dapri G, Marsetti M, Ghislandi R, Opocher E

HPB 2004; 6(1): 52-4

PERSPECTIVES AND DRAWBACKS OF MINIMALLY INVASIVE SURGERY FOR HEPATOCELLULAR CARCINOMA

Montorsi M, Santambrogio R, Bianchi P, Dapri G, Spinelli A, Podda M

Hepato-Gastroenterology 2002; 49(43): 56-61

LAPAROSCOPY WITH LAPAROSCOPIC ULTRASOUND FOR PRETREATMENT STAGING OF HEPATOCELLULAR CARCINOMA: A PROSPECTIVE STUDY

Montorsi M, Santambrogio R, Bianchi P, Opocher E, Cornalba GP, Dapri G,

Bonavina L, Zuin M, Podda M

J Gastrointest Surg 2001; 5(3): 312-5 